\title{
MECHANISCH-ENZYMATISCHER AUFSCHLUSS \\ VON KARTOFFELPÜLPE ALS BINDEMITTEL ZUR HERSTELLUNG \\ VON HOLZWERKSTOFFEN
}

\section{Dissertation}

zur Erlangung des Doktorgrades

der Fakultät für Forstwissenschaften und Waldökologie

der Georg-August-Universität Göttingen

\author{
vorgelegt von \\ Cora Müller \\ geboren in Höxter
}

Göttingen, im Mai 2005 
1. Berichterstatter: Prof. Dr. A. Kharazipour

2. Berichterstatter: Prof. Dr. E. Roffael

Tag der mündlichen Prüfung: 30. Juni 2005 


\section{Vorwort}

Die vorliegende Arbeit entstand am Institut für Forstbotanik der Georg-AugustUniversität Göttingen in der Zeit von Oktober 2001 bis Mai 2005 unter der Leitung von Herrn Prof. Dr. A. Kharazipour. Gefördert wurde die Arbeit durch das Stipendienprogramm der Deutschen Bundesstiftung Umwelt (DBU).

Für die Vergabe des Themas und die zahlreichen wissenschaftlichen Anstöße bedanke ich mich bei Herrn Prof. Dr. A. Kharazipour, der immer unterstützende und motivierende Worte fand.

Bedanken möchte ich mich vor allem bei den Mitgliedern der Arbeitsgruppe Kharazipour für ihre tatkräftige Hilfe und die fachliche Unterstützung. Mein Dank gilt Lars Kloeser, Christian Bohn und Michael Reichel.

Den Mitarbeiterinnen und Mitarbeitern des Instituts für Forstbotanik möchte ich danken für das freundliche Arbeitsklima und die große Hilfsbereitschaft. Insbesondere danke ich Karin Lange, Theres Riemekasten und Gisbert LangerKettner.

Bei den Mitarbeitern der DBU möchte ich mich bedanken für ihre Unterstützung. Besonderer Dank gilt Herrn Dr. Lay und Frau Wempe für ihre allzeit freundliche und unkomplizierte Betreuung.

Den Firmen Emslandstärke und AVEBE danke ich für die Bereitstellung der Kartoffelpülpe. Weiterhin gilt mein Dank den Firmen Novozymes und AB Enzymes für die freundliche Beratung und die unkomplizierte Belieferung mit Enzymen. Darüber hinaus möchte ich mich für die Durchführung der Wirbelschicht-Sprühgranulation bei der Firma Glatt GmbH bedanken. Insbesondere gilt mein Dank Herrn Roger Schuetz und seinem Team für die große Hilfsbereitschaft.

Dafür das ich nicht vergessen habe, dass es auch noch andere Dinge im Leben neben der Arbeit gibt, danke ich meinen Freunden.

Schließlich gilt mein besonderer Dank meiner Familie, die mich immer unterstützt hat. Meinem Mann Christian danke ich dafür, dass er immer ermutigend zur Seite stand und mir sowohl bei fachlichen Fragen als auch bei der Überwindung von Motivationstiefs geholfen hat. 



\section{Inhaltsverzeichnis}

$1 \quad$ Einleitung 1

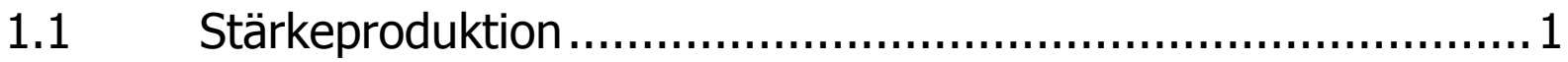

1.1.1 Kartoffelpülpe und ihre Verwendung ................................................ 4

1.2 Holzwerkstoffe ......................................................... 7

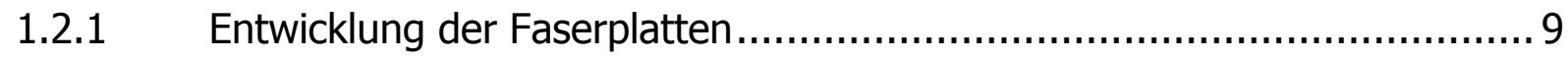

1.2.2 Entwicklung der MDF-Produktion ................................................ 10

$1.3 \quad$ Zielsetzung der Arbeit ................................................. 12

$2 \quad$ Allgemeiner Teil..............................................13

$2.1 \quad$ Pülpe............................................................... 13

2.1.1 Aufbau der Zellwand in einer Kartoffel........................................... 13

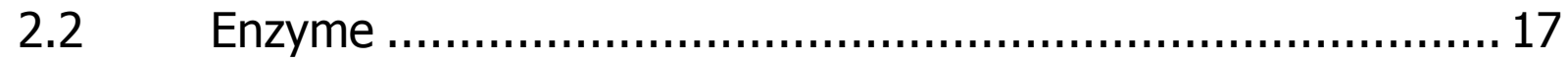

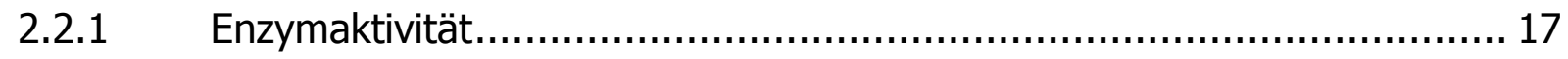

2.2.2 Hemmung der Enzymaktivität.................................................... 18

2.2.3 Verfahren zur Bestimmung der Enzymaktivität .................................. 19

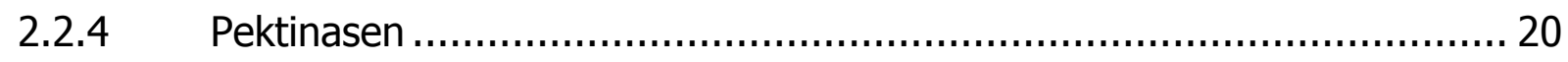

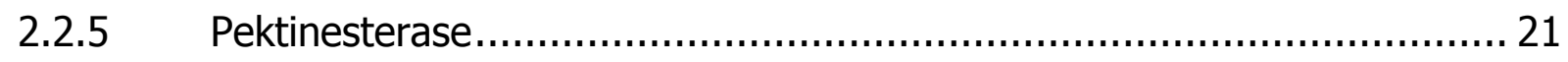

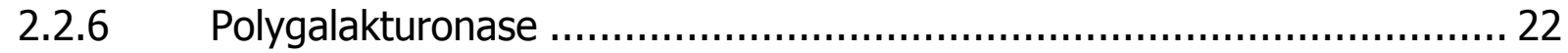

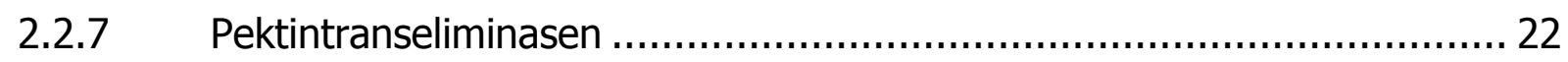

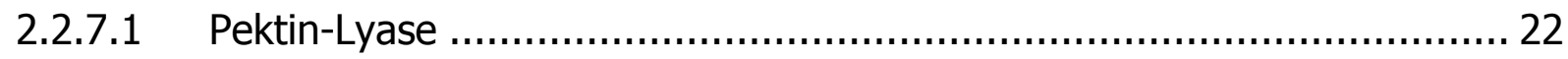

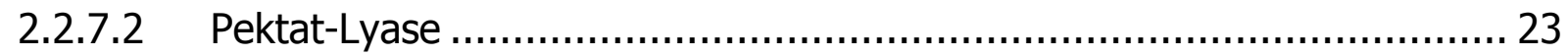

2.2.8 Cellulytische und hemicellulytische Enzyme..................................... 24

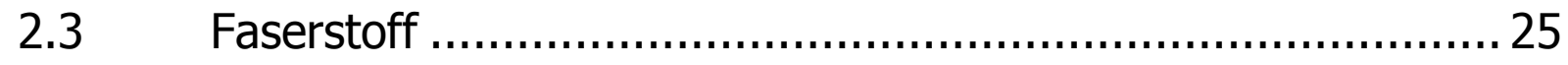

2.3.1 Faserherstellung durch Holzaufschluss............................................ 25

2.3.1.1 Dampfexplosionsverfahren nach MASON …....................................... 25

2.3.1.2 Das Dampfmahlverfahren nach ASPLUND ......................................... 27

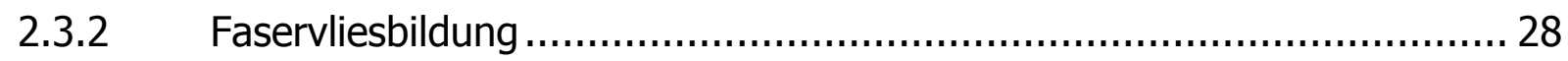

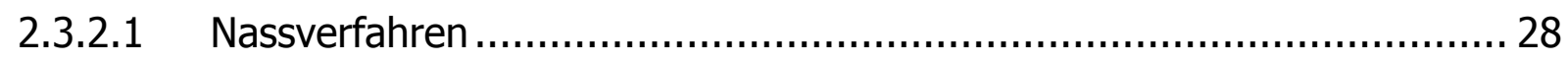

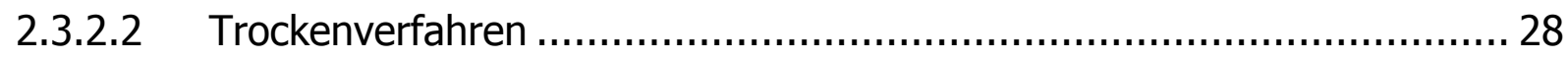


2.3.2.3 Produktion von mitteldichten Faserplatten (MDF) ............................. 29

2.4 Herkömmliche Bindemittel......................................... 31

2.4.1 Kondensationsharze auf der Basis von Formaldehyd .......................... 31

2.4.1.1 Harnstoff-Formaldehydharze (UF) ............................................... 31

2.4.1.2 Melamin- und Melaminmischharze.................................................. 32

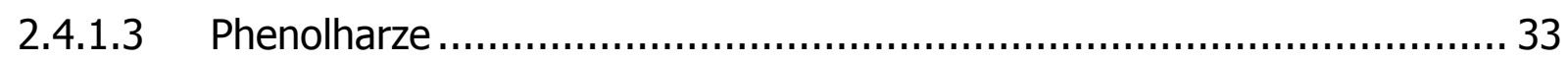

2.4.2 Bindemittel auf der Basis von Isocyanaten ........................................ 33

2.5 Bindemittel auf Basis nachwachsender Rohstoffe ................. 34

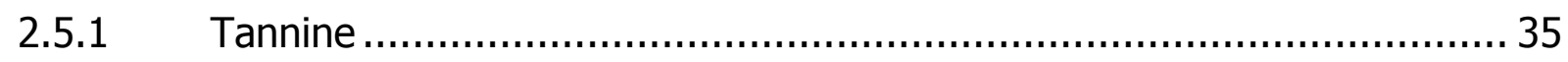

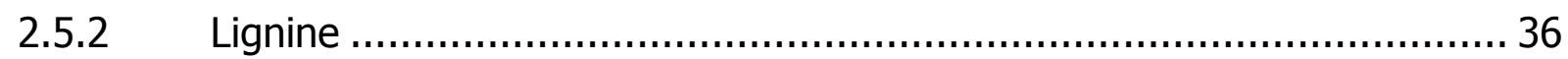

2.5.3 Bindemittel auf Kohlehydratbasis ................................................. 37

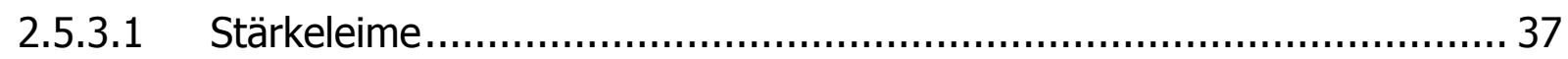

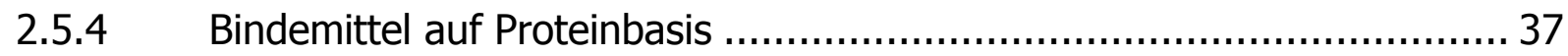

2.5.4.1 Bindemittel auf Basis tierischer Proteine ......................................... 37

2.5.4.2 Bindemittel auf Basis pflanzlicher Proteine ....................................... 38

2.6 Bindungskräfte ........................................................ 39

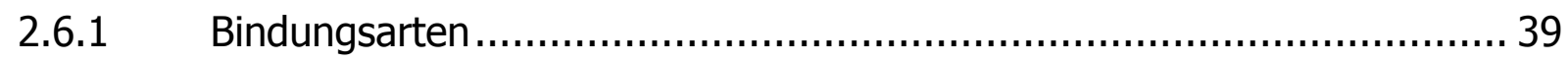

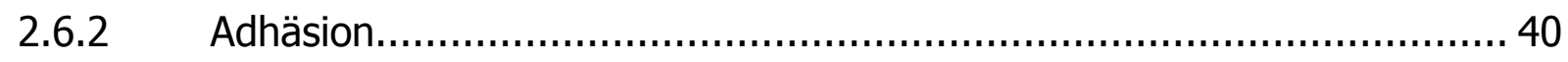

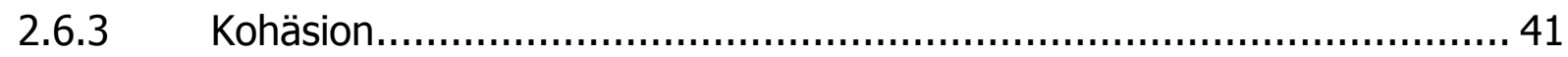

2.7 Konservierung ................................................. 42

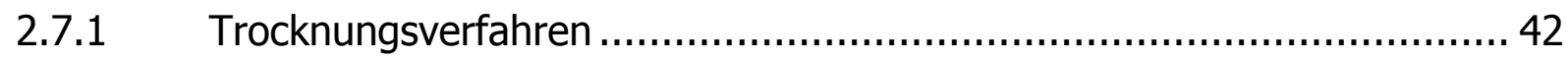

3 Material und Methoden ................................45

3.1 Material .......................................................... 45

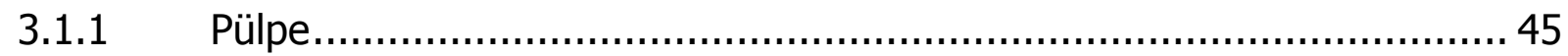

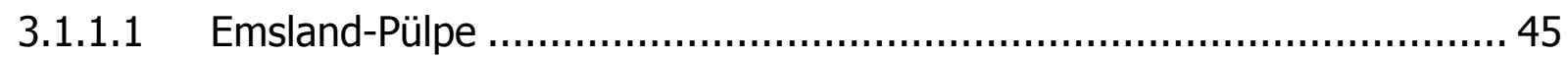

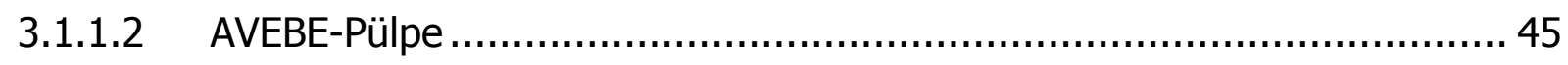

3.1.2 Einsatz von Enzymkomplexen der Firma Novozymes.......................... 46

3.1.3 Einsatz von Enzymkomplexen der Firma AB Enzymes.......................... 47

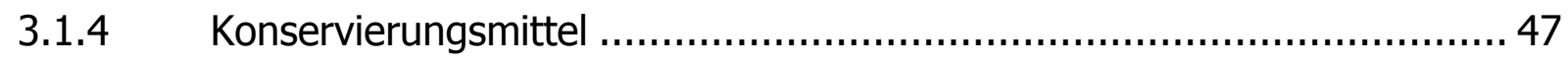

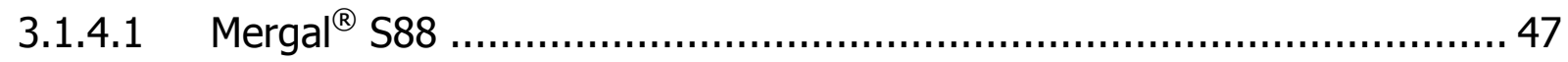


3.1.4.2 Sorbinsäure (Firma Merck, Darmstadt) .......................................... 48

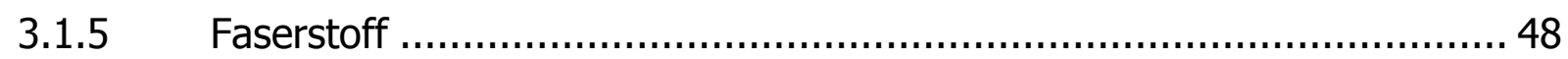

3.1.6 Hydrophobierungsmittel ......................................................... 48

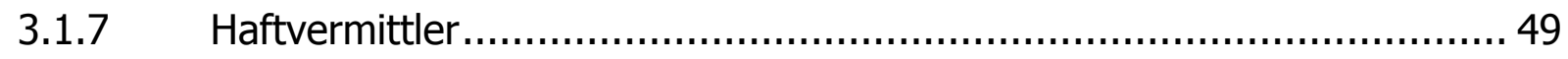

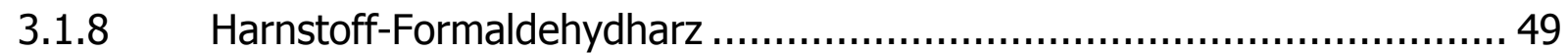

3.1.9 Mikroorganismen für den Abbau von Holzwerkstoffen ......................... 49

3.2 Technische Geräte.................................................. 50

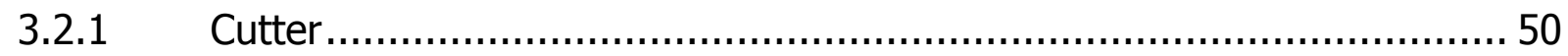

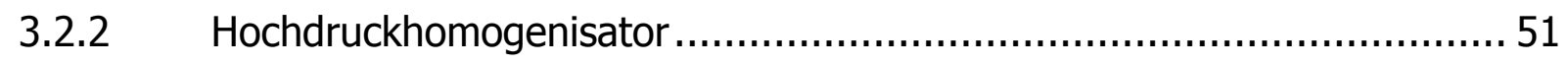

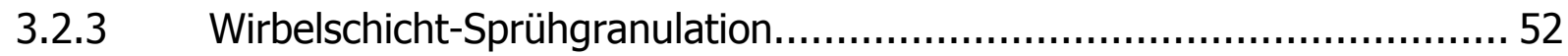

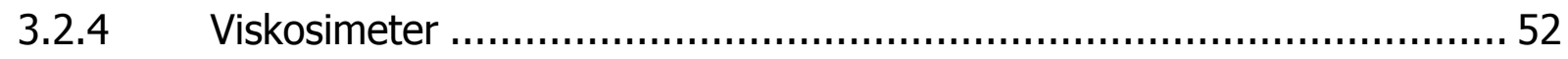

3.2.5 Pilotanlage zur MDF-Herstellung .................................................. 53

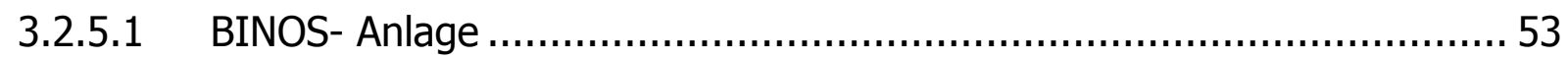

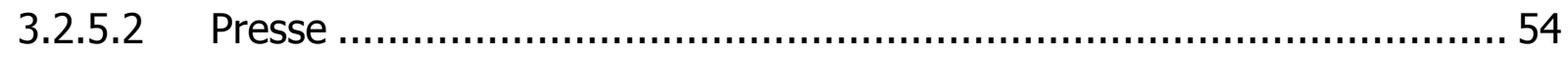

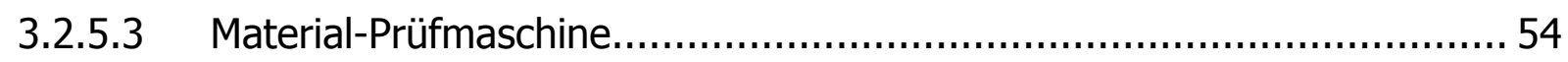

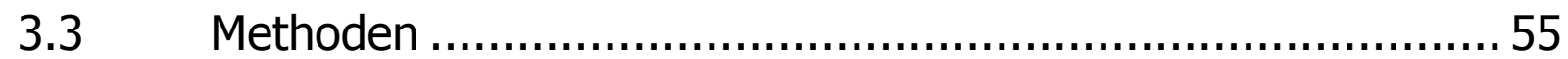

3.3.1 Auswahl und Charakterisierung der Kartoffelpülpe.............................. 55

3.3.2 Wassergehalt der Kartoffelpülpe ................................................... 55

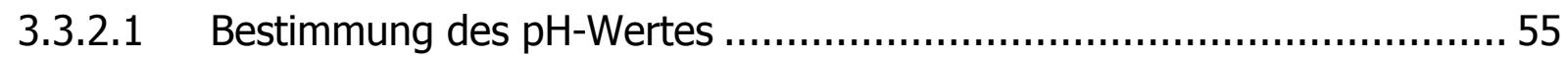

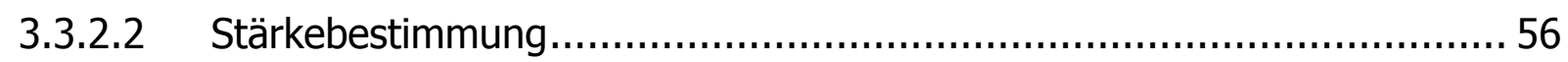

3.3.2.3 Bestimmung des Galacturonangehaltes von AVEBE- und Emsland-Pülpe

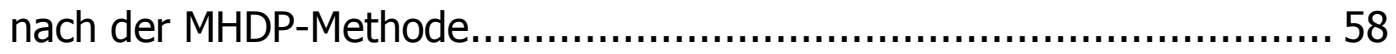

3.3.2.4 Lichtmikroskopische Untersuchungen der Kartoffelpülpe ..................... 58

3.3.2.5 Rasterelektronenmikroskopische (REM) Untersuchungen der Kartoffel-

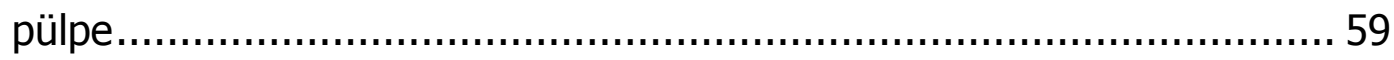

3.3.3 Mechanisch-enzymatischer Aufschluss der Kartoffelpülpe ..................... 59

3.3.3.1 Mechanische Zerkleinerung mit dem Cutter...................................... 59

3.3.3.2 Enzymatischer Aufschluss der Kartoffelpülpe....................................6 60

3.3.3.3 Mechanische Zerkleinerung mit dem Hochdruckhomogenisator.............. 61

3.3.4 Entwässerung der aufgeschlossenen Kartoffelpülpe............................. 61 
3.3.4.1 Entwässerung mit Westphalia Separatoren ...................................... 61

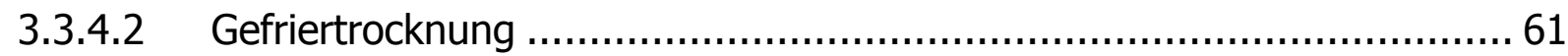

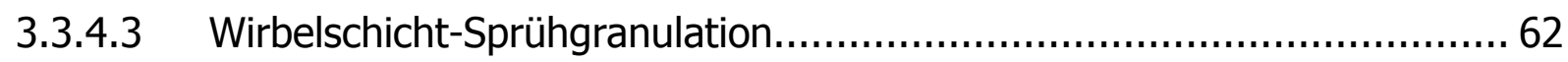

3.3.5 Verwendung der mechanisch-enzymatisch aufgeschlossenen Kartoffelpülpe als Bindemittel zur Herstellung von Holzwerkstoffen .....................63 63

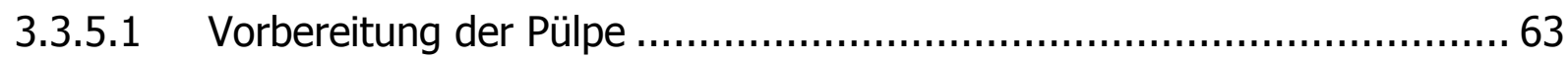

3.3.5.2 Feststoffmessung nach dem mechanisch-enzymatischen Aufschluss ...... 63

3.3.5.3 Berechnung der notwendigen Leimmenge ....................................... 64

3.3.5.4 Beleimung und Weiterverarbeitung der Fasern ...................................65 65

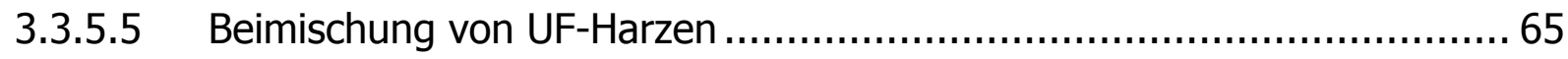

3.3.5.6 Viskositätsmessung der Bindemittelmischungen ................................66

3.3.6 Untersuchung der physikalisch-technologischen Eigenschaften der hergestellten Holzwerkstoffe in Abhängigkeit von der Euro-Norm (EN)

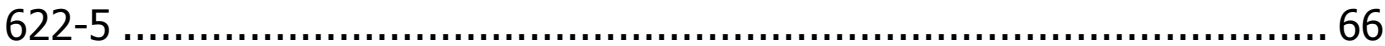

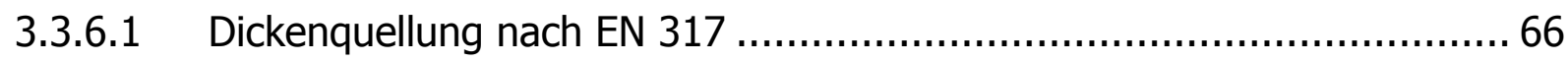

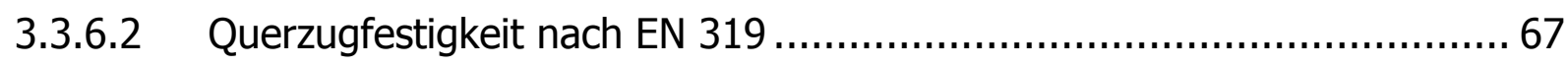

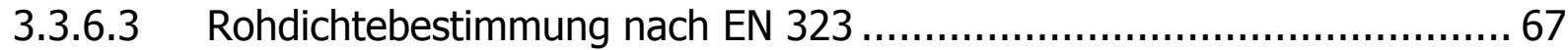

3.3.7 Beständigkeit der hergestellten MDF-Platten gegenüber holzabbauen-

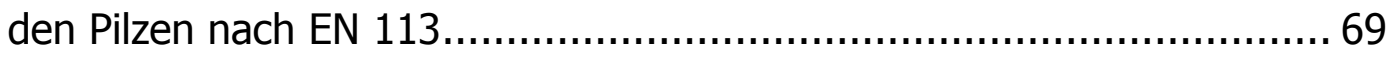

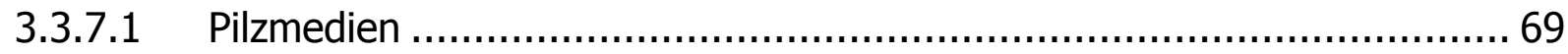

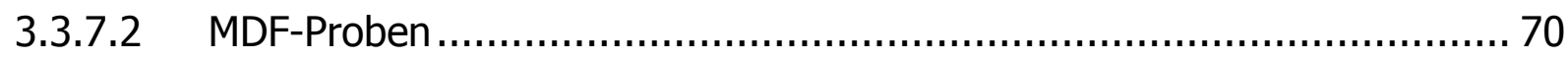

3.3.7.3 Schematischer Versuchsaufbau.................................................... 70

3.3.7.4 Vorbehandlung der Proben ........................................................... 72

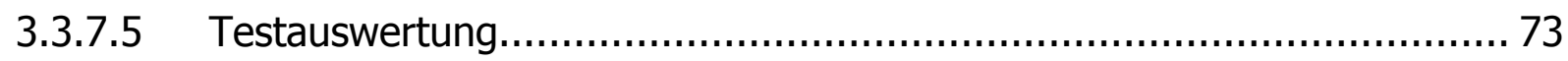

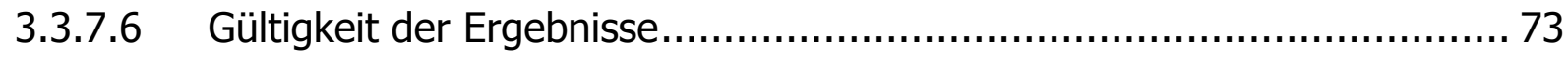

3.3.8 Überwachsungsgrad der MDF-Platten ............................................ 73

$4 \quad$ Ergebnisse und Diskussion .............................75

4.1 Analytische Untersuchungen..................................... 75

4.1.1 Feuchtegehalt der Kartoffelpülpe …............................................. 75

4.1.2 pH-Bereiche der nativen Kartoffelpülpe .......................................... 76

4.1.3 Stärkegehalt der Kartoffelpülpe................................................... 78 
4.1.4 Galacturonangehalt von AVEBE- und Emsland-Pülpe......................... 79

4.2 Mikroskopische Untersuchungen der nativen Kartoffelpülpe ... 80

4.2.1 Lichtmikroskopische Aufnahmen nativer Kartoffelpülpe ...................... 80

4.2.2 Aufnahmen mit dem Rasterelektronenmikroskop ................................ 83

4.3 Verfahren für den Aufschluss von Kartoffelpülpe ................. 85

4.3.1 Mechanischer Aufschluss der Kartoffelpülpe ...................................... 85

4.3.2 Aufschluss der Kartoffelpülpe mit Hilfe von Enzymkomplexen ................ 87

4.3.3 Pülpezerkleinerung mit dem Hochdruckhomogenisator......................... 89

4.4 Methoden zur Trocknung der mechanisch-enzymatisch aufgeschlossenen Kartoffelpülpe................................... 90

4.4.1 Mechanische Vorentwässerung durch Westfalia-Separatoren ................ 90

4.4.2 Trocknung durch Vakuumgefriertrocknung ...................................... 91

4.4.3 Trocknung mit der Wirbelschicht-Sprühgranulation ............................ 92

4.5 MDF-Platten hergestellt mit mechanisch-enzymatisch aufgeschlossener Kartoffelpülpe als Bindemittel .................. 95

4.5.1 Feststoffänderung nach dem mechanisch-enzymatischen Aufschluss...... 95

4.5.2 Rheologische Eigenschaften der mechanisch-enzymatisch aufgeschlossenen Kartoffelpülpe bei der Verwendung als Bindemittel............. 96

4.5.3 Physikalisch-technologische Eigenschaften der hergestellten MDFPlatten nach EN 622-5 ......................................................... 100

4.5.3.1 MDF-Platten hergestellt mit mechanisch-enzymatisch aufgeschlossener Pülpe, UF-Harz und Hydrophobierungsmittel ................... 100

4.5.3.2 MDF-Platten hergestellt mit mechanisch-enzymatisch aufgeschlossener Pülpe, UF-Harz und Haftvermittler .................................. 105

4.5.3.3 MDF-Platten hergestellt mit $100 \%$ mechanisch-enzymatisch aufgeschlossener Pülpe und 2 \% Haftvermittler ............................... 108

4.5.3.4 MDF-Platten hergestellt mit $100 \%$ mechanisch-enzymatisch aufgeschlossener Pülpe unter Zugabe von Hydrophobierungsmittel und Haftvermittler .....

4.5.3.5 Fazit der Prüfung der physikalisch-technologischen Eigenschaften und der Wirtschaftlichkeit der eingesetzten Bindemittel ........................... 114 
4.6 Abbau der MDF-Platten durch Weiß-, Braun- und Moderfäulepilze ........................................................ 117

4.6.1 Überwachsung der MDF-Proben mit Pilzmyzel ................................. 117

4.6.1.1 Myzelwachstum von Trametes versicolor ....................................... 118

4.6.1.2 Myzelwachstum von Coniophora puteana ...................................... 119

4.6.1.3 Myzelwachstum von Chaetomium globosum ................................... 120

4.6.2 Holzabbau durch holzzersetzende Pilze ......................................... 121

4.6.2.1 Holzzersetzung der mit UF-Harz hergestellten Proben ....................... 122

4.6.2.2 Holzzersetzung der mit mechanisch-enzymatisch aufgeschlossener Pülpe hergestellten Proben...................................................... 123

4.6.2.3 Holzzersetzung der Virulenzkontrollen ....................................... 124

4.6.2.4 Fazit des Holzabbaus ............................................................. 125

5 Zusammenfassung...................................128

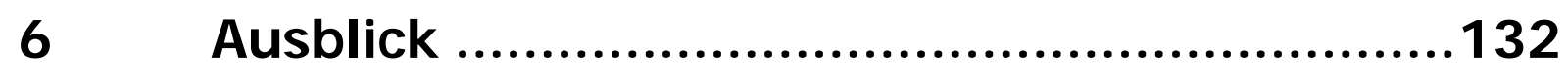

7 Literaturverzeichnis..................................133 


\section{Abbildungsverzeichnis}

Abb. 1-1: Verwendung der Stärke in unterschiedlichen Industriezweigen ................. 2

Abb. 1-2: Verbrauch von Industriekartoffeln in Deutschland seit 1990/01 ............... 3

Abb. 1-3: Schematische Darstellung der Stärkeproduktion. ................................. 4

Abb. 1-4: Die verschiedenen Holzwerkstoffe unterscheiden sich hinsichtlich der verwendeten Ausgangsmaterialien.................................................. 8

Abb. 1-5: Holzwerkstoffanteile in Europa, Stand 1999 ..................................... 11

Abb. 1-6: Entwicklung der europäischen MDF-Produktion von 1992-2003 ............. 11

Abb. 2-1: Schnitt durch die äußeren Gewebe einer Kartoffelknolle....................... 13

Abb. 2-2: Wasserstoffbrückenbindungen innerhalb der einzelnen Galakturonsäure-Moleküle........................................................................ 14

Abb. 2-3: (A) Ionenbindung zwischen zwei Galakturonsäure-Molekülen unter Beteiligung eines Calcium-Ions. (B) Vernetzung von Polygalakturonsäureketten durch Ionenbindung .................................................. 15

Abb. 2-4: Die Cellulose-Fibrillen sind eingebettet in die Matrix, die aus Pektin und Hemicellulose zusammengesetzt ist. Der blaue Bereich stellt die Mittellamelle dar.

Abb. 2-5: Spaltungsmechanismen der pektolytischen Enzyme............................ 21

Abb. 2-6: Reaktion von Pectat- bzw. Pectin-Lyase bei der Spaltung von Pektin ....... 23

Abb. 2-7: Abbau der kristallinen Cellulose durch cellulytische Enzyme.................... 24

Abb. 2-8: Ringmischer mit dem Prinzip der Innenbeleimung ............................... 29

Abb. 2-9: Herstellungsablauf in der industriellen MDF-Fertigung........................ 30

Abb. 2-10: Bindemittel auf der Basis nachwachsender Rohstoffe.......................... 35

Abb. 2-11: Schema zur Auswahl eines geeigneten Trocknungsverfahren; modifiziert nach Kneule .......................................................... 43

Abb. 3-1: Tischcutter für den mechanischen Aufschluss der Kartoffelpülpe............ 51

Abb. 3-2: Aufbau eines Homogenisierventils................................................. 52

Abb. 3-3: Technische Zeichnung der Binos-Pilotanlage ..................................... 53

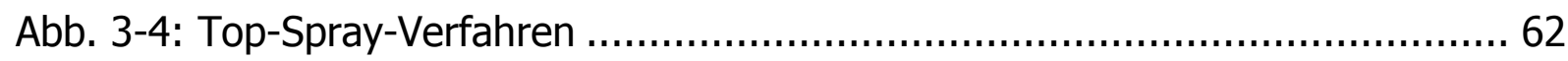

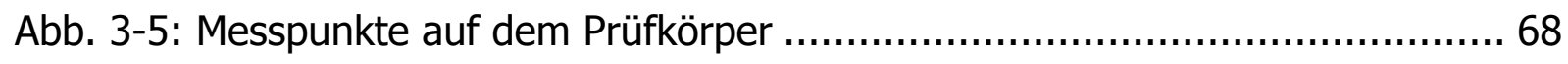

Abb. 3-6: Schematischer Aufbau der Probenverteilung ...................................... 71 
Abb. 4-1: Restfeuchte der untersuchten Pülpesorten der Fa. Emslandstärke und AVEBE.

Abb. 4-2: pH-Wert nativer und enzymatisch aufgeschlossener Kartoffelpülpe

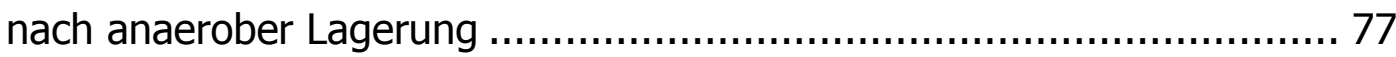

Abb. 4-3: Durchschnittlicher Stärkegehalt der untersuchten Pülpeproben 78

Abb. 4-4: Eichreihe für die Bestimmung des Galacturonangehaltes in Kartoffelpülpe. Die rote Linie zeigt den Gehalt für Emsland-Pülpe an und die grüne Linie den Gehalt für AVEBE-Pülpe

Abb. 4-5: 125-fache Vergrößerung nativer Kartoffelpülpe, eingefärbt mit Rutheniumrot.

Abb. 4-6: 500-fache Vergrößerung von Pülpe mit gut sichtbaren Pektinanteilen in der Zellwand

Abb. 4-7: 125-fache Vergrößerung nativer Kartoffelpülpe, mit eingefärbten

Stärkekörnern

Abb. 4-8: 30-fache Vergrößerung nach dem mechanisch-enzymatischen

Aufschluss der Pülpe.

Abb. 4-9: Native Kartoffelpülpe mit deutlich erkennbaren Zellstrukturen bei einer 150-fache Vergrößerung 84

Abb. 4-10: Enzymatisch aufgeschlossene Kartoffelpülpe mit freien Stärkekörnern bei einer 178x Vergrößerung.

Abb. 4-11: Viskositätsmessung mechanisch aufgeschlossener Kartoffelpülpe. 86

Abb. 4-12: Entwässerungsgrad von AVEBE- und Emslandpülpe nach dem enzymatischen Aufschluss mit unterschiedlichen Enzymkomplexen der Firmen Novozymes und AB Enzymes. die Kontrolle bestand aus nativer Kartoffelpülpe

Abb. 4-13: Relative Teilchengröße der Pülpe nach dem Aufschluss mit dem Hochdruckhomogenisator der Fa. Niro Soavi

Abb. 4-14: Struktur der gefriergetrockneten mechanisch-enzymatisch aufgeschlossenen Kartoffelpülpe 92

Abb. 4-15: Prinzip der Sprühgranulation bei der Trocknung von Flüssigkeiten 93

Abb. 4-16: 400-fache Vergrößerung von mechanisch-enzymatisch aufgeschlossener Pülpe, die mit der Wirbelschicht-Sprühgranulation getrocknet wurde. 
Abb. 4-17: Struktur der mechanisch-enzymatisch aufgeschlossenen Kartoffelpülpe nach der Wirbelschicht-Sprühgranulation

Abb. 4-18: Vergleich der Kartoffelpülpe hinsichtlich des Feststoffgehaltes vor und nach dem mechanisch-enzymatischen Aufschluss.

Abb. 4-19: Viskositätskurven der unterschiedlichen Pülpe- und UFHarzmischungen mit Zugabe von $1 \%$ Hydrophobierungsmittel (HPM).

Abb. 4-20: Viskositätskurven der Pülpe- und UF-Harzmischungen mit Zugabe von Haftvermittler (HVM)

Abb. 4-21: Rohdichten (gemittelt) der MDF-Platten, die mit Pülpe, UF-Harz und $1 \%$ Hydrophobierungsmittel verleimt wurden.

Abb. 4-22: Quellung nach 24 Stunden und Querzugfestigkeit der MDF-Platten, die mit $100 \%$ mechanisch-enzymatisch aufgeschlossener Pülpe als Bindemittel hergestellt wurden.

Abb. 4-23: Quellung nach 24 Stunden und Querzugfestigkeit der MDF-Platten, die mit einem Gemisch aus $80 \%$ mechanisch-enzymatisch aufgeschlossener Pülpe und 20 \% UF-Harz als Bindemittel hergestellt wurden.

Abb. 4-24: Quellung nach 24 Stunden und Querzugfestigkeit der MDF-Platten, die mit einem Gemisch aus $70 \%$ mechanisch-enzymatisch aufgeschlossener Pülpe und 30 \% UF-Harz als Bindemittel hergestellt wurden.

Abb. 4-25: Quellung nach 24 Stunden und Querzugfestigkeit der MDF-Platten, die mit einem Gemisch aus $60 \%$ mechanisch-enzymatisch aufgeschlossener Pülpe und $40 \%$ UF-Harz als Bindemittel hergestellt wurden. 104

Abb. 4-26: Quellung nach 24 Stunden und Querzugfestigkeit der MDF-Platten, die mit einem Gemisch aus $50 \%$ mechanisch-enzymatisch aufgeschlossener Pülpe und 50 \% UF-Harz als Bindemittel hergestellt wurden.

Abb. 4-27: Rohdichten (gemittelt) der MDF-Platten, die mit mechanischenzymatisch aufgeschlossener Kartoffelpülpe und UF-Harz unter Zugabe von einem Prozent Haftvermittler (bezogen auf atro Faser) hergestellt wurden. 106

Abb. 4-28: Quellung nach 24 Stunden und Querzugfestigkeit der MDF-Platten, die mit $100 \%$ mechanisch-enzymatisch aufgeschlossener Pülpe als 
Bindemittel hergestellt wurden. Zugabe von einem Prozent Haftvermittler 1154.

Abb. 4-29: Quellung nach 24 Stunden und Querzugfestigkeit der MDF-Platten, die mit einem Gemisch aus $80 \%$ mechanisch-enzymatisch aufgeschlossener Pülpe und 20 \% UF-Harz als Bindemittel hergestellt wurden. Zugabe von einem Prozent Haftvermittler 1154.

Abb. 4-30: Quellung nach 24 Stunden und Querzugfestigkeit der MDF-Platten, die mit einem Gemisch aus $50 \%$ mechanisch-enzymatisch aufgeschlossener Pülpe und 50 \% UF-Harz als Bindemittel hergestellt wurden. Zugabe von $1 \% 1154$. 108

Abb. 4-31: Rohdichten (gemittelt) der MDF-Platten, die mit 100 \% Pülpe als Bindemittel und $2 \%$ Haftvermittler (bezogen auf atro Faser) hergestellt wurden.

Abb. 4-32: Quellung nach 24 Stunden und Querzugfestigkeit der MDF-Platten, die mit $100 \%$ mechanisch-enzymatisch aufgeschlossener Pülpe als Bindemittel und $2 \%$ Haftvermittler (1154) hergestellt wurden.

Abb. 4-33: Quellung nach 24 Stunden und Querzugfestigkeit der MDF-Platten, die mit $100 \%$ mechanisch-enzymatisch aufgeschlossener Pülpe als Bindemittel und $2 \%$ Haftvermittler (2909) hergestellt wurden.

Abb. 4-34: Rohdichten (gemittelt) der MDF-Platten, die mit $100 \%$ Pülpe als Bindemittel hergestellt wurden. Additive waren Haftvermittler und Hydrophobierungsmittel.

Abb. 4-35: Quellung nach 24 Stunden und Querzugfestigkeit der MDF-Platten, die mit $100 \%$ mechanisch-enzymatisch aufgeschlossener Pülpe als Bindemittel und $1 \%$ Haftvermittler (1154) sowie $1 \%$ Hydrophobierungsmittel (bezogen auf atro Faser) hergestellt wurden.

Abb. 4-36: Quellung nach 24 Stunden und Querzugfestigkeit der MDF-Platten, die mit $100 \%$ mechanisch-enzymatisch aufgeschlossener Pülpe als Bindemittel und $1 \%$ Haftvermittler (2909) sowie $1 \%$ Hydrophobierungsmittel (bezogen auf atro Faser) hergestellt wurden.

Abb. 4-37: Quellung nach 24 Stunden und Querzugfestigkeit der MDF-Platten, die mit $100 \%$ mechanisch-enzymatisch aufgeschlossener Pülpe als Bindemittel und $2 \%$ Haftvermittler (1154) sowie $2 \%$ Hydrophobierungsmittel (bezogen auf atro Faser) hergestellt wurden.

Abb. 4-38: Überwachsungsgrad der MDF-Proben, die mit Trametes versicolor inkubiert wurden (UF = nur UF-Harz; UFF = UF-Harz mit Zugabe 
von Fungizid; KP = nur Kartoffelpülpe; KPF = Kartoffelpülpe mit Zugabe von Fungizid).

Abb. 4-39: Überwachsungsgrad der MDF-Proben, die mit Coniophora puteana inkubiert wurden (UF = nur UF-Harz; UFF = UF-Harz mit Zugabe von Fungizid; KP = nur Kartoffelpülpe; KPF = Kartoffelpülpe mit Zugabe von Fungizid).

Abb. 4-40: Überwachsungsgrad der MDF-Proben, die mit Chaetomium globosum inkubiert wurden (UF = nur UF-Harz; UFF = UF-Harz mit Zugabe von Fungizid; KP = nur Kartoffelpülpe; KPF = Kartoffelpülpe mit Zugabe von Fungizid).

Abb. 4-41: Abbaurate der MDF-Proben, die mit Harnstoff-Formaldehydharz als Bindemittel hergestellt wurden (UF = nur UF-Harz; UFF = UF-Harz mit Zugabe von Fungizid).

Abb. 4-42: Abbaurate der MDF-Proben, die mit mechanisch-enzymatisch aufgeschlossener Kartoffelpülpe als Bindemittel hergestellt wurden (KP = nur Kartoffelpülpe; KPF = Kartoffelpülpe mit Zugabe von Fungizid).....123

Abb. 4-43: Abbaurate der Virulenzkontrollen, die nur mit UF-Harz (UF) oder mechanisch-enzymatisch aufgeschlossener Kartoffelpülpe (KP) als Bindemittel hergestellt wurden, ohne Zugabe von Fungizid.

Abb. 4-44: Vergleich der Quellung der MDF-Proben am Beispiel zweier Proben, die mit mechanisch-enzymatisch aufgeschlossener Kartoffelpülpe (links) und UF-Harz (rechts) als Bindemittel hergestellt wurden. Inkubiert wurden die Proben mit C. puteana. 


\section{Tabellenverzeichnis}

Tab. 1-1: Anfallende Nebenprodukte pro Tonne verarbeiteter Kartoffeln ................ 4

Tab. 1-2: Allgemeine Einteilung von Faserplatten hinsichtlich der Rohdichte........... 10

Tab. 2-1: Einteilung der Pektinasen nach ihrer Wirkungsweise ............................ 20

Tab. 2-2: Einteilung der mitteldichten Faserplatten nach DIN EN 316 und DIN

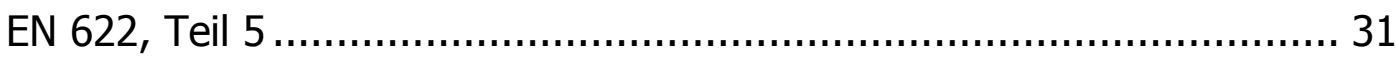

Tab. 2-3: Vor- und Nachteile von PMDI im Vergleich zu anderen Bindemitteln

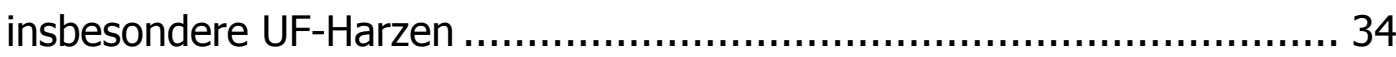

Tab. 3-1: Verwendete Fäuleerreger für den Abbau von Holzwerkstoffen ................ 50

Tab. 3-2: Versuchsreihen für die Verwendung von $100 \%$ mechanischenzymatisch aufgeschlossener Pülpe als Bindemittel..............................64 64

Tab. 3-3: Mischungsverhältnis [\%] der einzelnen Versuchsreihen..........................65

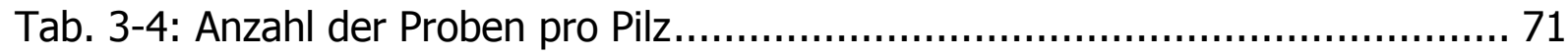

Tab. 3-5: Verteilung der MDF-Proben auf die Gläser.......................................... 72

Tab. 3-6: Verteilung der MDF-Proben auf die Gläser....................................... 72

Tab. 3-7: Überwachsungsgrad der Proben während der Inkubation mit holzzersetzenden Pilzen .................................................................. 74

Tab. 4-1: Auswirkung des mechanischen Aufschlusses auf die Teilchengröße

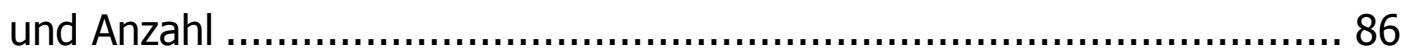

Tab. 4-2: Bezeichnung der Proben, die mit unterschiedlichem Druck im Hochdruckhomogenisator zerkleinert wurden...................................... 89

Tab. 4-3: Aufkonzentrierung der Pülpe durch Separatoren .................................. 91

Tab. 4-4: Materialkosten für den enzymatischen Aufschluss von $1 \mathrm{t}$ Kartoffelpülpe 


\section{Abkürzungsverzeichnis}

\begin{tabular}{ll}
$\%$ & Prozent \\
$\alpha$ & Alpha \\
$\beta$ & Beta \\
$\Delta$ & Delta \\
$\rho$ & Rho (griech. Buchstabe) = Symbol für Rohdichte \\
$\circledR$ & eingetragene Marke \\
${ }^{\circ} \mathrm{C}$ & Grad Celsius \\
$\mu \mathrm{g}$ & Mikrogramm \\
$\mu \mathrm{m}$ & Mikrometer (10-6 Meter \\
Abb. & Abbildung \\
ADP & Adenosindiphosphat \\
AGP & Arabine-Galactan-Protein \\
AGS & Amyloglucosidase \\
ATP & Adenosintriphosphat \\
atro & absolut trocken \\
bar & Bar = veralt. Maßeinheit des Druckes \\
bidest. & zweifach destilliertes Wasser \\
C/N & Verhältnis von Kohlenstoff zu Stickstoff \\
ca. & circa \\
Ca ${ }^{2+}$ & Calcium-Ion \\
CTMP & chemo-thermo-mechanical-pulp \\
DIN & Deutsche Industrie Norm(en) \\
DMSO & Dimethylsulfoxid \\
EN & Europäische Norm(en) \\
et al. & et alii (lat.) = und andere \\
EU & Europäische Union \\
FDU & Ferment-Depectinisation-Units \\
$\mathrm{g}$ & Gramm \\
g/cm ${ }^{3}$ & Gramm pro Kubikzentimeter = Maß für die Rohdichte \\
G-6-P-DH & Glucose-6-Phosphat-Dehydrogenase \\
GA & Galacturonsäure \\
h & hour (Stunde) \\
\hline
\end{tabular}




\begin{tabular}{|c|c|}
\hline $\mathrm{H}^{+}$ & Wasserstoff-Ion \\
\hline HK & Hexokinase \\
\hline HPRG & hydroxyprolinreiches Glykoprotein \\
\hline ISO & International Standardisation Organisation \\
\hline Jh. & Jahrhundert \\
\hline Kap. & Kapitel \\
\hline kat & katal \\
\hline $\mathrm{kg}$ & Kilogramm \\
\hline $\mathrm{kg} / \mathrm{m}^{3}$ & Kilogramm pro Kubikmeter = Maß für die Rohdichte \\
\hline KP & Proben mit Kartoffelpülpe \\
\hline KPF & Proben mit Kartoffelpülpe und Fungizid \\
\hline L & Liter \\
\hline lutro & lufttrocken \\
\hline M & Molarität \\
\hline $\mathrm{m}$ pas/s & Millipascal pro Sekunde \\
\hline m.-e. & mechanisch-enzymatisch \\
\hline $\mathrm{m} / \mathrm{s}^{2}$ & $\begin{array}{l}\text { Meter / (Sekunde zum Quadrat) = Einheit für die } \\
\text { Beschleunigung }\end{array}$ \\
\hline $\mathrm{m}^{3}$ & Kubikmeter \\
\hline mbar & Millibar \\
\hline MDF & Mitteldichte Faserplatte \\
\hline $\mathrm{mg}$ & Milligramm \\
\hline $\min$. & Minuten \\
\hline Mio. & Millionen \\
\hline $\mathrm{ml}$ & Milliliter \\
\hline $\mathrm{mm}$ & Millimeter \\
\hline $\mathrm{mm}^{3}$ & Kubikmillimeter \\
\hline mol & mol = Einheit der Stoffmenge \\
\hline Mrd. & Milliarden \\
\hline $\mathrm{N}$ & Normalität \\
\hline $\mathrm{n}$ & unbestimmte Anzahl \\
\hline $\mathrm{N} / \mathrm{mm}^{2}$ & Newton pro Quadratmillimeter \\
\hline $\mathrm{NADP}^{+}$ & Nicotinamidadenindinucleotidphosphat, oxidiert \\
\hline $\mathrm{NADPH}+\mathrm{H}^{+}$ & Nicotinamidadenindinucleotidphosphat, reduziert \\
\hline $\mathrm{nm}$ & Nanometer \\
\hline
\end{tabular}




$\begin{array}{ll}\text { pas/s } & \text { Pascal pro Sekunde } \\ \mathrm{pH} & \text { negativer dekadischer Logarithmus der Protonenkonztration } \\ \mathrm{rpm} & \text { rounds per minute (Umdrehungen / Minute) } \\ \mathrm{s.} & \text { siehe } \\ \mathrm{s}^{-1} & \text { Einheit der Scherrate } \\ \mathrm{t} & \text { Tonnen } \\ \text { Tab. } & \text { Tabelle } \\ \text { TMP } & \text { thermo-mechanical-pulp } \\ \text { U } & \text { units } \\ \text { UF } & \text { Harnstoff-Formaldehyd oder Proben mit UF-Harz } \\ \text { UFF } & \text { Proben mit Harnstoff-Formaldehydharz und Fungizid } \\ \text { UV } & \text { Ultraviolett } \\ \text { vgl. } & \text { vergleiche } \\ \text { Vol. } & \text { Volumen } \\ \text { z. B. } & \text { zum Beispiel }\end{array}$





\section{$1 \quad$ Einleitung}

Zurzeit werden in der Industrie, insbesondere in der chemischen Industrie, größtenteils Stoffe eingesetzt, die auf petrolchemischen Rohstoffen basieren. Der Nachteil dieser Rohstoffe ist die zu erwartende Verknappung fossiler Ressourcen. Daher ist in den letzten Jahren die alternative Verwendung nachwachsender Rohstoffe immer stärker in den Vordergrund getreten. Unter nachwachsenden Rohstoffen versteht man organische Stoffe aus pflanzlichem oder tierischem Ursprung, die ganz oder in Teilen als Rohstoffe für die Industrie oder als Energieträger genutzt werden. Im Gegensatz zu fossilen Rohstoffen erneuern sie sich jährlich oder in überschaubaren Zeiträumen (http://www.carmen-ev.de, Download vom 15.01.2005)

Jährlich entstehen durch Photosynthese ca. 170 Mrd. t Biomasse mit einem jährlichen Nutzungsanteil von etwa 6 Mrd. $t$ (WARVEL, 1998). Ein großer Teil davon dient der Nahrungsproduktion. Der übrige Anteil besteht aus nachwachsenden Rohstoffen aus land- und forstwirtschaftlichen Nutzpflanzen, hauptsächlich Holz, Mais, Kartoffeln, Weizen und Ölsaaten. Aus diesen Primärprodukten werden die Inhaltsstoffe gewonnen, die für eine chemische und technische Verarbeitung geeignet sind, z. B. natürliche Öle, Fette, Stärke, Cellulose und Zucker (WARVEL, 1998). Man unterscheidet diese in

- Werk-, Faser- und Gerüststoffe,

- Chemieroh- und Chemiegrundstoffe und

- Heiz- und Kraftstoffe (BMFt, 1990).

\subsection{Stärkeproduktion}

Die Verwendung von Stärke nimmt, nach Fetten und Ölen, den größten Anteil in der chemischen Industrie ein. Die Anwendungsbereiche von Stärke sind äußerst vielseitig, z. B. für die Gewinnung von Ethanol, Zucker, Glycerin, Aceton, Butanol, Essigsäure u.a. (SARATHI REDDY u. BASAPPA, 1993). Kationische Stärken und deren Folgeprodukte werden in der Papierindustrie als Füll- und Pigmentstoffe eingesetzt (MAURER, 1998). Ein breites Verwendungsspektrum der Stärke und ihrer Produkte findet sich im Einsatz als Klebstoff z. B. in der Wellpappen-, Klebeband- und Hülsenherstellung. Als Bindemittel in der Gips- und Mineralfaserplatten-Herstellung und bei der Herstellung von Gussformen (STROOT, 2001 u. POTENTE et al., 1991). 
Die Verwendung der Stärke ist sowohl im Nahrungsmittelbereich als auch im NonFood Bereich äußerst vielseitig (s. Abb. 1-1). Daher sind die Forschung und Industrie sehr daran interessiert immer wieder neue Gebiete für eine sinnvolle Nutzung der Stärke zu erschließen (MITTENZWEY et al., 1998). Zu den wichtigsten Stärkelieferanten zählen Weizen, Mais und Kartoffeln. Die Kartoffelernte für das Produktionsjahr 2000/1 betrug in der EU ca. 48 Mio. t. Davon gingen ca. $60 \%$ in den Nahrungsverbrauch und ca. $15 \%$ in die industrielle Verarbeitung und Verwertung. Auf Deutschland entfielen dabei 5,5 Mio. t Industriekartoffeln, wovon 2,8 Mio. $\mathrm{t}$ für die Stärkeherstellung eingesetzt wurden (s. Abb. 1-2).

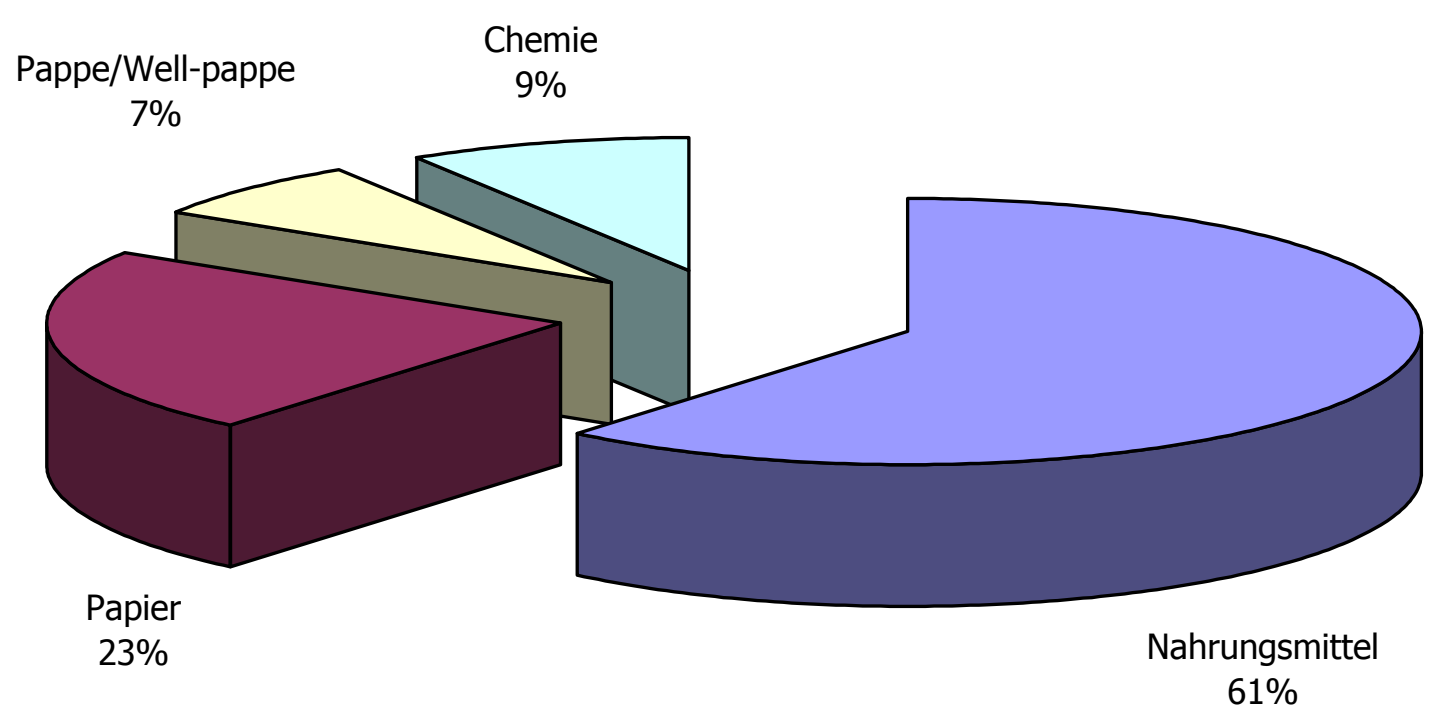

Abb. 1-1: Verwendung der Stärke in unterschiedlichen Industriezweigen (IENICA, 2003)

Der Anteil der zu verarbeitenden Menge an den insgesamt vorhandenen Kartoffeln stieg von gut $20 \%$ Mitte der 70er Jahre auf derzeit über $50 \%$ an. Stärkekartoffeln sind damit seit Ende der 80er Jahre die hinsichtlich der Verwendungsart größte Gruppe bei den zu verarbeitenden Kartoffeln (AGRARMÄRKTE, 2003). Seit 1995 gilt für die Mitgliedsstaaten der EU eine Kartoffelstärkequote. Dies bedeutete für das Produktionsjahr 2001/2002 eine EU-Gesamtmenge von 1,76 Mio. t Stärke und für Deutschland eine Produktionsmenge von 656.298 t (http://www.starch.dk, Download vom 14.07.04).

Die Kartoffel als Stärkelieferant hat den Vorteil, dass sie hohe Erträge pro Hektar liefert, eine höhere Quellkraft und Viskosität hat als ihre Konkurrenten (Weizen, Mais, etc.) und die größten Stärkekörner besitzt (http://www.biosicherheit.de, Download 
vom 20.09.2004). Anders als die ganzjährige Stärkegewinnung aus Mais oder Getreide, kann die Kartoffelstärke allerdings nur halbjährlich während der Kampagne von August bis Februar erfolgen. Eine Einlagerung der Kartoffeln ist aufgrund des hohen Wasseranteils nicht ohne Qualitätsverlust möglich (STROOT, 2001).

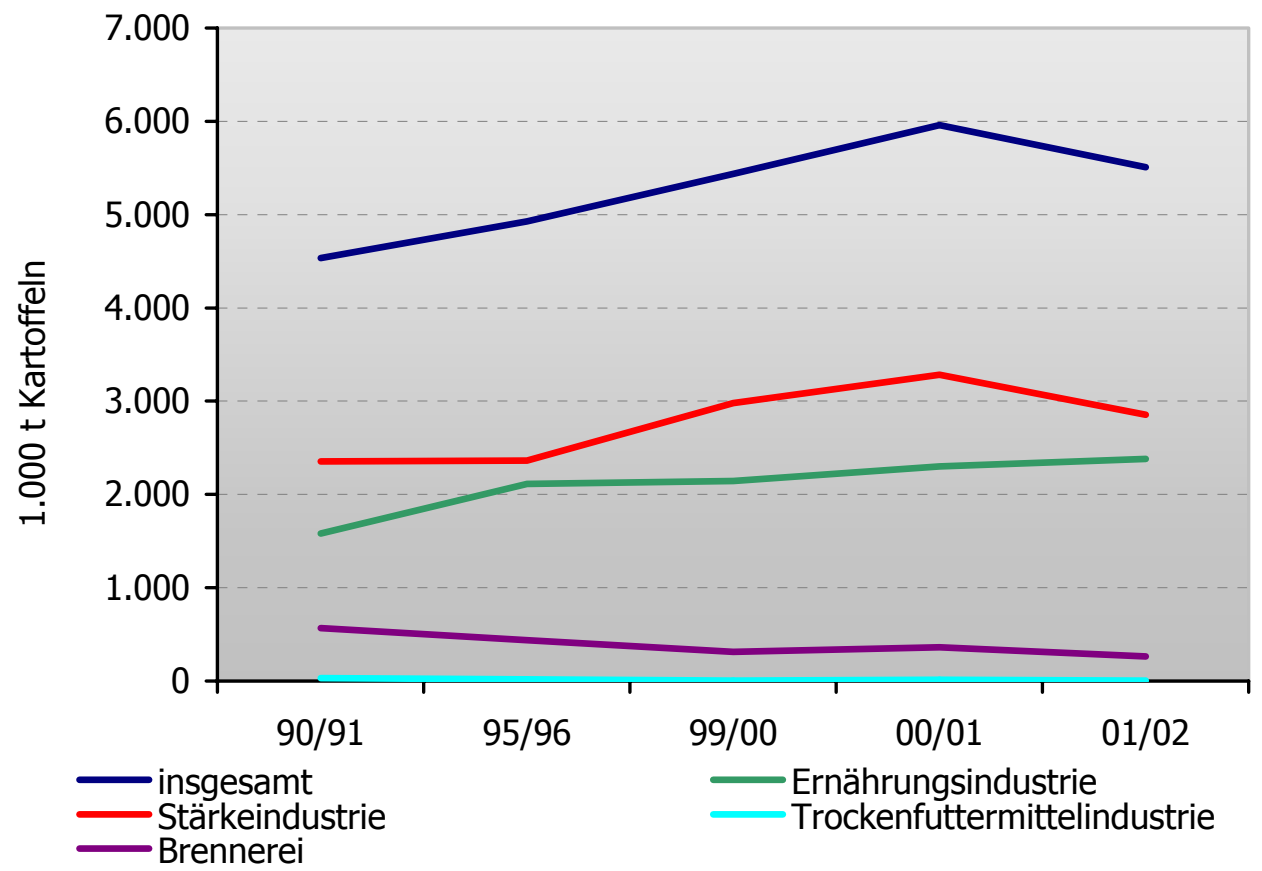

Abb. 1-2: Verbrauch von Industriekartoffeln in Deutschland seit 1990/01 (AGRARMÄRKTE, 2003)

Bei der Stärkeproduktion, insbesondere aus Kartoffeln, fallen enorme Mengen an Abfall an, wie in der Tab. 1-1: Anfallende Nebenprodukte pro Tonne verarbeiteter Kartoffeln (Olson, 2000) ersichtlich. Die größten Anteile machen dabei das Fruchtwasser und die so genannte Kartoffelpülpe aus. Bedingt durch den Produktionsprozess bei der Kartoffelstärkeherstellung (s. Abb. 1-3) besteht die Pülpe zu ca. $95 \%$ aus Restwasser. Aufgrund dieses hohen Wasseranteils und der in Pülpe reichlich vorhandenen Aminosäuren sowie organischen Polymere bietet sich dem autochthonen Mikroorganismenspektrum ein reichhaltiges Nährmedium (KRUSENBAUM, 1991). Dadurch unterliegt die unbehandelte Pülpe sehr schnell einem mikrobiellen Abbau. 


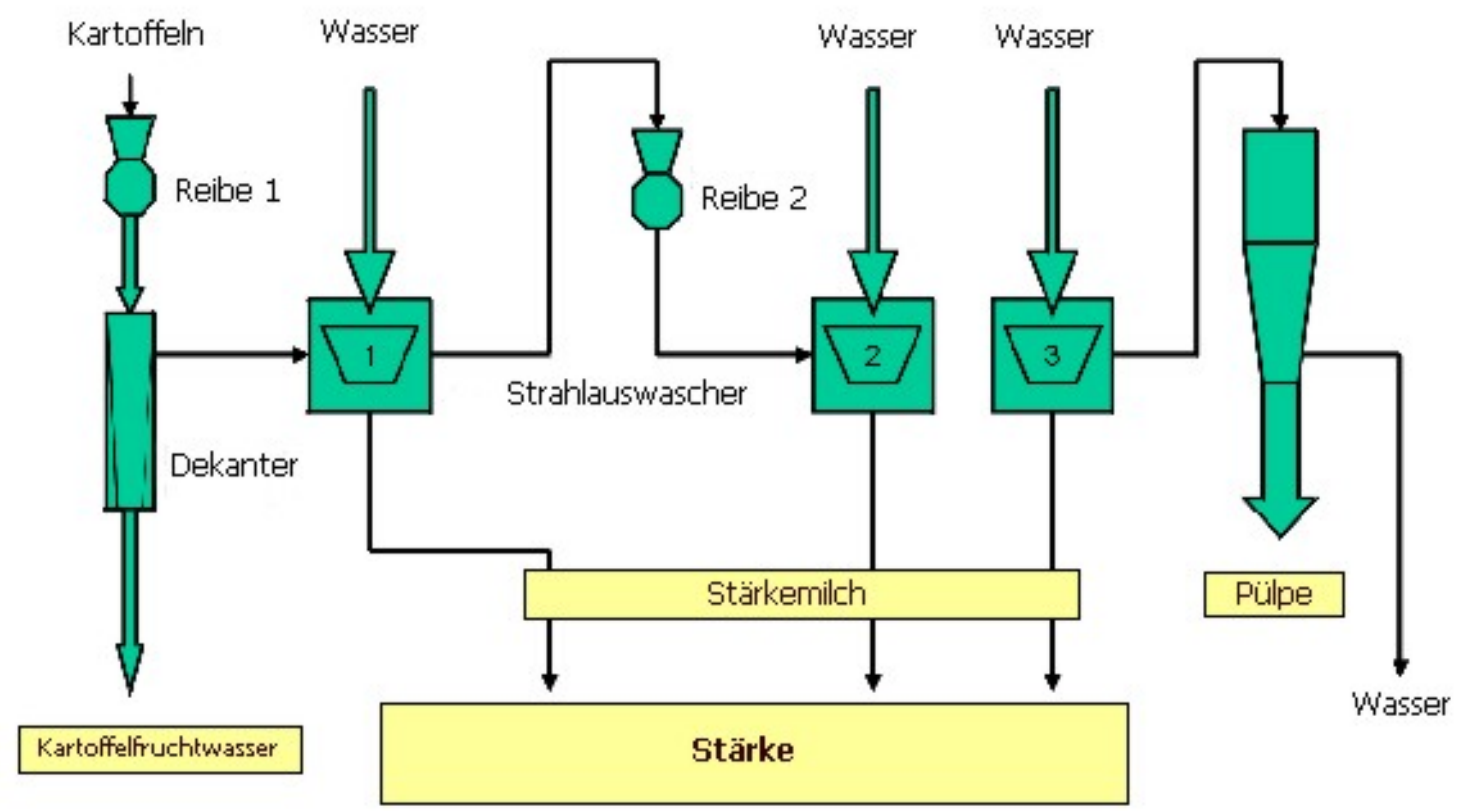

Abb. 1-3: Schematische Darstellung der Stärkeproduktion (verändert nach KEMPF, 1980).

Tab. 1-1: Anfallende Nebenprodukte pro Tonne verarbeiteter Kartoffeln (OLSON, 2000)

20 Liter Steine und Kies

40 Liter Boden und Sand

10 Liter Stroh

250 Liter Ausschwemmwasser

700 Liter Fruchtwasser (4-5 \% Trockensubstanz)

235 kg Pülpe (7-8 \% Trockensubstanz)

\subsubsection{Kartoffelpülpe und ihre Verwendung}

Die Stärkeindustrie ist mittlerweile in der Lage, die anfallende Pülpe umgehend zu Viehfutter weiterzuverarbeiten, wobei dieser Vorgang mit hohem energetischen Aufwand verbunden ist. Die Trocknung des Materials ist ein enormer Kostenfaktor für die Stärkeindustrie, weil sie die Pülpe erst mechanisch vorentwässern muss und anschließend in Stromtrocknern bei ca. $300{ }^{\circ} \mathrm{C}$ thermisch dehydratisiert (KEMPF, 
1980). Die Verwendung als Futtermittel ist aber nur beschränkt möglich, da die Verträglichkeit für die Tiere nicht optimal ist. Schweine sind nicht in der Lage, die zum Teil intakten Stärkezellen aufzuschließen. Man muss der Pülpe noch zusätzlich Fette und Proteine hinzufügen, allerdings kommt es nach länger andauernder Fütterung mit Kartoffelpülpe zu Durchfallerscheinungen, so dass eine alleinige Fütterung mit Kartoffelpülpe nicht in Frage kommt. Es handelt sich bei der Verfütterung eher um eine besondere Art der Entsorgung als um eine wirklich wertschöpfende Verwendung.

Eine industrielle Nutzung der Kartoffelpülpe wäre daher für die Stärkeindustrie von großer Bedeutung. Deshalb wurde derzeit auf sehr verschiedenen Wegen versucht, die Abfallprodukte Kartoffelfruchtwasser und -pülpe zu nutzen und daraus Rohstoffe herzustellen, welche aufgrund ihrer rein biologischen Komponenten und ihrer beträchtlich anfallenden Menge von großem ökologischen und ökonomischen Wert sein dürften. Mehrere Arbeitsgruppen haben daher bereits nach neuen Wegen gesucht, das Abfallprodukt Kartoffelpülpe für neue Verwendungszwecke einzusetzen.

In der Lebensmittelindustrie gab es bereits einige Ansätze zur Nutzung der Pülpe, wie z. B. die Gewinnung von Pektinpräparaten (VöLKSEN u. KRÖNER, 1944; ABOUSTEIT u. KeMPF, 1974; GsChWEND u. KeMPF, 1978; ABOUSTEIT, 1978; TURQUoIs et al., 1999). Die Herstellung von Ballaststoffpräparaten nach enzymatischer Behandlung (GIESEMANN u. KNOBLOCH, 1979; DONGOWSKI, 1993) und der Einsatz als Lebensmittelzusatzstoff nach Dampfbehandlung und chemischer Bleichung (WilliamS, 1973). Weitere Verwendungsmöglichkeiten zeigten sich in der Herstellung von Instantpüree, wo die Kartoffelpülpe zur Konsistenzverbesserung zugefügt wurde (BAUER, 1979), ebenso in der Zubereitung von Soßen, Backwaren, Kompott und Marmeladen (HUCHETTE u. BUSSIÈRE, 1976).

Die folgende Auflistung zeigt weitere Aufgabengebiete und Zielvorstellungen zur Nutzung der Kartoffelpülpe und des Fruchtwassers mit Angabe der beteiligten Arbeitsgruppen (vgl. HiLlEBRANDT, 1994):

- Gewinnung von Alkohol aus der Kartoffelpülpe (MARIHART, 1983)

- Gewinnung von Pektin und Stärke aus der Kartoffelpülpe zur Herstellung von Kosmetika (BADER et al., 1989)

- Gewinnung von extrazellulären Enzymen aus Pilzen unter der Verwendung von Kartoffelfruchtwasser und -pülpe als Substrat (KISHORE et al., 1988)

- Gewinnung von Sirup aus Kartoffelpülpe für die Kartoffelchip- und Pommes fritesProduktion (SLOMINSKA und STAROGARDZKA, 1987) 
- Gewinnung von Phenoloxidasen aus Weißfäulepilzen unter Verwendung von Kartoffelfruchtwasser und -pülpe als Substrat statt der bisher verwendeten synthetischen Nährmedien (KHARAZIPOUR et al., 1990)

- Kartoffelpülpe und Kartoffelfruchtwasser als Nährlösung zur Fermentation von Laccase-produzierenden Weißfäulepilzen (SHEKHOLESLAMI, 1991)

- Gewinnung von Methan aus Kartoffelfruchtwasser und -pülpe (WEILAND und SiNTAWARDANI, 1991)

- Anzucht von Pilzmyzelien mit Hilfe von Kartoffelpülpe (MAJCHERCZYK et al., 1991 a)

- Abbau von organischen Schadstoffen mit Hilfe von ligninabbauenden Mikroorganismen unter Verwendung von Kartoffelpülpe als Mischkomponente des zu dekontaminierenden Materials (MAJCHERCZYK et al., 1991 b)

Neuere Entwicklungen sind:

- Die Gewinnung von Asparaginsäure aus Kartoffelfruchtwasser (Fa. AVEBE Foxhol, Niederlande)

- Optimierung eines Substrates auf der Basis von Kartoffelpülpe und -fruchtwasser für die Anzucht von Pilzen (KRUSENBAUM, 1991)

- Herstellung von Formkörpern und Formpresslingen aus holz- und cellulosehaltigen Stoffen unter Verwendung von Kartoffelpülpe als Ersatzstoffund Bindemittelkomponente (MAYER et. al., 1990 und 1991)

- Herstellung verrottbarer Formkörper (z. B. Pflanztöpfe für die Anzucht) unter Verwendung von Kartoffelpülpe als Bindemittel (KHARAZIPOUR et al., 1994a)

- Direct utilization of potato-starch processing wastes by fungal fermentation (KHARAZIPOUR et al., 1994b)

- Formkörper, insbesondere in Form einer Faserplatte (KHARAZIPOUR et al., 1994C)

- Verwendung von Kartoffelpülpe und- fruchtwasser als Nährmedium zur Anzucht von Laccase-produzierenden Pilzen (TROJANOWSKI et al., 1995)

- Die Verwendung von parenchymatischem Zellwandmaterial als Bindemittel für Holzwerkstoffe (KHARAZIPOUR u. BERGMANN, 1998)

- Herstellung von Futtermittel durch enzymatische Behandlung von Kartoffelpülpe und Kartoffelfruchtwasser. Das Endprodukt hat den Namen Profiberlasse ${ }^{\circledR}$ (OLSEN, 2000) 


\subsection{Holzwerkstoffe}

Von Holzwerkstoffen spricht man, wenn die natürlich gewachsene Holzstruktur aufgelöst und ein neues Gefüge mit neuer Dimension aufgebaut wird, meist unter Zuhilfenahme von Bindemitteln. Die Entstehung von Holzwerkstoffen ist auf die Notwendigkeit zurückzuführen Resthölzer aus der Sägeindustrie und schwache Holzsortimente, die sonst keine Verwendung fänden, durch Zerkleinerung bzw. Zerfaserung und anschließendem Wiederzusammenfügen nutzbar zu machen. Dies war allerdings erst Mitte des 19. Jh. mit Einführung neuer technologischer Entwicklungen möglich. So entstanden um 1850 herum die ersten industriell gefertigten Schälfurniere. Durch die Entwicklung des Holzschliffs ab etwa 1840 begann die Verarbeitung des Holzes in mechanischen Faseraufschlussverfahren und ab Mitte der 40er Jahre des 20. Jh. lief die industrielle Produktion der Spanplatten an (PAULITSCH, 1989).

Mittlerweile ist die Holzwerkstoffindustrie der größte Faktor im Bereich der Holzverarbeitenden Industrie. Die verschiedenen Holzwerkstoffe werden üblicherweise nach folgenden Kriterien eingeteilt:

- Ausgangsmaterial

- Bindemittel /Herstellungsparameter

- Dichteverhältnisse

Die Auswahl der Ausgangsmaterialien ist der entscheidende Faktor bei dieser Einteilung, da die weiteren Kriterien sich aus dieser ergeben (s. Abb. 1-4). Holzwerkstoffe haben den großen Vorteil, dass die positiven Eigenschaften des Holzes wie z. B. leichte Bearbeitbarkeit, Dauerhaftigkeit und ein geringes Gewicht im Vergleich zur Festigkeit bestehen bleiben (http://www.forst.uni-freiburg.de; Download vom 27.05.04). Zudem ergeben sich durch Holzwerkstoffe weitere Vorteile, die vom Vollholz in diesem Maße nicht erfüllt werden können. Durch den Aufschluss des Holzes in kleinere Fraktionen bis hin zur Zerfaserung und die dadurch mögliche gezielte Anordnung der Holzbestandteile (Spanrichtung, Faserrichtung) ist eine Optimierung der Festigkeitseigenschaften und der Dimensionsstabilität (kaum Quell- und Schwindverhalten) möglich. Dabei gilt: Je kleiner die verwendeten Holzpartikel, desto homogener sind die Eigenschaften der daraus hergestellten Holzwerkstoffe. 


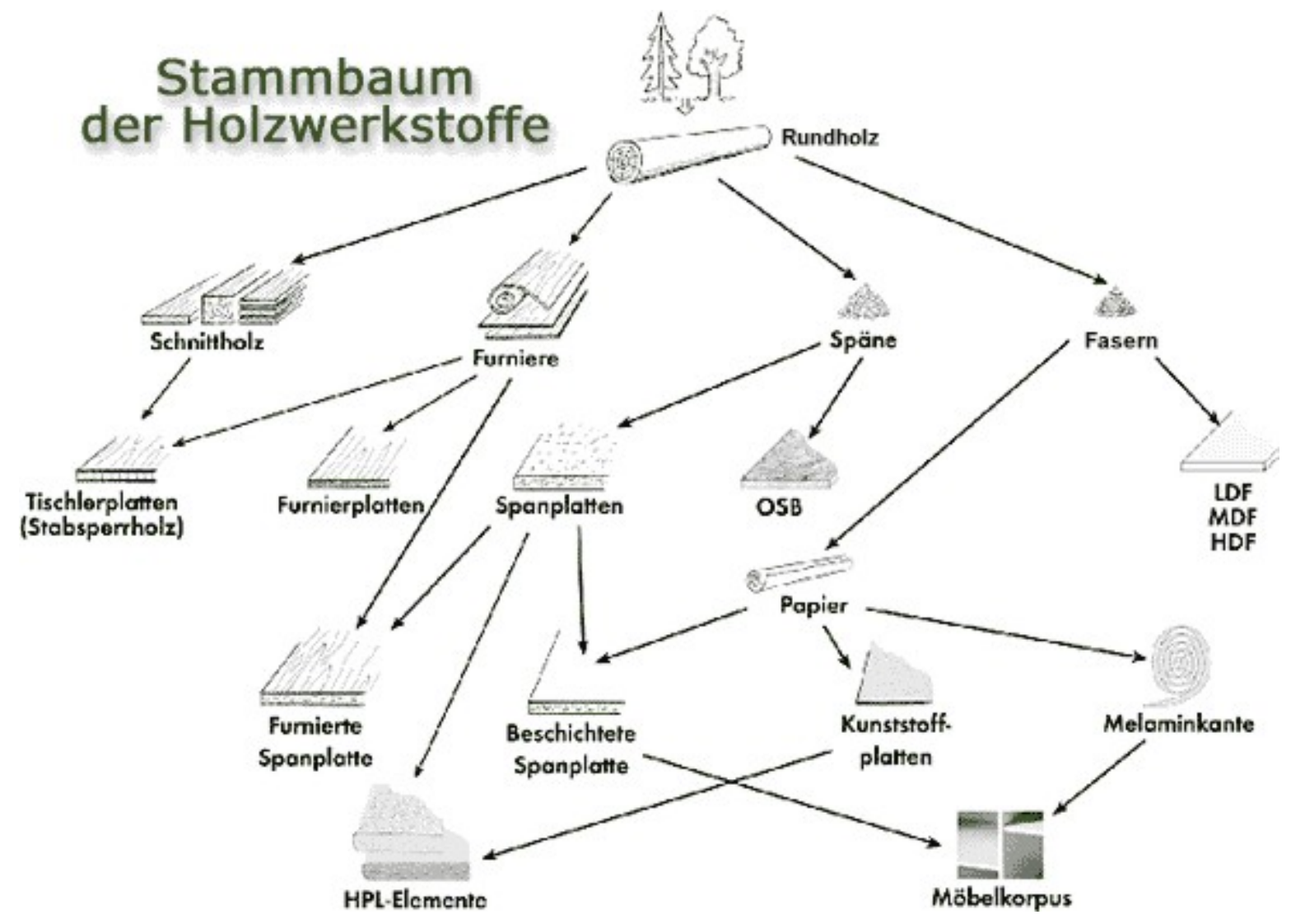

Abb. 1-4: Die verschiedenen Holzwerkstoffe unterscheiden sich hinsichtlich der verwendeten Ausgangsmaterialien (VHI, 2004)

Mit Hilfe von Klebstoffen können die Holzteile durch Verpressen zu verschieden geformten Elementen verarbeitet werden, deren Abmessungen vom Vollholz nicht erreicht werden können. Dabei sind sowohl platten- als auch stabförmige Produkte möglich, die je nach Verwendungszweck variiert werden können (http://www.infoholz.de; Download vom 26.05.04).

Ursprünglich wurden Holzwerkstoffe für die Möbelindustrie entwickelt. Mittlerweile werden die Platten und Balken ebenso im Bauwesen, Innenausbau, dem Behälterund Verkehrsmittelbau so wie bei zahlreichen anderen Anwendungen eingesetzt (http://www.forst.uni-freiburg.de). Dabei ergibt sich für Deutschland ein Produktionsvolumen der Holzwerkstoffindustrie von über 12 Mio. $\mathrm{m}^{3}$ für das Jahr 2001 (MANTAU et al., 2002).

Die Verwendung von Holzwerkstoffen hat zudem den ökologischen Vorteil, dass hauptsächlich Durchforstungs-, Industrierest- und Gebrauchthölzer / Gebrauchtholzwerkstoffe für die Herstellung eingesetzt werden. Diese Hölzer finden anderweitig kaum eine stoffliche Verwertung (VHI, 2004). 


\subsubsection{Entwicklung der Faserplatten}

Im 18. Jh. meldete Clay ein Patent für die Verwendung von „Papier maché" im Wohnbereich, in Möbeln, Türen und Kutschen an (NEUSSER, 1957). Obwohl viele kleine Entwicklungen im Bereich der Faserplatten folgten, dauerte es noch bis zum Beginn des 20. Jahrhunderts, bis in England und den USA eine nennenswerte Faserplatten-Industrie begann. Mit Einführung des Masonite-Verfahrens (1926) nach MASON war es möglich, große Mengen an Holz-Chips mit Hilfe von Druck und Dampf zu zerfasern und anschließend ohne Bindemittelzugabe heiß zu verpressen. 1931 entwickelte der Schwede ASPLUND die kontinuierliche Defibrierung von Hackschnitzeln unter Dampf und Druck und der anschließenden Verarbeitung zu Faserplatten. Die Faserplatten wurden noch papierähnlich in einem Nassverfahren geformt (SANDERMANN U. KüNNEMEYER, 1956). Erst nach 1940 entwickelte sich in den USA der Gedanke in Richtung auf eine trockene Formung der Faserplatten, die dann auch in Mitteleuropa in Produktionsanlagen umgesetzt wurde (PAULITSCH, 1989).

Es entstanden im Laufe der Zeit unterschiedliche Faserplatten hinsichtlich der Verfahrenstechnologie und der Werkstoffeigenschaften. Die Einteilung der Faserplatten in verschiedene Typen basiert auf folgenden Eigenschaften:

- Art des Ausgangsmaterials und Faserherstellung

- Vliesherstellung

- Rohdichte des Produktes $\left(\mathrm{g} / \mathrm{cm}^{3}\right.$ oder $\left.\mathrm{kg} / \mathrm{m}^{3}\right)$

- Verwendungsbereich

Üblicherweise unterscheidet man die Faserplatten zunächst hinsichtlich ihrer Rohdichte, diese kann zwischen 0,02 und über 1,45 g/ $\mathrm{cm}^{3}$ liegen (s. Tab. 1-2). Nach der DIN 68753 (DIN-TASCHENBUCH, 1999) werden Faserplatten mit einer Rohdichte von $0,35 \mathrm{~g} / \mathrm{cm}^{3}$ bis $0,8 \mathrm{~g} / \mathrm{cm}^{3}$ zu den Mitteldichten Faserplatten gezählt.

Eines der ersten Produkte war die Hartfaserplatte, die sich allerdings gegenüber Sperrholz, insbesondere Furnierplatten, als nicht konkurrenzfähig erwies. Die Nachteile der Hartfaserplatten sind die Siebrückseite, fehlende Dimensionsstabilität, relativ niedrige Festigkeit, hohes Gewicht und geringe Plattendicke. Durch die Entwicklung der Spanplatte verlor die Hartfaserplatte mehr und mehr an Bedeutung. Allerdings wurde die Spanplatte in den USA nur bedingt eingesetzt, da die Qualität der hergestellten Produkte nicht optimal war. 
Tab. 1-2: Allgemeine Einteilung von Faserplatten hinsichtlich der Rohdichte (LAMPERT, 1967)

\begin{tabular}{ll}
\hline Faserplatten & Rohdichte $\mathrm{g} / \mathrm{cm}^{3}$ \\
\hline Poröse & $\leq 0,4$ \\
Mitteldichte (halbharte) & $0,4 \ldots 0,8$ \\
Harte & $0,8 \ldots 1,2$ \\
Extra harte & $\geq 1,2$ \\
\hline
\end{tabular}

Dadurch entstand eine Marktlücke, die von der Fa. Allied Chemical in Deposit, New York 1966 mit Entwicklung der Mitteldichten Faserplatten (MDF) gefüllt wurde. Mit der MDF-Platte erhielt man einen flächigen und homogenen Werkstoff, der nicht nur im Möbel- und Innenraumbereich einsetzbar war.

\subsubsection{Entwicklung der MDF-Produktion}

In den USA wurden MDF-Platten bereits seit Anfang der 70er Jahre erfolgreich produziert, während die europäische Produktion erst etwa 10 Jahre später anlief. In Westdeutschland produzierte das erste MDF-Werk ab 1987 in Meppen. Der zögerliche Beginn der Produktion ist darauf zurückzuführen, dass die Be- und Verarbeitung hochwertiger Spanplatten einen Grad an Perfektion erreicht hatten, die das Bedürfnis nach einem neuen, teuren Holzwerkstoff gering erscheinen ließen (ERNST, 1997).

Obwohl die MDF-Platte zuerst in den USA entwickelt wurde, ist sie in Europa verbessert und weiterentwickelt worden (PAULITSCH, 1989). Die MDF-Produktion ist in Europa der zweitgrößte Produktbereich in der Holzwerkstoffindustrie, direkt nach der Spanplatte (s. Abb. 1-5). Allerdings wird die Spanplatte mittlerweile von der MDFPlatte in vielen Bereichen substituiert, was zu Einbußen in der Produktionskapazität bei der Spanplatte führte.

Die Vorteile der MDF-Platte gegenüber der herkömmlichen Möbel-Spanplatte, bzw. OSB-Platte sind die dichte, homogene Struktur, eine feine Oberfläche, eine bessere Schrauben- und Nagelfestigkeit in der Mittelschicht, bessere Bearbeitbarkeit, sowie ein gute Lackierbarkeit der Oberflächen und Kanten. Durch die Variabilität von Dichte, Festigkeit, Verleimungsart und der zwei- und dreidimensionalen Gestaltbarkeit durch Fräsen und Biegen sind MDF-Platten den Span- und OSB-Platten in der Be- und Verarbeitung überlegen. 


\section{Holzwerkstoffe und ihre Anteile in Europa}

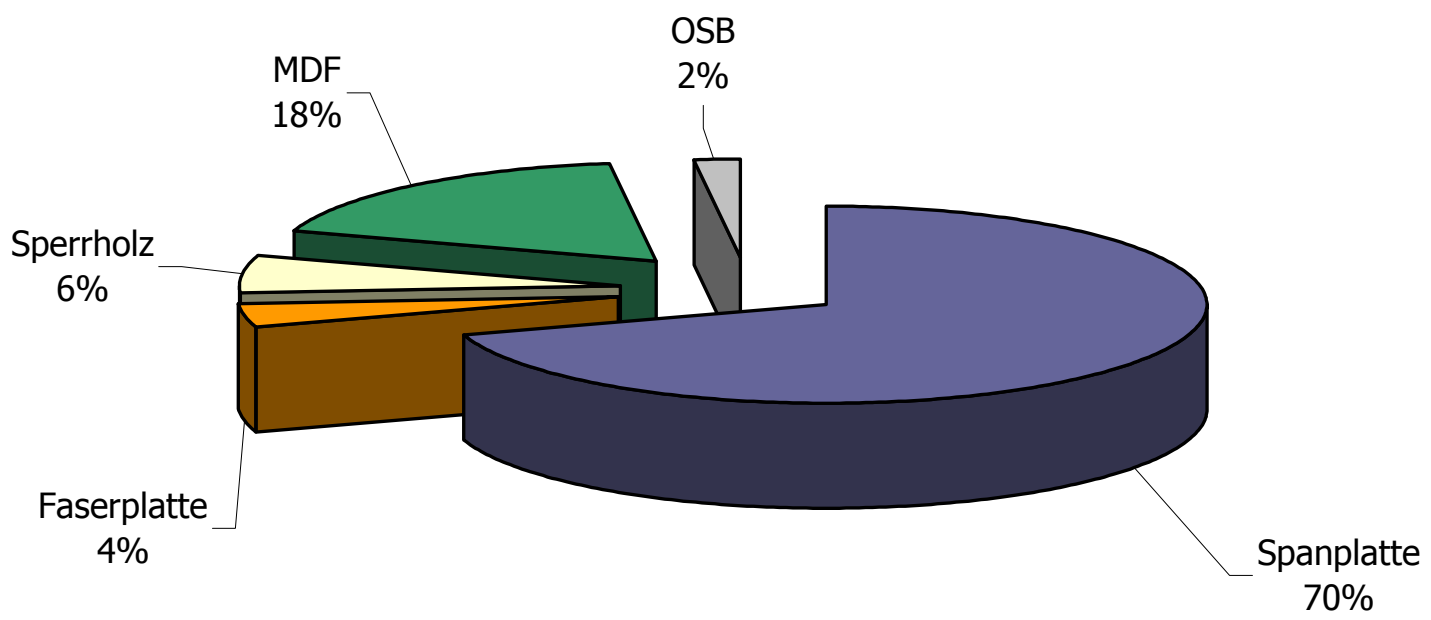

Abb. 1-5: Holzwerkstoffanteile in Europa, Stand 1999 (PFEIFFER und LANGHORST, 2000)

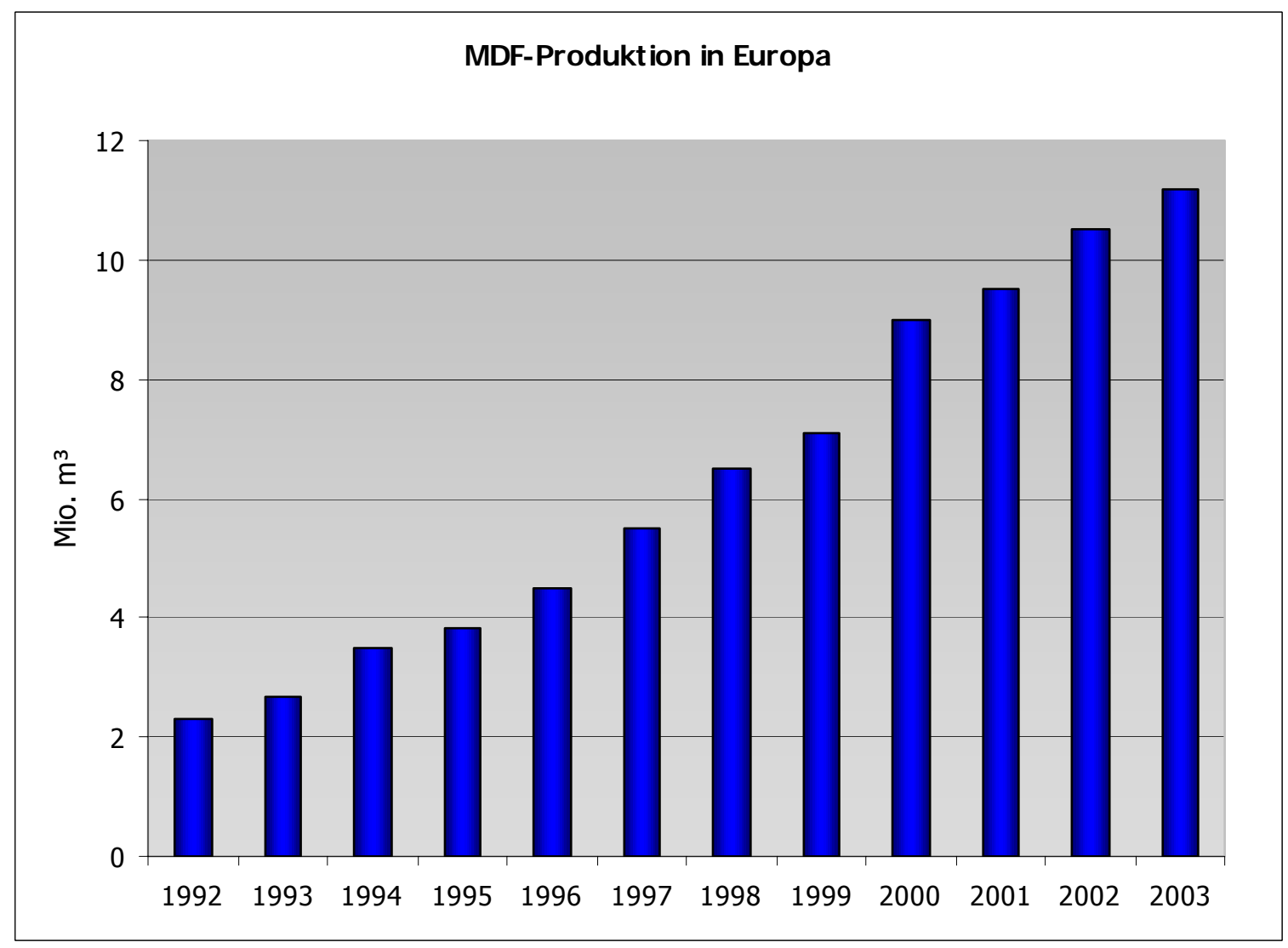

Abb. 1-6: Entwicklung der europäischen MDF-Produktion von 1992-2003 (EPF, 2004) 
Seit der Einführung der MDF-Platte in Deutschland bzw. Europa ist ein stetiger Produktionszuwachs zu verzeichnen (s. Abb. 1-6). Die europäische MDF-Produktion überschritt laut European Panelboard Federation (EPF) im Jahr 2002 erstmals die Marke von 10 Mio. $\mathrm{m}^{3}$ und lag mit 10,5 Mio. $\mathrm{m}^{3}$ um $9 \%$ über dem Vorjahreswert. Der MDF-Verbrauch stieg ebenfalls um $9 \%$ auf 9,6 Mio. $\mathrm{m}^{3}$ (EUWID Holz- und Holzwerkstoffe, 2003). Trotz momentan schwacher Konjunktur findet eine Kapazitätserweiterung der MDF-Produktion statt, insbesondere durch Investitionen in Süd- und Osteuropa.

\subsection{Zielsetzung der Arbeit}

Die vorliegende Arbeit soll einen Beitrag zur Nutzung einheimischer nachwachsender Rohstoffe schaffen. Dabei ist es wichtig, dass der Einsatz dieses Rohstoffes auf lange Sicht hin gesichert ist und eine $\mathrm{CO}_{2}$-neutrale Produktion möglich macht. Bei diesem Rohstoff handelt es sich um ein Nebenprodukt der Stärkeherstellung: die Kartoffelpülpe. Durch die Nutzung dieses Nebenproduktes zur Bindemittelherstellung soll eine höhere Wertschöpfung erzielt und zusätzlich ein großes Abfallproblem der Stärkeindustrie gelöst werden.

Das Ziel der Arbeit ist, die Kartoffelpülpe unter Zuhilfenahme von biotechnologischen Maßnahmen zu modifizieren, um die parenchymatischen Zellbestandteile als Bindemittel nutzen zu können. Für den Aufschluss werden Enzyme verwendet, die die Zellwandstruktur teilweise auflösen und somit die Bestandteile der Kartoffelpülpezellen verfügbar machen. Durch eine Optimierung des mechanischen und enzymatischen Aufschlusses, soll die Verarbeitung der Pülpe ermöglicht werden. Damit die mechanisch-enzymatisch aufgeschlossene Kartoffelpülpe ganzjährig verfügbar ist, soll ein Trocknungsverfahren zur Verbesserung der Lagerfähigkeit eingesetzt werden.

Die Holzwerkstoffindustrie stellt einen großen Absatzmarkt für Bindemittel dar, demzufolge wird ein Einsatz der mechanisch-enzymatisch aufgeschlossenen Kartoffelpülpe in diesem Bereich angestrebt. Durch den Einsatz von Kartoffelpülpe können Holzwerkstoffe mit geringeren Emissionen, insbesondere im Bereich der Formaldehydabgabe, hergestellt werden. Mit einer teilweisen Substitution der herkömmlichen Bindemittel auf petrolchemischer Basis erzielt man gleichzeitig eine Schonung der nicht erneuerbaren Ressourcen. 


\section{$2 \quad$ Allgemeiner Teil}

\subsection{Pülpe}

Die Kartoffelpülpe besteht hauptsächlich aus Zellwandresten wie Cellulose, Hemicellulose, Pektin und Resten der Schale. Neben diesen Bestandteilen finden sich noch Stärkekörner, unaufgebrochene Stärkezellen und ganze Zellverbände in der Kartoffelpülpe. Von besonderem Interesse sind die Zellwand- und Stärkereste, da diese aufgrund ihrer einzelnen Komponenten beim Verpressen die Fähigkeit haben Bindungen aufzubauen.

\subsubsection{Aufbau der Zellwand in einer Kartoffel}

Die Kartoffelknolle besteht hauptsächlich aus parenchymatischem Zellgewebe, auch Grundgewebe genannt. Dieses Gewebe ist am wenigsten spezialisiert und besteht im Allgemeinen aus großen, isodiametrischen und dünnwandigen Zellen. Bei der Kartoffelknolle handelt es sich um Speicherparenchym, d. h. die Kartoffelknolle ist in der Lage, organische Reservestoffe, in diesem Fall Stärke, in größeren Mengen zu speichern (StRASBURGER et al., 1991). Die Abb. 2-1 zeigt einen Querschnitt durch die äußeren Bereiche einer Kartoffelknolle. Der hohe Anteil an Parenchymgewebe ist deutlich zu erkennen.

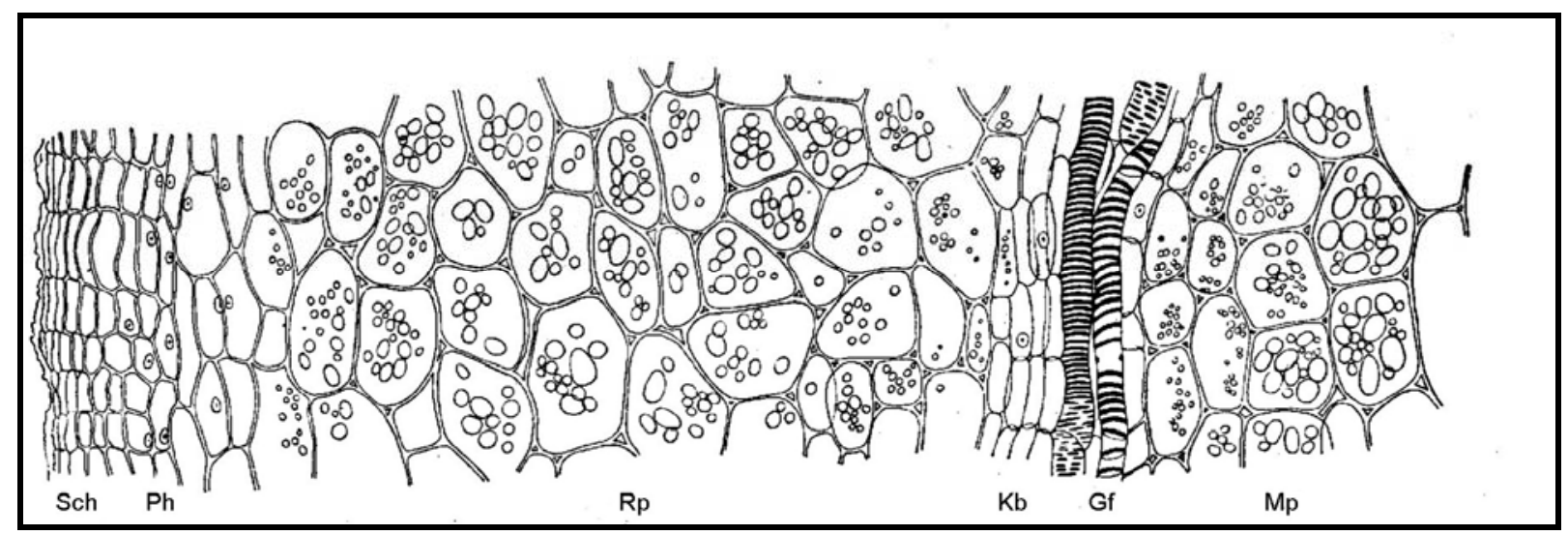

Abb. 2-1: Schnitt durch die äußeren Gewebe einer Kartoffelknolle. - Sch = Korkschichten der Schale, $\mathrm{Ph}=$ Korkkambium (Phellogen); $\mathrm{Rp}=$ Parenchymgewebe der Knollenrinde mit Stärkekörnern; Kb = Kambium; Gf = Ring- bzw. Netzgefäße des Hadroms, in Leitparenchym eingebettet; $\mathrm{Mp}=$ Markparenchym mit Stärkekörnern (BUHR und NEHE, 1958) 
Das Besondere an dem parenchymatischen Zellgewebe sind die Primärwände der Zellen. Die Primärwand soll pflanzlichen Zellen bereits zu einem Zeitpunkt Festigkeit gewährleisten in der die Zellentwicklung noch nicht abgeschlossen ist. Daher muss die Primärwand verfestigende Elemente enthalten, die in einer flexiblen Matrix so eingebettet sind, dass im Laufe der Zelldifferenzierung ein lateraler Zuwachs erfolgen kann (MAYER, 1993). In der Primärwand überwiegen die verschiedenen Komponenten der Zellwand-Grundsubstanz: Pektinstoffe, Hemicellulosen und Wandproteine, mengenmäßig weit über dem fibrillären Zellwand-Gerüst (Cellulose).

Die Pektinstoffe sind chemisch sehr heterogen. Als Protopektin bezeichnet man negativ geladene, saure Polysaccharide aus Galacturonsäure-Einheiten (Galacturonane und Rhamnogalakturonane). Die Pektinsäure des Protopektins hat Carboxylgruppen an seinen kurzen Seitenketten, die teilweise mit Methylalkohol verestern. Das Ergebnis ist Pektin. Zu den Pektinstoffen zählt man auch die vergleichsweise kurzkettigen Polysaccharide Arabinane, Galactane und Arabinogalactane. Insgesamt sind sie durch leichte Wasserlöslichkeit und ein extremes Quellungsvermögen gekennzeichnet (STRASBURGER et al., 1991). Protopektin ist daher ein amorphes, plastisch verformbares und sehr quellungsfähiges Gel (LÜTTGE et al., 1999).

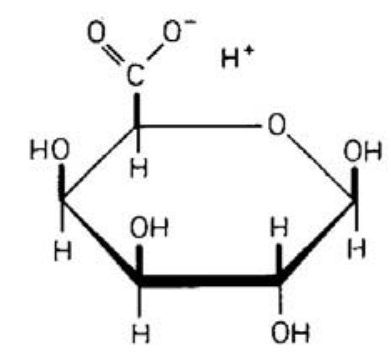

\section{D-Galakturonsäure}

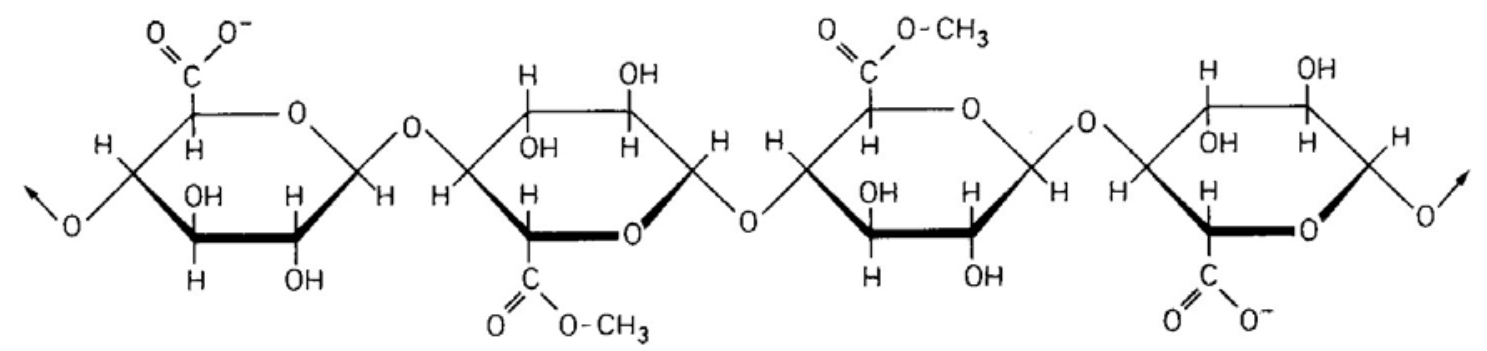

Abb. 2-2: Wasserstoffbrückenbindungen innerhalb der einzelnen GalakturonsäureMoleküle (LÜTTGE et al., 1999) 
Die Bindungen innerhalb der einzelnen Galacturonsäure-Moleküle werden durch Wasserstoffbrückenbindungen gewährleistet. Abb. 2-2 zeigt die Bindungsform der Moleküle untereinander. Diese Wasserstoffbrückenbindungen sind für spätere Verklebungen äußerst wichtig, da sie die Hauptbindungsform des Pektins ist.

Die Verknüpfung der Pektinsäure-Ketten untereinander findet mit Hilfe der freien Carboxylgruppen statt. Dabei gehen je zwei negativ geladene Carboxylgruppen eine Ionenbindung mit einem zweiwertigen Kation ein. Durch diese Ionenbindung werden die Galacturonsäure-Moleküle in einem dreidimensionalen Netz zusammen gehalten. (s. Abb. 2-3). Diese Bindungen können ohne großen Energieaufwand wieder gelöst werden, so dass es sich um eine reversible Vernetzung handelt (LÜTTGE et al., 1999).

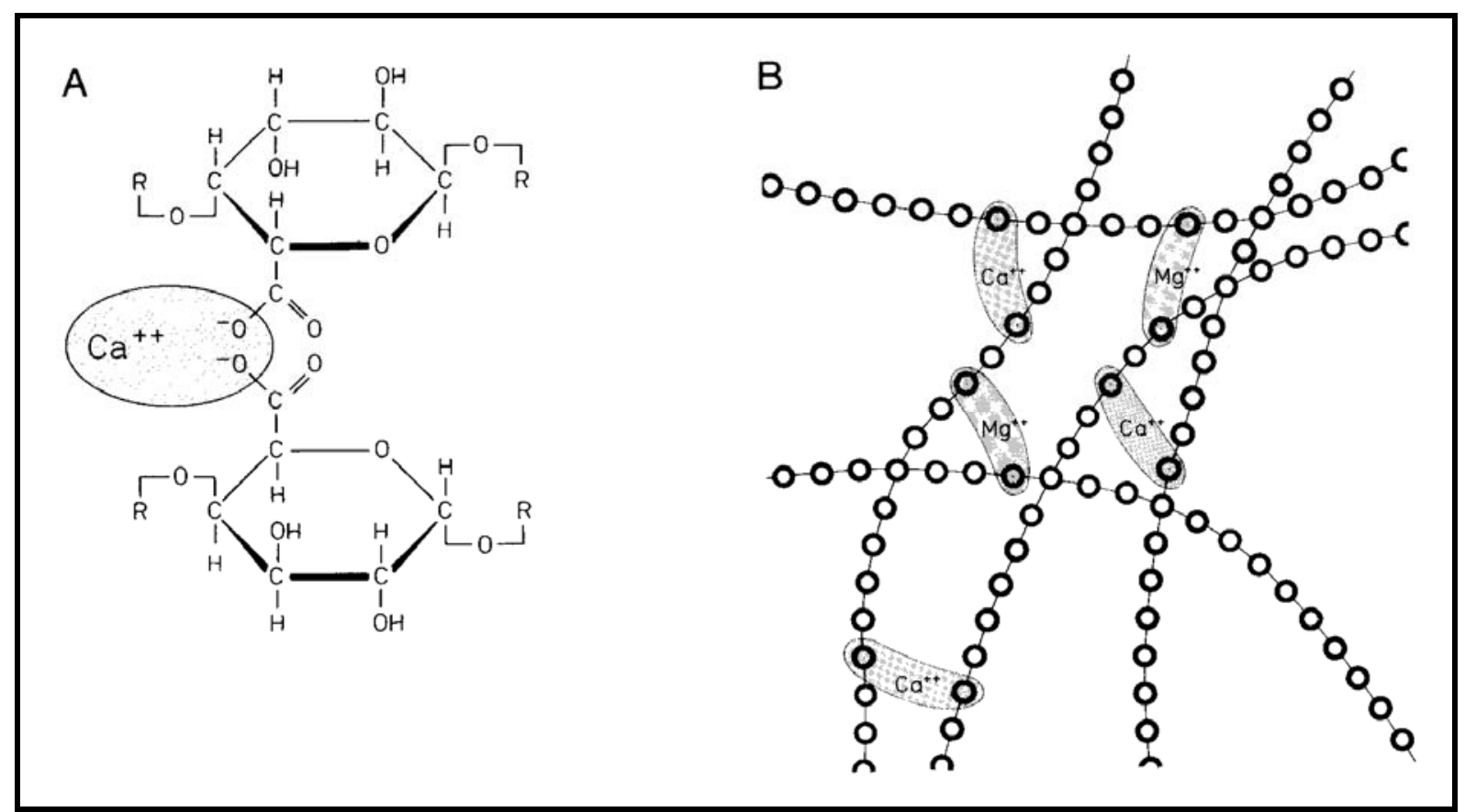

Abb. 2-3: (A) Ionenbindung zwischen zwei Galakturonsäure-Molekülen unter Beteiligung eines Calcium-Ions. (B) Vernetzung von Polygalakturonsäureketten durch Ionenbindung (LÜTTGE et al., 1999)

Die Hemicellulosen sind ebenfalls Polysaccharide, die jedoch keine Säuregruppen besitzen und neutral reagieren. Die wichtigsten Bausteine der Hemicellulosen sind Pentosane und Hexosane. Das Makromolekül der Pentosane besteht zum größten Teil aus D-Xylose und L-Arabinose. Die wesentlichen Bausteine der Hexosane sind vor allem D-Mannose, D-Galactose und D-Glucose (LÜTTGE et al., 1999). Zu den Hemicellulosen zählen Glucane, Gluco- und Galactomane, so wie Xylane (STRASBURGER et al., 1991).

Glykoproteine in der Primärwand bestehen aus dem sauren Arabino-Galactan-Protein (AGP) und dem basischen hydroxyprolinreichen Glykoprotein (HPRG). AGPs sind 
leicht wasserlöslich und stark quellbare Substanzen, während HPRG aus einem helicalen, stabförmigen Polypeptid von ca. $80 \mathrm{~nm}$ Länge besteht, welches von einer Arabinosid-Hülle umgeben ist (MOHR u. SCHOPFER, 1992). HPRG besitzt eine Tendenz, Bindungen einzugehen und man nimmt daher an, dass sie ein komplexes, räumliches Netzwerk in der Zellwandmatrix bilden (STRASBURGER et al., 1991).

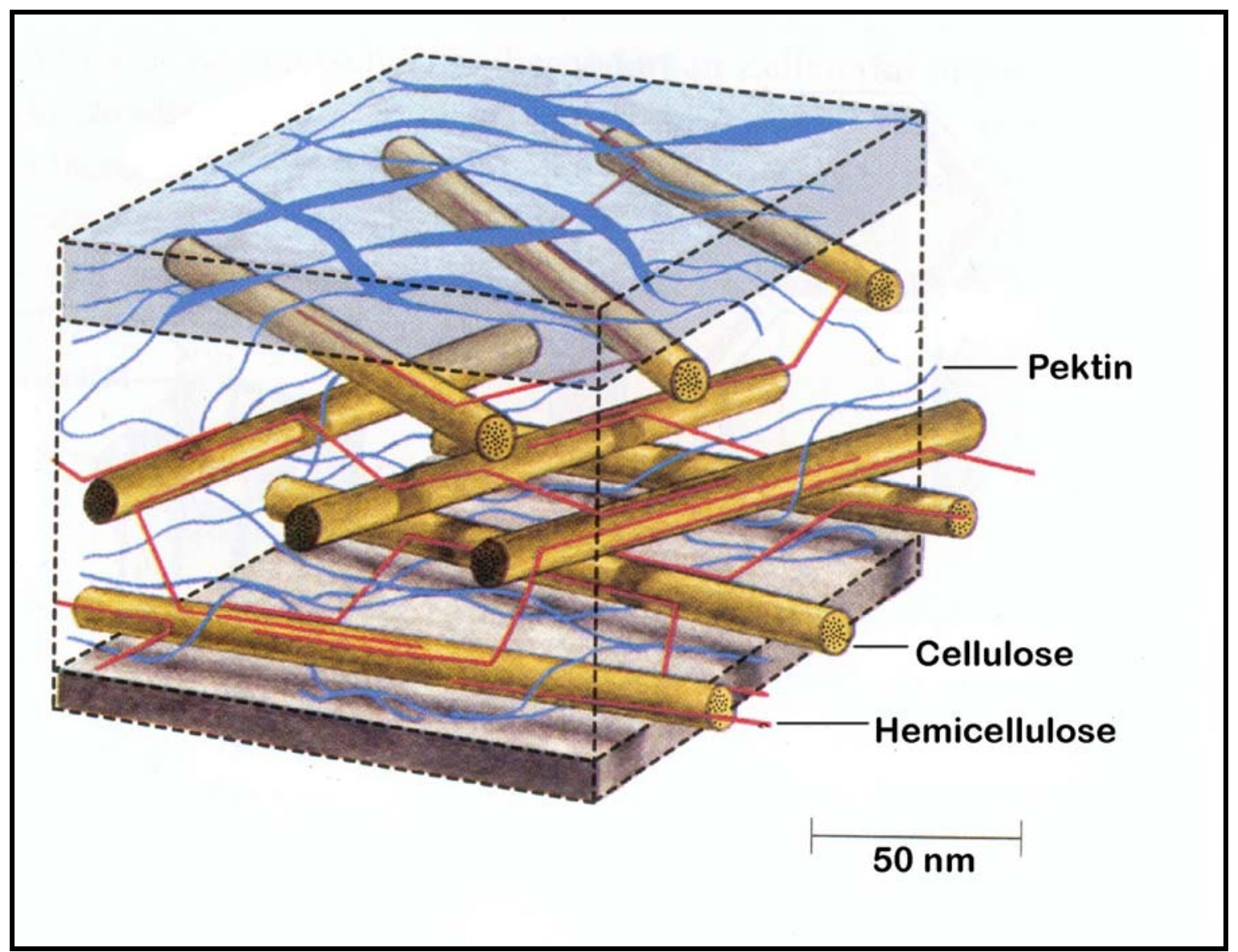

Abb. 2-4: Die Cellulose-Fibrillen sind eingebettet in die Matrix, die aus Pektin und Hemicellulose zusammengesetzt ist. Der blaue Bereich stellt die Mittellamelle dar (RAVEN et al, 2000).

Das Zellwand-Gerüst bildet die Cellulose. Diese ist ein Polysaccharin und besteht aus $\beta$-D-Glucose. Der Polymerisationsgrad dieses langen, unverzweigten und geradegestreckten Kettenmoleküls liegt bei 2.000 bis über $15.000 \beta$-D-GlucoseEinheiten. Die benachbarten Glucoseeinheiten entlang der Molekülachse sind jeweils um $180^{\circ}$ gegeneinander verdreht und werden durch Wasserstoffbrückenbindungen beidseits der glycosidischen Bindungen festgehalten (STRASBURGER et al., 1991). Durch inter- und intramolekulare Wasserstoffbrückenbindungen kommt es zur Ausbildung von bandförmigen Elementarfibrillen, die teilweise kristalline Regionen besitzen. Diese Parakristallinität bedingt eine extrem hohe Reißfestigkeit. Die 
Elementarfibrillen werden weiter gebündelt und man spricht dann von Mikrofibrillen (MOHR u. SCHOPFER, 1992). Diese Mikrofibrillen sind sehr reißfest und bilden in der Zellwand das Zellwand-Gerüst. Das Zellwand-Gerüst ist eingebettet in die ZellwandGrundsubstanz oder auch Matrix. Die Matrix hat die Aufgabe, die Fibrillen als so genannte Füllmasse teilweise zu verkitten, während die Cellulose eine Art Zellwandskelett bildet (s. Abb. 2-4).

\subsection{Enzyme}

Enzyme werden im Allgemeinen als Katalysatoren biologischer Systeme bezeichnet, d. h. sie verringern die Aktivierungsenergie und beschleunigen so den Ablauf von chemischen Reaktionen. Sie sind zelleigene Proteine, die auch außerhalb der Zelle agieren können, sofern die notwendigen Bedingungen vorliegen. Das Besondere an Enzymen ist die Substrat- und die Wirkungsspezifität. Bei der Substratspezifität katalysiert das Enzym nur Reaktionen einer chemischen Verbindung oder einer Gruppe von annähernd gleichen chemischen Verbindungen. Dadurch, dass das Enzym nur eine bestimmte Reaktion mit definiertem Substratumsatz katalysiert, spricht man von Wirkungsspezifität.

Mit Verfahren der Biotechnologie werden Enzyme für verschiedenste Einsatzzwecke industriell hergestellt. Man gewinnt sie sowohl aus tierischen und pflanzlichen als auch aus mikrobiellen Ausgangsmaterialien. Mittlerweile findet man Enzyme in vielen technischen Anwendungen wie z. B. in der Lebensmittelindustrie (MoskowiTz et al., 1987; ChEeSEMAN, 1981; CAUvin, 1985; MCCLEARY, 1986), der Getränkeindustrie (MCCleARY und NuRTHen., 1986; DubOuRdieu et al., 1981) und der Waschmittelindustrie (BAHN und SCHMID, 1986; NiELSON et al., 1981).

\subsubsection{Enzymaktivität}

Allgemein gibt die Enzymaktivität an, wie schnell ein Enzym die Umsetzung eines Substrates zu einem Produkt katalysiert. Wichtig bei der Messung der Enzymaktivität ist, dass die Umsetzung immer unter definierten Standardbedingungen durchgeführt wird:

- $\mathrm{pH}-$ und Temperatur-Optimum

- optimales Substratangebot 
- ungehinderter Kontakt zwischen Enzym und Substrat

Die Bestimmung der Enzymaktivität gibt Aufschluss über die Effektivität eines Enzyms. Man unterscheidet zwei gängige Einheiten für die Enzymaktivität. 1961 wurde „Enzyme Unit" durch die International Union of Biochemistry (IUB) eingeführt. Ein "Unit" eines Enzyms ist die Menge, die das Enzym pro Minute von einem $\mu \mathrm{mol}$ eines Substrates unter definierten Bedingungen umsetzt (IUB, 1965). Bei der Umsetzung von Polymeren wie z. B. Pektin spricht man von einem Mikroäquivalent der betreffenden Gruppe (REED, 1975). 1978 wurde durch das Système International d'Unités (SI) die Einheit "katal" eingeführt (IUB, 1979). Ein "katal" ist die Enzymmenge, die unter definierten Bedingungen, den Umsatz von einem mol Substrat pro Sekunde katalysiert (PRÄVE, 1994), dabei ist 1 kat $=6 * 10^{7}$ enzyme units, bzw. 1 enzyme unit $=16,67 * 10^{-9}$ kat $=16,67$ nkat.

Man unterscheidet zwischen der spezifischen und der molekularen Aktivität. Wenn ein Enzym in reiner Form vorliegt, gibt man seine spezifische Aktivität als Units* $\mathrm{mg}^{-1}$ Enzymprotein an. In einem Enzymgemisch gilt die spezifische Aktivität für das jeweilige Präparat und nicht für das reine Enzym. Man kann allerdings die Reinheit des Präparates bestimmen wenn die spezifische Aktivität des reinen Enzyms bekannt ist. Die molekulare Aktivität (Wechselzahl) eines Enzyms gibt an, wie viele Substratmoleküle in einer Sekunde von einem Enzymmolekül umgesetzt werden. Sie ist immer charakteristisch für ein bestimmtes Enzym, sagt aber nichts aus über die Reinheit des Enzyms in einem Präparat.

Da natürliche Polymere in ihrer chemischen Struktur und dem Molekulargewicht nicht einheitlich sind, ist die Bestimmung der Enzymaktivität schwieriger als bei definierten niedermolekularen Substraten (STROOT, 2001). Allerdings gibt es häufig keine einheitlichen Angaben der Enzymaktivität, weil die Messung oftmals abhängig ist von dem Verwendungszweck des Enzyms. Normalerweise wird die Aktivität unter den Bedingungen ermittelt, die auch später im praktischen Einsatz vorliegen.

\subsubsection{Hemmung der Enzymaktivität}

Die Aktivität der Enzyme wird durch äußere Einwirkungen, bzw. durch im Reaktionsgemisch vorhandene Stoffe leicht beeinflusst. Diese Stoffe fungieren in der enzymatischen Reaktion als Hemmstoffe, die so genannten Inhibitoren. Dabei gibt es zwei Arten der Hemmung, zum einen die reversible und zum anderen die irreversible.

Bei der irreversiblen Hemmung bindet sich ein Inhibitor fest an eine reaktive Gruppe wie $-\mathrm{SH}$ oder $-\mathrm{COOH}$ und dissoziiert nur sehr langsam von dem 
entsprechenden Enzym. Die reversible Hemmung zeichnet sich dadurch aus, dass eine schnelle Dissoziation des Enzym-Inhibitor-Komplexes möglich ist. Die Inhibitoren der reversiblen Hemmung werden dabei unterteilt in kompetative und nichtkompetative. Das Prinzip der kompetativen Hemmung basiert auf der Ähnlichkeit in der chemischen Struktur des Inhibitors und des umzusetzenden Substrats. Das Enzym bindet den Inhibitor am aktiven Zentrum, ohne diesen in ein Produkt zu katalysieren und blockiert das Enzym für die Katalyse des eigentlichen Substrates.

Die nichtkompetative Hemmung tritt dann ein, wenn der Inhibitor nicht am aktiven Zentrum, sondern an einer anderen Position (allosterisch) des Enzymmoleküls gebunden wird und dadurch die Konformation derart verändert, dass kein Substrat mehr am aktiven Zentrum gebunden werden kann.

\subsubsection{Verfahren zur Bestimmung der Enzymaktivität}

Die Vergleichbarkeit der Aktivität industriell eingesetzter Enzymkomplexe ist in der Praxis oftmals problematisch, da es keine einheitlichen Messvorschriften gibt. Häufig entwickeln die Enzymhersteller firmenspezifische Bestimmungsmethoden, die untereinander nicht vergleichbar sind.

Beim Einsatz von pektolytischen Enzympräparaten gibt es zahlreiche Methoden, die auf der Viskositätssenkung einer Pektin-Lösung oder auf der völligen Depektinisierung von Apfelsaft beruhen (UHLIG, 1991).

FDU: Ferment-Depectinisation-Unit beruht auf dem Prinzip, trüben, pasteurisierten Apfelsaft bei $55^{\circ} \mathrm{C}$ mit einer Enzymlösung so lange zu behandeln, bis keine Ausfällung des Pektins nach der Zugabe von Isopropanol (2 Vol. Isopropanol : 1 Vol. Saft) sichtbar ist. Durch den Vergleich mit einem bekannten Standardenzym sowie unter Berücksichtigung der Konzentration und Versuchszeiten wird die relative Enzymaktivität errechnet.

UPTE: Bestimmung von Pektintranseliminasen bei pH 3,5. Diese Methode zeigt, wie schnell ein Enzym gereinigtes Apfelpektin bei pH 3,5 und $30^{\circ} \mathrm{C}$ in Doppelbindungen abbaut, die mit Hilfe des Spektrophotometers bei $238 \mathrm{~nm}$ gemessen werden können (NovOZYM, 2002).

PTF: 1 PTF/mg entspricht der Enzymmenge, die pro Minute eine Extinktionszunahme von 0,01 bei $\mathrm{pH} 5,8$ und $30^{\circ} \mathrm{C}$ bei $235 \mathrm{~nm}$ in einer $0,5 \%$ igen Pektinlösung aufweist (AB ENZYME). 
PA: die PA ist der reziproke Wert der Enzymmenge in Kilogramm, die benötigt wird,

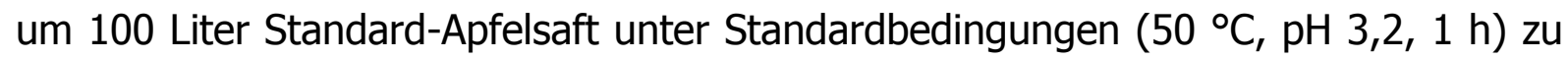
depektinisieren (AB ENZYME).

PGU: ein Polygalakturonase-Unit ist definiert durch die Enzymaktivität, welche die Viskosität $\eta$ einer Standard-Pektinlösung um $1 / \eta_{\text {spezifisch }}=0,000015$ unter Standardbedingungen ( $\mathrm{pH} \mathrm{3,9}$ bei $30^{\circ} \mathrm{C}$ ) senkt (SPRÖßLER, 1978).

\subsubsection{Pektinasen}

Aufgrund der Substratspezifität kann man Enzymgruppen hinsichtlich ihres spezifischen Substrates einteilen. Enzyme, die in der Lage sind, Pektin und seine Bausteine zu spalten, nennt man Pektinasen. Unter den Begriff Pektinasen fallen Esterasen, Glykosidasen und Lyasen. Bei den Pektinpolysacchariden der Mittellamelle und der Primärwand höherer Pflanzen sowie bei isolierten Pektin- und PektinsäureSubstraten katalysieren Enzyme aus diesen Gruppen die Abbaureaktionen. Man unterscheidet dabei nach der Hauptwirkung der Enzyme (s. Tab. 2-1).

Tab. 2-1: Einteilung der Pektinasen nach ihrer Wirkungsweise

\section{Wirkungsweise: Pektinentesterung Pektinhydrolyse}

\begin{tabular}{|c|c|c|}
\hline \multirow[t]{3}{*}{ Enzymgruppen: } & Pektinesterasen: & Pektindepolymerasen: \\
\hline & $\begin{array}{l}\text { Pektasen, } \\
\text { Pektinmethylesterasen, } \\
\text { Pektindemethoxvlasen }\end{array}$ & $\begin{array}{l}\text { Pektinasen, } \\
\text { Pektinglykosidasen }\end{array}$ \\
\hline & & $\begin{array}{l}\text { Spaltung nach } \beta \text { - } \\
\text { Eliminierungs-Mechanismus: } \\
\text { Polygalakturonasen, } \\
\text { Pektinlyasen, Pektatlyasen }\end{array}$ \\
\hline
\end{tabular}

Die wesentlichen Unterteilungsmerkmale ergeben sich nach dem Spaltungsmechanismus, Hydrolyse oder $\beta$-Elimination, der Wirkungsweise bzw. dem Polymerisationsgrad der entstehenden Spaltprodukte in der Anfangsphase, EndoMechanismus oder Exo-Mechanismus. Unterschieden wird auch nach dem bevorzugten Substrat, Pektin oder Pektinsäure, und nach dem Angriffsort, also dem 
reduzierenden oder nichtreduzierenden Kettenende des Substrats (STROOT, 2001). Die Abb. 2-5 zeigt die einzelnen Angriffsorte der jeweiligen Enzyme.

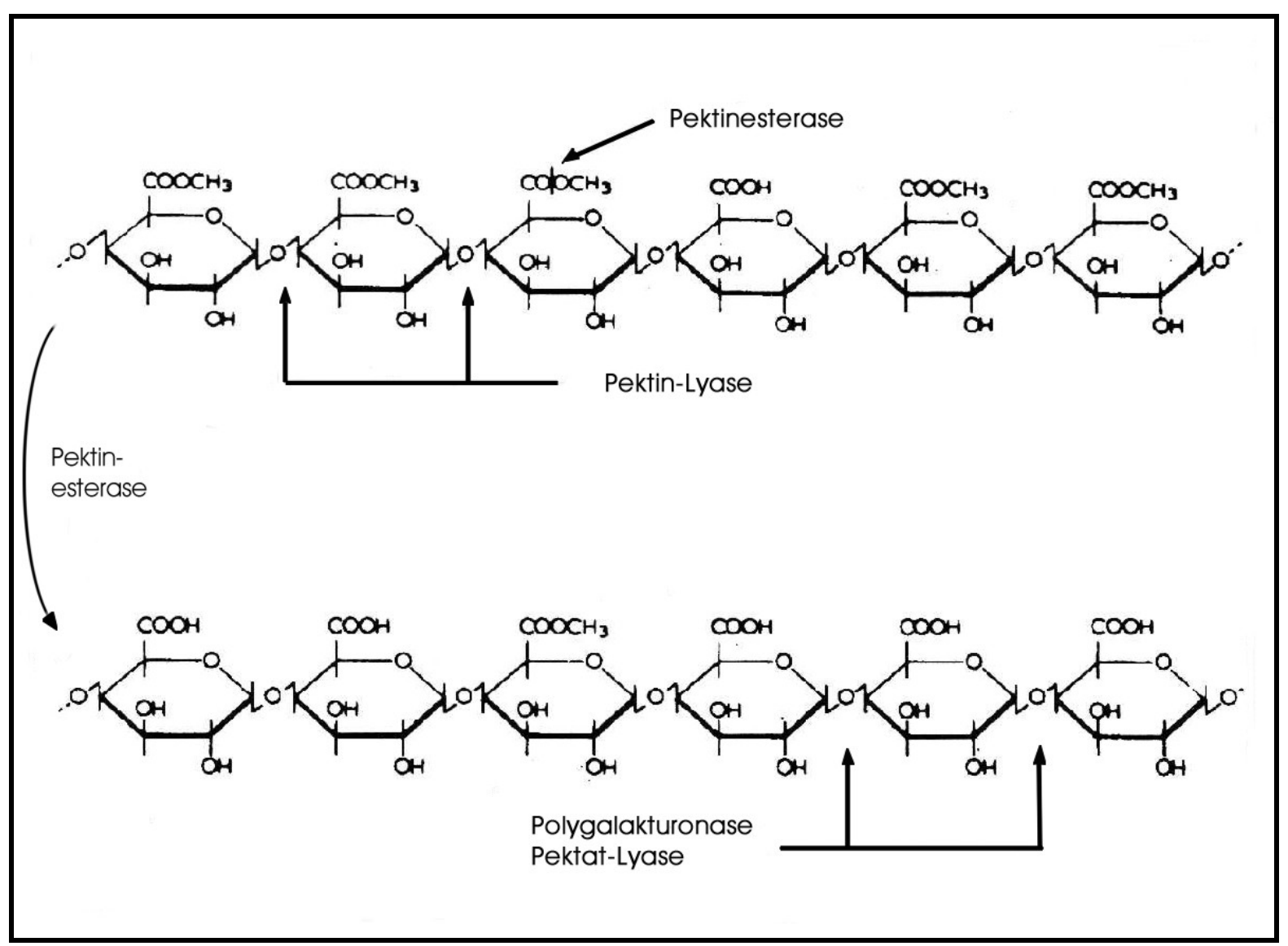

Abb. 2-5: Spaltungsmechanismen der pektolytischen Enzyme (RomBouTS u. PILNIK, 1978)

\subsubsection{Pektinesterase}

Die Pektinesterase hydrolysiert die Methylesterbindungen von Pektin und ist häufig sowohl in höheren Pflanzen als auch in Schimmelpilzen und Hefen vorhanden. Dieses Enzym weist eine hohe Pektinspezifität auf, die besonders an den Homogalakturonan-Sequenzen greift. Die enzymatische Entesterung von Pektin verläuft linear entlang der Galakturonan-Kette und führt zu Blöcken freier CarboxylGruppen, die das Polymer extrem leicht mit $\mathrm{Ca}^{2+}$ reagieren lassen (RombouTs U. PILNIK, 1978). Eine Entesterung erfolgt nur bis zu einem Grad von 5-10 \% aufgrund von Unregelmäßigkeiten in der Molekülstruktur des Pektins. Bei pflanzlicher Pektinesterase liegt das pH-Optimum über 7, während die Pektinesterase aus Pilzen ihr Optimum bei 4,5 hat. 


\subsubsection{Polygalakturonase}

Die Polygalakturonase ist ein Enzym, das in höheren Pflanzen, bestimmten niederen Tieren und verschiedenen Mikroorganismen vorkommt. In der Lebensmitteltechnologie ist es eines der wichtigsten pektinspaltenden Enzyme. Sein pH-Optimum liegt im Bereich von 4,0 bis 5,5.

Pektinsäure ist das bevorzugte Substrat der Polygalakturonase, diese wird zunächst in Makromoleküle und schließlich in Mono- bis Tri-Galakturonsäure-Einheiten gespalten. Die Polygalakturonasen werden in Endo- und Exo-Enzyme eingeteilt (STROOT, 2001).

Die Exo-Polygalakturonasen werden in einer großen Anzahl von Mikroorganismen und höheren Pflanzen vorgefunden. Ihre Wirkungsweise beruht darauf, dass sie vom nichtreduzierenden Kettenende des Galakturonsäuremoleküls Galakturonsäure abspaltet und im Gegensatz zur Endo-Polygalakturonase auch Di-Galakturonsäure hydrolysiert.

Die Spaltung des Substrats durch Endo-Galakturonasen erfolgt nach dem Zufallsprinzip. Gleichzeitig nimmt die Viskosität der Substratlösung relativ schnell ab, verursacht durch den Anstieg der reduzierten Gruppen als Folge der enzymatischen Aktivität.

\subsubsection{Pektintranseliminasen}

Diese Enzyme sind laut der EC-Nomenklatur unter den Namen Pektin- bzw. PektatLyase (E.C. 4.2.2.10 und E.C. 4.2.2.9) bekannt. Man findet sie hauptsächlich in Bakterien und Pilzen (PILNIK u. RomBouTS, 1981) aber auch in höheren Pflanzen (WING et al., 1990).

Der Abbau von Pektat bzw. Pektin erfolgt durch eine $\beta$-Eliminierung wobei die $\alpha$ glykosidische Bindung zwischen dem 0-1 und C-4 Atom gespalten wird (s. Abb. 2-6). Es entsteht ein Produkt mit einer ungesättigten C4-C5 Bindung am nicht reduzierenden Ende (WALTER, 2002; Deuel U. StUTZ, 1958).

\subsubsection{Pektin-Lyase}

Pektin-Lyase ist das einzige pektinspaltende Enzym, dass die $\alpha-1,4$ Bindungen von hochverestertem Pektin ohne zusätzliche Hilfe von anderen Enzymen spalten (ALANA 
et al., 1991) und hochveresterte Pektine zu Oligogalakturonan abbauen kann (ReXova-Benkova u. Markovic 1976). Sie wird nur durch Schimmelpilze, und einige pflanzenpathogene Bakterien wie z. B. Erwinia-Stämme, Bacillen, Pseumonaden und Clostridien gebildet (Rombouts U. PILNIK, 1980). Das Endo-Enzym spaltet bevorzugt hochveresterte Pektine unter Feisetzung ungesättigter veresterter Oligogalacturonide (STROOT, 2001).

\subsubsection{Pektat-Lyase}

Pektat-Lyase wird wie die Pektin-Lyase in Pilzen und einigen Bakterienstämmen gebildet. Anders als die Pektin-Lyase baut sie nur Pektin ab, das zuvor von Pektinmethylesterasen demethyliert wurde. Für den Abbau benötigt die Pektat-Lyase die Anwesenheit von $\mathrm{Ca}^{2+}$-Ionen als Aktivatoren und ein $\mathrm{pH}$-Optimum von $8-10$. Die kleinsten Fraktionen, in die das Pektin gespalten wird, sind Di- und TriGalakturonsäure-Einheiten. Pektat-Lyasen finden häufig Einsatz in der Gemüseverarbeitung.

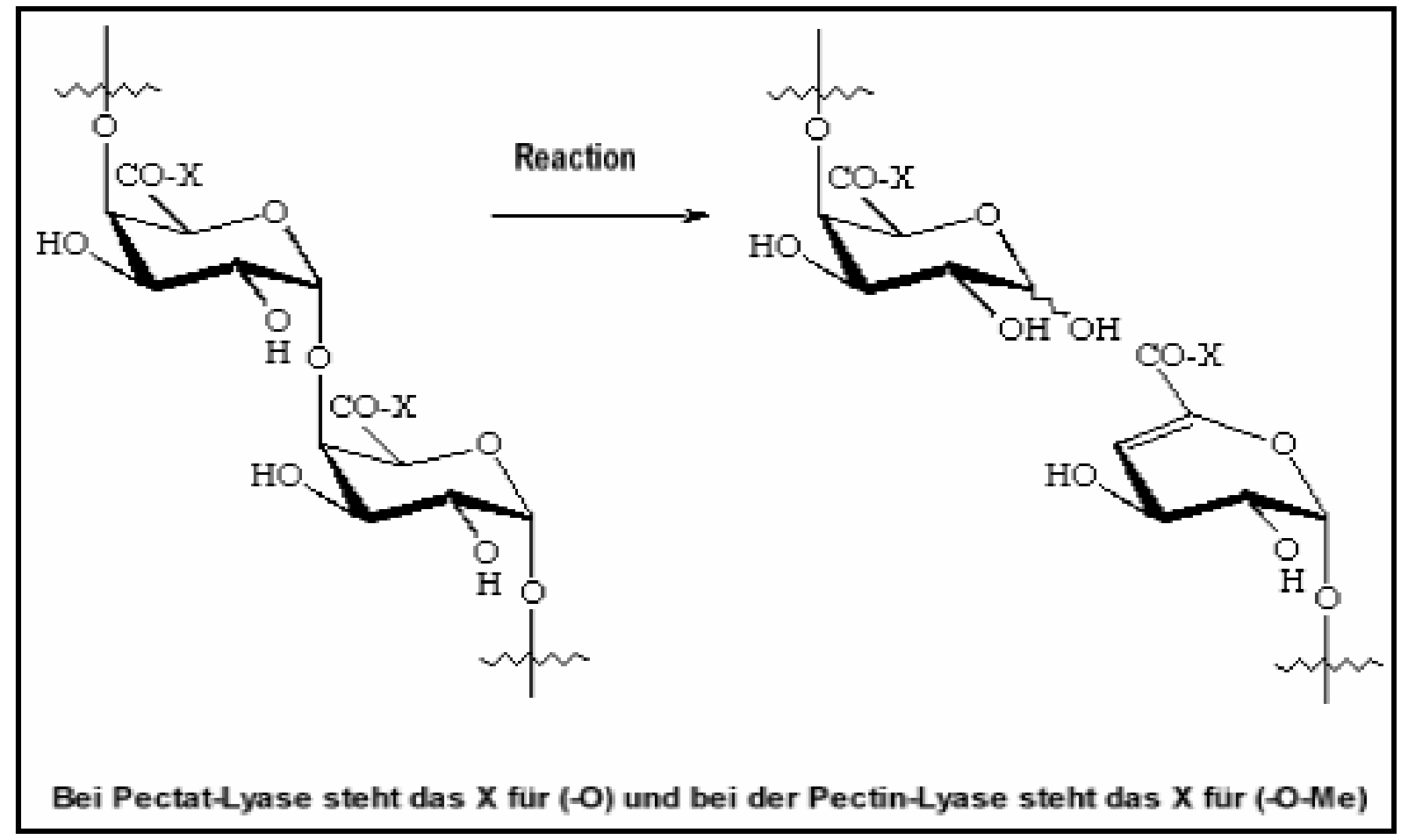

Abb. 2-6: Reaktion von Pectat- bzw. Pectin-Lyase bei der Spaltung von Pektin (IUBMB, 2001) 


\subsubsection{Cellulytische und hemicellulytische Enzyme}

Die cellulytischen Enzyme gehören zu der Gruppe der Glykosidasen. Der Abbau der Cellulose erfolgt in mehreren Schritten, an denen unterschiedliche Enzyme beteiligt sind. Man unterscheidet drei Hauptgruppen von Enzymen, die Endo-Cellulase (EC 3.2.1.4), die Exo-Cellulase (EC 3.2.1.91) und die $\beta$-Glukosidase (EC 3.2.1.21). Die Wirkungsweise der Enzyme ist in der Abb. 2-7 verdeutlicht. Zuerst spaltet die Endo$\beta$-Glukanase die Cellulose-Fibrillen auf, anschließend kann die Exo- $\beta$-Glukanase vom Ende der Glukanketten Cellobiose abspalten. Die Spaltung der Cellobiose in löslichen Zucker, die Glukosemonomere, erfolgt durch die $\beta$-Glukosidase.

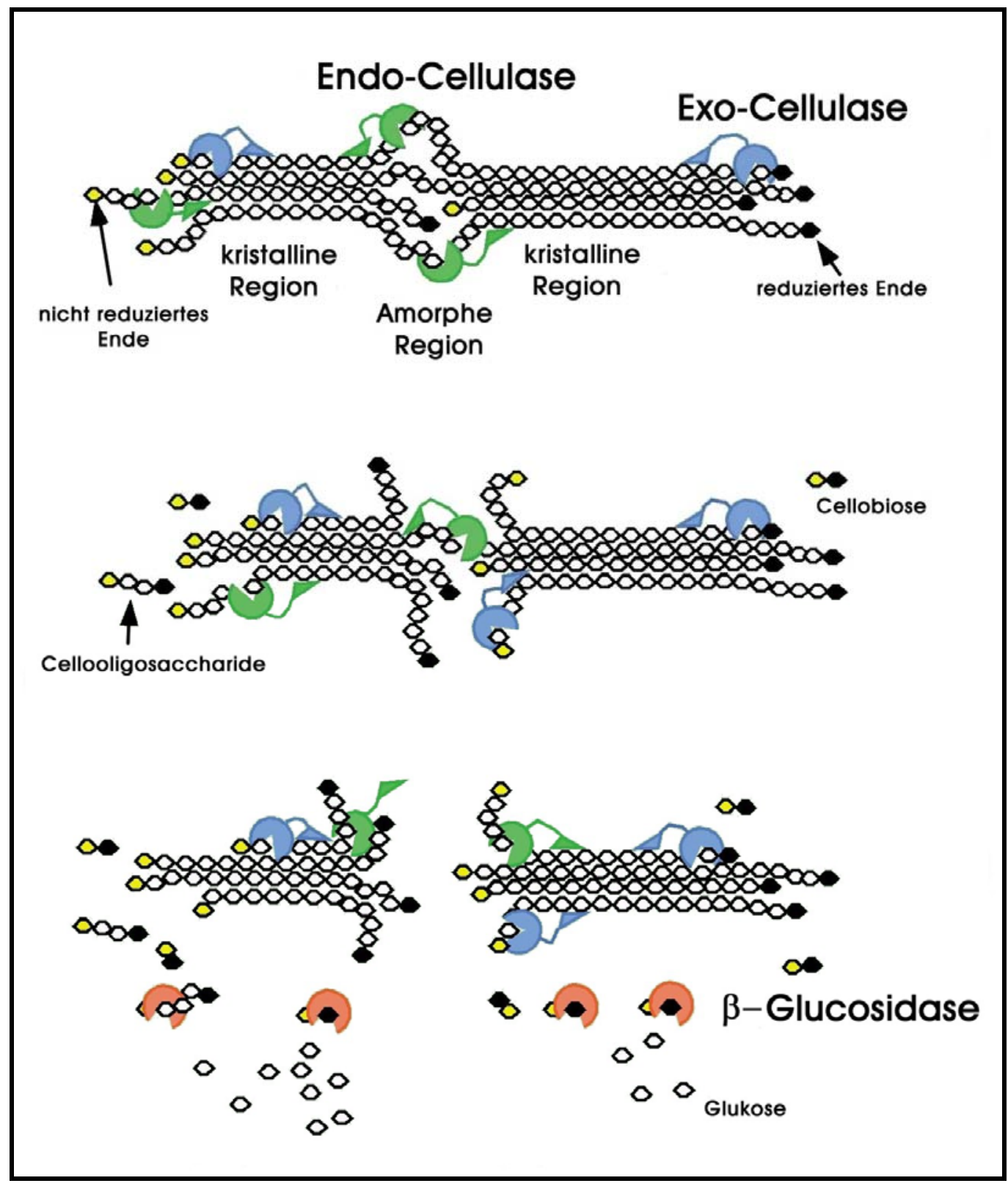

Abb. 2-7: Abbau der kristallinen Cellulose durch cellulytische Enzyme (http://bs.shinshu-u.ac.jp; Download vom 02.11.2004) 
Cellulolytische Enzyme findet man in Mikroorganismen, Pflanzen und Tieren. Für die industrielle Produktion werden hauptsächlich Aspergillus species und Trichoderma reesei verwendet. Diese Enzyme finden ihre Verwendung häufig in Kombination mit anderen Enzymen bei der Obst- und Gemüseverarbeitung.

Zusätzlich zu den cellulolytischen Enzymen müssen auch die Hemicellulasen genannt werden. Sie sind in der Lage, die Hemicellulose als Bestandteil der pflanzlichen Zellwand zu hydrolysieren. Hemicellulosen setzen sich aus unterschiedlichsten Monomeren mit verschiedenen Verknüpfungsmustern zusammen und erreichen dadurch häufig einen komplexen Aufbau. Die enzymatische Hydrolyse dieser polymeren Kohlenhydrate wird hauptsächlich von Enzymen erreicht, die zu der Gruppe der Glukanasen zählen. Die wichtigsten Vertreter sind die Endo-1,4- $\beta$ Glukanase, die Endo-1,3- $\beta$-Glukanase und die Endo-1,6- $\beta$-Glukanase. Die technischen Präparate werden meist aus Bacillus subtilis, aus Aspergillus spezies oder Trichoderma spezies hergestellt (STROOT, 2001).

\subsection{Faserstoff}

\subsubsection{Faserherstellung durch Holzaufschluss}

Die Ursprünge der Faserplattenherstellung liegen in der Papier- und Kartonherstellung. Für dieses Verfahren müssen zuerst zellulosehaltige Materialien zu Faserstoff aufbereitet, zu einem Vlies gebildet und getrocknet werden. Bei der Herstellung von Faserplatten erfolgt noch eine anschließende Trocknung oder Verdichtung. Erst durch die Entwicklung von so genannten thermo-mechanischen Zerfaserungsprozessen konnte sich die Faserplattenindustrie entwickeln. Hierbei sind besonders zwei Verfahren zu nennen, die auch heute noch eingesetzt werden. Zum einen das Dampfexplosionsverfahren nach MASON und zum anderen das Dampfmahlverfahren nach ASPLUND.

\subsubsection{Dampfexplosionsverfahren nach MAsON}

In den USA veranlassten riesige Mengen Holzabfall aus den Sägewerken Mason zu Überlegungen über die Verwendung dieses Rohstoffes. Es handelte sich hierbei besonders um harzreiche Kiefernsorten. Versuche nach dem Holzschliffverfahren 
sowie chemische Verfahren zur Zellulosegewinnung aus diesem Rohstoff waren gescheitert (LAMPERT, 1967).

Mason wollte die plastischen Eigenschaften von feuchtem Holz bei erhöhter Temperatur für die Zerlegung in einzelne Fasern ausnutzen. Die Erfindung von Mason beruht auf einem Patent des Amerikaners LYMAN dem Jahre 1858. Mason begann 1924 mit verschiedenen Entwicklungen und konnte 1926 die erste Anlage nach dem Dampfexplosionsverfahren in Betrieb nehmen.

Für diese Verfahren können unterschiedliche Holzsortimente eingesetzt werden. Zum einen werden Rundholz oder Abschnitte mit Rinde verwendet und zum anderen Abfälle aus der Sägeindustrie. Das Rundholz und die Abschnitte müssen vor der Verarbeitung im Hacker zerkleinert werden. Anschließend wird das Holz in fein, mittel und grob fraktioniert. Die Feinfraktion bestehend aus Holzstaub wird für die Energiegewinnung eingesetzt, die Mittelfraktion mit einer Größe zwischen 10 bis 25 mm gelangt in den Hackschnitzelbunker. Größere Teile müssen nochmals zerkleinert und fraktioniert werden.

Das Besondere an dem Masonite-Verfahren ist der Umstand, dass Zellulose-LigninBindungen aufgelöst und die Fasern teilweise mit Hilfe von hohem Druck hydrolysiert werden. Der eigentliche Aufschluss des Holzes findet in einem Hochdruckzylinder mit einer Höhe von 1.500 bis $1.600 \mathrm{~mm}$ und einem Durchmesser von 500 bis $600 \mathrm{~mm}$ statt. Die Hackschnitzel werden dem Zylinder chargenweise zugeführt und dieser wird luftdicht verschlossen. Dann wird der Druck in dem Zylinder durch Dampf innerhalb von 30 Sekunden auf 40 bar erhöht und für weitere 30 Sekunden gehalten. Anschließend erhöht sich der Druck sehr schnell auf 70 bis 80 bar bei einer Temperatur von etwa 284 bis $294^{\circ} \mathrm{C}$. Dieser Zustand wird für einige Sekunden beibehalten, bevor der Druck plötzlich absinkt. Der plötzliche Druckabfall geht einher mit einem lauten Knall, daher auch die Bezeichnung "Kanone". Die Holzschnitzel schießen durch kleine Schlitze am Boden der Kanone und platzen durch den entstandenen Druckunterschied im Inneren des Holzes und dem Umgebungsdruck auseinander. Die Holzstruktur wird dabei völlig zerstört und man erhält eine braune, moosartige Faserstruktur. Die Fasern werden anschließend gewaschen, gereinigt und eventuell im Refiner nachgemahlen.

Mit diesen Fasern können im Nassverfahren Faserplatten ohne Zugabe von Bindemitteln hergestellt werden. Der Grund liegt in der Freilegung der Primärlamellen in den Zellwänden der Holzfasern. Diese Primärlamellen sind bei späteren Verklebungen als Berührungsfläche wirksam. Ein weiterer Vorteil liegt in der weitestgehenden Beibehaltung der ursprünglichen Faserlänge.

Ein großer Nachteil dieses Verfahrens ist die geringe Ausbeute, da während des Holzaufschlusses Reaktionsprodukte (Essigsäure, Ameisensäure, Kohlendioxid) 
entstehen und der im Wasser lösliche Teil der Hemizellulose beim Waschen verloren geht. Weiterhin wirken sich das diskontinuierliche Verfahren des Aufschlusses und die dunklen Fasern nachteilig aus. Das Dampfexplosionsverfahren oder auch MasoniteVerfahren wird hauptsächlich in den USA, aber auch in Australien und teilweise in Europa angewendet.

\subsubsection{Das Dampfmahlverfahren nach ASPLUND}

Kurz nach der Entwicklung des Masonite-Verfahrens begann der Schwede Arne Asplund mit der Zerfaserung von Holz auf thermomechanische Weise. Das Verfahren von ASPLUND arbeitet mit deutlich geringerem Druck als bei Mason, nämlich nur 8 bis 12 bar, bei einer Temperatur von 170 bis $180{ }^{\circ} \mathrm{C}$. Asplund erreichte durch die Einwirkung des Dampfdruckes lediglich eine Plastifizierung, die als Vorstufe für die Zerfaserung auf mechanischem Wege mittels profilierter Mahlscheiben notwendig ist (LAMPERT, 1967). Das Dampfmahlverfahren wird hauptsächlich in Europa angewendet und wurde seit seiner Erfindung mehrfach modifiziert.

Für diese Verfahren werden ebenfalls hauptsächlich Hackschnitzel eingesetzt. Diese werden mittels einer Schnecke durch den Pfropfenbildner in einen Vorwärmer transportiert. Bereits im Pfropfenbildner beginnt die Plastifizierung und endet schließlich bei einem Druck von 6 bis 10 bar bei einer Temperatur von etwa $180{ }^{\circ} \mathrm{C}$ (DePPE u. ERNST, 1996). Anschließend gelangt das plastifizierte Material zwischen die Mahlscheiben des Defibrators und wird mechanisch zerfasert. Hierbei bleibt die Faserlänge annähernd erhalten. Aufgrund dieses Verfahrens spricht man auch von thermomechanischer Zerfaserung (Thermomechanical Pulp Process $=$ TMP). Durch Vorbehandlung des aufzuschließenden Holzes mit alkalischen Sulfiten verringert sich der Energiebedarf beim Aufschluss des Holzes teilweise um die Hälfte (vgl. Blechschmitdt et al., 1988; Poller u. KletZin, 1990; Roffael et al., 2001a). Diese chemo-thermo-mechanischen Fasern (CTMP) werden ebenfalls für die Faserplattenherstellung eingesetzt. Die Vorteile dieser Verfahren sind der schonende Aufschluss und der dadurch bedingte geringere Materialverlust sowie eine helle Faserfarbe. In ökonomischer Hinsicht sind der geringere Energieeinsatz und das kontinuierliche Aufschlussverfahren von Bedeutung. 


\subsubsection{Faservliesbildung}

Die Bildung eines Faservlieses kann nach mehreren Methoden erfolgen. Man unterscheidet hierbei zwischen den beiden häufigsten Verfahren: dem Nassverfahren und dem Trockenverfahren.

\subsubsection{Nassverfahren}

Das Nassverfahren wird normalerweise für die Produktion von harten Faserplatten und Faserdämmplatten eingesetzt, wobei die Produktion von harten Faserplatten nach diesem Verfahren zurückgeht. Dafür werden vermehrt Spezialprodukte, z. B. für den Dachbereich oder Fußbodenplatten hergestellt. Bedeutender sind die Faserplatten mit niedriger Dichte, sie werden vermehrt als Dämmplatten produziert.

Für die Vliesbildung im Nassverfahren wird der Faserstoff mit Wasser bis zu einer Stoffkonzentration von 0,8 bis 2,5\% aufgeschwemmt. Hier erfolgt auch die Zugabe von Klebstoff, Fällmittel oder Zusatzstoffen in Abhängigkeit von der jeweiligen Technologie. Anschließend wird die Fasersuspension kontrolliert auf eine Entwässerungsstrecke dosiert. Zur Herstellung von Faserdämmplatten wird der entwässerte Kuchen nur noch vorverdichtet und getrocknet, für die Herstellung von Hartfaserplatten wird der Faserkuchen in Mehretagenpressen gepresst.

\subsubsection{Trockenverfahren}

Nach dem Faseraufschluss werden die Fasern direkt beleimt. Man unterscheidet dabei die "Blowline-Beleimung" und die Beleimung im Blenderverfahren. Für die Blowline-Beleimung werden die Fasern in der Blasleitung zwischen Refiner und Trockner beleimt. Die beleimten Fasern werden anschließend direkt in Stromtrocknern bei etwa $160{ }^{\circ} \mathrm{C}$ getrocknet. Die getrockneten Fasern sollten eine Feuchte zwischen 5 bis $10 \%$ haben.

Diese Form der Beleimung wird mittlerweile am häufigsten bei der MDF-Herstellung eingesetzt. Allerdings hat sie den Nachteil, dass ca. $20 \%$ mehr Leim eingesetzt werden muss als bei der Beleimung im Mischer (s. Abb. 2-8). Mit dieser Beleimung kann zwar Leim eingespart werden, es kommt jedoch häufig zu unerwünschter Leimfleckenbildung. 
Die getrockneten Fasern werden mit Hilfe von speziellen Systemen zu einem Faservlies gestreut. Man unterscheidet hierbei zwischen der pneumatischen und der mechanischen Vliesbildung, wobei die mechanische häufiger eingesetzt wird. Anschließend erfolgt das Pressen, Auskühlen und Konditionieren.
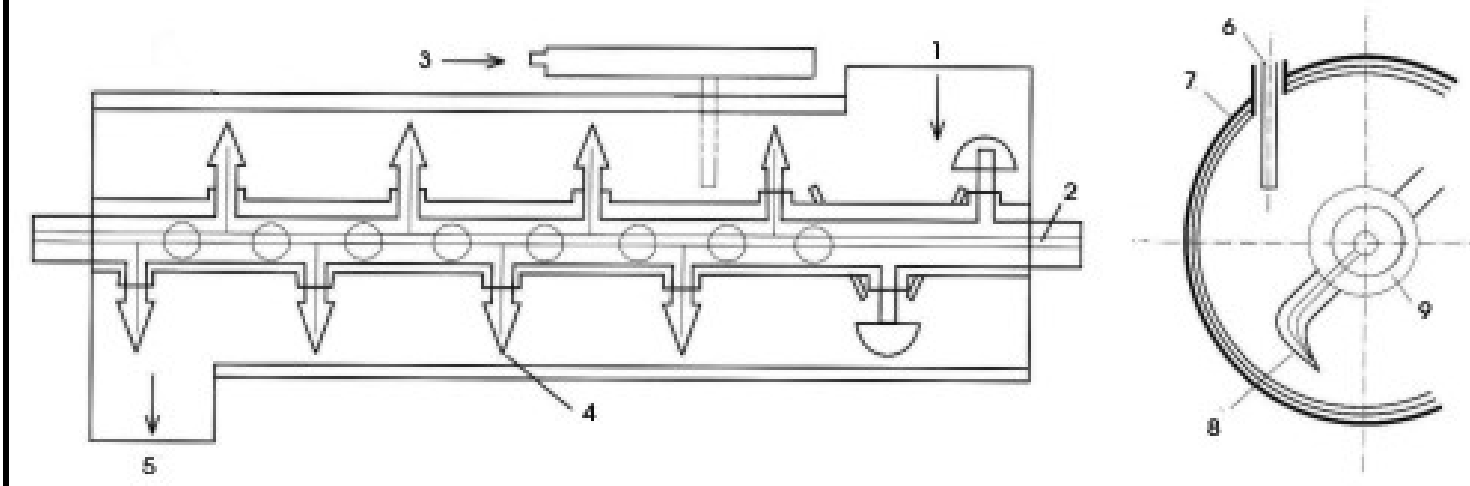

Abb. 2-8: Ringmischer mit dem Prinzip der Innenbeleimung: 1 Fasereintrag, 2 Mischwerkwelle, 3 Beleimungsdüse, 4 Mischwerkzeug, 5 Faseraustrag, 6 Leimzugabe von außen oben, 7 Mischzylinder, 8 Mischwerkzeug, 9 Mischwerkwelle (DUNKY u. NIEMZ, 2002)

\subsubsection{Produktion von mitteldichten Faserplatten (MDF)}

Die Definition von mitteldichten Faserplatten lautet nach DEPPE und ERNST (1996): „Ein trocken geformter Holzwerkstoff, hergestellt aus Lignozellulose-Fasermaterial, kombiniert mit synthetischem Klebstoff oder anderen geeigneten Bindemitteln. Die Platten werden in einem Dichtebereich von 550 bis $800 \mathrm{~kg} / \mathrm{m}^{3}$ durch Heißpressung erzeugt, wobei die Faserbindung durch die zugesetzten Bindemittel erfolgt. Weitere Zuschlagstoffe zur Eigenschaftsverbesserung können verwendet werden".

Für die Herstellung werden hauptsächlich TMP- und CTMP-Fasern (vgl. 2.3.1.2) aus Rohholz verwendet, in anderen Ländern aber auch Einjahrespflanzen, wie z. B. Bagasse (RosAmaH, 2003). Nach Untersuchungen von DiX und RofFAEL (1996) ist sogar der Einsatz von Altpapier möglich. Die eingesetzten Bindemittel sind hauptsächlich Harnstoff-Formaldehydharze und Bindemittel auf der Basis von Polymethylendiisocyanat (PMDI). In der Abb. 2-9 ist der schematische Ablauf der MDF-Herstellung aus Rundholz dargestellt. 


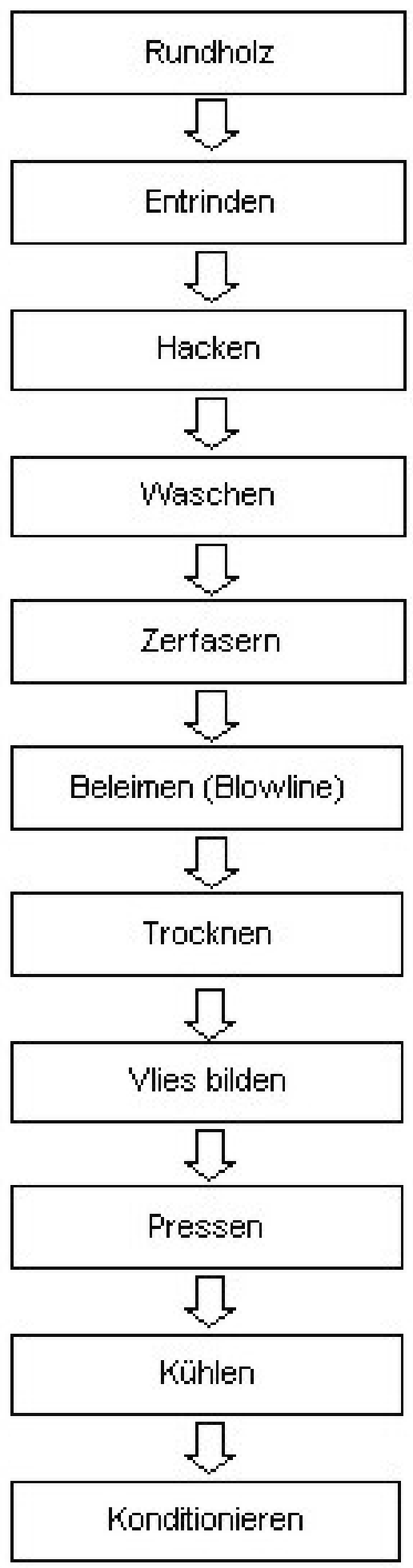

Abb. 2-9: Herstellungsablauf in der industriellen MDF-Fertigung

In der Tab. 2-2 sind die unterschiedlichen Typen der MDF-Platten aufgelistet, die hinsichtlich ihres Verwendungszwecks unterschieden werden. Die Einteilung erfolgt nach DIN EN 316 und DIN EN 622, Teil 5 (DIN-Taschenbuch 60, 1999). 
Man unterscheidet bei den MDF-Platten folgende Typen:

Tab. 2-2: Einteilung der mitteldichten Faserplatten nach DIN EN 316 und DIN EN 622 , Teil 5

\begin{tabular}{ll}
\hline \hline MDF & Platten für allgemeine Zwecke zur Verwendung im Trockenbereich \\
MDF.H & Platten für allgemeine Zwecke zur Verwendung im Feuchtbereich \\
MDF.E & Platten für allgemeine Zwecke zur Verwendung im Außenbereich \\
MDF.LA & Platten für tragende Zwecke zur Verwendung im Trockenbereich \\
MDF.HLS & Platten für tragende Zwecke zur Verwendung im Feuchtbereich \\
\hline
\end{tabular}

\subsection{Herkömmliche Bindemittel}

Neben dem Holz als Rohstoff ist der zweite wichtige Faktor der Einsatz des richtigen Bindemittels. Das eingesetzte Bindemittel hat einen entscheidenden Einfluss auf die Eigenschaften der damit hergestellten Holzwerkstoffe. Für unterschiedliche Beanspruchungen der Holzwerkstoffe müssen auch unterschiedliche Bindemittel eingesetzt werden.

\subsubsection{Kondensationsharze auf der Basis von Formaldehyd}

Diese Harze entstehen durch eine Reaktion von Formaldehyd mit verschiedenen Verbindungen wie Harnstoff, Melamin, Phenol oder Resorcin sowie mit Kombinationen dieser Verbindungen (DUNKY, 2002). Ein wichtiges Merkmal der Formaldehyd-Kondensationsharze ist das duroplastische Aushärten dieser Bindemittel.

\subsubsection{Harnstoff-Formaldehydharze (UF)}

Die UF-Harze sind in der Holzwerkstoffindustrie die wichtigste Gruppe der aminoplastischen Bindemittel. Diese Bindemittel besitzen eine Aminogruppe $\left(-\mathrm{NH}_{2}\right)$ entweder in Form der Aminbindung $\left(\mathrm{R}-\mathrm{NH}_{2}\right)$ oder der Amidbindung $\left(\mathrm{R}-\mathrm{CO}-\mathrm{NH}_{2}\right)$.

Bereits 1877 berichtete C. Goldschmidt über erste Arbeiten an Reaktionen zwischen Harnstoff und Formaldehyd. Allerdings erteilte man erst 44 Jahre später H. John das 
erste Patent betreffend UF-Harze. Die damalige Firma IG Farbenindustrie in Ludwigshafen war die erste, die 1931 UF-Holzleim herstellte.

UF-Harze sind einfach zu handhaben und unkompliziert in der Verarbeitung (DinwoOdIE, 1983). Sie können sowohl kalt als auch heiß verleimt werden und eine Kombination mit anderen Bindemittelsystemen ist möglich. Nach dem Verpressen haben die ausgehärteten Leimfugen ein duroplastisches Verhalten, sowie eine hohe Festigkeit der Verleimung. Besondere Vorteile der UF-Harze sind die Farblosigkeit und der niedrige Preis im Vergleich zu anderen Bindemitteln. Trotzdem ist der Einsatz von UF-Harzen nicht völlig problemlos. Zum einen sind mit UF-Harz hergestellte Holzwerkstoffe nicht unempfindlich gegen die Einwirkung von Feuchtigkeit und Wasser und zum anderen erfolgt eine Abspaltung von Formaldehyd während der Verarbeitung und bei der späteren Verwendung der Holzwerkstoffe (ROFFAEL, 1982). Zur Verringerung der Feuchteempfindlichkeit werden mittlerweile Melamin und teilweise auch Phenol in die UF-Harze eingebaut. Durch eine starke Reduzierung des Molverhältnisses zwischen Formaldehyd und Harnstoff konnte die Formaldehydemission stark reduziert werden.

\subsubsection{Melamin- und Melaminmischharze}

Melaminharze gehören ebenso wie UF-Harze zu den Aminoplasten. Der Einsatz von reinen Melaminharzen findet aus Kostengründen so gut wie gar nicht statt. Häufig werden sie als Imprägnier- und Tränkharze eingesetzt. Allerdings ist eine Beimischung von Melamin zu anderen Harzen üblich. Durch die Zugabe von Melamin kann die beschränkte Hydrolysebeständigkeit von ausgehärteten UF-Harzen verbessert werden und man erreicht eine Reduzierung der Dickenquellung.

Die Melaminharnstoff-Formaldehydharze (MUF), zeichnen sich gegenüber reinen UFHarzen dadurch aus, dass sie eine höhere Feuchtebeständigkeit und die Fähigkeit aufweisen, bei Temperaturen über $130{ }^{\circ} \mathrm{C}$ ohne einen besonderen Katalysator auszuhärten (ROFFAEL, 1976). Neben diesem Leim sind die gebräuchlichsten Mischharze Melaminharnstoff-Phenol-Formaldehydharze (MUPF) und PhenolMelamin-Harze (PMF). 


\subsubsection{Phenolharze}

Neben den bereits genannten Aminoplasten stellen Phenol-Formaldehydharze (PF) eine weitere bedeutende Gruppe im Bereich der Holzbindemittel dar. PF-Harze werden hauptsächlich bei wasser- und witterungsbeständigen Verleimungen eingesetzt. Vorteilhaft beim Einsatz von PF-Leimen sind zum einen die geringe bis weitgehend fehlende Formaldehydabgabe und zum anderen die niedrige Dickenquellung. Allerdings härten PF-Harze im Vergleich zu aminoplastischen Harzen langsamer aus. Die hergestellten Holzwerkstoffe besitzen eine dunklere Farbe, verursacht durch eine dunkle Leimfuge, die sich bei der Verendung von sehr hellem Furnier abzeichnen kann. Das eingesetzte Phenol kann sowohl im alkalischen als auch im sauren Bereich mit Formaldehyd kondensieren und vernetzen. Man unterscheidet dabei die alkalisch härtenden Phenole als Resole und die säurehärtenden als Novolake. In der Holzwerkstoffindustrie werden nur die alkalisch härtenden Phenole eingesetzt (KIRCHNER, 1997). Phenolharzleime sind wässrige, alkalische Lösungen, die aus oligomeren bis polymeren Ketten bestehen (DUNKY, 2002). Durch den alkalischen pH-Wert können beim Beschichten dieser Holzwerkstoffe Probleme auftreten, ebenso bei der Verwendung von verschiedenen sauren Holzarten.

\subsubsection{Bindemittel auf der Basis von I socyanaten}

Isocyanate gehören nicht wie UF- und PF-Harze zu den Kondensationsharzen, sondern basieren auf Polymethylendiisocyanat (PMDI) und werden vorwiegend für die Herstellung von Holzwerkstoffen für den Einsatz im Feuchtebereich und für "formaldehydfrei" verleimte Platten eingesetzt. Besonders geeignet ist PMDI als Bindemittel bei schwer zu verleimenden Einjahrespflanzen wie z. B. Stroh und Bagasse. PMDI weist ein sehr hohes Klebeverhalten auf, allerdings wird dadurch die Verarbeitung enorm erschwert, da es nicht nur mit der Holzoberfläche reagiert.

Nach WitTMANN und LeHNERT (1974) können bei der Verwendung von Isocyanaten als Bindemittel verschiedene Grundreaktionen ablaufen. Dazu gehören die Reaktion mit Wasser, mit den Hydroxylgruppen der Cellulose und Hemicellulose und anderen Kohlenhydraten, mit Hydroxylgruppen des Lignins und der Gerbstoffe und mit den $\mathrm{COOH}-G r u p p e n$ der Polygalakturonsäuren, Uronsäuren und Lignine. In der Tab. 2-3 sind im Einzelnen die Vor- und Nachteile von PMDI aufgelistet. 
Tab. 2-3: Vor- und Nachteile von PMDI im Vergleich zu anderen Bindemitteln insbesondere UF-Harzen (DUNKY, 2002)

Vorteile $\quad$ - hohe Lagerstabilität
- formaldehydfreie Verleimung
- hohe Reaktivität
- hohe Bindefestigkeiten
- hohe Feuchtigkeitstoleranz der Verklebung
- geringer Klebstoffverbrauch

Nachteile

- hoher Preis

- Verwendung meist nur in der Mittelschicht, bei Einsatz in der Deckschicht sind spezielle Trennmittel erforderlich

- Einsatz von Emulgatoren (EMDI) oder spezieller Dosier- und Beleimungstechniken

- Notwendigkeit höherer Arbeitsschutzmaßnahmen: niedriger, jedoch sehr wohl vorhandener Dampfdruck

\subsection{Bindemittel auf Basis nachwachsender Rohstoffe}

Bereits seit Jahrtausenden werden Bindemittel auf Basis nachwachsender Rohstoffe verwendet. Allerdings haben sie durch den Einsatz synthetischer Bindemittel an Bedeutung verloren. Mittlerweile gibt es jedoch wieder Entwicklungen, Bindemittel aus nachwachsenden Rohstoffen zu optimieren und industriell einzusetzen.

Trotzdem werden diese Bindemittel im Vergleich zu den herkömmlichen Bindemitteln nur im kleinen Maßstab zur Produktion von Holzwerstoffen eingesetzt. Hierfür gibt es mehrere Gründe. Die Herstellungskosten von natürlichen Bindemitteln sind im Vergleich zu synthetischen Bindemitteln deutlich höher, zudem müssten die bisherigen industriellen Beleimungsanlagen modifiziert werden, da natürliche Bindemittel meist anders verarbeitet werden.

Bindemittel, die auf nachwachsenden Rohstoffen basieren, haben häufig den Nachteil, dass sie nicht ganzjährig verfügbar sind und durch verschiedene Wachstumsparameter häufig inhomogene Strukturen aufweisen. Bei einer Mischung von natürlichen und synthetischen Bindemitteln erreicht man zwar technologische Vorteile, aber man entzieht dadurch dem Produkt das Merkmal "rein biologisch" zu 
sein. Eine schematische Übersicht über die wichtigsten natürlichen Bindemittel ist in der Abb. 2-10 dargestellt.

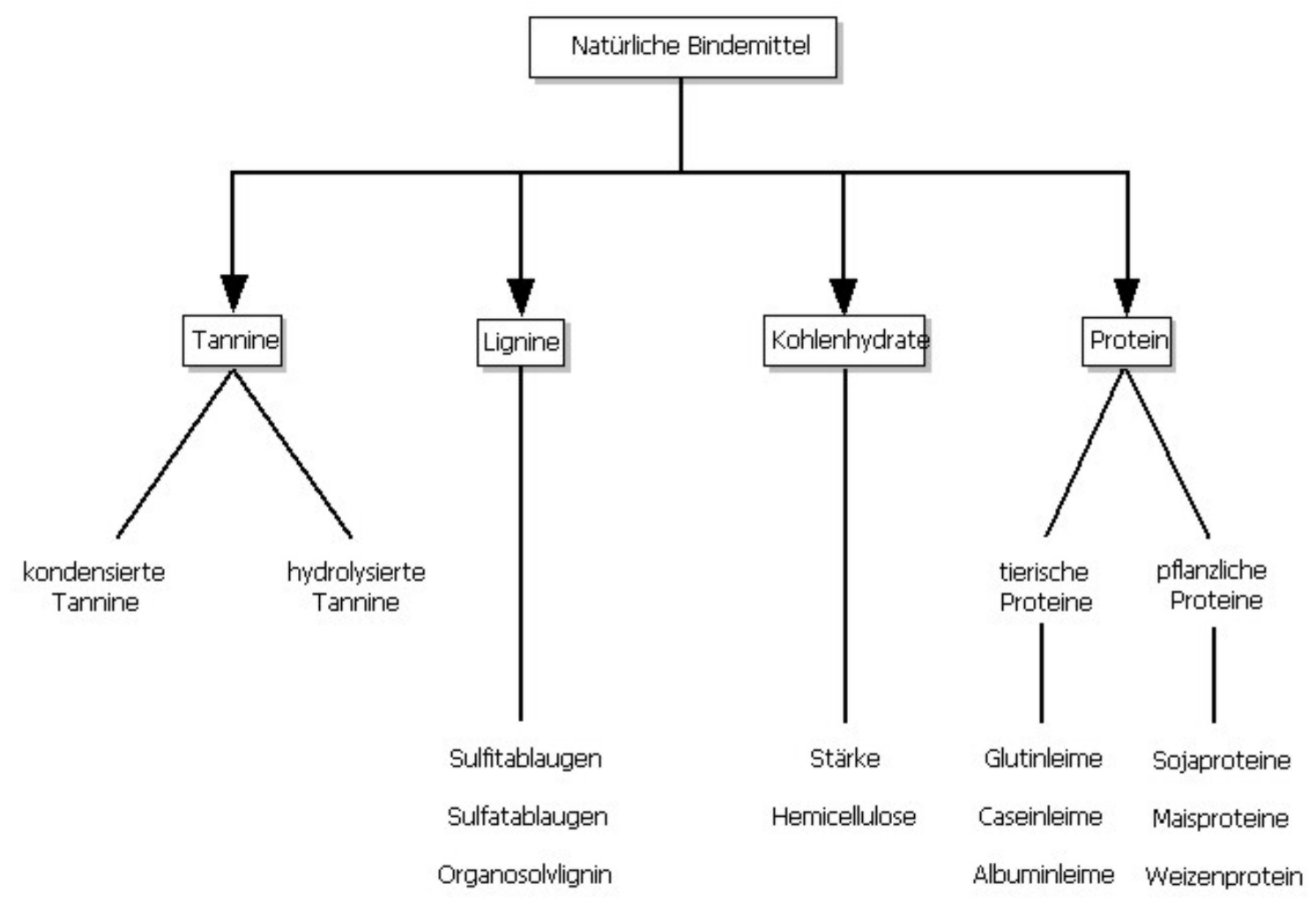

Abb. 2-10: Bindemittel auf der Basis nachwachsender Rohstoffe (vgl. RofFAEL, 1997a u. ROSAMAH, 2003)

\subsubsection{Tannine}

Unter Tanninen versteht man pflanzliche Polyhydroxyphenole (Gerbstoffe), die in Wasser, Alkoholen und Aceton löslich sind. Hauptsächlich gewinnt man Tannine durch Extraktion aus Hölzern, Rinden, Blättern und Früchten. Es gibt zahlreiche Untersuchungen zur Verwendung von Extraktstoffen aus Rinden von Mimosaceen (DALTON, 1953; Plomley et al., 1976; Pizzi, 1982) und Rinden aus verschiedenen Kiefernarten (LIIRI et al., 1982; DiX und MARUTZKY, 1985).

Chemisch werden die Tannine in hydrolysierbare und kondensierte Typen unterteilt. Der Einsatz von Tanninen als Bindemittel erfolgt entweder mit einer FormaldehydKomponente als Vernetzer oder in Kombination mit amino- oder phenolischen Harzen. 
Durch die chemischen Eigenschaften der pflanzlichen Phenole, die aufgrund ihrer molekularen Struktur denen der synthetischen Phenole sehr ähnlich sind, eignen sie sich ebenfalls als Ausgangsmaterial für Holzleime (KHARAZIPOUR, 1996). Tanninharze gelten als das billigste Bindemittel mit dem kochfeste Vernetzungen erzielt werden können (Jung u. RofFael, 1989; RofFAel u. Dix, 1994).

1995 wurde in Deutschland die industrielle Herstellung von mit TanninFormaldhydharzen gebundenen Spanplatten aufgenommen, die eine extrem geringe Formaldehydabgabe aufweisen (ROFFAEL et al., 2001b). Zurzeit werden Tannine aus Mimosa, Quebracho, Akazie und Kiefer (Pinus radiata) technisch eingesetzt. Trotz dieser Entwicklung liegt der Schwerpunkt der Tanninverwendung hauptsächlich in Ländern, die in ausreichendem Maße über die pflanzlichen Rohstoffe verfügen (Südafrika, Australien, Indien, etc.).

\subsubsection{Lignine}

Lignin macht neben der Cellulose den zweitgrößten Anteil im Holz aus. Man findet es hauptsächlich in der Primärwand und der Mittellamelle, aber auch in der Tertiärwand neben Cellulose und Hemicellulose. Die Hauptaufgaben des Lignins in der Zellwand bestehen darin, die Cellulosefasern zusammenzuhalten, Druckstabilität zu schaffen und eine Hygroskopizität des Holzes zu erreichen.

Der Molekülstruktur des Lignins liegt ein dreidimensional verzweigtes Polymer zu Grunde, das durch die oxidative Polymerisation der drei Substituenten, ZimtalkoholDerivate, p-Cumaryl- (I) Coniferyl- (II) und Sinapinalkohol (III) entsteht, die größtenteils durch $\mathrm{C}-\mathrm{C}$-Bindungen und Etherbindungen miteinander verbunden sind (Pettersen, 1984; Fengel u. Wegener, 1984). Allerdings ist die Struktur des Lignins noch nicht vollständig bekannt, es gibt jedoch zahlreiche Modelle (z. B. FREUDENBERG u. NeISH, 1968; GLASSER, 1981). Chemisch betrachtet handelt es sich um höhermolekulare Abkömmlinge des Phenylpropans, an dessen Phenylring teilweise Methoxy- und $\mathrm{OH}-$ Gruppen gebunden sind. Dadurch erhält das Lignin quasi "phenolischen" Charakter, so dass es als Alternative zu den Phenolen für die entsprechenden Formaldehydharze eingesetzt werden kann (HABENICHT, 1997).

Ein Nachteil beim Lignin ist die im Vergleich zum Phenol niedrige Reaktivität auf Grund der geringeren Anzahl an reaktiven Stellen im Molekül. Technische Lignine, die beim chemischen Aufschluss des Holzes anfallen, können ebenfalls als Bindemittel eingesetzt werden. Diese Ablaugenlignine besitzen allerdings einen hohen Anteil an Hemicellulosen und monomeren Zuckern, die unter konventionellen Pressbedingungen in der Industrie kaum eine nennenswerte Klebewirkung entfalten 
(AYLA, 1980; Okum 1999, Rosamah, 2003). Durch die enzymatische Behandlung mit Laccase können diese Ablaugenlignine als Bindemittel eingesetzt werden (KHARAZIPOUR, 1983; 1993; 1996), so wie bei einer Mischung dieser Lignine mit Phenolformaldehyd- bzw. Harnstoffformaldehyd-Harzen. Mittlerweile gibt es Leimsysteme, die auf Zusätzen technischer Lignine basieren (vgl. ForSS u. FUHRMANN, 1976; PECINA u. KüHNE, 1986).

\subsubsection{Bindemittel auf Kohlehydratbasis}

\subsubsection{Stärkeleime}

Stärke wird bereits seit langem als Bindemittel für verschiedene Einsatzbereiche verwendet. Die native Stärke (Reis, Kartoffeln, Mais etc.) ist allerdings nicht wasserlöslich und wird erst bei einer Verkleisterungstemperatur von ca. $65^{\circ} \mathrm{C}$ oder durch Alkalieinwirkung in eine lösliche Form überführt. Durch unterschiedliche Molekülmodifikationen konnte der Verwendungsbereich der Stärke erweitert werden.

Als "polymerisierende Stärken" wurden Produkte vorgestellt, bei denen den Stärkemolekülen Acrylamidogruppen aufgepfropft wurden, die über eine Strahlenhärtung zu einem Polymernetzwerk abbinden. Sie besitzen verbesserte Festigkeits- und Adhäsionseigenschaften sowie eine höhere Wasserbeständigkeit (HINTERWALDNER, 1986).

Für die Verwendung als Bindemittel in der Holzwerkstoffindustrie kann die Stärke in Kombination mit Tannin eingesetzt werden (DIX et al., 1998). Eine weitere Möglichkeit ist die Mischung von Stärkeleim mit Phenolharzen, Melamin- oder Harnstoff-Formaldehydharzen zur Verbesserung der Bindefestigkeit.

\subsubsection{Bindemittel auf Proteinbasis}

\subsubsection{Bindemittel auf Basis tierischer Proteine}

Man unterscheidet bei diesen Bindemitteln zwischen Glutin- und Kaseinleimen. Glutin wird aus Bindegewebe, Haut, Knorpel, Knochen und Sehnen von Tieren durch Hydrolyse dieser eiweißhaltigen Verbindungen gewonnen. Es ist ein in Wasser kolloidal lösliches Eiweißabbauprodukt mit einer kompliziert aufgebauten 
Proteinstruktur und wird hauptsächlich als körnige oder pulverförmige Substanz vermarktet. Durch Zugabe von Wasser entsteht eine gallertartige Masse, die durch Erwärmung auf ca. 60 bis $70^{\circ} \mathrm{C}$ zu der verarbeitungsfähigen Leimflotte (Solbildung) wird.

Glutinleime erhalten beim Abkühlen unter den Gelierpunkt eine starke Anfangshaftung, die eine schnelle Weiterverarbeitung ermöglicht. Innerhalb einiger Stunden verdunstet das in diesem Leimfilm enthaltene Wasser, wodurch die wesentlich höhere Endfestigkeit erreicht wird (STEIN, 1994). Glutinleime eignen sich für alle Anwendungen, bei denen eine hohe Endfestigkeit und eine hohe Elastizität der Leimfuge gefordert werden. Auf Grund der Fähigkeit, Feuchtigkeit aufzunehmen, haben die Leimfugen ein ähnliches Ausdehnungsverhältnis wie Holz. Hierdurch entsteht eine dauerhafte elastische Verbindung, bei der keine Spannungsrisse auftreten (DUNKY, 2002). Die Verwendung solcher Leime ist besonders geeignet für anfeuchtbare Klebestreifen, die dadurch wieder klebaktiv werden, insbesondere in der Papier- und Pappindustrie. In der Holzwerkstoffindustrie finden solche Leime keinen Einsatz.

Ein weiteres Bindemittel auf der Basis tierischer Eiweiße ist das Kasein. Es ist der wichtigste Eiweißbestandteil der Milch. Die Gewinnung von Kasein erfolgt durch Säurefällung (Milchsäure, Salzsäure) mit anschließender Reinigung, Trocknung und Zerkleinerung. Kasein wird in alkalischen Medien (Natronlauge, Ammoniak) aufgeschlossen, da es in kaltem Wasser nicht löslich ist. Verleimungen mit Kasein sind wasserfest und unempfindlich, allerdings neigen sie auf Grund des alkalischen Charakters zu unerwünschten Holzverfärbungen. Häufig werden Kaseinleime bei der Flaschenetikettierung eingesetzt, da sie auf feuchten Oberflächen gut haften und mittels gering prozentiger Natronlauge leicht wieder zu entfernen sind.

\subsubsection{Bindemittel auf Basis pflanzlicher Proteine}

Die bekanntesten pflanzlichen Proteine, die als Bindemittel eingesetzt werden, sind Soja- und Weizenprotein. In den USA wurden bereits in den 50 und 60 Jahren Sojaleime bei der Herstellung von Douglasiensperrholz verwendet. Der Einsatz von Weizenprotein als Bindemittel zur Herstellung von Holzwerkstoffen ist bisher nur im Labormaßstab erfolgt. Hierbei wurden sowohl Span- als auch Faserplatten mit Weizenprotein als Bindemittel verpresst (SCHÖPPER, 2004; KLOESER, 2004; KRUG und SIRCH, 1999; SIRCH u. KEHR, 1997).

Die bindungsfähigen Elemente bei Proteinen sind die Aminosäuren, die sowohl Aminogruppen (-NH$)$ als auch Carboxylgruppen (-COOH) aufweisen. Diese Gruppen 
sind in der Lage kovalente Bindungen einzugehen und können entsprechend dem pH-Wert als Säure oder Base zu agieren.

Die alleinige Verwendung von Bindemitteln auf Proteinbasis ist zurzeit in der Holzwerkstoffindustrie noch nicht möglich, da die hergestellten Produkte nicht die erforderlichen Normen erfüllen. Reine Proteinleime weisen eine geringe Feuchtebeständigkeit in der Klebfuge auf, ungünstiges rheologisches Verhalten und eine relativ geringe Widerstandsfähigkeit gegenüber mikrobiellen Einflüssen (SIRCH u. KEHR, 1997).

\subsection{Bindungskräfte}

Als Bindungskräfte in Verklebungen bezeichnet man die Kräfte, die in der Grenzschicht und der Klebeschicht wirken. Man unterscheidet dabei zwischen den Adhäsionskräften (Haftungskräfte) in der Grenzschicht und den in der Klebschicht wirkenden Kohäsionskräften.

Allgemein betrachtet bewirken die Bindungskräfte den Zusammenhalt von zwei oder mehreren Atomen bzw. Atomgruppen innerhalb von Molekülen und auch Phasengrenzen, dabei gibt die Bindungsenergie die Stärke der Bindung an. Diese ergibt sich aus der Differenz zwischen der Summe der Einzelenergien der beteiligten Partner, wenn sie sich in unendlicher Entfernung voneinander befinden und der Energie beider Partner nach der erfolgten Bindung (HABENICHT, 1997).

\subsubsection{Bindungsarten}

Man unterteilt die möglichen Bindungsarten in Abhängigkeit von den Wechselwirkungen zwischen Atomen und / oder Molekülen in chemische und zwischenmolekulare Bindungen.

Chemische Bindungen sind Hauptvalenzbindungen und eine für Verklebungen wichtige Form ist die homöopolare Bindung (Atombindung, unpolare Bindung, kovalente Bindung). Sie ist die Bindungsart der organischen Chemie und beruht auf der Austauschwechselwirkung der Valenzelektronen der Bindungspartner. Bei dieser Bindungsform teilen sich die beiden miteinander verbundenen Atome ein Elektronenpaar. Die chemische Bindung ist die stärkste Bindungsform mit der höchsten Bindungsenergie. Eine kovalente Bindung zwischen der Holzoberfläche und dem Bindemittel wäre die optimale Form der Verleimung. Zurzeit ist es aber noch 
nicht eindeutig geklärt, ob während der Aushärtung oder Abbindung des Harzes zwischen Bindemittel und Holzoberfläche eine chemische Bindung entsteht oder nicht (PIzzI, 1992). Neben der homöopolaren Bindung finden sich noch die heteropolare Bindung (Ionenbindung, polare Bindung, elektrostatische Bindung) und die metallische Bindung, wobei die heteropolare Bindung bei der Erklärung der Bindungskräfte in Klebungen keine große Rolle spielt.

Die Bindungsart der zwischenmolekularen Bindungen basiert auf Anziehungsund Abstoßungskräften zwischen valenzmäßig ungesättigten Molekülen. Man bezeichnet diese Anziehungskräfte auch als „van-der-Waalssche Kräfte", die durch Dipol-, Induktions- und Dispersionskräfte verursacht werden. Eine besondere Form der zwischenmolekularen Bindungskräfte stellen Wasserstoffbrückenbindungen dar. Bei dieser Bindungsform kommt es zu einer Wechselwirkung zwischen einer Gruppe A-H (Protonendonator) und einer Gruppe B (Protonenakzeptor). Daraus ergibt sich das Schema A-H B.

Verbindungen, die $\mathrm{OH}_{-}, \mathrm{NH}-$ oder andere Gruppen enthalten, in denen ein Wasserstoffatom mit besonders elektronegativen und kleinen Atomen verbunden ist, bilden besonders häufig Wasserstoffbrücken aus (HABENICHT, 1997). Hierbei kann eine Wechselwirkungsenergie von bis zu $50 \mathrm{~kJ} \mathrm{~mol}^{-1}$ entstehen. Bedingt durch den stark polaren Charakter der A-H-Gruppe, wobei sich das positive Ende am Wasserstoffatom befindet, werden elektronegative Atome (B) wie z.B. Sauerstoff und Stickstoff angezogen. Da das H-Atom kleiner ist, können sich die Dipole sehr gut annähern und es entsteht eine starke Wechselwirkung. Indem das H-Atom eine Mittelstellung zwischen seinem ursprünglichen Bindungspartner und dem neuen Partner einnimmt, wird eine Art „Brücke" ausgebildet.

\subsubsection{Adhäsion}

Während man früher von einem rein mechanischen Vorgang bei der Adhäsion ausging, d. h. durch eine Verankerung bzw. Verklammerung des in Poren oder Kapillaren der Oberflächenstruktur ausgehärteten flüssigen Klebstoffs, ist heute bekannt, dass die Adhäsion ein komplexes Zusammenspiel von vielen Faktoren ist. Daher unterscheidet man mehrere Adhäsionsarten.

Bei der mechanischen Adhäsion kommt es zu dem bereits beschriebenen Vorgang der Verankerung in Poren und Hinterschneidungen der Fügeteiloberfläche. Die Autohäsion ist bei der Vereinigung kautschukelastischer Polymerschichten des gleichen Materials unter hohem Druck wirksam. Unter der spezifischen Adhäsion versteht man alle Adhäsionserscheinungen, die auf chemischen, physikalischen und 
thermodynamischen Gesetzmäßigkeiten beruhen. Diese Form der Adhäsion macht den Hauptanteil der Adhäsionskräfte in Klebungen aus.

Eine tatsächliche Messung der Adhäsion ist momentan technisch nicht möglich, so dass bei der Erklärung der Bindungsmechanismen viele verschiedene Theorien und Aussagen über die wirksam werdenden Faktoren bei Klebungen zum Tragen kommen. Man kann davon ausgehen, dass bei der Adhäsion eine Kombination von chemischen, physikalischen und mechanischen Vorgängen ihre Wirkung ausübt.

\subsubsection{Kohäsion}

Die Kohäsion bezeichnet die „innere Festigkeit" eines Stoffes, d. h. es werden dieselben Kräfte wie bei der Adhäsion wirksam, allerdings nur innerhalb der Atome bzw. Moleküle eines Stoffes. Je nach chemischer Struktur des Klebstoffes stellt die Kohäsion von Klebschichten ein Zusammenwirken von kovalenten und zwischenmolekularen Bindungskräften (Nebenvalenzkräften) dar (DuNKY, 2002).

Über die Zugfestigkeit und das Dehnungsvermögen eines Werkstoffes erhält man quantitative Angaben über die Kohäsionsfestigkeit. Sie ist eine werkstoff- und temperaturabhängige Größe. Bei Klebschichten (Klebfugen) ist sie insbesondere für das Kriechen bzw. Fließen unter mechanischer Belastung eine charakteristische Eigenschaft in Abhängigkeit von der chemischen Art und Zusammensetzung des Bindemittels. Bei zunehmender Temperatur sinkt die Kohäsionsfestigkeit ab, da die Moleküle beweglicher werden und der Molekülzusammenhalt schwächer wird.

Durch Fehlstellen in der Klebfuge, die Eigenspannungen ausbilden, bilden sich Ausgangspunkte für Kohäsionsbrüche bei Belastung. Solche Fehlstellen können durch mangelhafte Vernetzung, bedingt durch zu geringe oder zu hohe Härtungstemperaturen entstehen. Weitere Ursachen sind eingeschlossene Restlösungsmittel, unterschiedliche Feuchtigkeitsverhältnisse oder nicht an der Reaktion beteiligte Monomeranteile. Wichtige Faktoren, die direkten Einfluss auf die Kohäsionsfestigkeit haben sind:

- Molmasse und durchschnittlicher Kondensationsgrad des Bindemittels

- Chemische Struktur der Bindemittelmoleküle

- Orientierung der Moleküle (Kristallinitätsgrad)

- Zusammensetzung und Menge anderer anwesender Stoffe (Füllstoffe, Streckmittel, Lösungsmittel u. a.) (DuNKY, 2002). 
Für die Ausbildung einer optimalen Bindefestigkeit müssen sowohl die Adhäsionskräfte als auch die Kohäsionskräfte aufeinander abgestimmt sein. Wenn sich keine Adhäsionskräfte an der Fügeteiloberfläche ausbilden, kann sich auch bei hoher Kohäsionskraft keine Festigkeit in der Klebung ausbilden. Umgekehrt gilt der gleiche Fall.

\subsection{Konservierung}

Konservieren heißt, ein gegebenes Produkt über einen genügend langen Zeitraum unter den vorhandenen Bedingungen in einem unveränderten Zustand zu erhalten. Zu diesem Zweck müssen alle verderbenden Einflüsse ausgeschaltet werden (WALLHÄUSSER, 1990). Unabhängig von rein chemischen und physikalischen Vorgängen (z. B. Oxidations- und Hydrolyseprozessen) ist der Abbau durch Mikroorganismen die Hauptursache für den Verderb von biologischen Produkten. Diesem Abbau kann entgegengewirkt werden, indem die entsprechenden Mikroorganismen zerstört (Sterilisation) oder in ihrem Wachstum gehemmt werden (kühlen, trocknen bzw. Zusatz keimhemmender Stoffe). Man unterscheidet die hierfür notwendigen Verfahren in Herstellung von Sterilprodukten und Herstellung von keimarmen Produkten mit begrenzter Lagerfähigkeit (WALLHÄUSSER, 1990).

Zwei Verfahren zur Herstellung von keimarmen Produkten sind bei der Verwendung von Kartoffelpülpe als Bindemittel von besonderem Interesse:

- der Wasserentzug des Gutes durch Trocknung, bzw. Trockenlagerung und

- die partielle Keimtötung bzw. Hemmung durch Konservierungsstoffe

\subsubsection{Trocknungsverfahren}

Im Allgemeinen versteht man unter Trocknen das Entfernen von Flüssigkeiten durch Verdunsten oder Verdampfen aus einem bestimmten Gut. Dabei unterscheidet man die mechanische Trocknung wie Abpressen, Filtrieren und Zentrifugieren von der thermischen Trocknung, wobei mit Hilfe von Wärme die Flüssigkeit verdunstet oder verdampft. 


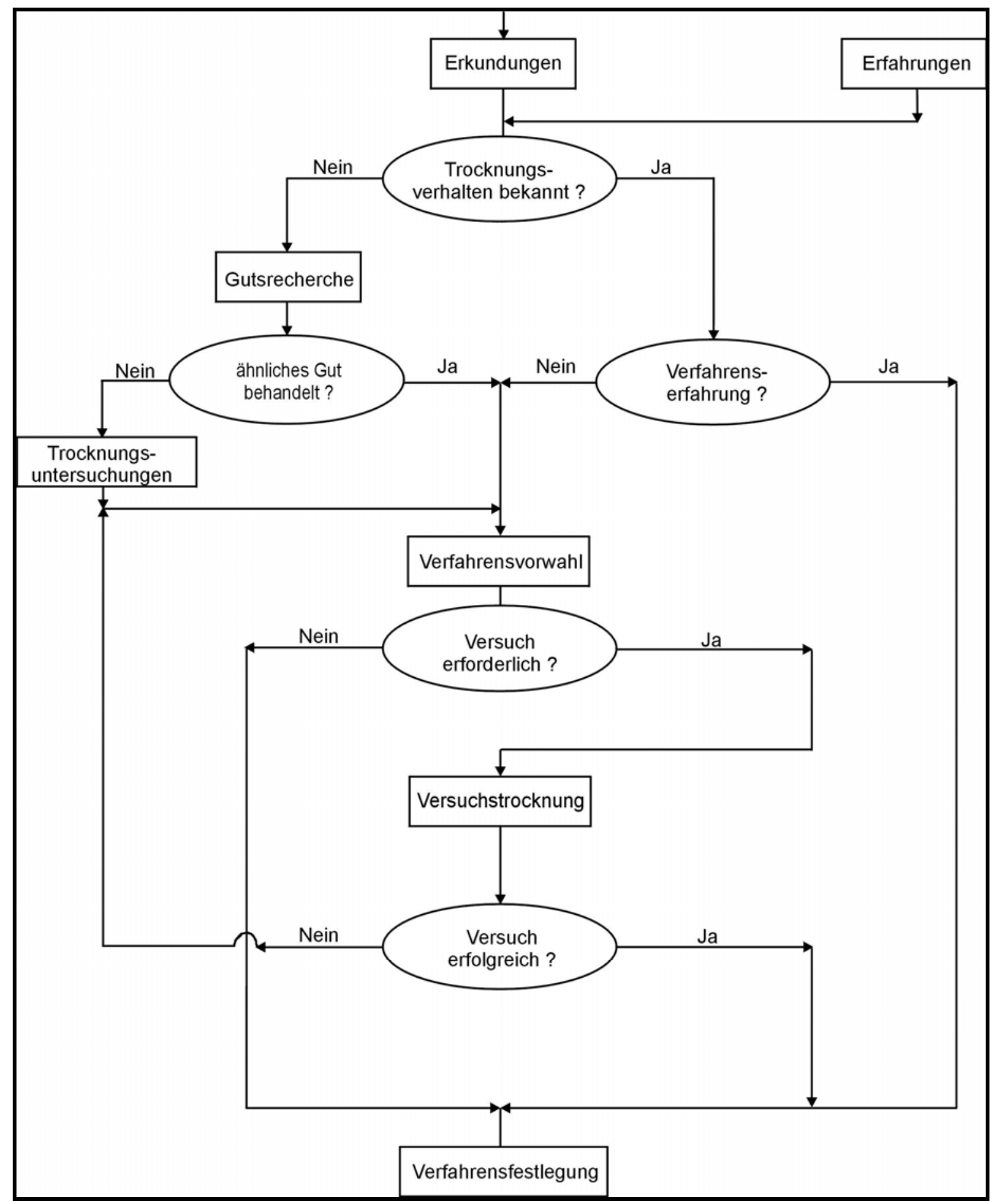

Abb. 2-11: Schema zur Auswahl eines geeigneten Trocknungsverfahren; modifiziert nach KNEULE, 1975

Die Probleme der mechanischen Trocknung bestehen darin, dass immer eine gewisse Restfeuchte in dem Gut verbleibt und eventuell wichtige Bestandteile, gelöst im Wasser, durch Auspressen o. ä. verloren gehen. Allerdings ist eine Kombination aus der mechanischen und der thermischen Trocknung möglich, um den Vorgang der thermischen Trocknung durch vorherigen Wasserentzug aus dem Gut zu verkürzen. 
Die Wahl eines geeigneten Trocknungsverfahrens richtet sich nach der Beschaffenheit des Gutes und dem weiteren Verwendungszweck (KNEULE, 1975).

Es gibt verschiedene Trocknungsverfahren bei der thermischen Trocknung. Die Konvektionstrocknung arbeitet, indem die Wärme durch ein gas- oder dampfförmiges Trocknungsmittel übertragen wird, welches über oder durch das Gut geführt wird. Bei der Kontakttrocknung wird die benötigte Wärme durch Wärmeleiter auf das Gut übertragen (z. B. beheizbare Flächen). Die Trocknung durch Strahlung arbeitet ohne materiellen Träger, die Wärme wird durch in der Umgebung befindliche strahlende Flächen übertragen. Bei der dielektrischen Trocknung (z. B. durch Mikrowellen) wird die Wärme genutzt, die durch die im hochfrequenten Wechselfeld im Gutsinnern auftretenden Verschiebungsströme erzeugt wird (KNEULE, 1975). Für diese verschiedenen Verfahren gibt es eine Vielzahl an einsetzbaren Trocknern, die mit Hilfe des Schemas in Abb. 2-11 ausgewählt werden können.

Bei der Kartoffelpülpe handelt es sich um einen Stoff von pastöser Beschaffenheit, der möglichst schonend getrocknet werden muss, um eine Karamellisierung der Oberfläche zu verhindern, da ansonsten die bindenden Eigenschaften der Pülpe verloren gehen. Anhand dieser Kriterien müssen geeignete Verfahren zur Trocknung der Pülpe ausgewählt werden, wobei die ökonomischen Gesichtspunkte ein Hauptkriterium sind. 


\section{Material und Methoden}

\subsection{Material}

\subsubsection{Pülpe}

\subsubsection{Emsland-Pülpe}

Die Firma Emsland-Pülpe, mit Stammsitz in Emlichheim, ist Deutschlands größter Kartoffelstärkeproduzent und weltweit führend in der Herstellung von Stärkeveredelungsprodukten, Kartoffeleiweiß, Flocken und Granulat. Im Stammwerk Emlichheim sowie in den weiteren Produktionsstandorten Wietzendorf, Golßen und Kyritz werden derzeit 1,6 Mio. $\mathrm{t}$ Kartoffeln zu Kartoffelstärke verarbeitet (http://www.emsland-staerke.de, Download vom 04.11.2004).

Die Kartoffelpülpe, die bei der Herstellung der Stärke als Nebenprodukt anfällt, wurde kostenlos von der Firma Emsland-Pülpe für die Untersuchungen abgegeben. Die Abholung der Pülpe erfolgte in luftdicht verschließbaren Behältern. Nach dem Transport konnte die Pülpe in $1,5 \mathrm{~kg}$ Portionen eingefroren werden.

\subsubsection{AVEBE-Pülpe}

Die AVEBE-Gruppe ist ein weltweit agierendes Stärkeunternehmen, das Stärkeprodukte für die Nahrungs-, Tierfutter-, Papier-, Klebstoff- und Textilindustrie herstellt. Mittlerweile besitzt das Unternehmen neben Anlagen in den Niederlanden auch Betriebe in Deutschland, Frankreich, Schweden und China. Die Pülpe, die bei der Herstellung von Kartoffelstärke anfällt, wird zum großen Teil als Nassfutter in der Viehwirtschaft eingesetzt. Es gibt aber auch modifiziertes, proteinhaltiges Trockenfutter auf der Basis von Kartoffelpülpe (http://www.avebe.com, Download vom 04.11.2004).

Der Herstellungsprozess der Kartoffelstärke entspricht weitestgehend dem der Emslandstärke. Die anfallende Pülpe kann aufgrund der eingesetzten Stärkekartoffeln etwas in der quantitativen Zusammensetzung variieren. AVEBE züchtet auch in eigenen Anbauten Kartoffeln mit höherem Stärke- und Proteingehalt. 
Die von AvEBE kostenlos zur Verfügung gestellte Pülpe wurde ebenfalls luftdicht transportiert und anschließend bei $-18{ }^{\circ} \mathrm{C}$ tiefgefroren, um einen Abbau der Inhaltstoffe zu verhindern.

\subsubsection{Einsatz von Enzymkomplexen der Firma Novozymes}

Die Firma Novozymes ist weltweit eine der größten Hersteller für industriell einsetzbare Enzyme. Ein Schwerpunkt bei der Enzymproduktion ist der Einsatz von Enzymen in der Fruchtsaftindustrie. Daher liegt die ursprüngliche Verwendung dieser Enzymkomplexe in der Herstellung von Fruchtsäften, wenn eine rasche und vollständige Depektinisierung erwünscht wird. Die folgenden Enzymkomplexe wurden in Absprache mit der Firma Novozymes ausgewählt und unentgeltlich zur Verfügung gestellt.

Pectinex 3XL wird durch einen selektionierten Stamm von Aspergillus niger produziert. Die Hauptbestandteile dieses Enzympräparates sind Polygalakturonasen, denen zusätzlich Pektinesterasen, Pektintranseliminasen und Arabinasen zugesetzt wurden. Die Enzymaktivität liegt bei 3000 FDU/ml.

Pectinex 100 L ist eine Kombination aus Polygalakturonasen und Pektinesterase mit einer zusätzlichen Pektintranseliminase und Arabinase. Diese Enzymlösung ist identisch mit Pectinex $3 \mathrm{XL}$, allerdings 1,7-fach stärker und die Aktivität wird mit 5000 UPTE/ml angegeben.

Eine weitere Enzymlösung ist Ultrazym AFP-L, ein Pektinasenpräparat mit einer Polygalakturonase und einer Cellulase. Die Produktionsorganismen setzen sich aus Aspergillus aculeatus, Aspergillus niger und Trichoderma reesei zusammen. Diese Enzymkombination wird in der Fruchtsaftindustrie für die Tresterbehandlung eingesetzt. Die Aktivität, gemessen bei Standardbedingungen, liegt bei 3000 UPTE/ml.

Die vierte Enzymlösung Pectinex AFP L-2 beinhaltet die gleichen Enzyme wie Pectinex $100 \mathrm{~L}$, stammt aber aus einer anderen Fermentation und wird in die Enzymklasse der Polygalakturonasen eingeordnet. Dieses Präparat wird durch Organismen wie Aspergillus aculeatus und Aspergillus niger produziert. 


\subsubsection{Einsatz von Enzymkomplexen der Firma AB Enzymes}

$A B$ Enzymes ist weltweit einer der ältesten und traditionsreichsten Enzymanbieter. Firmengründer war Dr. Otto Röhm, der Anfang des 20. Jahrhunderts die Firma Röhm und Haas gründete. 1999 wurde die Röhm Enzyme $\mathrm{GmbH}$ in die britische Konzerngruppe ABITEC integriert und änderte 2001 ihren Namen in AB Enzymes $\mathrm{GmbH}$. Die Produktpalette umfasst Lebensmittelenzyme, Enzyme für Futtermittel und für den Einsatz in der Textil-, Zellstoff- und Papierwarenindustrie. Im Rahmen der vorliegenden Arbeit wurden gratis Enzyme aus der Frucht- und Gemüseverarbeitung bereitgestellt.

Rohapect $10 \mathbf{~}$ ist ein hochkonzentriertes, pektolytisches und arabinasehaltiges Enzympräparat zur Fruchtverarbeitung und eignet sich sowohl zur Maischebehandlung als auch zur Saftdepektinisierung und ermöglicht einen vollständigen Pektinabbau. Die Vorteile dieses Präparates sind zum einen die gute Säurestabilität und zum anderen die Fähigkeit zur Spaltung von löslichem und unlöslichem Pektin. Gewonnen wird das Produkt aus Aspergillus niger. Die Mindestaktivität liegt bei 260 PA.

Rohament PL ist ein spezielles pektolytisches Präparat zur Mazeration von Früchten und Gemüse. Es enthält überwiegend Polygalacturonase-Aktivität. Beim Aufschluss der Zellwände entsteht lösliches, hochmolekulares Pektin. Das Produkt stammt aus Kulturen von Aspergillus niger und besitzt nach der Fermentation eine Mindestaktivität von $28.000 \mathrm{PGU} / \mathrm{ml}$.

Rohapect PTE wird hauptsächlich in der Frucht- und Gemüseverarbeitung eingesetzt. Die Hauptbestandteile sind Pektintranseliminasen und Endopektinlyasen. Diese sollen eine schnelle Viskositätsabsenkung bei den zu behandelnden Produkten herbeiführen. Die gemessene Mindestaktivität liegt bei $75 \mathrm{PTF} / \mathrm{mg}$. Für die Produktion dieser Enzyme werden Aspergillus niger- Kulturen verwendet.

\subsubsection{Konservierungsmittel}

\subsubsection{Mergal $^{\circledR} \mathrm{S} 88$}

Mergal ${ }^{\circledR}$ S88 (Firma Troy Chemie, Seelze) ist ein technisches Konservierungsmittel zur bakteriziden und fungiziden Ausrüstung von Farben und Putz für Innenanwendungen, findet aber auch in anderen Bereichen Anwendung. Es hat ein breites, ausgeglichenes Wirkungsspektrum gegen Bakterien, Hefen und Pilze sowie 
Algen. Typische Einsatzgebiete für Mergal $^{\circledR}$ sind Dispersionsfarben und Kunstharzputze. Mergal ${ }^{\circledR}$ S88 wurde speziell für Systeme entwickelt, die z. B. in Lebensmittel verarbeitenden Betrieben wie Bäckereien, Brauereien etc. Anwendung finden. Die beiden Hauptkomponenten von Mergal ${ }^{\circledR}$ sind Methyl-benzimidazol-2ylcarbamat und Zink-bis-dimethyldithiocarbamat (TECHNISCHES DATENBLATT, 2003)

\subsubsection{Sorbinsäure (Firma Merck, Darmstadt)}

Sorbinsäure (E 200) und ihre Salze (E 201, E 202 und E 203) sind häufig verwendete Konservierungsmittel. Die antimikrobielle Wirkung der Sorbinsäure hängt hauptsächlich von ihrem undissoziierten Anteil und dieser wiederum vom pH-Wert ab. Daher ist die Sorbinsäure auch im schwach sauren Bereich noch wirksam. Sie wird als fungistatischer Wirkstoff eingestuft, unterliegt in der bakteriellen Wirkung jedoch starken Schwankungen. So werden katalasepositive Bakterien eher gehemmt und Aerobier reagieren empfindlicher als Anaerobier. Das pH-Optimum geht bis 6,0, die mikrobizide Wirkung bis etwa pH 4,5 (WALLHÄUSSER, 1990). Da Kartoffelpülpe im nativen Zustand einen pH-Wert bis 6 aufweisen kann, eignet sich die Sorbinsäure als Konservierungsmittel.

\subsubsection{Faserstoff}

Für die Herstellung der MDF-Platten wurden Fasern der Firma STEICO (Polen) verwendet. Die Fasern wurden nach dem ASPLUND-Verfahren (Defibratorverfahren) hergestellt. Den größten Anteil bei den verwendeten Holzarten macht mit ca. $80 \%$ die Kiefer aus und ca. $20 \%$ werden durch Buchenholz abgedeckt. Die Lagerung der Fasern erfolgte in Paketen à $15 \mathrm{~kg}$ (lutro).

\subsubsection{Hydrophobierungsmittel}

Das verwendete Hydrophobierungsmittel "Hydrowax 730" von SASOL, Hamburg, hat eine Paraffinbasis und einen Feststoffgehalt von $60 \%$. Es wird als konventionelles Wachs bei der Herstellung von Holzwerkstoffen eingesetzt. 
Bei den Paraffinen handelt es sich um gesättigte aliphatische Kohlenwasserstoffe, die durch das Fehlen von Mehrfachbindungen und reaktiven funktionellen Gruppen sehr reaktionsträge sind (ROFFAEL et al. 1982).

\subsubsection{Haftvermittler}

Neben dem Hydrophobierungsmittel wurden Haftvermittler auf der Basis siliziumorganischer Verbindungen eingesetzt. Diese dienten zur Ausbildung bzw. Verstärkung von zwischenmolekularen Kräften. Verwendet wurden zwei unterschiedliche Silane.

\subsubsection{Harnstoff-Formaldehydharz}

Für die Mischung der mechanisch-enzymatisch aufgeschlossenen Kartoffelpülpe mit Harnstoff-Formaldehydharz wurde Kauritec ${ }^{\circledR} 407$ (flüssig) von BASF (Ludwigshafen) verwendet. Dabei handelt es sich um eine wässrige Lösung eines stark verstärkten Harnstoff-Formaldehyd-Kondensationsproduktes.

Dieses UF-Harz besitzt einen Feststoffgehalt von $67 \pm 1 \%$. Die Viskosität betrug bei Abfüllung im Werk $150-300 \mathrm{mPa} \cdot \mathrm{s}$ (bei $20^{\circ} \mathrm{C}$ ).

\subsubsection{Mikroorganismen für den Abbau von Holzwerkstoffen}

Für die Überprüfung der Abbaufähigkeit der hergestellten Holzwerkstoffe wurden drei verschiedene holzabbauende Pilze verwendet, die nach der EN 113 (European Standard, 1996) einsetzbar sind. In der Tab. 3-1 sind die einzelnen Pilze aufgelistet, eingeteilt nach Klasse und Fäuleform. Die verwendeten Pilzstämme kommen von DSMZ - Deutsche Sammlung von Mikroorganismen und Zellkulturen GmbH mit Sitz in Braunschweig.

Weißfäulepilze sind in der Lage, Cellulose, Hemicellulose und Lignin abzubauen. Hierbei unterscheidet man zwischen einem selektiven und einem simultanen Abbau. Beim selektiven Abbau erfolgt zuerst der Abbau des Lignins und der Hemicellulose und im Anschluss erst der Celluloseabbau. Werden alle drei Zellwandbestandteile gleichzeitig zersetzt, spricht man von einem simultanen Abbau. Die Kolonisierung der Pilze erfolgt über das Strahlenparenchym, während sich die Pilzhyphen über Tüpfel 
oder direkt durch die Zellwand ausbreiten. Da die Pilze auch das Lignin abbauen, bekommt das befallene Holz häufig eine weißliche Färbung, daher auch der Name.

Tab. 3-1: Verwendete Fäuleerreger für den Abbau von Holzwerkstoffen

\begin{tabular}{llll}
\hline & Weißfäulepilz & Braunfäulepilz & Moderfäulepilz \\
\hline Klasse: & & \\
Basidiomycota & Trametes versicolor & Coniophora puteana & \\
& & & Chaetomium \\
Ascomycota & & & globosum \\
\hline
\end{tabular}

Bei den Braunfäulepilzen verhält es sich eher umgekehrt. Hier werden zuerst die Cellulose und Hemicellulose vom Pilz abgebaut und zurück bleibt das schwer abbaubare Lignin. Die Braunfäule wird auch Destruktionsfäule genannt und gehört zu den wichtigsten Fäuletypen im Außen- und Innenbereich und befällt vornehmlich Nadelhölzer. Durch das zurückbleibende Lignin kommt es zu einer rötlich bis braunen Färbung des Holzes.

Die Moderfäulepilze gehören zu den Ascomyceten und bauen hauptsächlich Cellulose $a b$, wodurch sie ein ähnliches Erscheinungsbild wie bei der Braunfäule verursachen. Allerdings benötigen die Moderfäulepilze ein deutlich höheres Feuchteniveau. Das Hyphenwachstum erfolgt bevorzugt innerhalb der Sekundärwand, die auch vollständig abgebaut wird, während die Tertiär- und Primärwand erhalten bleiben (LIESE, 1981).

\subsection{Technische Geräte}

\subsubsection{Cutter}

Für den mechanischen Aufschluss der Kartoffelpülpe wurde im Labormaßstab ein Tischcutter (s. Abb. 3-1) der Firma Mado (Maschinenfabrik Dornhan), Typ „MTK 560", verwendet. Die rotierenden Messer des Cutters können sowohl mit 1400 rpm (Stufe 1) als auch mit 2800 rpm (Stufe 2) das Gut zerschlagen, während sich die Schüssel mit 12 bzw. 24 rpm dreht. 


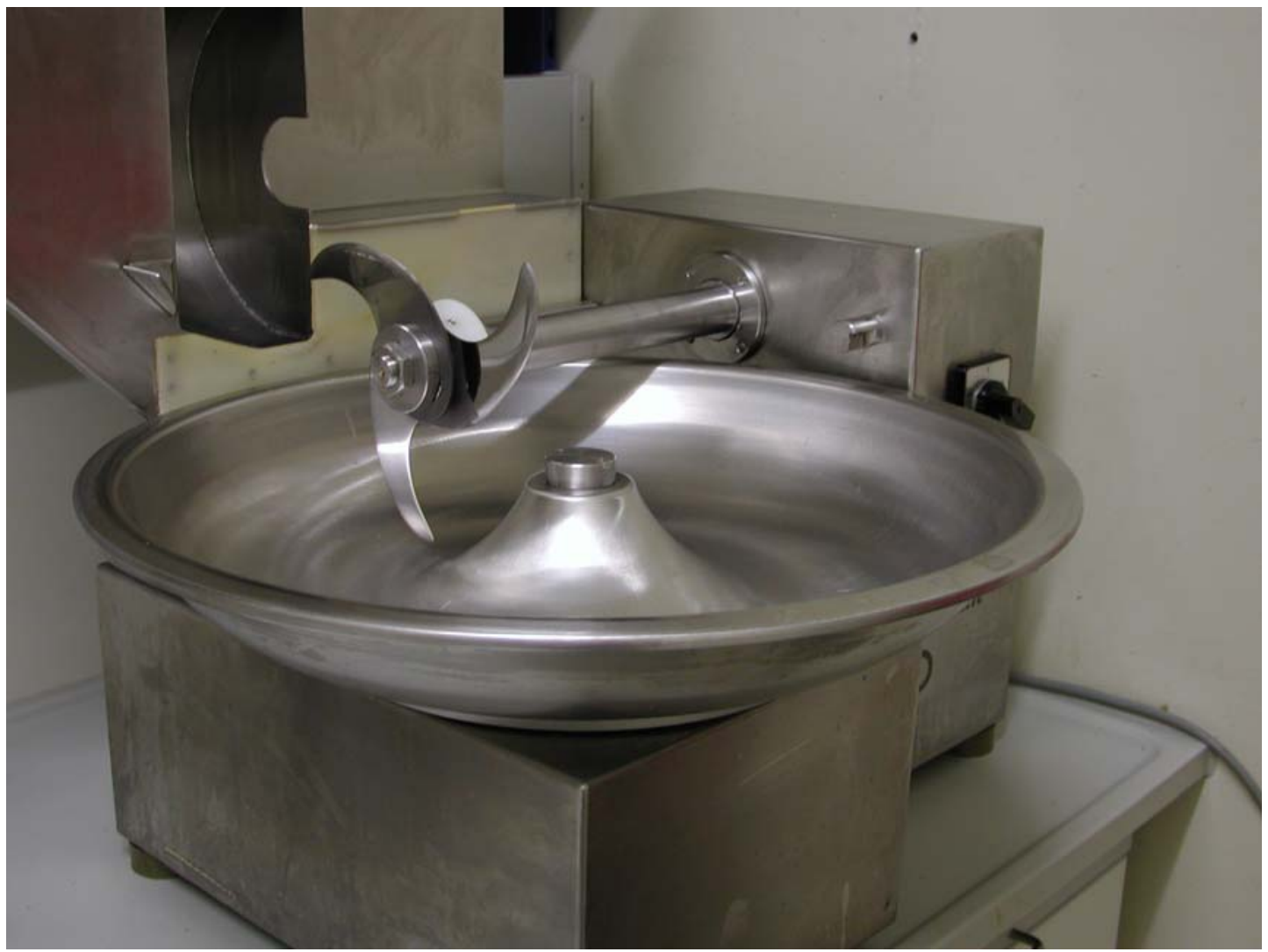

Abb. 3-1: Tischcutter für den mechanischen Aufschluss der Kartoffelpülpe

\subsubsection{Hochdruckhomogenisator}

Hochdruck-Homogenisieren bedeutet die Zerkleinerung und gleichmäßige Verteilung der in einer Flüssigkeit befindlichen Partikel und Tröpfchen, wodurch eine stabile Dispersion geschaffen wird (NIRO SOAVI, 2002). Die Funktionsweise des Hochdruckhomogenisators beruht darauf, dass die Suspension mit hohem Druck auf den Ventilkörper umgelenkt und durch den Homogenisierspalt auf den Prallring geführt wird (s. Abb. 3-2). In dem Homogenisierspalt wirken große Scher- und Dehnungskräfte sowie Turbulenzen auf die Partikel, die dadurch zerkleinert werden. Durch Verschieben des Ventilkörpers können die Spaltweite und somit auch der Druckverlust bzw. die Geschwindigkeit verändert werden. In Abhängigkeit von der Viskosität der aufzuschließenden Suspension und der darin enthaltenen Zellverbände kann das entsprechende Homogenisierventil ausgesucht werden.

Der Hochdruckhomogenisator "NS 1001L Panda 2K" der Firma Niro Soavi in Lübeck wurde eingesetzt, um die mechanisch-enzymatisch aufgeschlossene Kartoffelpülpe noch weiter zu zerkleinern. Die Funktionsweise beruht auf der Kombination einer produktschonenden Hochdruckpumpe mit einem Homogenisierventil für die 
Feindispergierung, Mikrofibrillierung und dem Hochdruckaufschluss. Die Leistung der Pumpe beträgt $10 \mathrm{l} / \mathrm{h}$ bei einem Druck von max. 1500 bar (NIRO SOAVI, 2002).

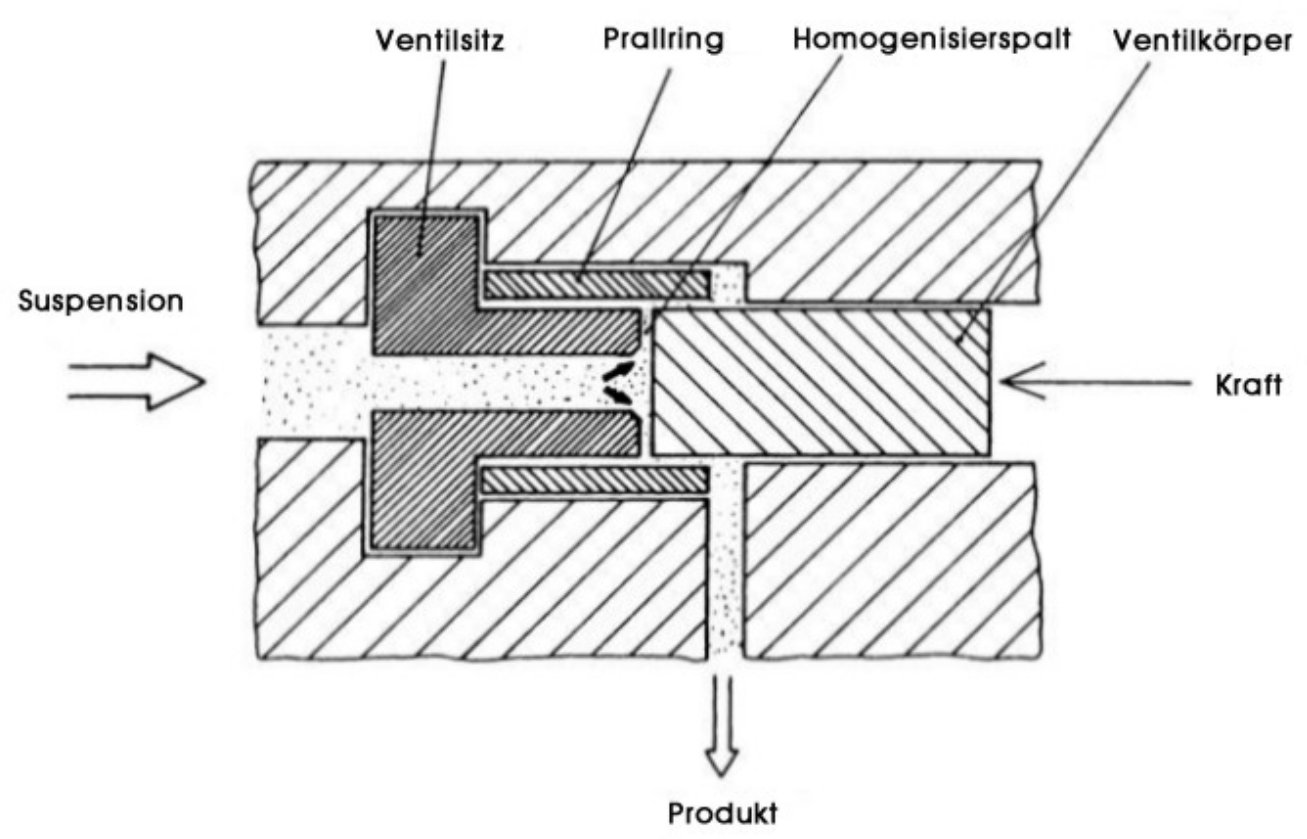

Abb. 3-2: Aufbau eines Homogenisierventils (http://www.imvt.tu-bs.de; Download vom 26.11.2003).

\subsubsection{Wirbelschicht-Sprühgranulation}

Die Wirbelschicht-Sprühgranulation erfolgte bei der Firma Glatt GmbH Process Technology in Binzen. Verwendet wurde das Laborgerät GPCG 1.1 mit einem Füllvolumen von 4,7 $\mathrm{dm}^{3}$. Dieses Gerät eignet sich, um kleinere Probenmengen zu trocknen und zu granulieren. Die Temperatur ist bis $80{ }^{\circ} \mathrm{C}$ einstellbar und wird elektrisch erzeugt. Die Druckluft, die den Fließdruck erzeugt, hat eine maximale Stärke von 6 bar (GLATT, 2003).

\subsubsection{Viskosimeter}

Das Viskosimeter der Firma PHYSICA, Ostfildern, ist ein Rotations-, Schubspannungsund Kriechrheometer (Typ Rheolab MC 1). Ausgestattet ist es mit zwei unterschiedlichen Messsystemen und der Software US 200. Das Rheolab MC 1 misst 
die Viskosität nach dem Searle-Prinzip, d. h. die zu messende Substanz befindet sich im Messspalt zwischen dem feststehenden Messbecher und dem rotierenden Messkörper. Das Viskosimeter ermittelt die Viskosität aus dem Fließwiderstand der Messsubstanz, der sich auf das Drehmoment des Messkörpers auswirkt.

\subsubsection{Pilotanlage zur MDF-Herstellung}

\subsubsection{BINOS- Anlage}

Die Herstellung der MDF-Platten erfolgte mit der Pilot-Anlage der Firma BiNos, Springe. In der Anlage werden die Fasern aufgelockert, beleimt, getrocknet, vorverdichtet und anschließend in der Heißpresse verpresst.

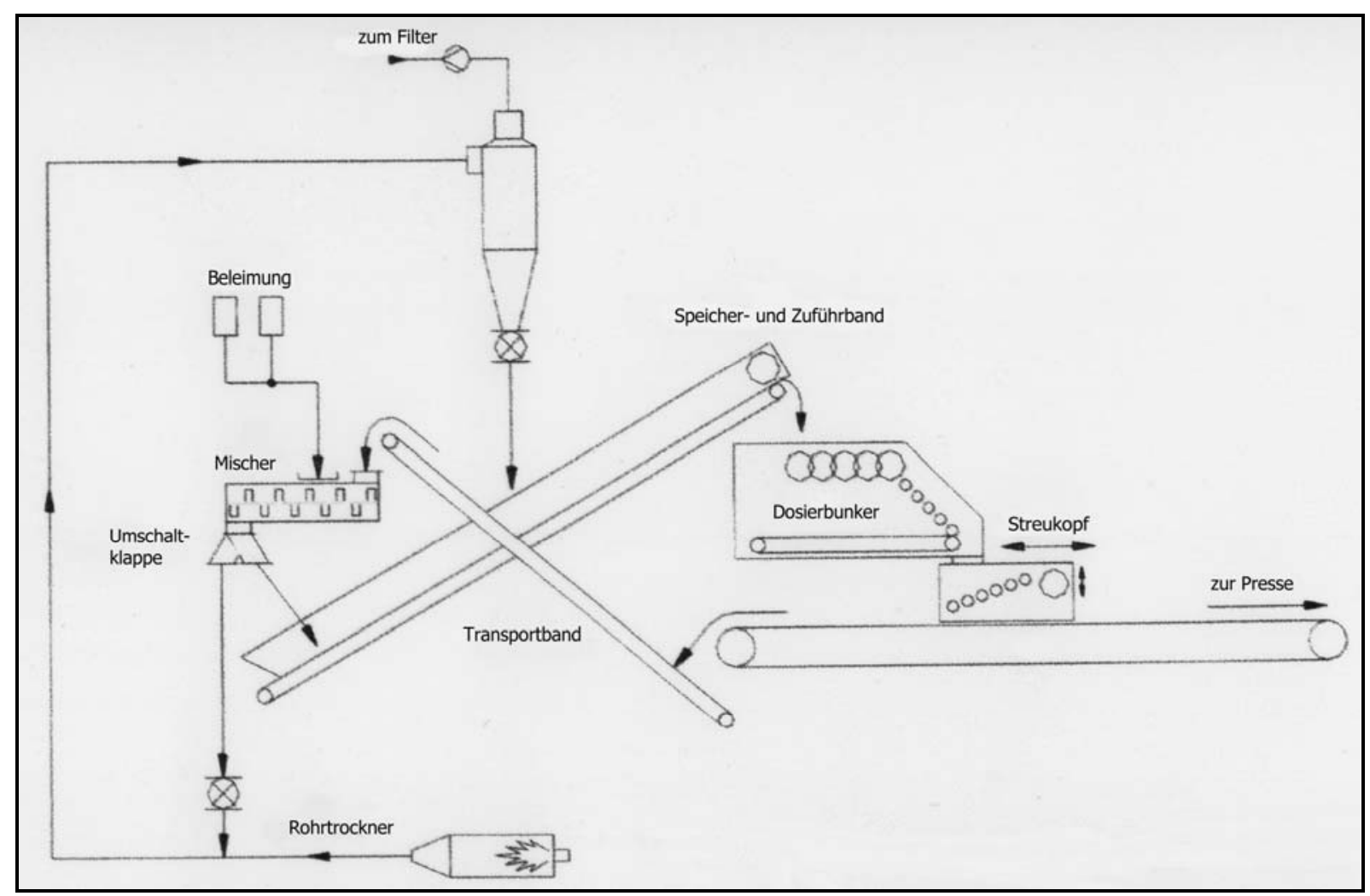

Abb. 3-3: Technische Zeichnung der Binos-Pilotanlage

Die aufgelockerten Fasern werden über den Muldengurtförderer zum Mischer transportiert. Im Mischer, in diesem Fall ein Ringmischer (s. Abb. 2-8) mit einer innen liegenden Stachelwalze, erfolgt die Beleimung mit dem Bindemittel. Während 
die Fasern durch den Mischer befördert werden, können diese über die Beleimungsdüse mit Bindemittel benetzt werden.

Die beleimten Fasern gelangen über eine Ausfallschleuse in die Rohrtrocknerleitung, die in einem Hochleistungszyklon endet. Von hier aus fallen die getrockneten Fasern auf das Zuführband, das an dem Dosierbunker endet (s. Abb. 3-3). Erst wenn alle Fasern im Bunker sind, wird mit der Vliesstreuung begonnen. Die Fasern werden über einen Faserstreukopf, bestehend aus sechs Stachelwalzen und einem Rückstreifrechen, auf dem Formband verteilt. Mit Hilfe des Rückstreifrechens bekommt das Vlies eine gleich bleibende Höhe.

Damit MDF-Platten in der Heißpresse hergestellt werden können, muss das Vlies erst in der Kaltpresse vorverdichtet werden. Das so vorverdichtete Vlies wird in Abschnitte mit einer Länge von je $400 \mathrm{~mm}$ geschnitten und anschließend zwischen zwei Pressblechen in der Heißpresse verpresst.

\subsubsection{Presse}

Die Heißpresse der Firma Simpelkamp, Krefeld, ist eine hydraulische Ein-Etagen Unterkolbenpresse mit einem Pressplattenformat von $600 \times 800 \mathrm{~mm}$ und einem Ölpumpen- und Steueraggregat. Die Heizplatten im Ober- und Untertisch sind elektrisch bis auf maximal $250{ }^{\circ} \mathrm{C}$ beheizbar und mit Wasser rückkühlbar. Der Kolben leistet einen hydraulischen Arbeitsdruck von ca. 283 bar bei einer Gesamtpresskraft von 200 kN. Der spezifische Druck auf der gesamten Pressfläche beträgt 417 N/cm³ (SCHÖPPER, 2002).

\subsubsection{Material-Prüfmaschine}

Die Prüfmaschine (Type T1-FR010TH.A50 der Firma ZwICK ROELL, Ulm) ist eine TischPrüfmaschine mit einer maximalen Prüfkraft von $10 \mathrm{kN}$. Man kann mit der Prüfmaschine Zug-, Druck- und Biegeversuche nach DIN bzw. EN durchführen. Die Grundeinheit der Prüfmaschine besteht aus dem Lastrahmen und der elektronischen Mess-, Steuer- und Regeleinheit. Am unteren Rahmen befinden sich eine feste untere und eine fahrbare mittlere Traverse, an die das Prüfwerkzeug oder der Kraftaufnehmer befestigt werden. 


\subsection{Methoden}

\subsubsection{Auswahl und Charakterisierung der Kartoffelpülpe}

\subsubsection{Wassergehalt der Kartoffelpülpe}

Die Bestimmung des Wassergehaltes erfolgte mit Hilfe der Restfeuchtebestimmung. Dabei wurden zum einen Trockenpülpe und zum anderen Presspülpe untersucht. Jeweils $10 \mathrm{~g}$ des zu untersuchenden Materials wurden bei $75{ }^{\circ} \mathrm{C}$ im Vakuumtrockenschrank bis zur Gewichtskonstanz getrocknet. Von jeder Probe wurden zehn Wiederholungen vorbereitet.

Die Restfeuchte berechnet sich nach folgender Formel:

$$
a=\frac{\left(a_{0}-a_{1}\right)}{a_{0}} * 100
$$

$\mathrm{a}=$ Restfeuchte in $[\%]$

$\mathrm{a}_{0}=$ Einwaage in $[\mathrm{g}]$ vor der Trocknung

$\mathrm{a}_{1}=$ Einwaage in $[\mathrm{g}]$ nach der Trocknung

\subsubsection{Bestimmung des pH-Wertes}

Die Bestimmung des pH-Wertes erfolgte nach DIN 53124 (DiN-TASCHENBUCH 123, 1996). Untersucht wurde der pH-Wert nativer Kartoffelpülpe, die im Kühlraum lagerte. Zu diesem Zweck wurden je $5 \mathrm{~g}$ der feuchten Pülpe entnommen und der Feststoffanteil mit einem Feuchtemessgerät (Fa. Sartorius, Göttingen) bestimmt. Die Bestimmung des pH-Wertes erfolgte im Heißextraktionsverfahren, d. h. von der Probe wurden $0,5 \mathrm{~g}$ Feststoff in $100 \mathrm{ml}$ und $100{ }^{\circ} \mathrm{C}$ heißes bidest. Wasser gegeben. Anschließend musste dieses Gemisch für eine Stunde unter Rückfluss sieden. Für die Messung wurde die auf Raumtemperatur abgekühlte Suspension filtriert. Das Filtrat konnte für die Bestimmung des pH-Wertes (Microprozessor pH-Meter, Typ pH 535 MultiCal; Wissenschaftlich-Technische Werkstätten $\mathrm{GmbH}$, Weilheim) eingesetzt werden. 


\subsubsection{Stärkebestimmung}

Die Bestimmung des Stärkegehaltes erfolgte mit Hilfe einer in der Lebensmittelanalytik verwendeten Methodensammlung zur Bestimmung nativer Stärke in Lebensmitteln und anderen Probenmaterialien. Verwendet wurde ein Chemikalien-Kit der Firma Boehringer Mannheim, der aus vier Bestandteilen zusammengesetzt ist. Lösung 1 enthält Citrat-Puffer ( $\mathrm{pH} \mathrm{4,6)} \mathrm{und} \mathrm{Amyloglukosidase}$ (ca. $84 \mathrm{U}$ ), Lösung 2 enthält Triethanolamin-Puffer ( $\mathrm{pH} \mathrm{7,6),} \mathrm{NADP,} \mathrm{ATP} \mathrm{und}$ Magnesiumsulfat, die Suspension 3 besteht aus Hexokinase (ca. $200 \mathrm{U}$ ), Glucose-6phosphat-Dehydrogenase (ca. $100 \mathrm{U})$ und schließlich noch eine StärkeStandardsubstanz zur Testkontrolle. Das Prinzip des Tests beruht auf gekoppelten enzymatischen Reaktionen und dem photometrischen Nachweis von dabei gebildetem NADPH (vgl. KePPLER u. DeCKER, 1974 und BeUtLeR, 1978). Folgende Reaktionen sind daran beteiligt:

\begin{tabular}{|c|c|c|}
\hline Stärke $+(n-1) \mathrm{H}_{2} \mathrm{O}$ & $\overline{\text { AGS }}$ & n D-Glucose \\
\hline D-Glucose + ATP & $\mathrm{HK}$ & $G-6-P+A D P$ \\
\hline G-6-P + NADP ${ }^{+}$ & G-6-P-DH & Gluconat-6-phosphat $+\mathrm{NADPH}+\mathrm{H}^{+}$ \\
\hline
\end{tabular}

Die bei der hydrolytischen Spaltung von Stärke gewonnene Menge an D-Glucose ist äquivalent zur gebildeten Menge an NADPH und daher gilt NADPH als Messgröße. Die photometrische Messung erfolgt bei $340 \mathrm{~nm}$ im UV-Bereich. Die Berechnung der Stärkekonzentration ergibt sich aus folgender Formel:

$$
\mathrm{c}=\frac{\mathrm{V} * \mathrm{MG}}{\varepsilon * \mathrm{~d}^{*} \mathrm{~V} * 1000} * \Delta \mathrm{E}[\mathrm{g} / \mathrm{L}]
$$

$V=$ Testvolumen $[\mathrm{ml}]$

$\mathrm{v}=$ Probevolumen $[\mathrm{ml}]$

MG = Molekulargewicht der zu bestimmenden Substanz $[\mathrm{g} / \mathrm{mol}] ;$

(für Stärke $\left.=M_{G_{\text {Glucose }}}-M_{G_{2} \mathrm{O}}=162,1\right)$

$\mathrm{d}=$ Schichtdicke $[\mathrm{cm}]$

$\varepsilon=$ Extinktionskoeffizient von NADPH bei $340 \mathrm{~nm} \Rightarrow 6,3\left[1 * \mathrm{mmol}^{-1} * \mathrm{~cm}^{-1}\right]$ 
Da es sich bei der Kartoffelpülpe um eine Analyse von festen Proben handelte, bezog sich das Analyseergebnis auf die Einwaage:

$$
\text { Gehalt }_{\text {Stärke }}=\frac{\mathrm{C}_{\text {Stärke }}[\mathrm{g} / \mathrm{L} \text { Probelösung }]}{\text { Einwaage }_{\text {Pr obe }} \text { in } \mathrm{g} / \mathrm{L} \text { Probelösung }} * 100[\mathrm{~g} / 100 \mathrm{~g}]
$$

Nach der Trocknung der Proben bei $75^{\circ} \mathrm{C}$ bis zur Gewichtskonstanz wurden diese in einer Planetenmühle (Fa. FRITSCH, Typ Pulverisette) fein zermahlen. Anschließend nahm man $400 \mathrm{mg}$ von jeder Probe ab und es folgten insgesamt drei Alkoholextraktionen mit jeweils $10 \mathrm{ml}$ Ethanol (40 v/v). Nach jeder Extraktion wurde das Zellwandmaterial zentrifugiert (4000 rpm, HETTICH ZENTRIFUGEN, Rotanta $96 \mathrm{R}$ ) und der Überstand verworfen. Nachfolgend versetzte man das Zellwandmaterial mit $20 \mathrm{ml}$ DMSO und $5 \mathrm{ml}$ Salzsäure $(8 \mathrm{~mol} / \mathrm{l})$. Es folgten eine Inkubation für $60 \mathrm{~min}$ bei $60{ }^{\circ} \mathrm{C}$ und rasches Abkühlen der Lösung auf Raumtemperatur. Nach Zugabe von 50 $\mathrm{ml}$ bidest. Wasser und Einstellung des $\mathrm{pH}$-Wertes mit Natronlauge $(5 \mathrm{~mol} / \mathrm{l})$ auf $\mathrm{pH}$ 4,5 wurden die Probelösungen mit bidest. Wasser auf $100 \mathrm{ml}$ aufgefüllt und abschließend zur Abtrennung grober Zelltrümmer durch einen Papierfilter gegeben. Von dem Filtrat wurde direkt $0,1 \mathrm{ml}$ für die enzymatisch-photometrische Stärkebestimmung abgenommen.

Reaktionsansatz:

Probe

Reagenzienleerwert

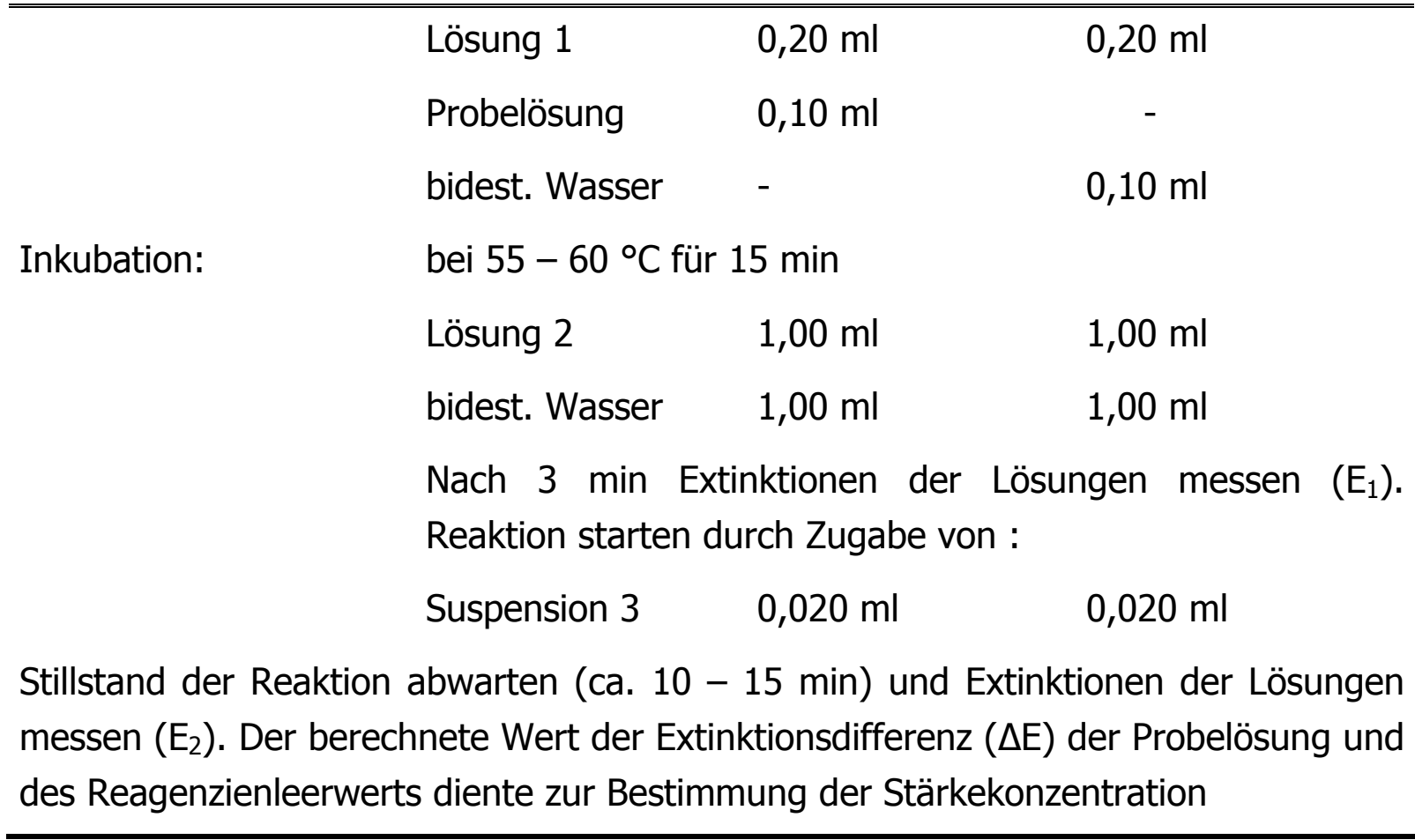




\subsubsection{Bestimmung des Galacturonangehaltes von AVEBE- und Emsland-Pülpe nach der MHDP-Methode}

Die Bestimmung des Galacturonangehaltes erfolgte nach BLUMENKRANTZ und ASBOEHANSEN (1973) mittels der m-Hydroxydiphenyl (MHDP)-Methode. Da das Galacturonan in der Pülpezellwand gebunden vorliegt, wurde es vor der Messung in eine lösliche Form gebracht.

$100 \mathrm{mg}$ der getrockneten und zermahlenen Proben wurden in $30 \mathrm{ml}$ Wasser suspendiert und anschließend durch Zugabe von $1 \mathrm{M} \mathrm{NaOH}$ bei pH 11,5 alkalisch entestert. Nach Einstellung des pH-Wertes auf 4,5 mit 2,5 M Essigsäure inkubierten die Proben mit einem pektolytischen Enzympräparat (Pectinex $3 \mathrm{XL}$ ) für $2 \mathrm{~h}$ bei $20^{\circ} \mathrm{C}$. Danach wurden je $50 \mathrm{ml}$ EDTA-Lösung den Proben zugegeben und diese für mindestens $16 \mathrm{~h}$ bei $20^{\circ} \mathrm{C}$ stehen gelassen. Für die Messung wurden die Proben auf $100 \mathrm{ml}$ aufgefüllt und filtriert. $\mathrm{Zu} \mathrm{0,2} \mathrm{ml} \mathrm{der} \mathrm{Probe} \mathrm{wurden} 1,2 \mathrm{ml}$ einer Schwefelsäure-Tetraboratlösung hinzugegeben und anschließend im $100{ }^{\circ} \mathrm{C}$ warmen Wasserbad für 5 Minuten erhitzt. Nach dem Abkühlen in Eiswasser gab man $20 \mu \mathrm{l}$ der m-Hydroxydiphenyl-Lösung hinzu, und innerhalb von 5 Minuten wurde die Absorption bei $520 \mathrm{~nm}$ im Beckmann DU Spektrophotometer gemessen. Als Blank wurde eine Probe ohne die Zugabe der Reagenz, die durch $20 \mu \mathrm{l} \mathrm{0,5 \%} \mathrm{NaOH}$ ersetzt wurde, gemessen. Da die Konzentration für die Messung zu hoch war, wurde die Lösung im Verhältnis 1:10 verdünnt. Die ermittelten Extinktionen gaben mit Hilfe einer zuvor erstellten Eichreihe die Pektinkonzentrationen der zu untersuchenden Proben an.

\subsubsection{Lichtmikroskopische Untersuchungen der Kartoffelpülpe}

Beim histochemischen Nachweis von Stärke und Pektin in der Kartoffelpülpe wurden geringe Mengen der nativen und mechanisch-enzymatisch aufgeschlossenen Kartoffelpülpe entnommen und eingefärbt. Am Lichtmikroskop konnten mit Hilfe der digitalen Kamera (Nikon GmbH, Düsseldorf; Type Coolpix 990) die Proben untersucht und fotografiert werden.

Stärkenachweis: Für den Stärkenachweis mussten die Proben mit Jodkaliumjodid (Lugol `sche Lösung) eingefärbt werden (LEHNINGER et al., 1994).

Rezeptur: $5 \mathrm{~g} \mathrm{Jod}$

$10 \mathrm{~g}$ Kaliumjodid in $500 \mathrm{ml}$ bidest. Wasser lösen 
Pektinnachweis: Pektin und andere saure Polysaccharide wurden durch Rutheniumrot nachgewiesen.

Rezeptur: 25 mg Rutheniumrot auf $25 \mathrm{ml}$ Wasser und einige Tropfen Ammoniak zugeben

\subsubsection{Rasterelektronenmikroskopische (REM) Untersuchungen der Kartoffelpülpe}

Die zu untersuchende Kartoffelpülpe wurde bei $40{ }^{\circ} \mathrm{C}$ im Trockenschrank schonend getrocknet, um eine Karamellisierung der Oberfläche zu verhindern. Für die REMAufnahmen wurden kleine Proben abgenommen und präpariert. Die Aufnahmen erfolgten mit einer Kleinbildkamera (Kontax, Typ SEM 515) an dem Rasterelektronenmikroskop Emscope SC 500 der Firma Philips.

\subsubsection{Mechanisch-enzymatischer Aufschluss der Kartoffelpülpe}

\subsubsection{Mechanische Zerkleinerung mit dem Cutter}

Der mechanische Aufschluss der Kartoffelpülpe fand im Labormaßstab mit Hilfe des Cutters (Firma MADO, Dornhan; Typ MTK 560) aus der Fleischverarbeitung statt. Die native Pülpe wurde dabei von drei Messern, die auf einer Welle sitzen, mechanisch zerschlagen. Zur Vorbereitung des mechanischen Aufschlusses musste zuerst der Feststoffgehalt der Kartoffelpülpe mit einem Feuchtemessgerät (MA 40, Sartorius AG) bestimmt werden. Anschließend konnte eine genau abgewogene Menge an Pülpe (max. $5 \mathrm{~kg}$ ) in den Cutter gefüllt werden. Untersucht wurde der Aufschlussgrad in Abhängigkeit von der Zeit und den Umdrehungen der Cuttermesser pro Minute.

Die Messung der Teilchengröße der aufgeschlossenen Pülpe erfolgte mit einem Netzmikrometer. Dafür setzte man ein Netzmikrometer in das Messokular und ermittelte anschließend mit Hilfe eines Objektmikrometers (Fa. Zeiss) den Mikrometerwert, der angibt wie viele $\mu \mathrm{m}$ einem Teilstrich auf dem Netzmikrometer entsprechen. Bei den nachfolgenden Messungen mussten die Teilstriche, die durch eine Objektabmessung gedeckt wurden, nur noch mit dem Mikrometerwert multipliziert werden. Die Pülpe wurde im Verhältnis 1:1.000 mit Wasser verdünnt und anschließend unter dem Mikroskop untersucht. 
Mit der THOMA-Kammer konnte die Anzahl der Teilchen gemessen werden. Sie ist ein dicker, plangeschliffener Objektträger, in den in der Mitte ein von zwei Rinnen begrenzter Steg eingeschliffen ist. In diesen Steg ist ein Netzquadrat eingeätzt, das 400 Kleinquadrate mit je 0,05 mm Kantenlänge mit einer Fläche von 0,0025 mm² enthält. 16 dieser Kleinquadrate bilden wiederum 1 mittleres Quadrat mit einer Fläche von 0,04 $\mathrm{mm}^{2}$. Insgesamt gibt es ein Großquadrat mit einer Fläche von 1 $\mathrm{mm}^{2}$, bestehend aus 16 mittleren Quadraten. Aus den verdünnten Pülpesuspensionen wurde eine definierte Menge entnommen und unter dem Mikroskop ausgezählt. Neben der Teilchengröße und -anzahl sollte die Bestimmung der Viskosität erfolgen. Die Viskositätsmessung wurde mit einem Rotationsviskosimeter (Fa. Physica, Typ MC 1) durchgeführt und mit der Software US 200 (Fa. Physica) ausgewertet. Die Messungen fanden bei einer Probentemperatur von $20^{\circ} \mathrm{C} \pm 2$ statt.

\subsubsection{Enzymatischer Aufschluss der Kartoffelpülpe}

Aufgeschlossen wurden je $210 \mathrm{~g}$ der jeweiligen nativen Kartoffelpülpe mit $10 \%$ (w/w) bzw. 5 \% (w/w) Enzymlösung bezogen auf den Feststoffgehalt der Pülpe. Bei den eingesetzten Enzymlösungen handelt es sich um Produkte der Firma NovozYmES und $A B$ ENZYMES. Für die Feststoffmessung wurde das Feuchtemessgerät MA 40 (Sartorius) eingesetzt.

In optimierenden Vorversuchen wurden bereits die Aufschlussbedingungen ermittelt. Die Proben inkubierten im Wasserbad bei $45^{\circ} \mathrm{C}$ für vier Stunden (MüLLER, 2001). Nach der Inkubation wurde nochmals der Feststoff ermittelt. Je $200 \mathrm{~g}$ der Proben wurden in der Zentrifuge bei 15.000 rpm für 15 Minuten zentrifugiert. Der Überstand konnte mit Hilfe eines Messzylinders ermittelt und für die Berechnung des Entwässerungsgrades eingesetzt werden. Der Entwässerungsgrad ergibt sich aus folgenden Daten:

$\frac{\text { Gesamtgewicht }(\mathrm{g}) \text { der Proben x Gesamtwassergehalt der Proben (\%) }}{100 \%}=$ Wassergehalt gesamt (ml)

$\frac{\text { Wassermenge durch Zentrifugation }(\mathrm{ml}) \times 100 \%}{\text { Wassergehalt gesamt }(\mathrm{ml})}=$ Entwässerungsgrad $(\%)$ 


\subsubsection{Mechanische Zerkleinerung mit dem Hochdruckhomogenisator}

Für die Zerkleinerung mit dem Hochdruckhomogenisator wurden $7.700 \mathrm{~g}$ feuchte Kartoffelpülpe mit einem Feststoffgehalt von $15 \%$ mit $10 \%$ (w/w) Enzymlösung, bezogen auf den Feststoff, für vier Stunden im Cutter aufgeschlossen. Die mechanisch-enzymatisch aufgeschlossene Kartoffelpülpe wurde anschließend im Hochdruckhomogenisator bei unterschiedlichem Druck weiter zerkleinert. Der Druck variierte zwischen 600 und 1500 bar Zur Auswertung des Zerkleinerungsgrades wurden die Proben unter einem Lichtmikroskop hinsichtlich ihrer Teilchengröße untersucht. Zu diesem Zweck wurden die Proben im Verhältnis 1:1000 verdünnt und auf ein zuvor mit einem Okularmikrometer geeichtes Netzmikrometer aufgetragen. Dadurch konnte die Größe der einzelnen Partikel im $\mu \mathrm{m}$-Bereich ermittelt werden. Die Messungen wurden bei 10-facher Vergrößerung durchgeführt.

\subsubsection{Entwässerung der aufgeschlossenen Kartoffelpülpe}

\subsubsection{Entwässerung mit Westphalia Separatoren}

Die enzymatisch aufgeschlossene Kartoffelpülpe sollte mit Hilfe von Separatoren der Westfalia-Separator AG in Oelde von einem Feststoffgehalt von $15 \%$ bis zu einem Feststoffgehalt von $40-60 \%$ aufkonzentriert werden. Zu diesem Zweck wurden 5 Liter enzymatisch aufgeschlossener Kartoffelpülpe in einer heizbaren Becherschleuder mit $6000 \mathrm{rpm}$ und mit einer mittleren Zentrifugalbeschleunigung von $4500 \mathrm{~g}\left(\mathrm{~m} / \mathrm{s}^{2}\right)$ bei 20 und $50{ }^{\circ} \mathrm{C}$ und einer Schleuderzeit von 0,5; 1 und 2 Minuten geschleudert.

\subsubsection{Gefriertrocknung}

Gefriertrocknung bedeutet, dass aus gefrorenem Material Wasser entzogen wird, wobei eine Umgehung des flüssigen Aggregatzustandes durch eine direkte Überführung von Eis in Dampf erfolgt. Dies geschieht unter Vakuum, wobei in dem eingebrachten Gut Temperaturen tiefer als $-10^{\circ} \mathrm{C}$ herrschen.

Für die Gefriertrocknung wurde ein Gerät der Firma Dieter Piatkowski/Forschungsgeräte-Vertrieb (München), vom Type P4K-S verwendet. Da in dem Gerät nur relativ wenig Platz war, konnten nur geringe Pülpemengen getrocknet 
werden. Es wurden jeweils $100 \mathrm{~g}$ feuchte Proben von AVEBE- und Emsland-Pülpe eingewogen und in der Anlage getrocknet. Zu diesem Zweck mussten die Proben zunächst bei $15.000 \mathrm{rpm}$ zentrifugiert und der Überstand verworfen werden. Bevor die Proben in die Gefriertrocknungsanlage gestellt wurden, musste die Stellfläche, bei einem Druck von 800 mbar, eine Temperatur von ca. $-48{ }^{\circ} \mathrm{C}$ aufweisen.

Da die Pülpeproben sehr viel Feuchtigkeit enthielten, kühlte man im ersten Teil der Trocknung die Stellfläche für etwa eine Stunde auf $-60{ }^{\circ} \mathrm{C}$ herunter. Anschließend war es möglich, die Stellflächentemperatur auf ca. $-15{ }^{\circ} \mathrm{C}$ zu erhöhen. Die Trocknung der Proben erfolgte bei einem Druck von etwa 0,03 mbar und einer Kondensatortemperatur von $-60{ }^{\circ} \mathrm{C}$. Nach zweieinhalb Tagen konnten die Proben aus der Gefriertrocknungsanlage entnommen werden.

\subsubsection{Wirbelschicht-Sprühgranulation}

Für die Trocknung der Kartoffelpülpe wurden $3.000 \mathrm{~g}$ Kartoffelpülpe mit einem Feststoffgehalt von $15 \%$ mechanisch-enzymatisch aufgeschlossen. Nach Zugabe von $10 \%$ (w/w) Ultrazym AFP-L und 900 ml Mc-Ilvain-Puffer $(\mathrm{pH} \mathrm{6,0)} \mathrm{wurde} \mathrm{die}$ Pülpe $4 \mathrm{~h}$ im Cutter aufgeschlossen. Nach dem Aufschluss betrug der Feststoffgehalt der Pülpe ca. 17-18 \%. Zur Konservierung der feuchten Pülpe erfolgte die Zugabe von $0,1 \%$ Mergal $^{\circledR}$ S88 und $1 \%$ Sorbinsäure, bezogen auf den Feststoff der Pülpe.

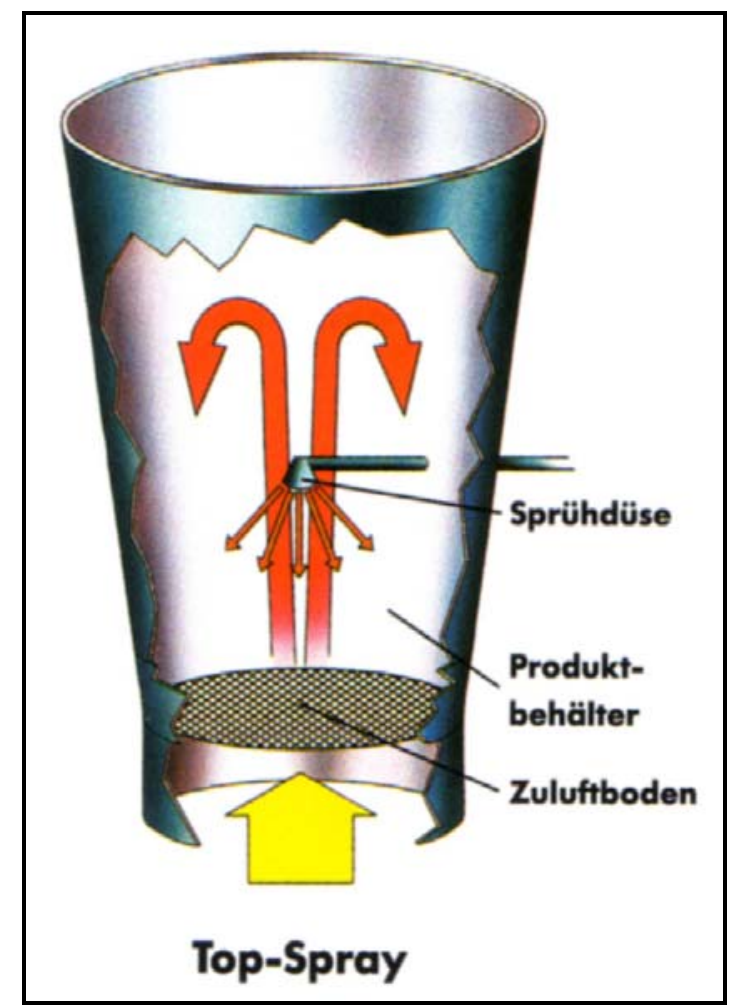

Abb. 3-4: Top-Spray-Verfahren (GLATT GMBH, 2003). 
Damit die Pülpe über eine Schlauchpumpe gefördert werden konnte, musste sie noch zusätzlich mit $500 \mathrm{~g}$ Wasser verdünnt werden. Als Trägerstoff, den so genannten Fremdkeimen, wurden $300 \mathrm{~g}$ Maisstärke verwendet. Die Trocknung erfolgte im Labormaßstab in einem Batch-Verfahren. Die eingesetzte Technik war ein Top Spray, dabei wird das Gut über die oben liegende Düse in den Produktbehälter gesprüht und lagert sich an den Fremdkeimen an. Von unten wird das Gut mit Hilfe von warmer Luft getrocknet (s. Abb. 3-4).

\subsubsection{Verwendung der mechanisch-enzymatisch aufgeschlossenen Kartoffelpülpe als Bindemittel zur Herstellung von Holzwerk- stoffen}

Die mechanisch-enzymatisch aufgeschlossene Pülpe sollte hinsichtlich ihrer Bindungseigenschaften überprüft und als Bindemittel für die Herstellung von Holzwerkstoffen eingesetzt werden. Es wurden daher Mitteldichte Faserplatten (kurz: MDF) im Technikum des Institutes für Forstbotanik hergestellt.

\subsubsection{Vorbereitung der Pülpe}

Da die Pülpe ein heterogener Stoff ist, musste vor jedem enzymatischen Aufschluss der Feststoff der Kartoffelpülpe mit einem Feuchtemessgerät ermittelt werden. Anschließend konnten $10 \%(\mathrm{w} / \mathrm{w})$ der entsprechenden Enzymlösung bezogen auf den Feststoffgehalt der Pülpe für den Aufschluss eingesetzt werden. Der Aufschluss erfolgte für vier Stunden im Cutter. Da das Fassungsvermögen des Cutters nur maximal fünf Kilogramm Pülpe (lutro) beträgt, musste der Aufschluss in Etappen stattfinden. Nach dem mechanisch-enzymatischen Aufschluss der Kartoffelpülpe wurde diese im feuchten Zustand eingesetzt, da eine Trocknung der beleimten Fasern im Stromrohrtrockner erfolgte.

\subsubsection{Feststoffmessung nach dem mechanisch-enzymatischen Aufschluss}

Die Pülpe wurde hinsichtlich einer Feststoffveränderung nach dem mechanischenzymatischen Aufschluss untersucht. Zu diesem Zweck wurden jeweils ein Gramm 
Pülpe entnommen und mit Hilfe des Feuchtemessgerätes bei $70{ }^{\circ} \mathrm{C}$ getrocknet. Von jeder Probe wurden drei Wiederholungen gemessen.

\subsubsection{Berechnung der notwendigen Leimmenge}

Für die Herstellung der MDF-Platten wurde immer eine $15 \%$ ige Beleimung auf atro Faser eingesetzt. Zu diesem Zweck musste vor jeder Beleimung die Feuchte der Fasern und der Feststoff der mechanisch-enzymatisch aufgeschlossenen Kartoffelpülpe mit dem Feuchtemessgerät (MA 30, Fa. Sartorius, Göttingen) ermittelt werden. Anhand der erhaltenen Werte wurde die Menge Pülpe errechnet, die für eine $15 \%$ Beleimung der Fasern notwendig ist. Je nach Versuchsaufbau wurden noch 1 bis $2 \%$ Hydrophobierungsmittel und Haftvermittler eingesetzt. Die Plattenparameter wurden nicht verändert, d. h. innerhalb der Versuchsreihen blieben die Beleimung, die Rohdichte und die Plattenabmessungen unverändert.

- $15 \%$ ige Beleimung auf atro Faser

- Rohdichte: $800 \mathrm{~kg} / \mathrm{m}^{3}$

- Plattenmaße (Höhe x Breite x Länge): 10 mm x 450 mm x 600 mm

Es wurden MDF-Platten unter Verwendung von $100 \%$ mechanisch-enzymatisch aufgeschlossener Kartoffelpülpe als Bindemittel hergestellt. Dabei ergaben sich folgende Versuchsreihen (Tab. 3-2):

Tab. 3-2: Versuchsreihen für die Verwendung von $100 \%$ mechanisch-enzymatisch aufgeschlossener Pülpe als Bindemittel

\begin{tabular}{ll}
\hline Bindemittel & Additive \\
\hline \hline & $+1 \%$ Hydrophobierungsmittel \\
$100 \%$ & $+1 \%$ Haftvermittler \\
mechanisch-enzymatisch & $+2 \%$ Haftvermittler \\
aufgeschlossene Kartoffel- & $+1 \%$ Hydrophobierungsmittel / 1\% Haftvermittler \\
pülpe & $+2 \%$ Hydrophobierungsmittel / $2 \%$ Haftvermittler \\
& \\
\hline
\end{tabular}




\subsubsection{Beleimung und Weiterverarbeitung der Fasern}

Die aufgeschlossene Pülpe konnte ohne weitere Vorbehandlung für die Beleimung eingesetzt werden. Das Bindemittel wurde über die Beleimungsdüse mit Hilfe einer Pumpe im Ringmischer gleichmäßig auf die Fasern gebracht. Die beleimten Fasern gelangten vom Ringmischer direkt in die Trocknerleitung. Für die Trocknung musste eine Eingangstemperatur von $120^{\circ} \mathrm{C}$ und eine Ausgangstemperatur von $70{ }^{\circ} \mathrm{C}$ im Trocknersystem eingestellt werden. Nach der Trocknung sollten die Fasern eine durchschnittliche Feuchte zwischen 10 und $13 \%$ haben. Die weitere Verarbeitung ist Kapitel 3.2.5.1 beschrieben. Die Pressparameter änderten sich nur hinsichtlich der Presszeiten. Pressdruck und -temperatur blieben unverändert.

- Pressdruck: $22 \mathrm{~N} / \mathrm{mm}^{2}$

- Presstemperatur: $190^{\circ} \mathrm{C}$

- Presszeiten: zwischen 3 und 6 Minuten

\subsubsection{Beimischung von UF-Harzen}

Zur Verbesserung der Bindemitteleigenschaften wurde Harnstoff-Formaldehydharz (K407, Fa. BASF in Ludwigshafen) in unterschiedlichen Verhältnissen der mechanisch-enzymatisch aufgeschlossenen Kartoffelpülpe zugegeben (s. Tab. 3-3). Die Verhältnisangaben bezogen sich immer auf den jeweiligen Feststoffanteil der einzelnen Komponenten. Die notwendige Gesamtmenge an Bindemittel und Additiven wurde auf atro Faser mit einer jeweils 15 \%igen Beleimung bezogen (s. 3.3.5.3).

Tab. 3-3: Mischungsverhältnis [\%] der einzelnen Versuchsreihen

\begin{tabular}{ccc}
\hline Kartoffelpülpe & UF-Harz & Additive \\
\hline 80 & 20 & 1 Hydrophobierungsmittel \\
70 & 30 & 1 Hydrophobierungsmittel \\
60 & 40 & 1 Hydrophobierungsmittel \\
50 & 50 & 1 Hydrophobierungsmittel \\
\hline 80 & 20 & 1 Haftvermittler \\
50 & 50 & 1 Haftvermittler \\
\hline
\end{tabular}




\subsubsection{Viskositätsmessung der Bindemittelmischungen}

Die Viskosität der Bindemittelmischungen wurde vor ihrer Verarbeitung im Rotationsviskosimeter gemessen. Die Messung erfolgte bei $20 \pm 2{ }^{\circ} \mathrm{C}$. Der Messzylinder war ein DIN Z3. Gemessen wurde nach der Searle-Methode, d. h. der Messkörper rotiert, während der Messbecher still steht. Insgesamt gab es 25 Messpunkte mit einer Messpunktdauer von je 7,2 Sekunden und somit eine gesamte Abschnittsdauer von 180 Sekunden. Neben der Zeit war die Scherrate eine weitere Vorgabe. Da eine Viskositätskurve erreicht werden sollte, wurde die Scherrate mit zunehmender Steigung vorgegeben. Der Versuch startete mit $1 \mathrm{~s}^{-1}$ und stoppte bei $999 \mathrm{~s}^{-1}$

\subsubsection{Untersuchung der physikalisch-technologischen Eigenschaften der hergestellten Holzwerkstoffe in Abhängigkeit von der Euro-Norm (EN) 622-5}

Die hergestellten MDF-Platten wurden nach den Kriterien der Europäischen Norm EN 622-5 geprüft. Grundlagen für die Überprüfung der technologischen Eigenschaften der Platten waren die "Anforderungen an Platten für allgemeine Zwecke zur Verwendung im Trockenbereich" (DIN-TASCHENBUCH 60, 1999). Die MDF-Platten mussten die Anforderungen bei der Dickenquellung und der Querzugfestigkeit erfüllen.

\subsubsection{Dickenquellung nach EN 317}

Das Prinzip der Dickenquellung beruht auf der Messung der Quellung des Prüfkörpers nach einer Lagerung im Wasser in Abhängigkeit von der Zeit. Hierfür mussten die Prüfkörper zu Quadraten mit einer Kantenlänge von $50 \pm 1 \mathrm{~mm}$ zugeschnitten werden. Vor der Wasserlagerung wurden die Prüfkörper bis zur Massekonstanz bei vorgegebenen Parametern klimatisiert und anschließend die Dicke auf $0,01 \mathrm{~mm}$ genau bestimmt. Die Lagerung im Wasser sollte in $20^{\circ} \mathrm{C}$ warmen Wasser bei pH 7 stattfinden. Nach 24 Stunden wurden die Proben entnommen, vom überschüssigen Wasser befreit und die Plattendicke gemessen. Die Dickenquellung $G_{t}$ errechnet sich nach folgender Formel: 


$$
\mathrm{G}_{\mathrm{t}}=\frac{\mathrm{t}_{2}-\mathrm{t}_{1}}{\mathrm{t}_{1}} * 100
$$

$t_{1}=$ die Dicke des Prüfkörpers vor der Wasserlagerung, in Millimeter

$\mathrm{t}_{2}=$ die Dicke des Prüfkörpers nach der Wasserlagerung, in Millimeter

\subsubsection{Querzugfestigkeit nach EN 319}

Bei dieser EN wird die Zugfestigkeit senkrecht zur Plattenebene der Prüfkörper ermittelt. Sie wird bestimmt, indem ein Prüfkörper mit einer gleichmäßig verteilten Zugkraft bis zum Bruch belastet wird. Die Zugfestigkeit ergibt sich aus dem Verhältnis der Bruchkraft zur Querschnittsfläche des Prüfkörpers (DiN-TASCHENBUCH 60, 1999).

Die Prüfung der Querzugfestigkeit wurde an einer Prüfmaschine der Fa. Zwick Roell (Type: Z 010) durchgeführt. Zu diesem Zweck mussten die Prüfkörper wiederum in Quadrate mit einer Kantenlänge von $50 \pm 1 \mathrm{~mm}$ geschnitten werden. Weiterhin wurden Prüfjochen benötigt, die in die Prüfmaschine eingespannt werden konnten. Anschließend konnten die Proben und die Prüfjochen mit Hilfe von Schmelzkleber miteinander verbunden werden. Nach einer Aushärtzeit von mindestens 24 Stunden wurde der mit den Jochen verklebte Prüfkörper in die Einspannvorrichtung der Prüfmaschine eingehängt und bis zum Bruch belastet. Die Zugfestigkeit $\left(\mathrm{f}_{\mathrm{t}}\right)$ errechnete sich nach folgender Formel:

$$
f_{t}=\frac{F_{\max }}{a * b}
$$

dabei ist: $\quad F_{\max }$ die Bruchkraft, in Newton

$a$, b die Länge und Breite des Prüfkörpers, in Millimeter

Zur Bestimmung der Zugfestigkeit einer MDF-Platte wurde das arithmetische Mittel der Ergebnisse aller aus dieser Platte entnommenen Prüfkörper errechnet und in $\mathrm{N} / \mathrm{mm}^{2}$ angegeben.

\subsubsection{Rohdichtebestimmung nach EN 323}

Diese Europäische Norm legt ein Verfahren zur Bestimmung der Rohdichte von Prüfkörpern aus Holzwerkstoffen fest. Die Rohdichte wird angegeben als das 
Verhältnis der Masse jedes Prüfkörpers zu seinem Volumen, wobei beide Messungen bei demselben Feuchtegehalt durchgeführt werden und diese Ergebnisse zur Beurteilung der Rohdichte ganzer Platten benutzt werden dürfen (DIN-Taschenbuch 60, 1999).

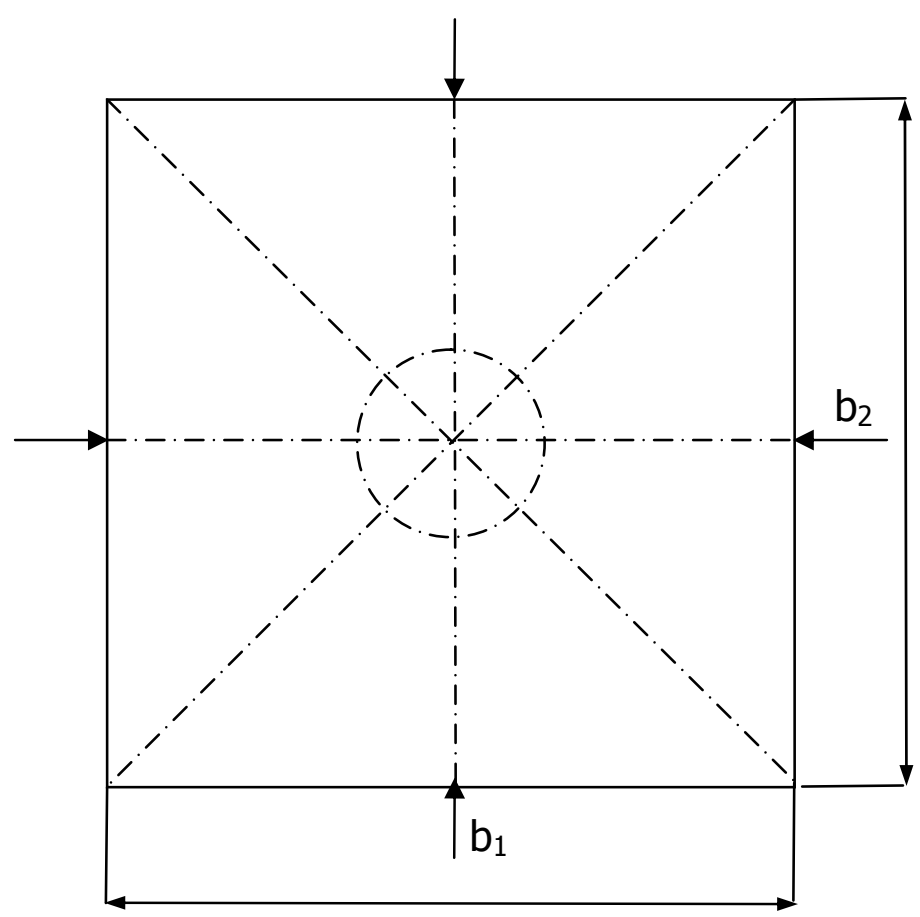

Abb. 3-5: Messpunkte auf dem Prüfkörper

Für die Prüfung der Rohdichte müssen 6 quadratische Proben mit einer Kantenlänge von $50 \mathrm{~mm}$ aus der zu prüfenden Platte gesägt werden. Die Prüfkörper werden auf 0,01 g genau gewogen, sobald sie Massekonstanz erreicht haben. Anschließend werden die Maße der Prüfkörper ermittelt. Für diesen Zweck wird mit einem Dickenmessgerät (Käfer Messuhrenfabrik, Villingen-Schwenningen) im Probenmittelpunkt die Dicke auf $0,05 \mathrm{~mm}$ genau bestimmt. Die Seitenlängen ( $b_{1}$ und $b_{2}$ ) des Prüfkörpers werden parallel zu den Kanten in Höhe des Diagonalenschnittpunktes auf 0,1 mm genau gemessen (s. Abb. 3-5).

Die Rohdichte jedes Prüfkörpers wird nach folgender Formel berechnet:

$$
\rho=\frac{\mathrm{m}}{\mathrm{b}_{1} * \mathrm{~b}_{2} * \mathrm{t}} * 10^{6}
$$

$\mathrm{m}=$ Masse des Prüfkörpers, in $\mathrm{g}$

$b_{1}$ und $b_{2}=$ Seitenlänge des Prüfkörpers, in $\mathrm{mm}$

$\mathrm{t}=$ Dicke des Prüfkörpers, in $\mathrm{mm}$ 
Die Rohdichte der Platten ist das arithmetische Mittel der Rohdichten aller Prüfkörper, die aus der derselben Platte entnommen wurden. Die Rohdichte wird in $\mathrm{kg} / \mathrm{m}^{3}$ angegeben.

\subsubsection{Beständigkeit der hergestellten MDF-Platten gegenüber holzabbauenden Pilzen nach EN 113}

Der Holzabbau der hergestellten MDF-Platten wurde nach der modifizierten EN 113 durchgeführt. Diese EN gilt ursprünglich für die Überprüfung von Holzschutzmitteln an Vollholz und wurde für diesen Versuch leicht verändert. Bei den zu untersuchenden Proben handelte es sich um MDF-Platten, die zum einen mit UF-Harz und zum anderen mit Kartoffelpülpe als Bindemittel hergestellt wurden. Ein Teil der MDF-Proben hatte das Fungizid Mergal ${ }^{\circledR}$ S88 mit $1 \%(w / w)$, bezogen auf den Feststoffgehalt des Bindemittels, in der Beleimung.

\subsubsection{Pilzmedien}

Medium für Trametes versicolor und Coniophora puteana:

$$
\begin{aligned}
& \checkmark \text { Malzextrakt (pulverförmig) } \quad 40 \pm 0,5 \mathrm{~g} \\
& \checkmark \text { Agar } 20-30 \mathrm{~g} \\
& \checkmark \text { mit bidest. Wasser auffüllen auf } 1000 \mathrm{ml}
\end{aligned}
$$

Medium für Chaetomium globosum:

$$
\begin{array}{llc}
\checkmark & \text { Malzextrakt } & 20 \mathrm{~g} \\
\checkmark & \text { Pepton } & 5 \mathrm{~g} \\
\checkmark & \text { Agar } & 10 \mathrm{~g} \\
\checkmark & \text { mit bidest. Wasser auffüllen auf } 1000 \mathrm{ml}
\end{array}
$$

Die Medien wurden in die entsprechenden Kulturgefäße mit einer Mindesthöhe von 3-4 mm gefüllt und anschließend bei $121^{\circ} \mathrm{C}$ für 20 Minuten autoklaviert. Nach der Abkühlung wurden die Medien mit den entsprechenden Pilzen beimpft. 


\subsubsection{MDF-Proben}

Für den Abbauversuch mit drei unterschiedlichen Pilzen wurden die MDF-Proben unterteilt in Proben mit und ohne Mergal ${ }^{\circledR}$ S88. Benötigt wurden jeweils 60 Klötzchen (50 mm x $25 \mathrm{~mm} \times 10 \mathrm{~mm}$ ), einmal mit UF-Harz und einmal mit mechanischenzymatisch aufgeschlossener Kartoffelpülpe als Bindemittel. Jeweils 24 dieser Klötzchen wurden mit Bindemittel hergestellt, dem vorher das Fungizid Mergal ${ }^{\circledR}$ S88 zugegeben worden war (s. Kap. 3.3.7.4.).

Die Proben wurden zuerst gewogen $\left(m_{0}\right)$ und anschließend bei $103{ }^{\circ} \mathrm{C}$ für mindestens $18 \mathrm{~h}$ im Trockenschrank getrocknet. Um die Feuchte der Proben zu erhalten, fand eine zweite Messung des Gewichtes $\left(m_{1}\right)$ nach der Trocknung statt. Die Feuchte ergibt sich aus $m_{0}-m_{1}$. Zur Errechnung des prozentualen Anteils der Feuchte wurde folgende Formel verwendet:

$$
\frac{\left(\mathrm{m}_{0}-\mathrm{m}_{1}\right)}{\mathrm{m}_{1}} * 100
$$

\subsubsection{Schematischer Versuchsaufbau}

Nach der Sterilisation des Mediums wurden die Gläser mit dem Medium spätestens nach 7 Tagen mit den Pilzen beimpft. Die Probenzugabe fand statt, sobald das Medium völlig mit Pilzmyzel überwachsen war. In jedes Glas kamen sterilisierte Probenauflagen (unter sterilen Bedingungen) und jeweils darauf die sterilisierten Proben.

Probenunterteilung: $\quad e_{1}=$ mit Fungizid behandelte Proben; jeweils 4 Stück

$\mathrm{e}_{2} \quad=$ unbehandelte Proben

$\mathrm{e}_{2.1}=$ Kontrollen $\Rightarrow$ identisch in der Anzahl Proben mit $\mathrm{e}_{1}$

Je eine Probe kam in ein Glas mit Proben von $e_{1}$

$e_{2.2}=6$ der nicht behandelten Proben mussten mit jeder verwendeten Pilzart inkubiert werden

$\mathrm{e}_{3}=$ behandelte Kontrollproben zur Berechnung des Korrekturfaktors (c). Wurden identisch behandelt wie $e_{1}$, allerdings ohne Pilz inkubiert; zwei in jedes Glas 
Es wurden jeweils eine behandelte $\left(e_{1}\right)$ und eine unbehandelte $\left(e_{2.1}\right)$ Probe in jedes Glas gegeben und von den Proben $e_{2.2}$ jeweils 2 Proben in ein Glas. In die Gläser ohne Pilz wurden immer zwei Proben von $e_{3}$ eingebracht (s. Tab. 3-4).

Tab. 3-4: Anzahl der Proben pro Pilz (KPF = mit Kartoffelpülpe gebunden und mit Fungizid behandelt; KP = mit Pülpe gebunden, ohne Fungizid; UFF = mit UF-Harz gebunden und mit Fungizid behandelt; UF = mit UF-Harz gebunden, ohne Fungizid):

\begin{tabular}{|l|c|c|c|c|c|c|c|}
\hline Probe & behandelt & unbehandelt & $\mathbf{e}_{\mathbf{1}}$ & $\mathbf{e}_{\mathbf{2 . 1}}$ & $\mathbf{e}_{\mathbf{2 . 2}}$ & $\mathbf{e}_{\mathbf{3}}$ & Gesamt \\
\hline KPF & $\mathbf{X}$ & & $\mathbf{6}$ & & & 6 & 12 \\
\hline KP & & $\mathbf{X}$ & & 6 & 6 & & 12 \\
\hline UFF & $\mathbf{X}$ & & $\mathbf{6}$ & & & 6 & 12 \\
\hline UF & & $\mathbf{X}$ & & 6 & 6 & & 12 \\
\hline
\end{tabular}

Anzahl der notwendigen Kulturgefäße je Pilz:

$\checkmark$ Abbauversuch $=6$ mit Pilz

$\checkmark$ Virulenzkontrolle $=3$ mit Pilz

$\checkmark$ Korrekturwert $\quad=3$ ohne Pilz

$\checkmark$ Gesamt $\quad=12$

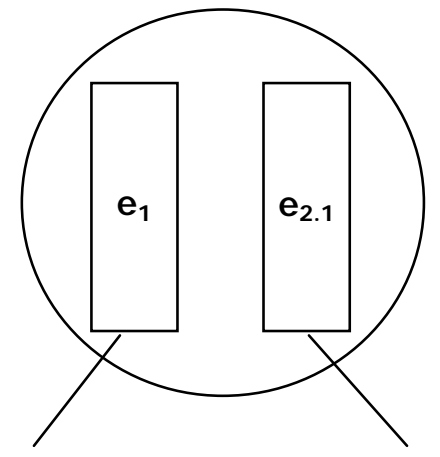

behandelt

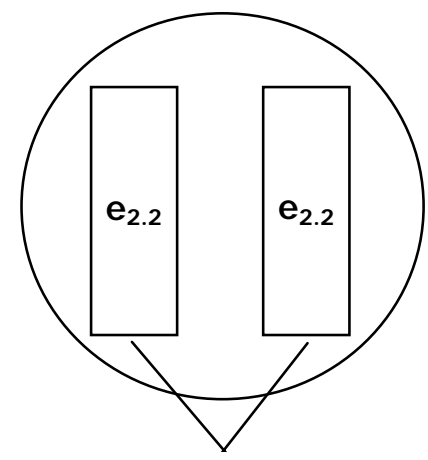

unbehandelt

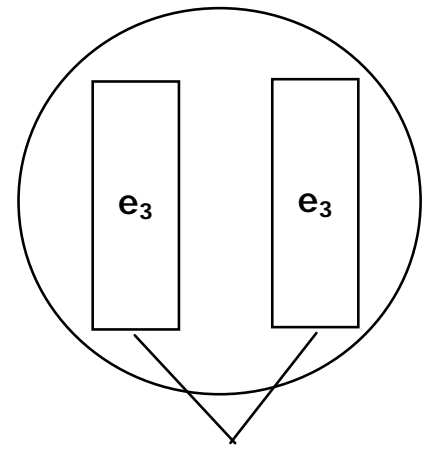

behandelt (ohne Pilz)

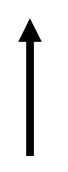

Virulenzkontrolle

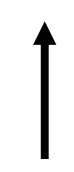

Korrekturwert

Abbauversuch

Abb. 3-6: Schematischer Aufbau der Probenverteilung 
Tab. 3-5: Verteilung der MDF-Proben auf die Gläser (UF = UF-Harz gebundene MDF-Platten ohne Fungizid; UFF = UF-Harz gebundene MDF-Platten mit Fungizid)

\begin{tabular}{|l|c|c|c|}
\hline Pilz & $\begin{array}{c}\mathbf{e}_{\mathbf{1}}+\mathbf{e}_{\mathbf{2 . 1}} \\
\text { Abbauversuch }\end{array}$ & $\begin{array}{c}\mathbf{e}_{\mathbf{2 . 2}} \\
\text { Virulenzkontrolle }\end{array}$ & $\begin{array}{c}\mathbf{e}_{\mathbf{3}} \\
\text { Korrekturwert }\end{array}$ \\
\hline Trametes versicolor & UF 1-6 & UF 19-24 & UFF 19-24 \\
\hline UFF 1-6 & UF 7 - 12 & UF 25 - 30 & \\
\hline $\begin{array}{l}\text { Chaetomiophora puteana } \\
\text { globosum }\end{array}$ & UFF 7 - 12 $13-18$ & UF 31-36 & \\
\hline
\end{tabular}

Tab. 3-6: Verteilung der MDF-Proben auf die Gläser (KP = Kartoffelpülpe gebundene MDF-Platten ohne Fungizid; KPF = Pülpe gebundene MDFPlatten mit Fungizid)

\begin{tabular}{|c|c|c|c|}
\hline Pilz & $\begin{array}{c}\mathbf{e}_{1}+\mathbf{e}_{2.1} \\
\text { Abbauversuch }\end{array}$ & $\begin{array}{c}\mathbf{e}_{2.2} \\
\text { Virulenzkontrolle }\end{array}$ & $\begin{array}{c}\mathbf{e}_{3} \\
\text { Korrekturwert }\end{array}$ \\
\hline Trametes versicolor & $\begin{array}{l}\mathrm{KP} 1-6 \\
\mathrm{KPF} 1-6\end{array}$ & KP $19-24$ & KPF $19-24$ \\
\hline Coniophora puteana & $\begin{array}{l}\mathrm{KP} 7-12 \\
\mathrm{KPF} 7-12\end{array}$ & KP $25-30$ & \\
\hline Chaetomium globosum & $\begin{array}{l}\text { KP } 13-18 \\
\text { KPF } 13-18\end{array}$ & KP $31-36$ & \\
\hline
\end{tabular}

\subsubsection{Vorbehandlung der Proben}

Für die unbehandelten Proben wurden MDF-Platten zum einen mit UF-Harz und zum anderen mit aufgeschlossener Kartoffelpülpe als Bindemittel hergestellt, ohne weitere Zugaben von anderen Stoffen. Die behandelten Proben hatten noch zusätzlich zu dem entsprechenden Bindemittel eine Zugabe von 1\% (w/w) des Fungizids Mergal ${ }^{\circledR}$ S88. 


\subsubsection{Testauswertung}

Die Proben wurden vom Myzel befreit und hinsichtlich abnormer Wasseraufnahme und Pilzbewuchs bzw. Infektion untersucht. Anschließend musste jede Probe bis auf die zweite Stelle hinter dem Komma genau gewogen werden $\left(m_{2}\right)$. Die Proben wurden getrocknet und nochmals gewogen $\left(m_{3}\right)$. Der Feuchtigkeitsgehalt wurde anhand der folgenden Formel bestimmt:

$$
\frac{\left(\mathrm{m}_{2}-\mathrm{m}_{3}\right)}{\mathrm{m}_{3}} * 100
$$

und gibt das Ergebnis in Prozent an.

Der Masseverlust der Proben $e_{1}\left(e_{3}\right)$ ergab sich aus folgender Formel:

$$
\frac{\left(\mathrm{m}_{1}-\mathrm{m}_{3}\right)}{\mathrm{m}_{3}} * 100
$$

Um den korrekten Masseverlust der Proben $e_{1}$ zu bestimmen, wurde der Korrekturfaktor von dem Masseverlust der Proben $e_{1}$ abgezogen. Den Korrekturfaktor erhielt man durch den Masseverlust der Proben $e_{3}$. Falls eine Probe $\left(e_{1}\right)$ oder $\left(e_{3}\right)$ einen Anstieg in der korrigierten Masse zeigte, wurde die Probe als Null angegeben

\subsubsection{Gültigkeit der Ergebnisse}

Es wurden alle Proben aussortiert, die einen geringeren Masseverlust als $3 \%(\mathrm{~m} / \mathrm{m})$, einen Feuchtigkeitsgehalt von größer als $80 \%(\mathrm{~m} / \mathrm{m})$ und kleiner als $20 \%(\mathrm{~m} / \mathrm{m})$ hatten oder die infiziert waren.

\subsection{8 Überwachsungsgrad der MDF-Platten}

Während der tatsächliche Holzabbau erst nach Inkubationsende ermittelt werden konnte, sollte das Pilzwachstum während der Inkubation untersucht werden. SHEKHOLESLAMI (1986) verwendete eine Methode der visuellen Überprüfung des Pilzwachstums, modifiziert von WINKELMANN (1997). Das Wachstum der holzzersetzenden Pilze wurde im prozentualen Überwachsungsgrad der Probenoberfläche gemessen (s. Tab. 3-7). 
Tab. 3-7: Überwachsungsgrad der Proben während der Inkubation mit holzzersetzenden Pilzen

\begin{tabular}{|c|c|c|c|c|c|}
\hline $20 \%$ & $40 \%$ & $60 \%$ & $80 \%$ & $100 \%$ & $120 \%$ \\
\hline $\begin{array}{c}\text { Seitenflächen } \\
1 / 4 \\
\text { überwachsen }\end{array}$ & $\begin{array}{c}\text { Seitenflächen } \\
1 / 2 \\
\text { überwachsen }\end{array}$ & $\begin{array}{c}\text { Seitenflächen } \\
3 / 4 \\
\text { überwachsne }\end{array}$ & $\begin{array}{c}\text { Oberkante } \\
\text { erreicht }\end{array}$ & $\begin{array}{c}\text { vollständig } \\
\text { überwachsen }\end{array}$ & $\begin{array}{c}\text { üppig } \\
\text { überwachsen }\end{array}$ \\
\hline
\end{tabular}




\section{$4 \quad$ Ergebnisse und Diskussion}

\subsection{Analytische Untersuchungen}

\subsubsection{Feuchtegehalt der Kartoffelpülpe}

Für die Verwendung der Kartoffelpülpe als Bindemittel in der Holzwerkstoffindustrie ist der Feststoffgehalt von enormer Bedeutung, da ein hoher Restfeuchtegehalt des Bindemittels in der Holzwerkstoffproduktion normalerweise nicht erwünscht ist. Um eine effiziente Entwässerung der Pülpe zu erreichen, muss der Wasseranteil der nativen Kartoffelpülpe bekannt sein. Untersucht wurden dabei Kartoffelpülpe der Firma Emslandstärke, Deutschland und Pülpe der Firma AVEBE, Niederlande. Die Ergebnisse sind in der Abb. 4-1 aufgezeigt.

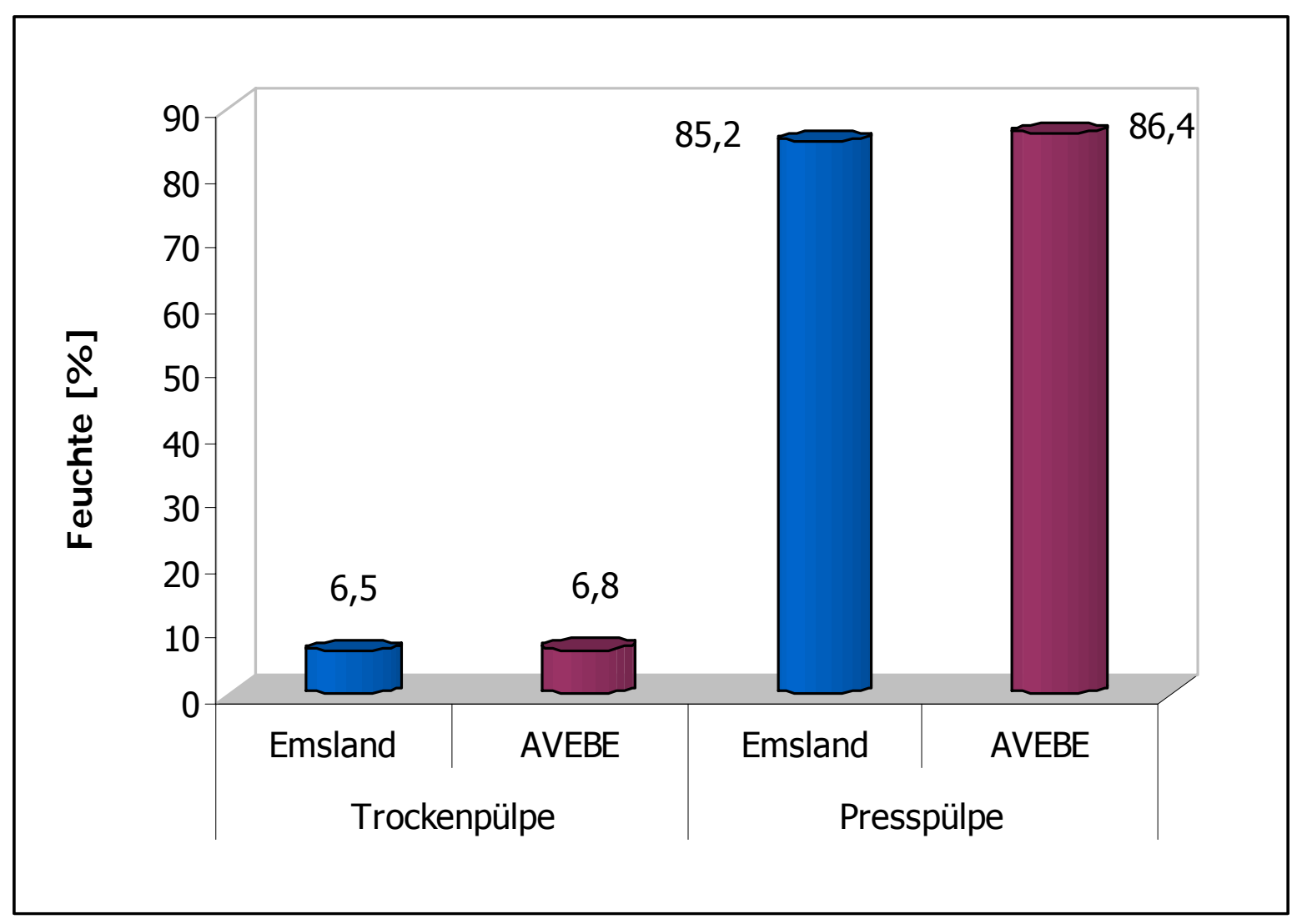

Abb. 4-1: Restfeuchte der untersuchten Pülpesorten der Fa. Emslandstärke und AVEBE 
Die Untersuchung der Presspülpe ergab für beide Proben einen durchschnittlichen Feststoffgehalt von etwa $15 \%$. Bei der Trockenpülpe lag der Feststoffgehalt zwischen 93 - $94 \%$.

Bei der Presspülpe handelt es sich um leicht vorentwässerte Pülpe direkt aus der Produktion. Der Feststoffgehalt der Presspülpe variiert zwischen $13-20 \%$, je nach Produktionsstandort und Verfahren (KRUSEnBAUM, 1991; Mayer, 1998). Trockenpülpe wird hauptsächlich in der Futterindustrie verwendet, allerdings nur als Zusatz bzw. unter Zugabe von Proteinen. Die hier untersuchte Trockenpülpe wurde nicht thermisch, sondern mit Hilfe einer Gefriertrocknungsanlage getrocknet. Die ermittelten Werte entsprechen der Ausgleichsfeuchte der Raumluft. Die Trockenpülpe besitzt bereits einen hohen Feststoffgehalt, allerdings sind die Nachteile der Trockenpülpe die hohen Kosten, die bei der Trocknung entstehen und die Karamellisierung der Pülpeoberfläche beim thermischen Trocknen.

\subsection{2 pH-Bereiche der nativen Kartoffelpülpe}

Die native Kartoffelpülpe ist aufgrund ihrer Zusammensetzung einem starken mikrobiellen Abbau unterworfen. Die Pülpe enthält Stärke, Proteine und lösliche Aminosäuren. Bereits in anderen Untersuchungen wurde gezeigt, dass der Kohlenstoff- und Stickstoffgehalt sowie das hohe $\mathrm{C} / \mathrm{N}$-Verhältnis eine mikrobielle Abbaubarkeit der Pülpe begünstigen (Krusenbaum, 1991; HillebrandT, 1994). Die Pülpe enthält bereits zu Beginn ein großes autochthones Mikroorganismenspektrum, das eine Zersetzung der Pülpe fördert. Der pH-Wert ist ein wichtiger Faktor bei diesem Abbau. Durch Untersuchungen von HILLEBRANDT (1994) wurde nachgewiesen, dass Pülpe, die unter Luftabschluss gelagert wird, einen pH-Bereich von 4,0 bis 4,2 aufweist. Zurückzuführen ist dies auf das Vorkommen von Bakterien der Gattung Lactobacillus, die durch ihren fermentativen Stoffwechsel unter Luftabschluss Milchsäure ausscheiden, die das Wachstum konkurrierender Mikroorganismen hemmen können (HILLEBRANDT, 1994).

Die untersuchte Pülpe wurde unter Luftabschluss gelagert und wies einen durchschnittlichen pH-Wert von 4,4 auf. Durch den enzymatischen Aufschluss verringerte sich dieser Wert nochmals (s. Abb. 4-2). Ein Grund dafür ist wahrscheinlich die partielle Entesterung des Pektins. Die Herabsetzung des pHWertes unterstützt die natürliche Konservierung der Pülpe, die somit auch im feuchten Zustand eine verbesserte Lagerfähigkeit aufweist.

Für den enzymatischen Aufschluss ist der pH-Wert ebenfalls von Bedeutung, da jedes Enzym ein pH-Optimum aufweist in dem seine Enzymaktivität am höchsten 
ist. Enzyme sind Ampholyten, d. h. sie besitzen Dissoziationskonstanten sowohl für ihre sauren als auch alkalischen Gruppen, da einige Aminosäuren an ihrem Rest zusätzliche Amino- bzw. Carboxylgruppen aufweisen. Eine Änderung des pH-Wertes bedeutet eine Veränderung in der Konzentration der $\mathrm{H}^{+}$-Ionen. Dadurch bedingt ist eine Änderung in der Ionenladung dieser Gruppen, d. h. die Tertiärstruktur des Proteinmoleküls wird verändert. Die Folge ist, dass die Enzyme kein Substrat mehr umsetzen können. Die eingesetzten Enzymkomplexe haben ihre pH-Optima zwischen 3,2 und 5,8. Somit sind die Bedingungen in der Pülpe nicht ideal, liegen aber noch soweit im pH-Bereich der Enzymkomplexe, dass diese Substrat umsetzen können. Durch die Zugabe von entsprechenden Puffern wäre es möglich den pHWert weitestgehend optimal einzustellen. Allerdings wird dies im technischen Maßstab immer schwieriger.

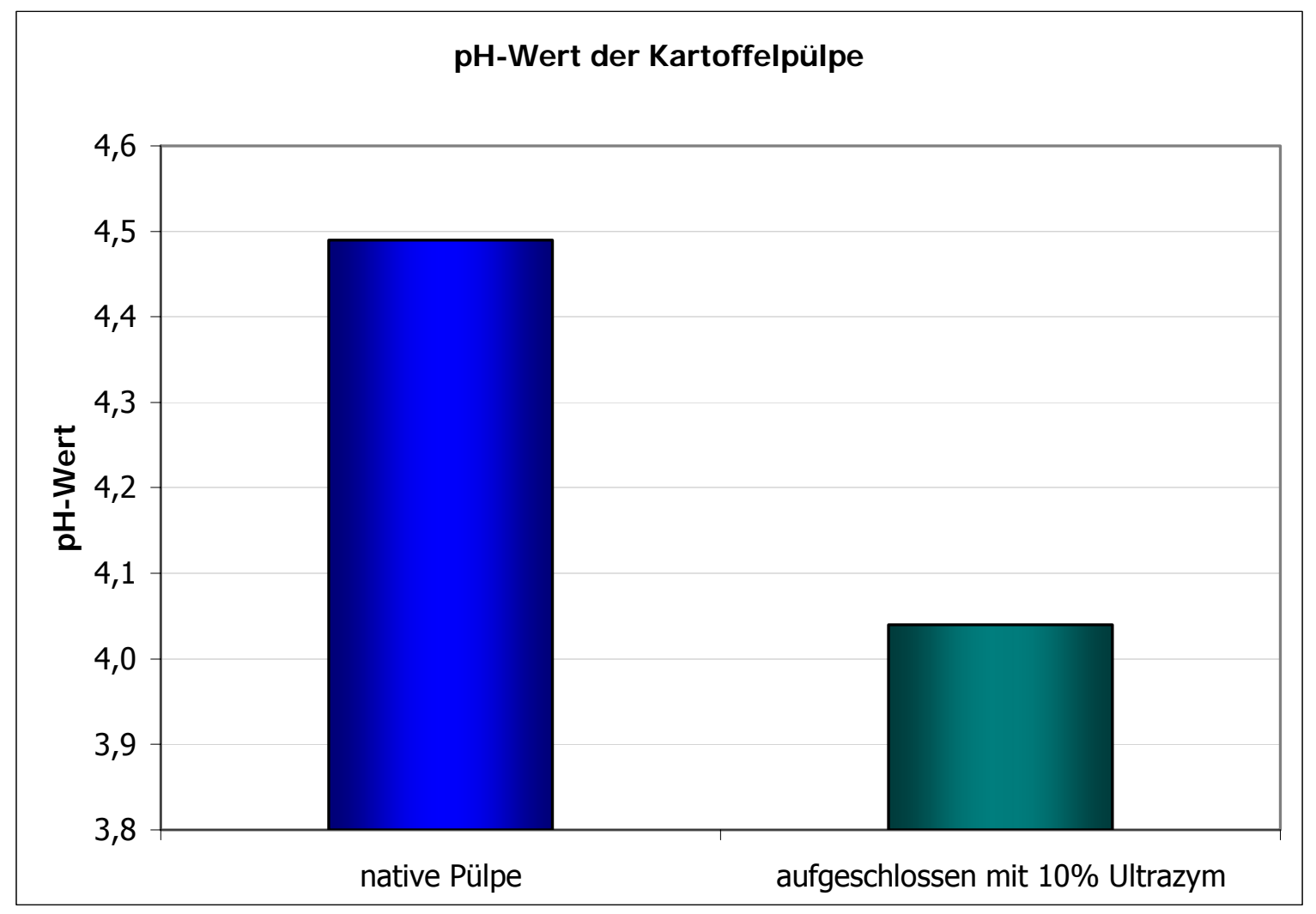

Abb. 4-2: pH-Wert nativer und enzymatisch aufgeschlossener Kartoffelpülpe nach anaerober Lagerung

Für eine Mischung mit Harnstoff-Formaldehydharz ist der niedrige pH-Wert vorteilhaft. Bei der Herstellung von Harnstoff-Formaldehydharz wird die Polykondensation durch Zugabe von $\mathrm{NaOH}$ abgebrochen. Das Harz hat dann einen leicht basischen pH-Wert. Beim Pressvorgang wird durch die Freisetzung von Holzsäuren, die bei der Herstellung abgebrochene Polymerisation fortgesetzt und 
man erreicht dadurch eine schnellere Aushärtung und somit kürzere Presszeiten (KLOESER, 2004). Einen ähnlichen Effekt beim Verpressen erhält man durch die Verwendung von Kartoffelpülpe, die ebenfalls einen sauren $\mathrm{pH}-$ Wert aufweist.

\subsubsection{Stärkegehalt der Kartoffelpülpe}

Der Reststärkegehalt der Kartoffelpülpe ist ein wichtiger Faktor beim Einsatz als Bindemittel, da die Stärke eine Hauptkomponente der Pülpe mit bindungsfähigen Eigenschaften ist. Je nach Stärkegewinnungsverfahren der einzelnen Firmen kann der Reststärkegehalt bis zu $35 \%$ und mehr betragen. Weitere Faktoren sind die verwendeten Kartoffelsorten und Wachstumsbedingungen wie Düngung, Klima und Boden, die den Stärkegehalt beeinflussen. Daher ist die Kartoffelpülpe nie homogen in ihrer Zusammensetzung (Geibler, 1980; MOHABIR u. John., 1988; KRUSEnBaum, 1991).

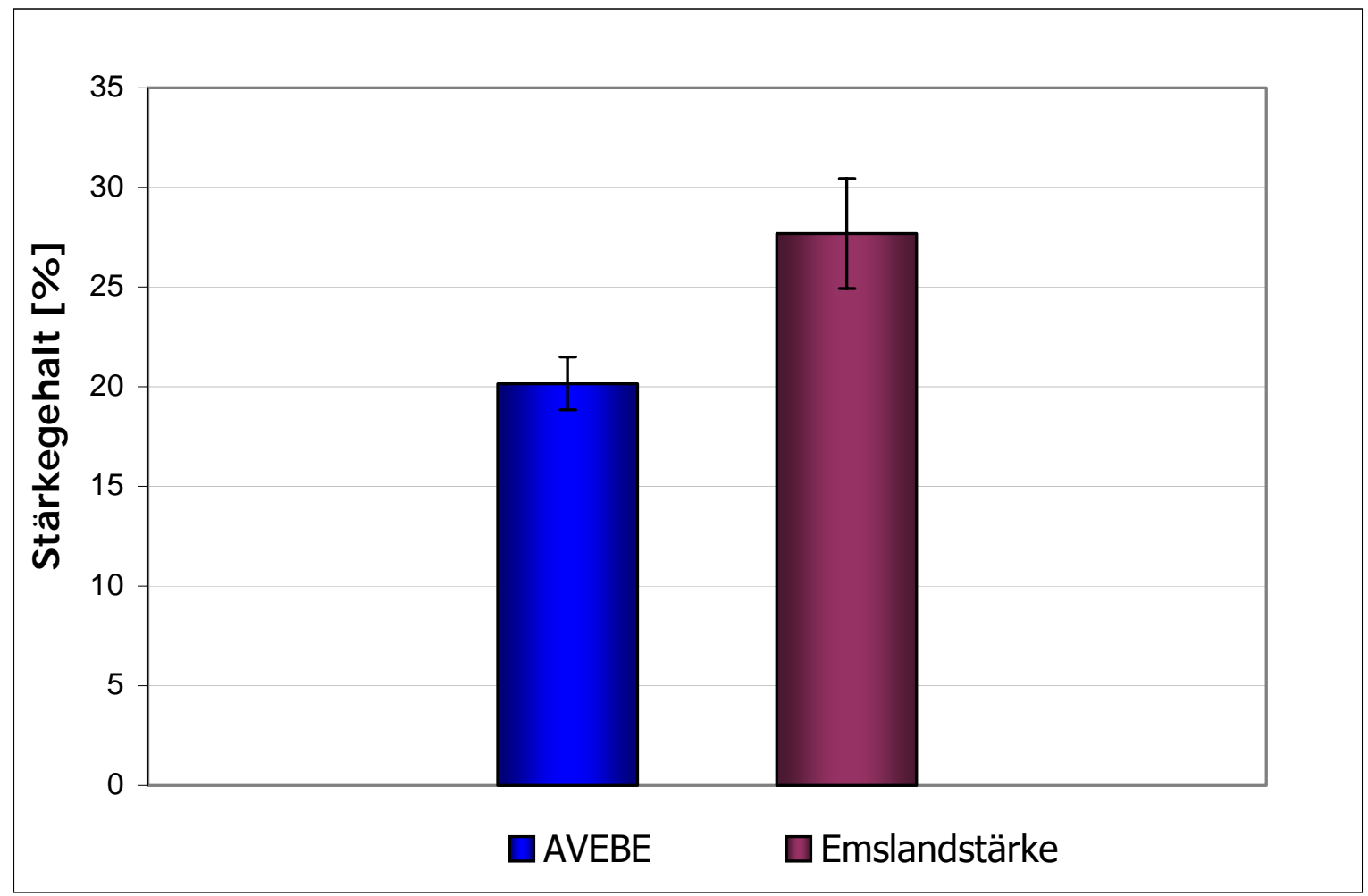

Abb. 4-3: Durchschnittlicher Stärkegehalt der untersuchten Pülpeproben

Im Vergleich der beiden Pülpesorten (s. Abb. 4-3) ist ein deutlicher Unterschied im Gehalt der Stärke zu erkennen. Die AVEBE-Pülpe weist im Durchschnitt nur einen Stärkegehalt von etwa 21 \% auf, während die Emsland-Pülpe einen Stärkegehalt 
von bis zu $27 \%$ hat. Andere Quellen ermittelten einen maximalen Reststärkegehalt (bezogen auf den Feststoff) von 35-40 \% (OLSON, 2000), bzw. eine Menge die zwischen 3,3 und 70 \% variiert (vgl. TEGGE, 1984/88; GIESEMANN U. KNOBLOCH, 1979; Huchette u. Bussière, 1976; Beldman et al., 1984; SlominsKa u. StarogardzKa, 1987).

Durch einen mechanisch-enzymatischen Aufschluss der Pülpe soll unter anderem eine Freisetzung der zellgebundenen Stärke und dadurch eine Erhöhung der Bindungsfähigkeit erreicht werden. Die Pülpe mit dem höheren Stärkegehalt ist der mit dem niedrigeren Gehalt vorzuziehen, allerdings können in diesem Fall beide Pülpesorten für die Verwendung als Bindemittel eingesetzt werden. Der Unterschied im Stärkegehalt zwischen den beiden Pülpesorten ist nicht gravierend.

\subsubsection{Galacturonangehalt von AVEBE- und Emsland-Pülpe}

Der Galacturonangehalt in AVEBE- und Emsland-Pülpe gibt den Pektingehalt der Kartoffelpülpe, bezogen auf das Trockengewicht, an. Das Pektin ist aufgrund seiner chemischen Struktur und Eigenschaften ideal für die Verwendung als Bindemittel. Daher ist der Pektinanteil in der Pülpe von großer Bedeutung.

Die MHDP-Methode hat eine hohe Empfindlichkeit und Spezifität (BLUMENKRANTZ u. ASBOE-HANSEN, 1973). Die Vorbehandlung der Pülpe mit einem pektolytischen Enzym ist erforderlich, weil das primäre Enzym, die endo-Polygalacturonase, unveresterte Galacturonsäure-Einheiten benötigt. Durch eine Umrechnung des Gehaltes ergibt sich ein Galacturonan-, bzw. Pektingehalt von $13 \%$ für EmslandPülpe und $14 \%$ für AVEBE-Pülpe (bezogen auf die Trockensubstanz der Pülpe) (s. Abb. 4-4). Vergleicht man diese Werte mit anderen Literaturangaben (vgl. DONGOWSKI, 1993; BELDMAN et al., 1984; MAYER, 1993), stimmen sie mit den dort angegebenen Werten annähernd überein.

Bisher gab es nur wenige Arbeiten, die sich mit der Nutzung und Isolierung des in der Pülpe enthaltenen Pektins beschäftigt haben. ABOusTEIT und KEMPF (1974) haben die Gewinnung von Pektin aus Kartoffelpülpe und den späteren Einsatz in der Lebensmittelindustrie beschrieben. TURQUOIS et al. (1999) haben unter anderem aus Kartoffelpülpe Pektine isoliert und deren gelierende Eigenschaften untersucht. Im Gegensatz zu diesen Arbeiten wird das Pektin für den Einsatz als Bindemittel nicht aus der Pülpe isoliert, sondern mit Hilfe der Enzymlösung depolymerisiert. Durch den enzymatischen Aufschluss entstehen Galacturonsäure-Monomere, die im weiteren Verlauf wieder Bindungen eingehen können und somit die zweitwichtigsten Faktoren beim Einsatz als Bindemittel sind (vgl. KHARAZIPOUR, 1994a; KHARAZIPOUR u. BERGMANN, 1998). 


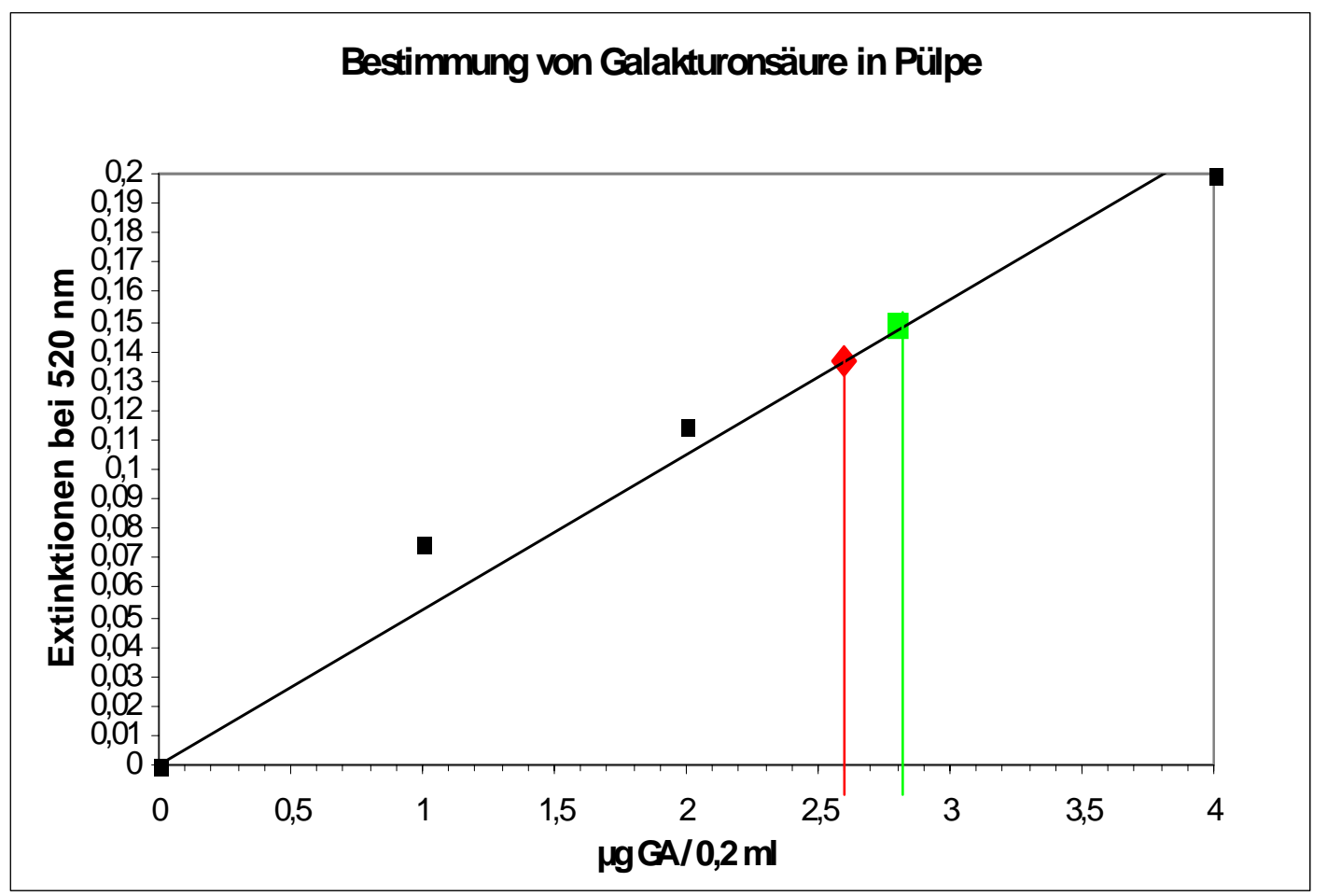

Abb. 4-4: Eichreihe für die Bestimmung des Galacturonangehaltes in Kartoffelpülpe. Die rote Linie zeigt den Gehalt für EmslandPülpe an und die grüne Linie den Gehalt für AVEBE-Pülpe

Der Gehalt an Pektin in Kartoffelpülpe ist nicht so großen Schwankungen unterlegen wie der Stärkegehalt. Trotzdem steht nicht immer eine gleich bleibende Menge Pektin zur Verfügung, da der enzymatische Aufschluss relativ unkontrolliert abläuft und daher mal mehr mal weniger Galacturonsäure-Monomere entstehen können.

\subsection{Mikroskopische Untersuchungen der nativen Kartoffelpülpe}

\subsubsection{Lichtmikroskopische Aufnahmen nativer Kartoffelpülpe}

Durch die histochemischen Untersuchungen konnten in der nativen Kartoffelpülpe Zell- und Zellwandbestandteile nachgewiesen werden. Mit Hilfe von Rutheniumrot wurden Pektine, bzw. D-Galakturonan nachgewiesen. Rutheniumrot ist ein Farbstoff, der sich gezielt in den zwischenmolekularen Raum der Carboxyl-Gruppen des Pektins anlagert. Die Bindung der reaktiven Gruppe des Farbstoffes findet mit einem Sauerstoff einer Carboxyl-Gruppe von einem D-Galakturonan und einem 
Sauerstoff einer Carboxyl-Gruppe eines benachbarten D-Galakturonan in einer Pektatkette statt (WeN-CHI Hou et al., 1999).

Durch die Einfärbung der Zellwände war es möglich eine qualitative Bestimmung des Pektins in der Zellwand durchzuführen. In Abb. 4-5 und Abb. 4-6 sind rötlich eingefärbte Zellwände zu sehen, die freiliegendes Pektin bzw. D-Galakturonan zeigen. Anhand der eingefärbten Zellwände lassen sich jedoch keine quantitativen Aussagen über den Pektingehalt machen, allerdings ist die Verteilung des Pektins innerhalb der Kartoffelpülpe gut zu erkennen.

Für den Stärkenachweis in Kartoffelpülpe wurden Proben der nativen Pülpe mit Jodkaliumjodid eingefärbt. Die Stärke färbte sich innerhalb kurzer Zeit blauschwarz. Grund dieser Reaktion ist das Jod, welches sich in den zentralen Hohlraum der Amylosehelix in linearer Anordnung einfügt. Diese Amylosehelix hat eine relativ hydrophobe innere Oberfläche, die einen Wasserfilm aufweist. Aufgrund dieses Films ist eine Bindung zwischen der Amylose und der Kette der geladenen Jodmoleküle möglich. Die blaue Verfärbung wird verursacht durch die DonorAkzeptor- Wechselwirkung zwischen dem Wasser und den Polyjodiden (KEUSCH, Download vom 17.01.05).

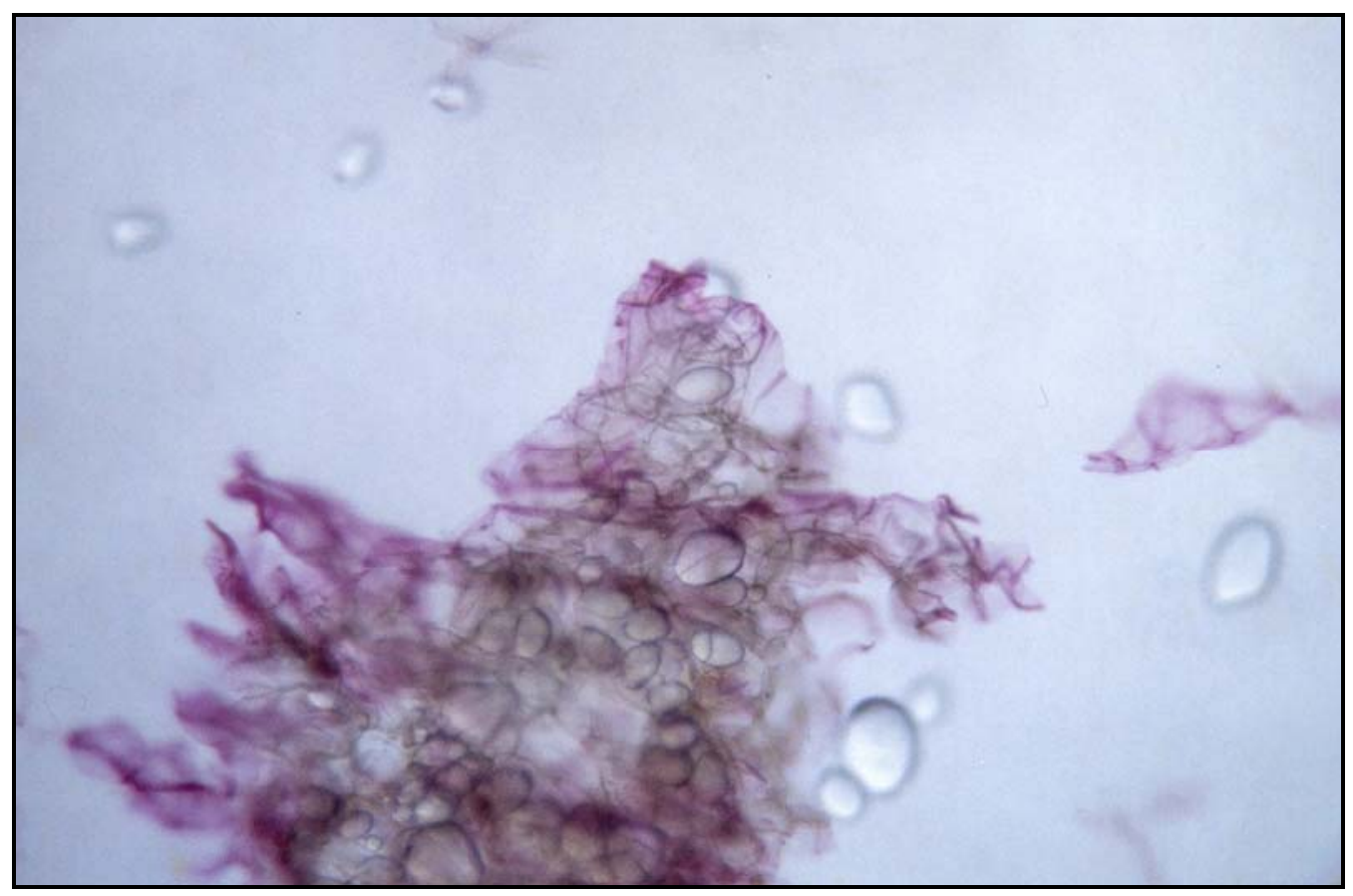

Abb. 4-5: 125-fache Vergrößerung nativer Kartoffelpülpe, eingefärbt mit Rutheniumrot 


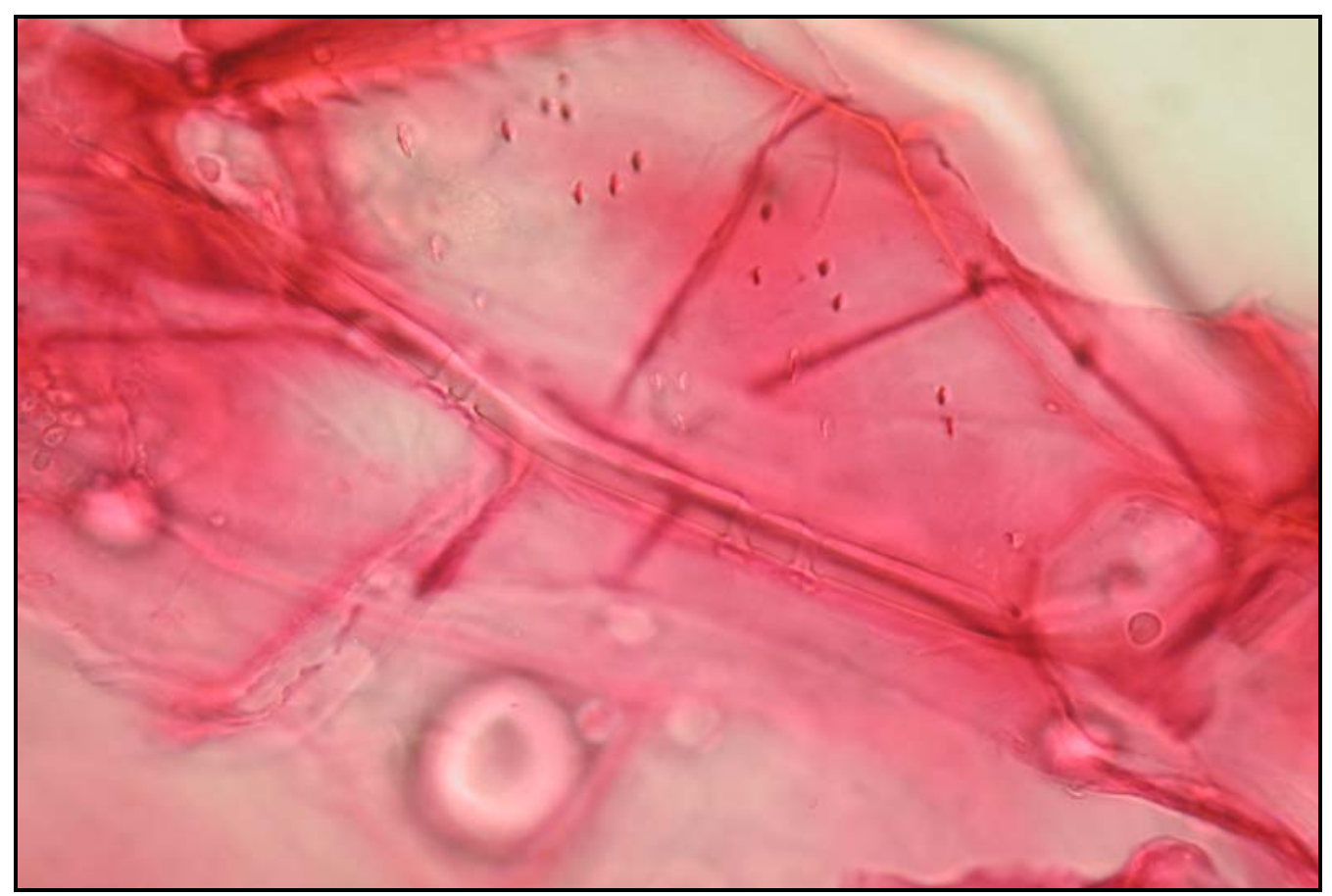

Abb. 4-6: 500-fache Vergrößerung von Pülpe mit gut sichtbaren Pektinanteilen in der Zellwand

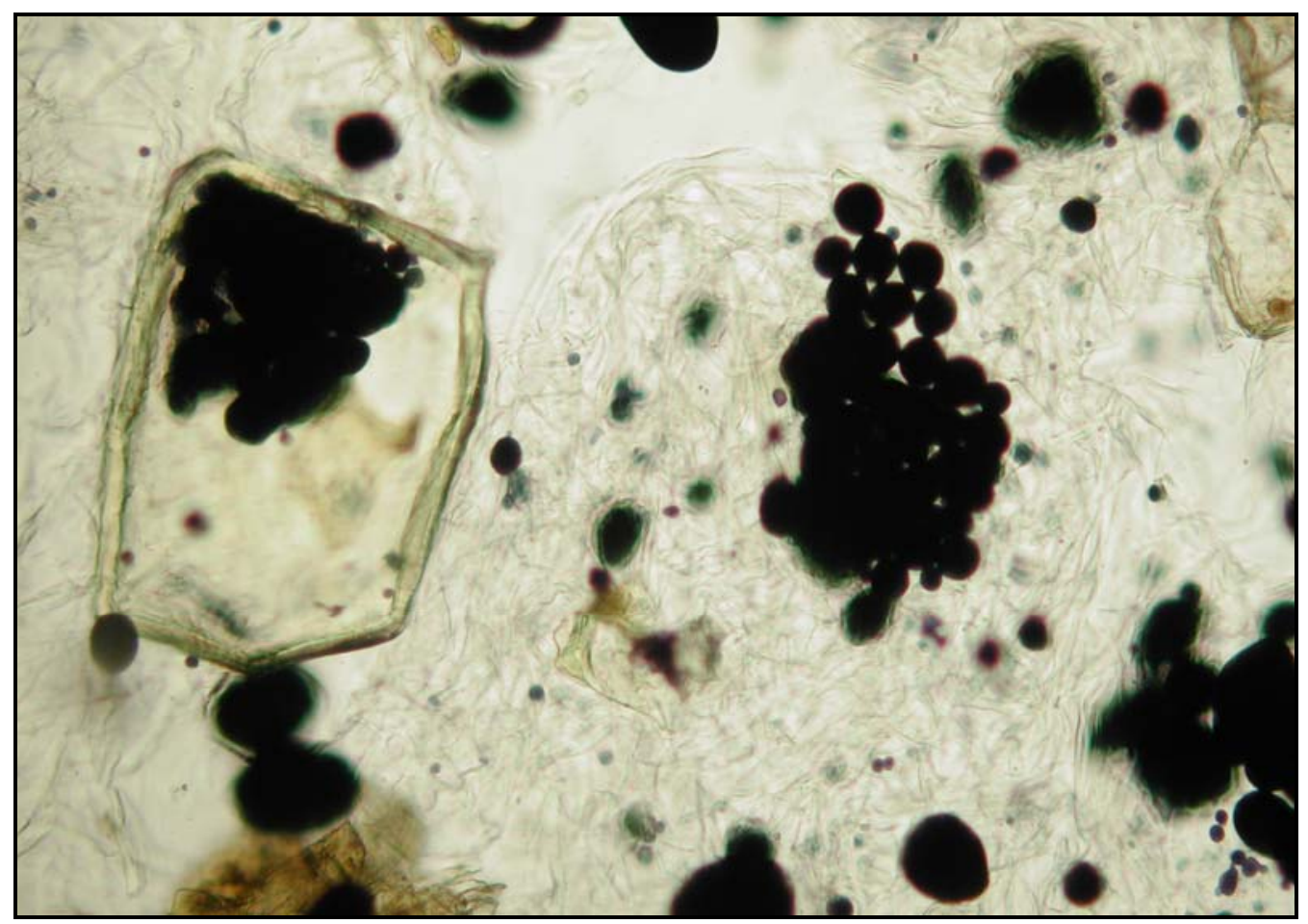

Abb. 4-7: 125-fache Vergrößerung nativer Kartoffelpülpe, mit eingefärbten Stärkekörnern 


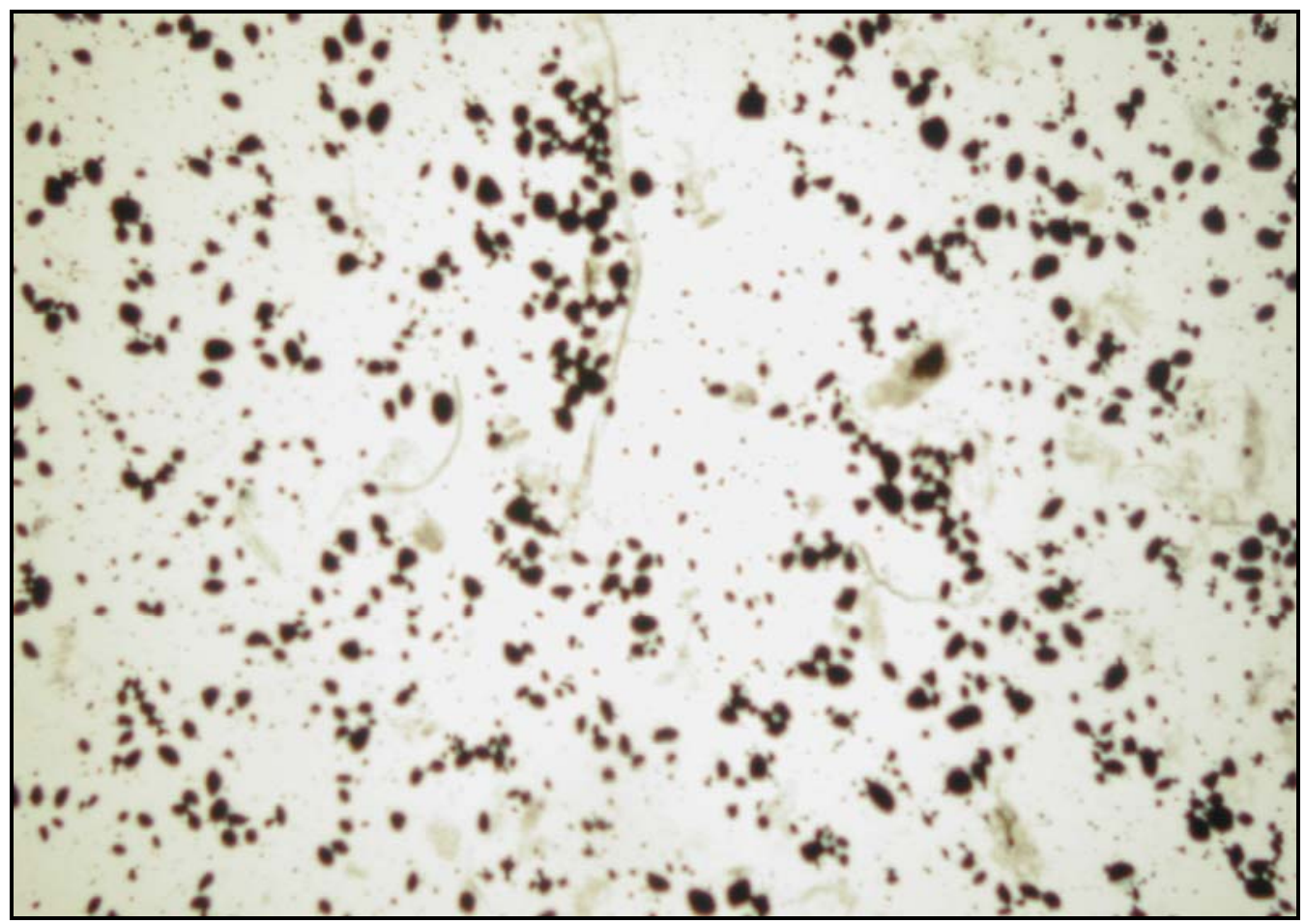

Abb. 4-8: 30-fache Vergrößerung nach dem mechanischenzymatischen Aufschluss der Pülpe

Durch eine Anfärbung der Stärkekörner mit Jodkaliumjodid wurde deutlich wie sich freie und zellgebundene Stärkekörner in der nativen Kartoffelpülpe verteilen. In Abb. 4-7 ist die zellgebundene Stärke deutlich zu erkennen. Zum großen Teil sind die Zellen des parenchymatischen Gewebes noch vollständig intakt und umschließen die Stärkekörner. Nach dem mechanisch-enzymatischen Aufschluss wurden viele der intakten Zellen zerstört und die Stärke wurde freigesetzt. In Abb. 4-8 sind neben der zellgebundenen Stärke deutlich freie, einzelne Stärkekörner zu erkennen. Anhand der Stärkeeinfärbung konnte bereits visuell ein Effekt des Aufschlusses auf die Zellstruktur nachgewiesen werden.

\subsubsection{Aufnahmen mit dem Rasterelektronenmikroskop}

Mit Hilfe des Rasterelektronenmikroskops war es möglich detaillierte Aufnahmen von der nativen Kartoffelpülpe zu bekommen. Diese Aufnahmen geben Aufschluss über den Aufbau der Zellen und der darin gebundenen Stärke. In der Abb. 4-9 sind deutlich Teile von intakten Zellwandstrukturen und in Zellen eingeschlossene Stärkekörner zu erkennen. Vereinzelt sind freie Stärkekörner in der Kartoffelpülpe verteilt. Die zellgebundene Stärke ist durch den Einschluss nicht verfügbar und somit beim Einsatz als Bindemittel nicht von Bedeutung. 


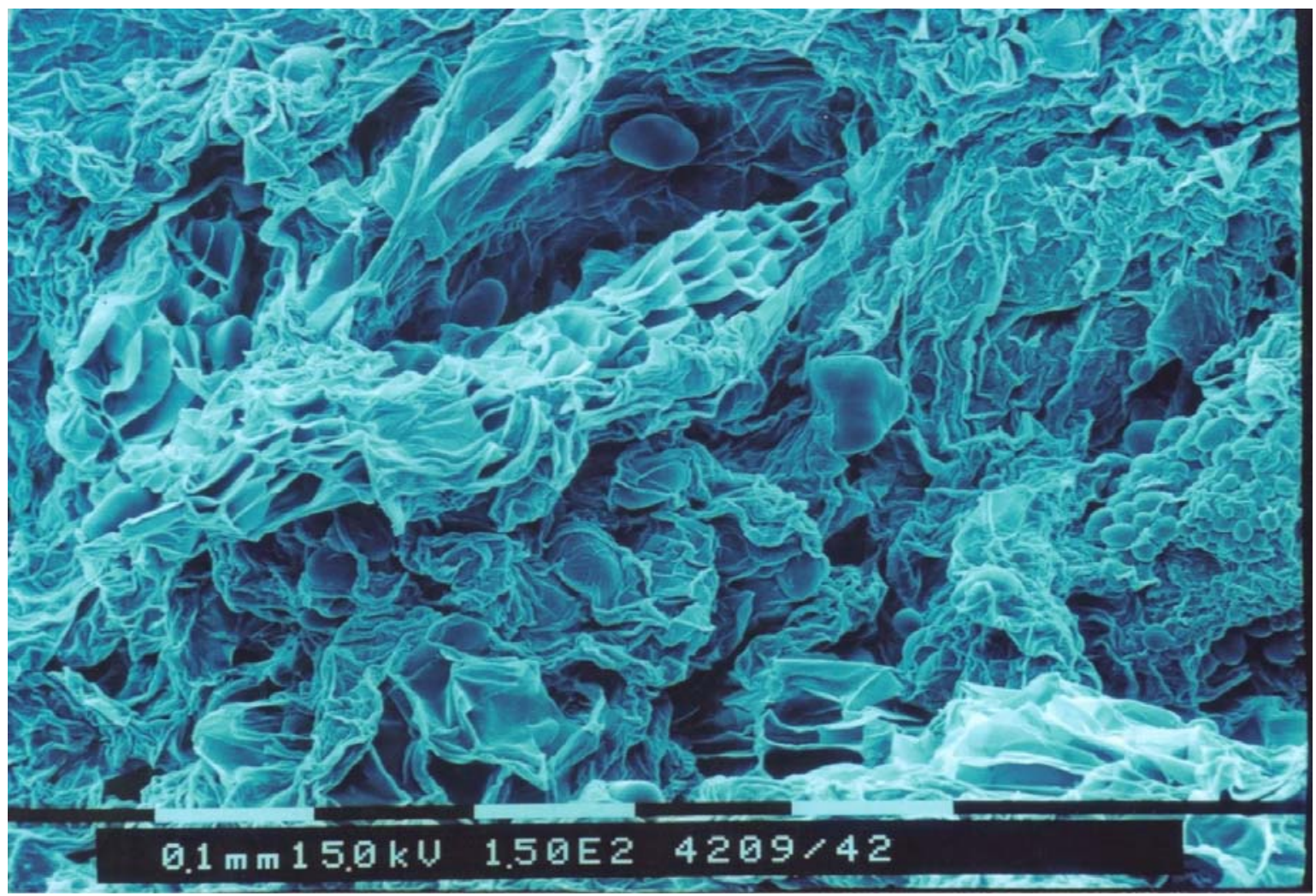

Abb. 4-9: Native Kartoffelpülpe mit deutlich erkennbaren Zellstrukturen bei einer 150-fache Vergrößerung

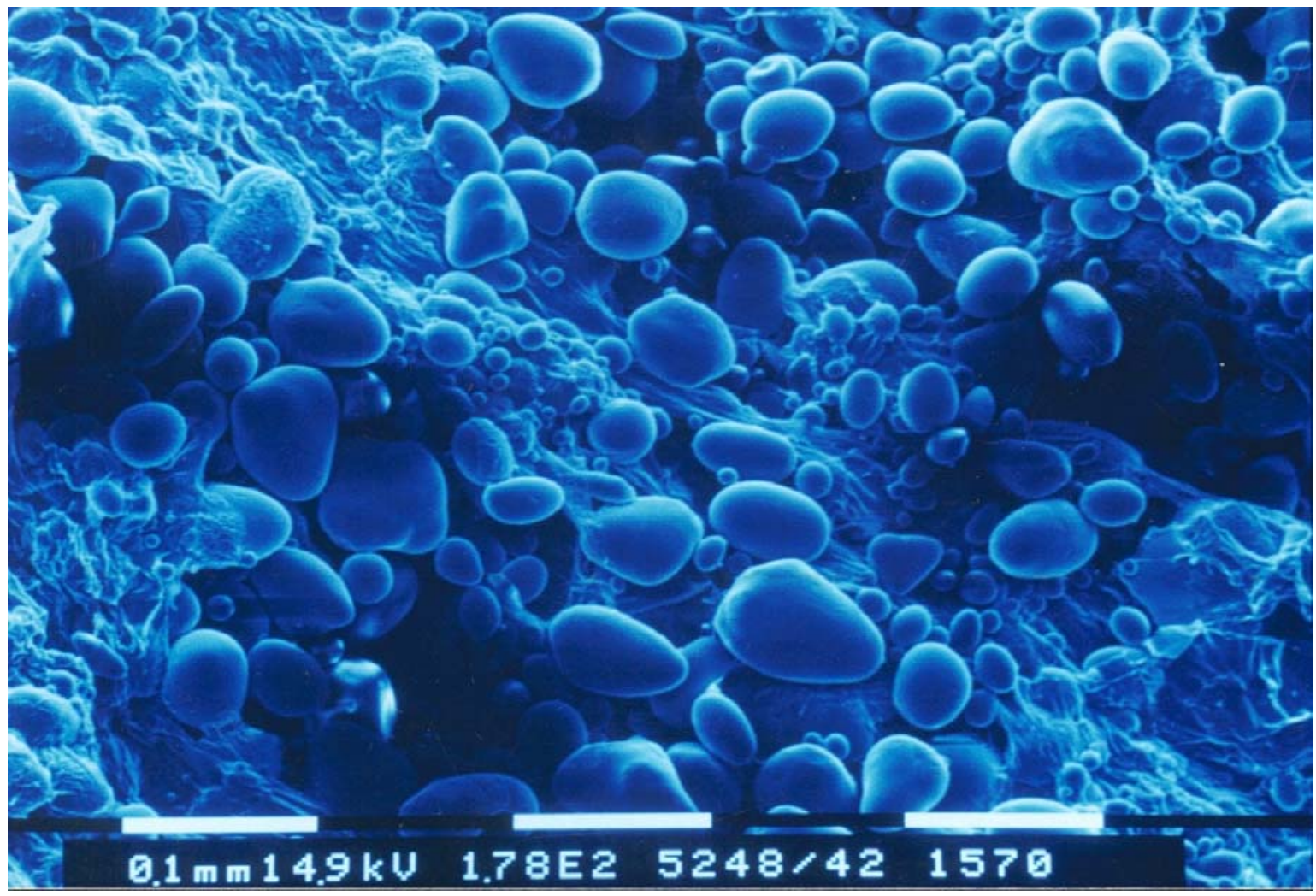

Abb. 4-10: Enzymatisch aufgeschlossene Kartoffelpülpe mit freien Stärkekörnern bei einer 178-fachen Vergrößerung 
Durch den mechanischen und enzymatischen Zellaufschluss soll diese Struktur zerstört und die Stärke freigesetzt werden. Die Aufnahme von Abb. 4-10 zeigt eine dementsprechend behandelte Kartoffelpülpe. Durch das Enzympräparat wurde der Zellverband der Pülpe so stark geschädigt, dass keine vollständigen Zellstrukturen mehr zu erkennen sind. Die Anzahl der freien Stärkekörner ist angestiegen, d. h. sie sind für die Bindung verfügbar. Dies bedeutet, dass die in der nativen Kartoffelpülpe reichlich vorhandene Stärke ohne mechanisch-enzymatische Vorbehandlung der Pülpe nicht verfügbar ist. Erst mit Hilfe von pektolytischen Enzympräparaten, welche die Zellwandstruktur auflösen, wird diese Stärke freigesetzt.

\subsection{Verfahren für den Aufschluss von Kartoffelpülpe}

\subsubsection{Mechanischer Aufschluss der Kartoffelpülpe}

Bei dem mechanischen Aufschluss wurde der Einfluss der Messergeschwindigkeit und der Zeit auf den Pülpeaufschluss untersucht. Die Untersuchungen fanden nach zwei bzw. vier Stunden mechanischen Aufschlusses statt.

Das Auszählen der Pülpezellen und ihrer Fragmente mit der THomA-Kammer erwies sich als relativ schwierig, da das definierte Volumen der Zählkammer von $1 \mathrm{~mm}^{3}$ für viele Teilchen der unbehandelten und der zweistündig behandelten Pülpe zu klein war. Dadurch konnten nur die kleineren Partikel der Pülpe in der THомAKammer ausgezählt werden. Durch das Auszählen zeigte sich allerdings ein deutlicher Unterschied in der Anzahl der Pülpeteilchen. Bereits nach 2 Stunden mechanischen Aufschlusses im Cutter konnte eine erhöhte Anzahl von Pülpepartikeln gezählt werden. Durch eine höhere Drehzahl der Cuttermesser erreichte man eine weitere Erhöhung der Teilchenanzahl. Nach vier Stunden wies die mechanisch behandelte Pülpe ca. 1,5-mal mehr Partikel auf als die native Pülpe.

Mit dem Netzmikrometer konnte die Größenbestimmung der Partikel relativ exakt durchgeführt werden. Da die Partikel eine sehr unregelmäßige Struktur aufwiesen, wurde immer die längste Ausdehnung als Messgrundlage angenommen. Auch hier konnte ein Effekt des mechanischen Aufschlusses anhand der Teilchengröße nachgewiesen werden. 
Tab. 4-1: Auswirkung des mechanischen Aufschlusses auf die Teilchengröße und Anzahl

Kartoffelpülpe $\quad$ Teilchengröße $[\mu \mathrm{m}] \quad$ Anzahl der Teilchen $/ \mathrm{mm}^{3}$

unbehandelt

$600-1500$

$1500-1800$

nach 2 h Cuttern

bei Stufe I [1400 rpm]

$500-1300$

$1700-2000$

nach 2 h Cuttern

bei Stufe II [2800 rpm]

$300-1000$

$1800-2100$

nach $4 \mathrm{~h}$ Cuttern

bei Stufe II

$300-700$

$2000-2500$

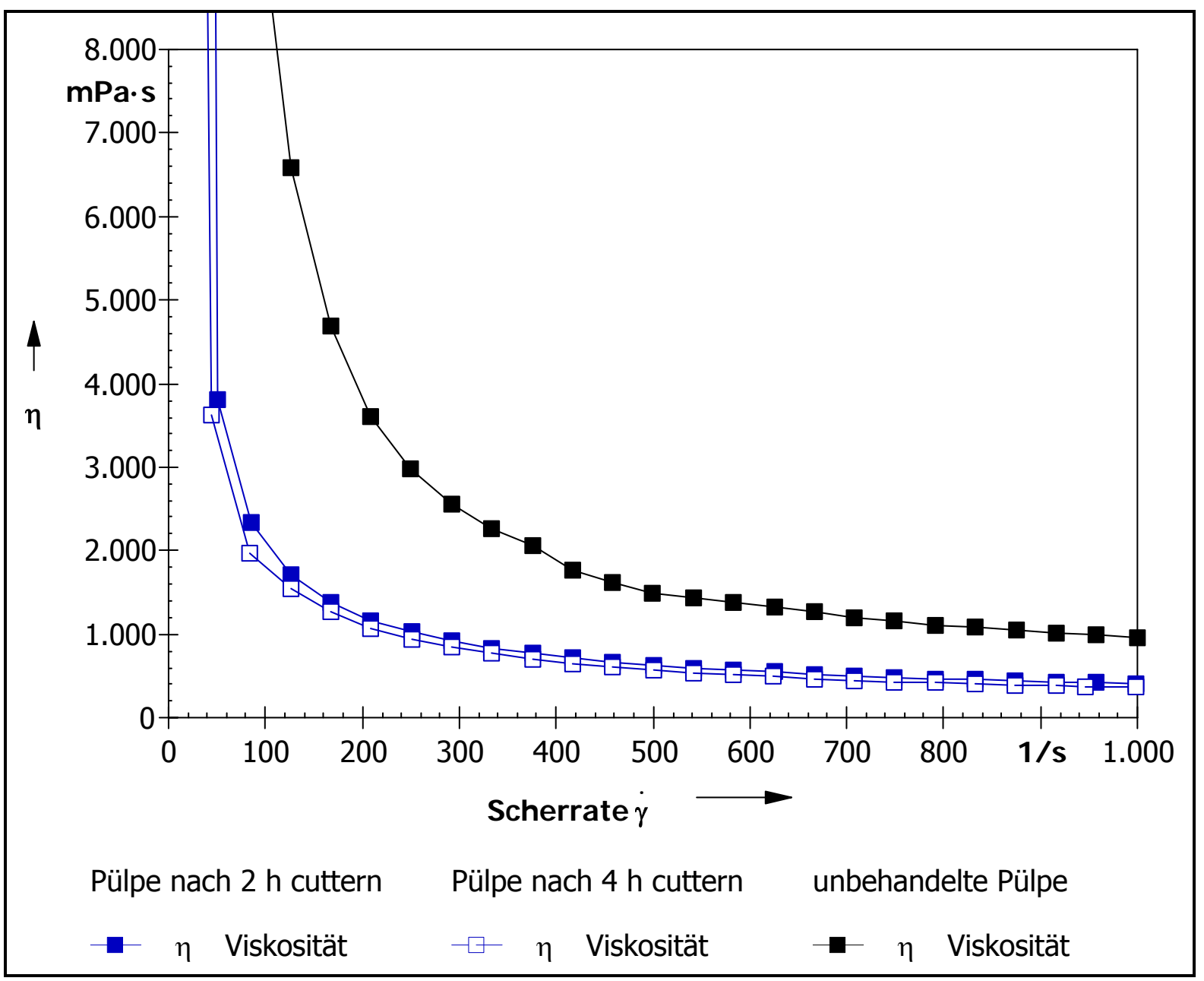

Abb. 4-11: Viskositätsmessung mechanisch aufgeschlossener Kartoffelpülpe 
Zusammenfassend kann man sagen, dass sich mit zunehmender Drehzahl der Messer und zunehmender Zeit des Aufschlusses die Teilchengröße verringerte und die Teilchenmenge zunahm (s. Tab. 4-1). Durch die mechanische Zerstörung der Zellstruktur in der Kartoffelpülpe konnte zellgebundenes Wasser freigesetzt werden, das wiederum Einfluss auf die Viskosität der Pülpe hat. Die Messungen der Viskosität mit dem Rotationsviskosimeter sind in der Abb. 4-11 dargestellt.

Kartoffelpülpe zeigt ein scherverdünnendes Fließverhalten, d. h. die Scherviskosität ist abhängig von der Höhe der Scherbelastung. Dadurch kommt das in der Abb. 4-11 aufgezeigte Kurvenverhalten zustande. Im Falle von scherverdünnenden Substanzen kann man keine eindeutige Aussage über die Viskosität des zu untersuchenden Stoffes machen. Die Viskosität ist immer in Abhängigkeit von der jeweiligen Scherrate und Temperatur zu nennen. Anhand des Kurvenverlaufes kann man erkennen, dass die unbehandelte Pülpe eine deutlich höhere Viskosität aufweist als die mechanisch aufgeschlossenen Proben.

Die Viskosität oder auch Zähigkeit eines Bindemittels ist für die Verarbeitung von großer Bedeutung. Bei der Beleimung wirken laufend Scherkräfte auf das Bindemittel ein, insbesondere bei der Leimzufuhr und in der Beleimungsdüse. Hierbei gilt: Je geringer die Viskosität, desto einfacher sind der Leimtransport und der Auftrag auf die Fasern. Ziel des mechanischen Aufschlusses ist es daher, durch eine Zerstörung der Zellen das zellgebundene Wasser und die Stärke freizusetzen und die Viskosität herabzusetzen. Durch die Zerteilung der Zellwände werden zusätzlich kleinere Pektinpartikel geschaffen. Diese Effekte werden durch den mechanischen Aufschluss zwar begünstig, sind für den Einsatz als Bindemittel allerdings noch nicht ausreichend, so dass ein enzymatischer Zellaufschluss notwendig ist.

\subsubsection{Aufschluss der Kartoffelpülpe mit Hilfe von Enzymkomplexen}

Der Einsatz von unterschiedlichen Enzympräparaten sollte Unterschiede in der Wirkungsweise dieser Enzymkomplexe aufzeigen. Anhand des Entwässerungsgrades konnten die spezifischen Wirkungsweisen verdeutlicht werden. Zu diesem Zweck wurden die Proben für vier Stunden im Wasserbad bei $45^{\circ} \mathrm{C}$ mit der jeweiligen Enzymmenge inkubiert (vgl. Kap. 3.3.3.2).

Wie in der Abb. 4-12 ersichtlich, zeigen die verwendeten Enzymkomplexe der Firma Novozymes sowohl bei unterschiedlichen Pülpesorten als auch unterschiedlichen Enzymmischungen keine deutlichen Unterschiede. Bei der Verwendung von $5 \%$ Enzymlösung (w/w) war der Entwässerungsgrad insgesamt etwas geringer. Eine 
Tendenz ist dahingehend, dass das Ultrazym AFP $L$ die beste Wirkungsweise hat, gefolgt von Pectinex, wobei leichte Unterschiede zwischen den beiden Pülpesorten zu erkennen sind. Wahrscheinlich wird diese Wirkung durch eine Kombination von pektolytischen und cellulolytischen Enzymen hervorgerufen. Ähnliche Ergebnisse hatte bereits DONGOWSKI (1993) mit Kombipräparaten erzielt.

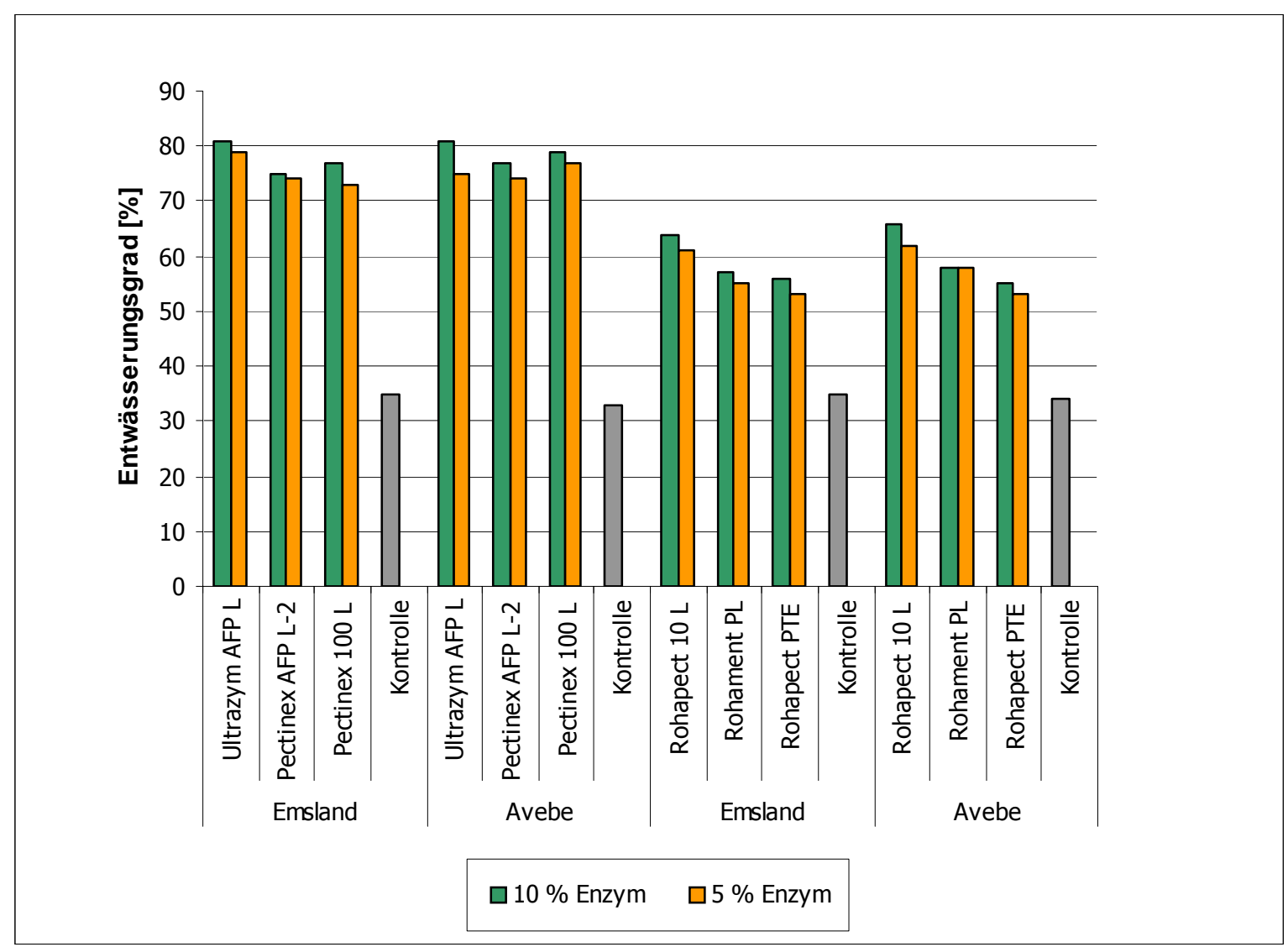

Abb. 4-12: Entwässerungsgrad von AVEBE- und Emslandpülpe nach dem enzymatischen Aufschluss mit unterschiedlichen Enzymkomplexen der Firmen Novozymes und AB Enzymes. die Kontrolle bestand aus nativer Kartoffelpülpe

Der Einsatz der Enzymkomplexe der Firma $A B$ Enzymes zeigte innerhalb der unterschiedlichen Pülpesorten keine signifikanten Unterschiede beim Entwässerungsgrad. Die effektivste Entwässerung wurde mit dem Präparat Rohapect $10 \mathrm{~L}$ erreicht. Am unzweckmäßigsten erwies sich die Enzymlösung Rohapect PTE. Der Grund für die geringere Entwässerung liegt wahrscheinlich an den verwendeten Enzymen, die das Pektin auf transelimativen Weg ohne vorherige Entesterung spalten.

Alle Kontrollproben, die ohne enzymatische Vorbehandlung zentrifugiert wurden, zeigten nur einen geringen Entwässerungsgrad und verdeutlichten wie schwierig 
eine Entwässerung der nativen Pülpe ist. Beim Vergleich der Novozymes- und $A B$ Enzymes-Präparate erreichten die Novozymes-Produkte einen höheren Entwässerungsgrad, so dass im Folgenden nur diese Enzymlösungen eingesetzt wurden.

\subsubsection{Pülpezerkleinerung mit dem Hochdruckhomogenisator}

Ursprünglich setzte man Hochdruckhomogenistoren in der Molkereitechnik zum Aufrahmen von Milch ein. Mittlerweile finden sie Einsatz in der Lebensmitteltechnik und Chemie sowie beim Zellaufschluss von Mikroorganismen. Daher lag eine Anwendung beim mechanischen Aufschluss der Pülpe nahe.

Die bereits mechanisch und enzymatisch aufgeschlossene Kartoffelpülpe sollte mit Hilfe eines Hochdruckhomogenisators noch weiter zerkleinert werden. Die erwünschten Effekte waren eine Verringerung der Viskosität und eine verstärkte Freisetzung des zellgebundenen Wassers.

Tab. 4-2: Bezeichnung der Proben, die mit unterschiedlichem Druck im Hochdruckhomogenisator zerkleinert wurden

\begin{tabular}{ccccccccc}
\hline Proben & $\mathrm{a}$ & $\mathrm{b}$ & $\mathrm{c}$ & $\mathrm{d}$ & $\mathrm{e}$ & $\mathrm{f}$ & $\mathrm{g}$ & Kontrolle \\
\hline $\begin{array}{l}\text { Druck } \\
\text { [bar] }\end{array}$ & 600 & 700 & 800 & 900 & 1000 & 1300 & 1500 & unbehandelt \\
\hline
\end{tabular}

Die Abb. 4-13 zeigt, dass die Teilchengröße der untersuchten Kartoffelpülpe wie erwartet mit zunehmendem Druck (vgl. Abschnitt 3.3.3.3) des Homogenisators abnimmt. Der Unterschied zwischen den Proben, die mit verschiedenen Drücken (s. Tab. 4-2) aufgeschlossen wurden ist allerdings nicht signifikant. Trotzdem kann man davon ausgehen, dass sich bei zunehmendem Druck und damit ansteigender Zerkleinerungsenergie die Anzahl der aufgeschlossenen Zellen vergrößert. Im Vergleich mit der Kontrolle zeigte sich deutlich, dass eine Probenzerkleinerung stattgefunden hat. Für eine Anwendung im labortechnischen Maßstab war der Durchfluss ausreichend. Es gibt aber auch Geräte für den Produktionsbetrieb mit Durchsatzraten von einigen Kubikmetern. Daher wäre eine Anwendung im großtechnischen Bereich durchaus möglich.

Der Einsatz eines Hochdruckhomogenisators zum weiteren Aufschluss der behandelten Pülpe erscheint sinnvoll, insbesondere hinsichtlich der weiteren Verwendung als Bindemittel. Da die Pülpe bei der Verwendung als Bindemittel beim 
Prozess der Beleimung durch eine Düse mit geringem Querschnitt gepresst wird, sollte die Teilchengröße möglichst gering sein.

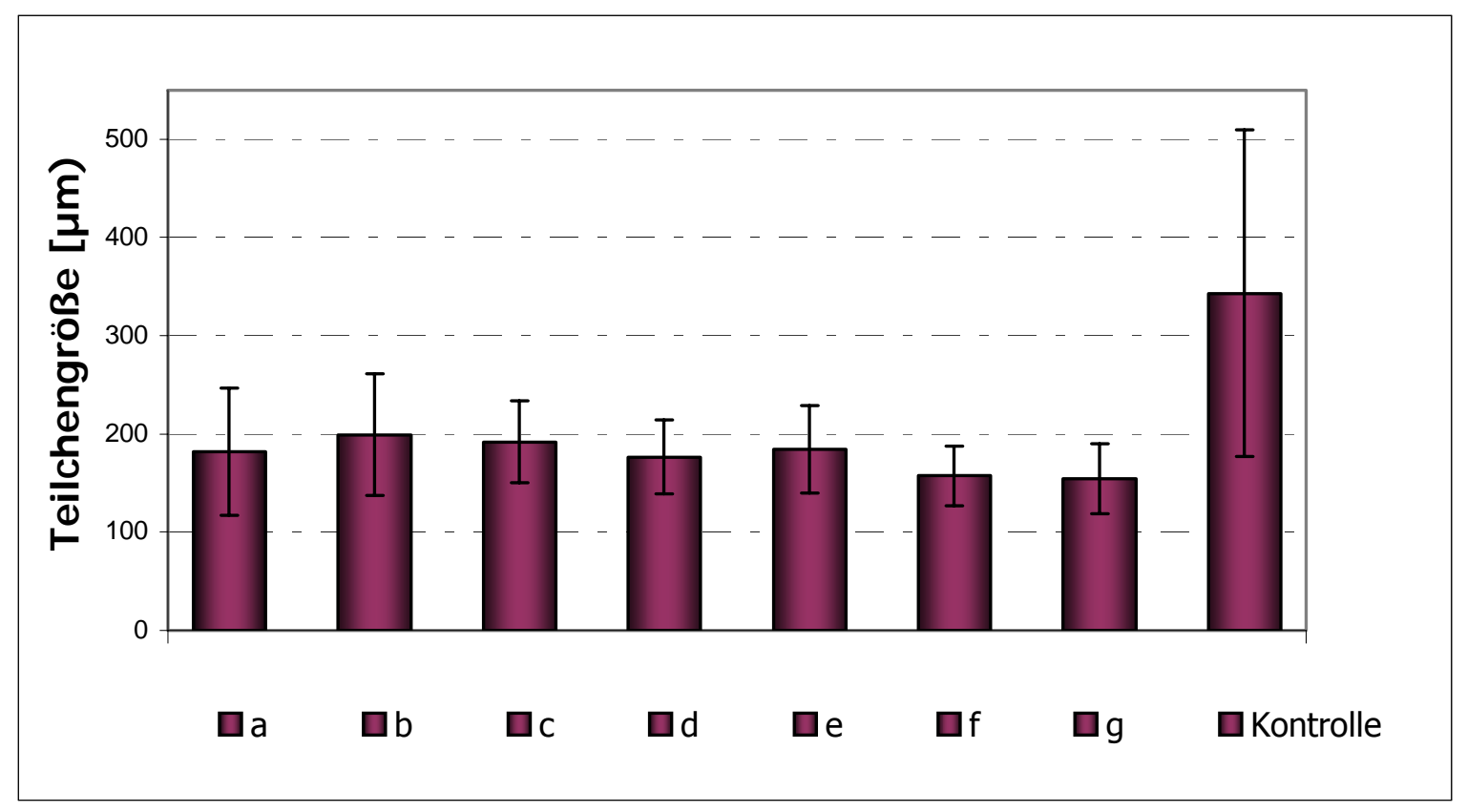

Abb. 4-13: Relative Teilchengröße der Pülpe nach dem Aufschluss mit dem Hochdruckhomogenisator der Fa. Niro Soavi

\subsection{Methoden zur Trocknung der mechanisch-enzymatisch aufgeschlossenen Kartoffelpülpe}

\subsubsection{Mechanische Vorentwässerung durch Westfalia-Separatoren}

Separatoren sind Zentrifugen, die verwendet werden um Feststoffe aus Flüssigkeiten zu separieren oder Flüssigkeitsgemische bei gleichzeitiger Feststoffabschleuderung zu trennen. Die Anwendungsgebiete von Separatoren liegen in der Getränke- bzw. Saftherstellung, Molkereien, der Chemie- und Pharmaindustrie, der Biotechnologie und Umwelttechnik. Auch in der Stärkeindustrie werden Separatoren bzw. Dekanter eingesetzt. Dadurch lag es nahe, bei der Entwässerung der mechanisch-enzymatisch aufgeschlossenen Pülpe die Technik der Separatoren zu nutzen.

Die Schleuderung der enzymatisch aufgeschlossenen Pülpe brachte nicht die erwünschten Resultate (s. Tab. 4-3). Ziel der Entwässerung war es, den Feststoffgehalt der Pülpe zu erhöhen. Die enzymatisch aufgeschlossene Pülpe war 
schlecht aufkonzentrierbar und es gab fast keine Feststofferhöhung. Dieses Verfahren ist in der Form nicht einsetzbar, allerdings gab die Westfalia Separator AG die Empfehlung, für eine Aufkonzentrierung auf 20 - $30 \%$ Feststoff Dekanter einzusetzen.

Tab. 4-3: Aufkonzentrierung der Pülpe durch Separatoren

\begin{tabular}{|c|c|c|c|c|}
\hline upm & $\begin{array}{c}\text { Temperatur } \\
\text { der Proben } \\
\left({ }^{\circ} \mathrm{C}\right)\end{array}$ & $\begin{array}{c}\text { Schleuderzeit } \\
\text { (min) }\end{array}$ & Überstand & $\begin{array}{c}\text { Feststoffe } \\
\text { (Vol. \% ) }\end{array}$ \\
\hline \multirow{6}{*}{6000} & \multirow{3}{*}{20} & 0,5 & $\begin{array}{l}\text { leicht trübe } \\
\text { Wasserphase }\end{array}$ & 56 \\
\hline & & 1 & $\begin{array}{l}\text { leicht trübe } \\
\text { Wasserphase }\end{array}$ & 47 \\
\hline & & 2 & $\begin{array}{l}\text { leicht trübe } \\
\text { Wasserphase }\end{array}$ & 47 \\
\hline & \multirow{3}{*}{50} & 0,5 & $\begin{array}{c}\text { fast blanke } \\
\text { Wasserphase }\end{array}$ & 57 \\
\hline & & 1 & $\begin{array}{c}\text { fast blanke } \\
\text { Wasserphase }\end{array}$ & 50 \\
\hline & & 2 & $\begin{array}{c}\text { blanke } \\
\text { Wasserphase }\end{array}$ & 47 \\
\hline
\end{tabular}

\subsubsection{Trocknung durch Vakuumgefriertrocknung}

Das Ziel der Gefriertrocknung ist, ein sehr leicht wasserlösliches Produkt zu erhalten, das nach Hinzufügen von Wasser die Eigenschaften des Ausgangsgutes unverändert aufweist. Das getrocknete Gut kann sich allerdings während der Lagerung verändern. Beeinflusst werden diese Veränderungen durch die Restfeuchte, die Temperatur und die Gaszusammensetzung, mit dem die Vakuumkammer am Ende der Trocknung geflutet wird (OETJEN, 1997).

Bei der Trocknung der Pülpe wurde die Kammer mit $\mathrm{N}_{2}$ geflutet. Dagegen konnte die weitere Lagerung der getrockneten Pülpe aufgrund ökonomischer Aspekte nicht im Stickstoff stattfinden. Die Pülpe wurde anschließend bei Raumluft in verschlossenen Gefäßen gelagert. Die gefriergetrocknete Pülpe wies nach 14 Tagen Lagerung eine Restfeuchte von ca. 7 \% auf, was der Ausgleichsfeuchte entspricht und hatte eine pulverige Konsistenz. Anders als bei der Trocknung im 
Trockenschrank hatte sich das Volumen und die Farbe der Pülpe nicht verändert (s. Abb. 4-14).

Überprüft wurden die Wasserwiederaufnahme und die Löslichkeit. Durch Zugabe von Wasser konnte sie wieder in ihren vorherigen Zustand überführt und als Bindemittel eingesetzt werden.

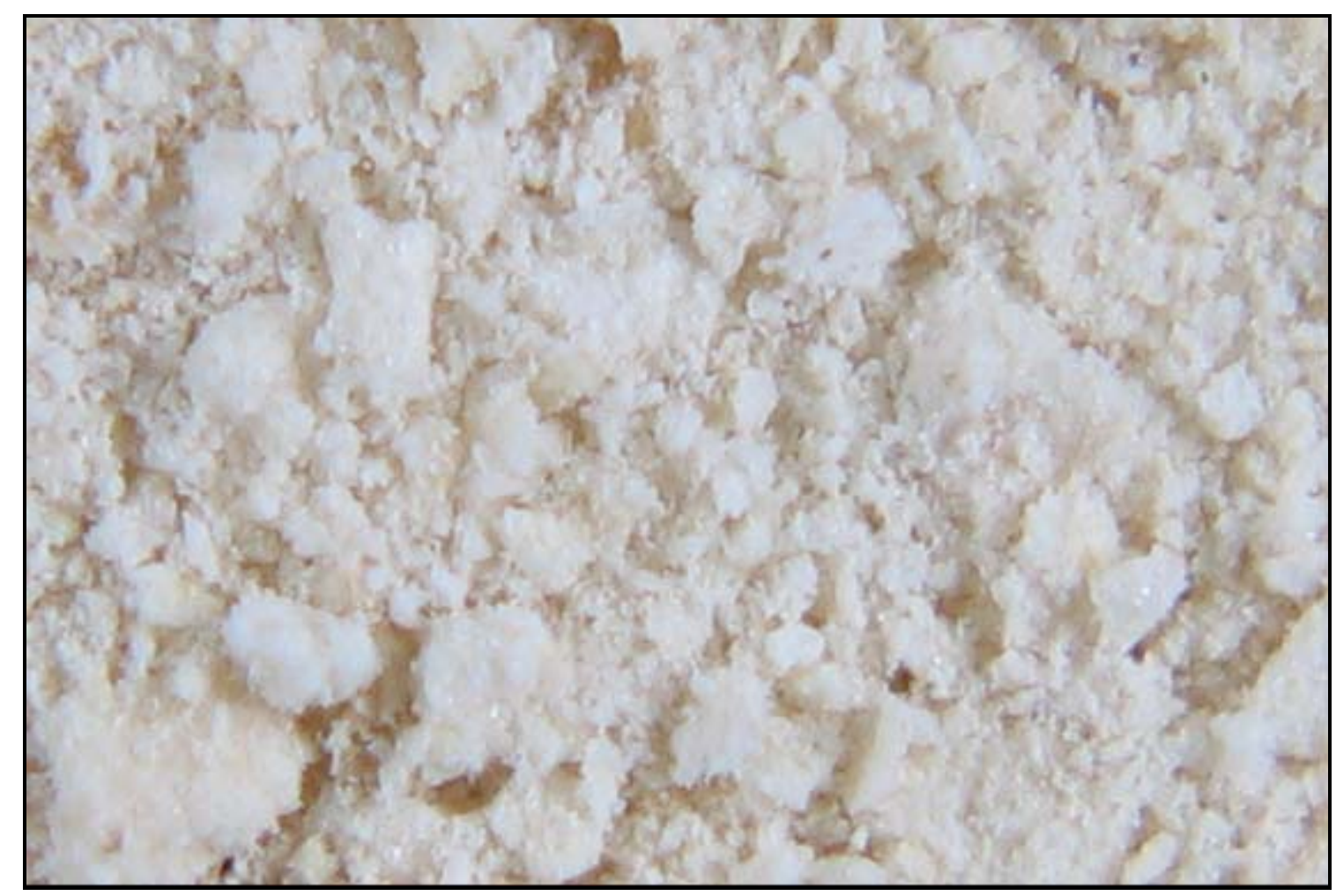

Abb. 4-14: Struktur der gefriergetrockneten mechanisch-enzymatisch aufgeschlossenen Kartoffelpülpe

Die Methode der Gefriertrocknung wird häufig eingesetzt bei Produkten, die sehr empfindlich gegenüber Wärme sind und in ihrer ursprünglichen Form erhalten bleiben sollen. Häufige Verwendung findet sie in der Pharma- und Lebensmittelindustrie. Der Vorteil dieser Methode ist die schonende Trocknung des Gutes. Allerdings ist die Gefriertrocknung mit hohen Kosten verbunden und daher für den Einsatz bei der Pülpetrocknung bedenklich.

\subsubsection{Trocknung mit der Wirbelschicht-Sprühgranulation}

Die Wirbelschicht-Sprühgranulation ist ein Verfahren, das in vielen Bereichen der pharmazeutischen, chemischen, Lebensmittel- sowie Futtermittelindustrie 
eingesetzt wird. Sie wird auch bei der Trocknung empfindlicher Produkte eingesetzt, da der Trocknungsvorgang relativ gut gesteuert werden kann.

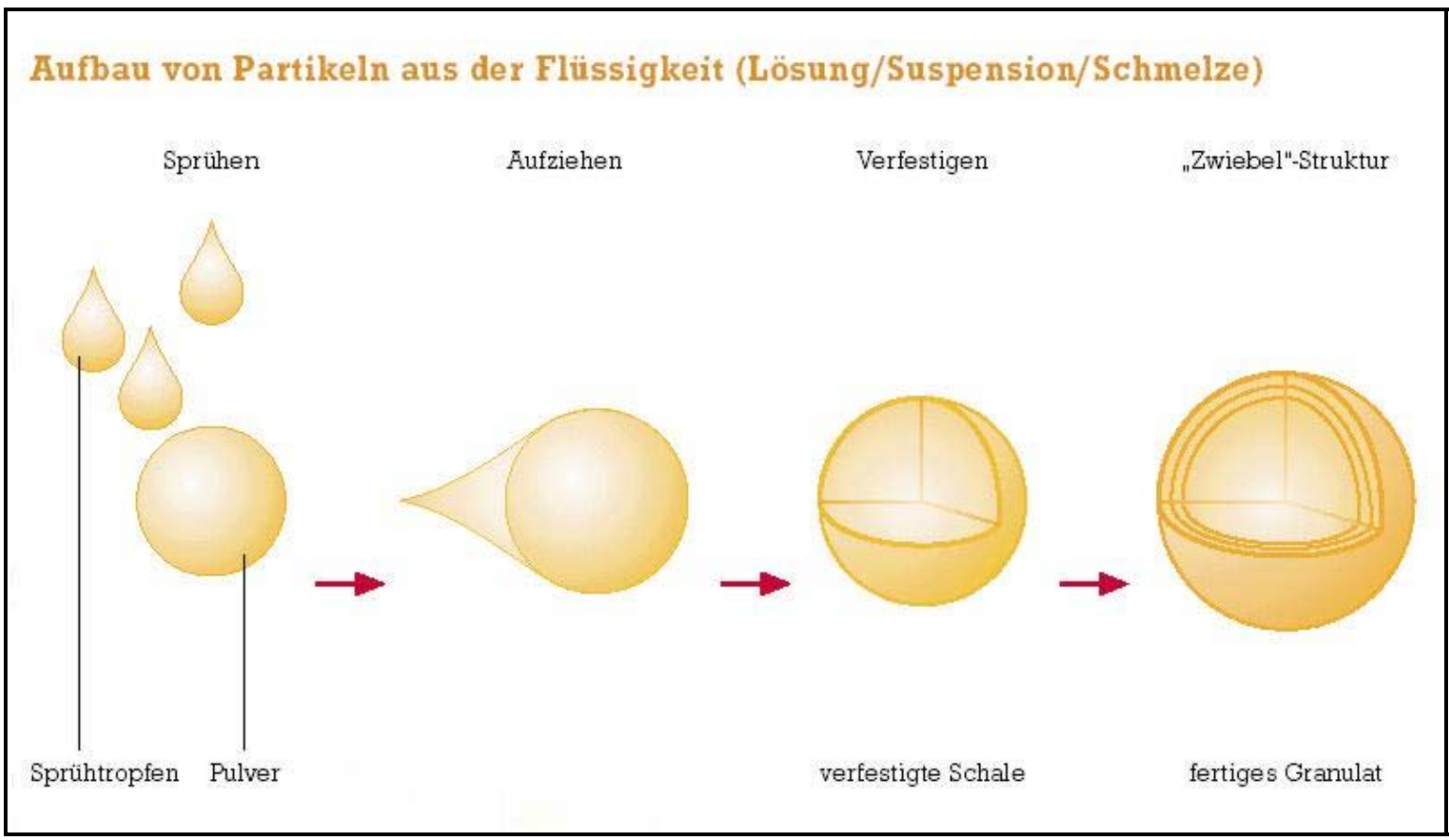

Abb. 4-15: Prinzip der Sprühgranulation bei der Trocknung von Flüssigkeiten (GLATT, 2003)

Mit dieser Methode ist es möglich, die Kartoffelpülpe schonend zu trocknen und dadurch einen lagerfähigen Zustand zu erreichen. Bereits MAYER (1996) hatte mechanisch aufgeschlossene Kartoffelpülpe mit Hilfe von Sprühgranulation getrocknet, wobei das angewendete Verfahren sich von der WirbelschichtSprühgranulation deutlich unterscheidet. Anders als bei MAYER wurde bei dieser Trocknung Maisstärke als Trägerstoff eingesetzt, an den sich die Partikel der Pülpe während der Trocknung anlegten (s. Abb. 4-15). Durch die Verwendung der Maisstärke ergab sich ein Vorteil, da somit der Stärkegehalt der Pülpe indirekt erhöht wurde. Durch die geringe Wärmezufuhr während der Trocknung der mechanisch-enzymatisch aufgeschlossenen Kartoffelpülpe wurde eine Karamellisierung an der Oberfläche der Granulate vermieden. In Abb. 4-16 ist deutlich die rundliche Form der getrockneten Pülpepartikel zu erkennen. Teilweise liegen die freien Stärkekörner gut sichtbar an der Oberfläche der Granulate. 


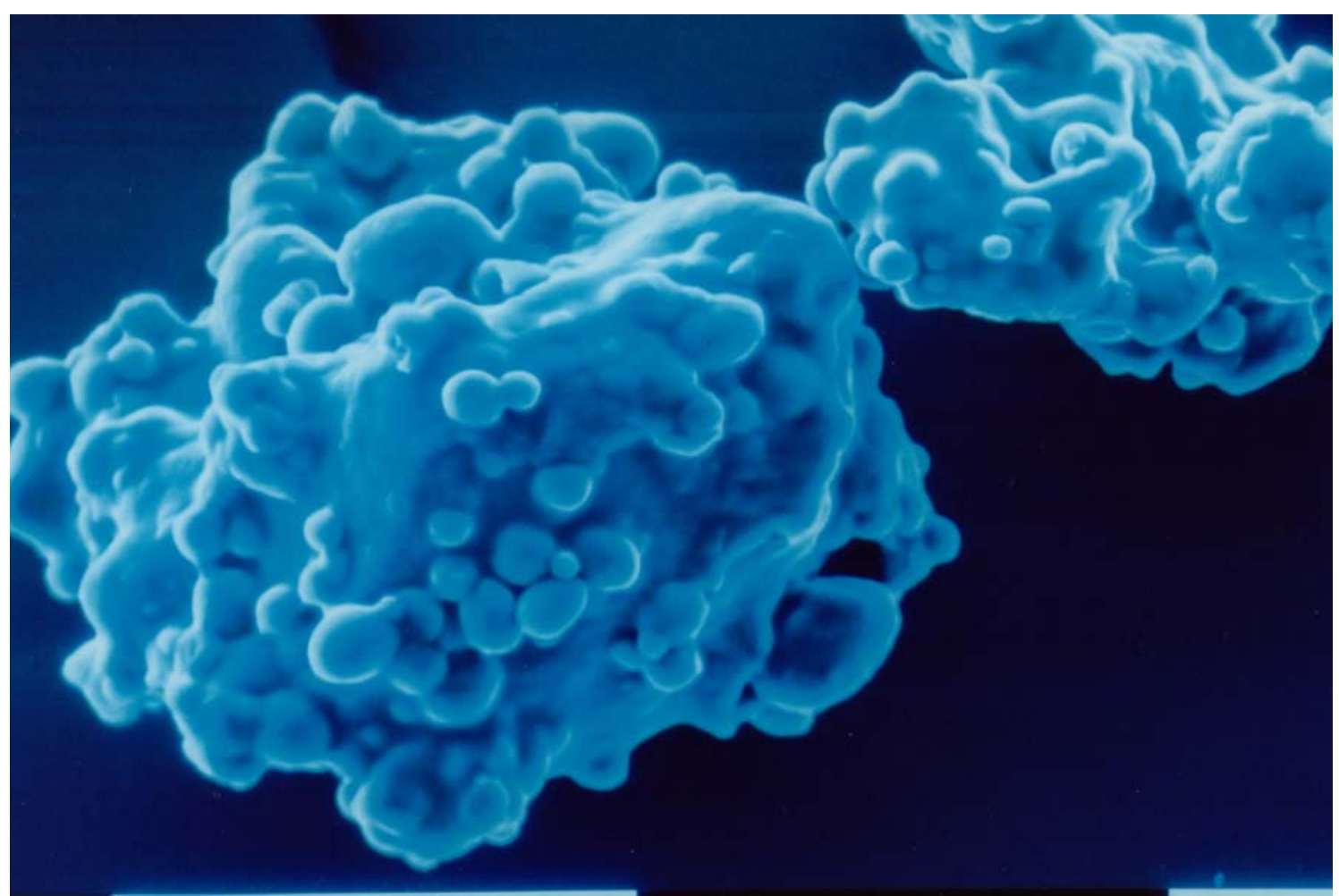

Abb. 4-16: 400-fache Vergrößerung von mechanisch-enzymatisch aufgeschlossener Pülpe, die mit der Wirbelschicht-Sprühgranulation getrocknet wurde

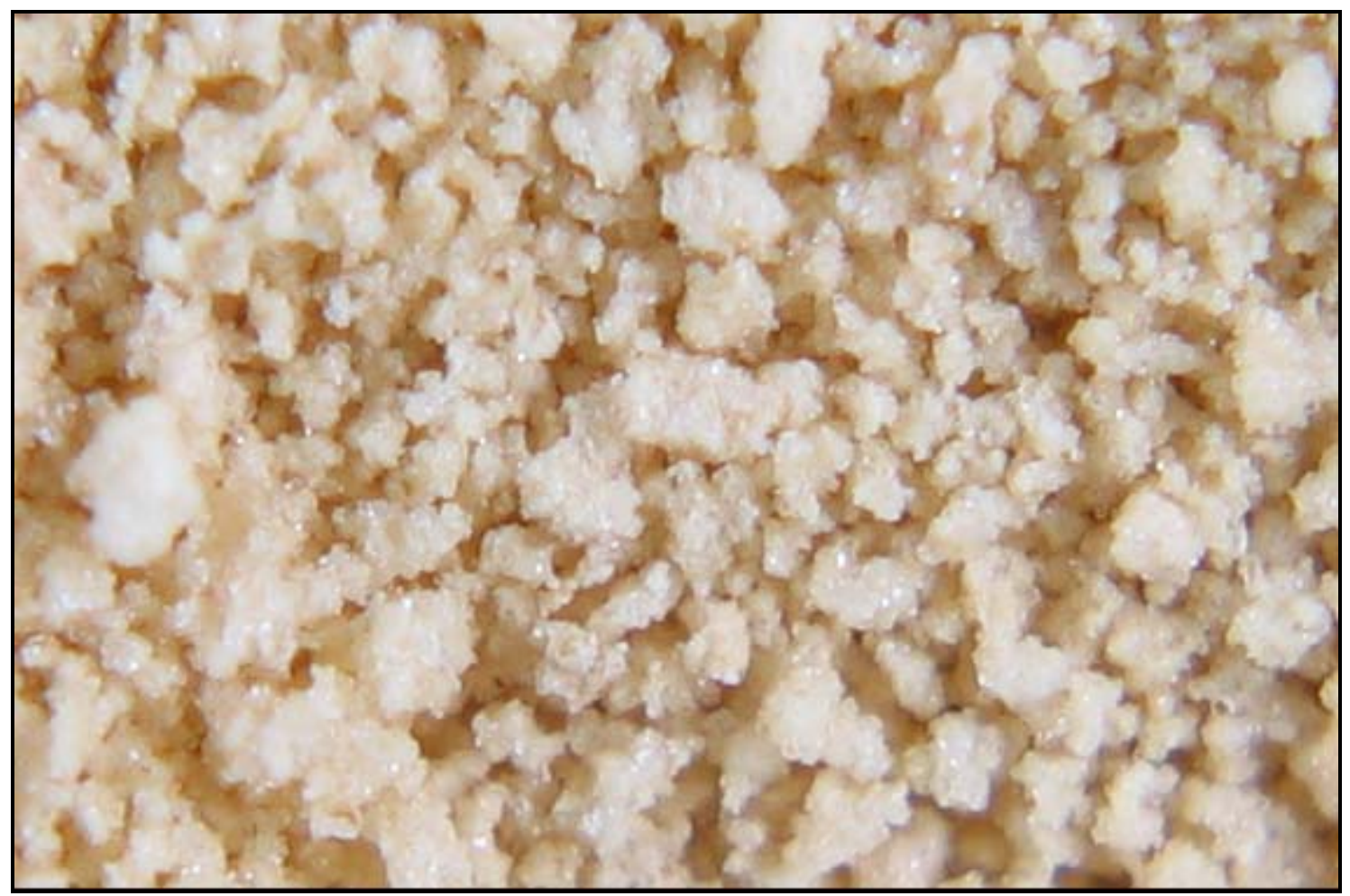

Abb. 4-17: Struktur der mechanisch-enzymatisch aufgeschlossenen Kartoffelpülpe nach der Wirbelschicht-Sprühgranulation 
Das Granulat (s. Abb. 4-17) zeigte bei einem Feuchtigkeitsgehalt von $10 \%$ gutes Schüttverhalten. Vereinzelt kam es zu leichten Verklumpungen, die sich aber bei geringem Druck wieder problemlos auflösten. Die Farbe des Granulates war, bedingt durch den Wärmeeinfluss bei der Trocknung, im Vergleich zur gefriergetrockneten Pülpe dunkler. Nach Zugabe von Wasser bekam die Pülpe wieder eine pastöse Struktur ohne nennenswerte Verklumpungen. Hinsichtlich der schonenden Trocknung und der geringen Energiezufuhr eignet sich die Wirbelschicht-Sprühgranulation gut für die Trocknung der mechanisch-enzymatisch aufgeschlossenen Kartoffelpülpe.

\subsection{MDF-Platten hergestellt mit mechanisch-enzymatisch aufgeschlossener Kartoffelpülpe als Bindemittel}

Für Herstellung der mitteldichten Faserplatten musste der Feststoff der mechanisch-enzymatisch aufgeschlossenen Kartoffelpülpe immer wieder neu bestimmt werden, zur Berechnung der korrekten Beleimung. Ebenso erfolgten Viskositätsmessungen der jeweiligen Bindemittelmischungen. Anschließend wurden die Bindemittel zur Beleimung der Fasern eingesetzt. Nach der Fertigung und Konditionierung der MDF-Platten wurden diese nach der EN 622-5 hinsichtlich ihrer physikalisch-technologischen Eigenschaften überprüft.

\subsubsection{Feststoffänderung nach dem mechanisch-enzymatischen Aufschluss}

Ein Grund für den Einsatz des mechanisch-enzymatischen Aufschlusses war die Erhöhung des Feststoffanteils durch Zerschlagen bzw. Auflösung der intakten Zellwände. In der Abb. 4-18 ist die Erhöhung des Feststoffgehaltes dargestellt. Demzufolge erhöhte sich der Feststoffgehalt durchschnittlich um $2 \%$. Eine Feststofferhöhung durch den enzymatischen Aufschluss hat nachweisbar stattgefunden und bestätigt die Ergebnisse von SLOMINSKA und STAROGARDZKA (1987), die ebenfalls mit einem Multienzym-Komplex gearbeitet haben und eine Feststofferhöhung nachweisen konnten. 


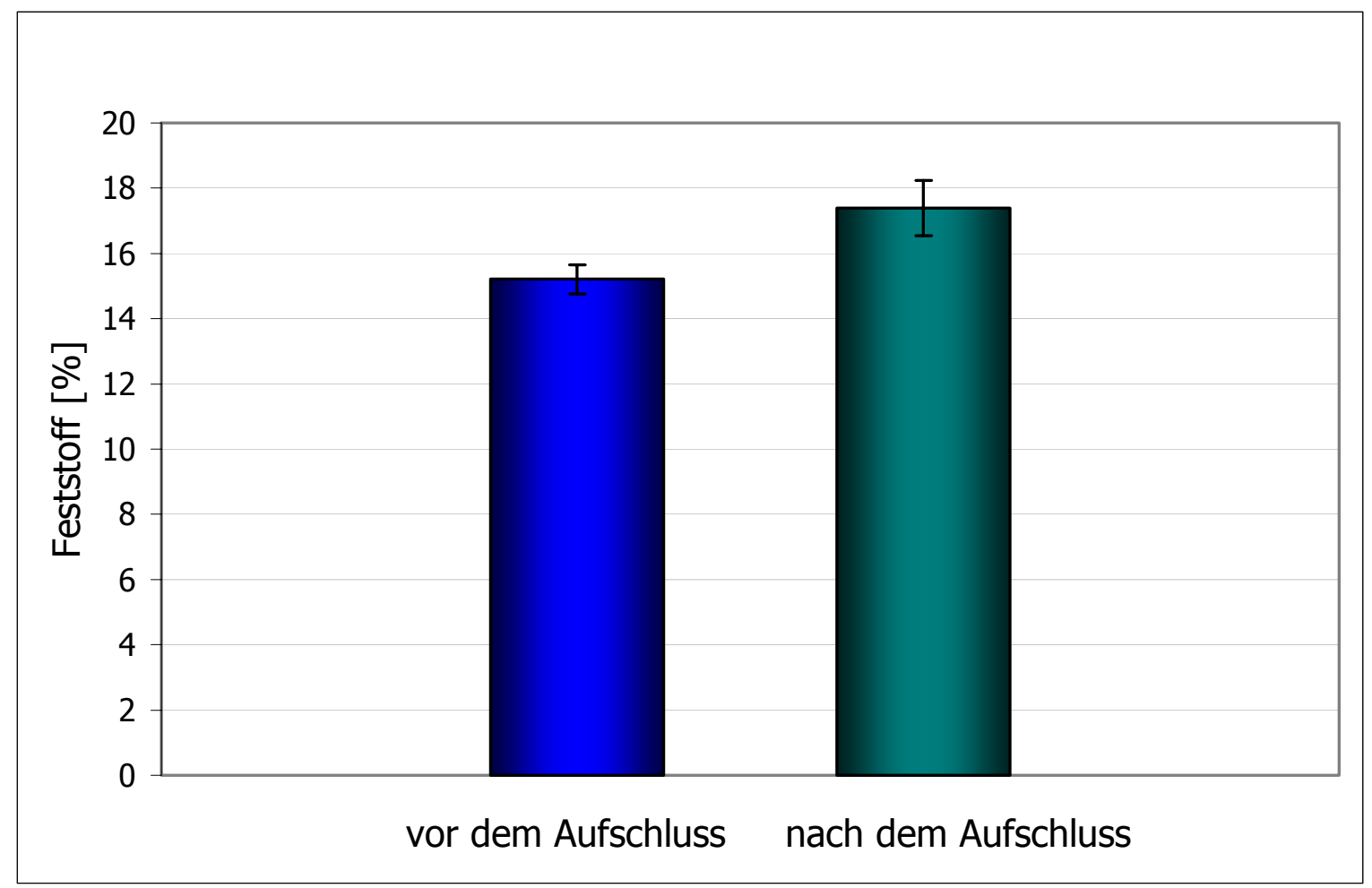

Abb. 4-18: Vergleich der Kartoffelpülpe hinsichtlich des Feststoffgehaltes vor und nach dem mechanisch-enzymatischen Aufschluss

Das Ergebnis zeigt den insgesamt positiven Einfluss des Aufschlusses auf die Erhöhung des Feststoffes. Allerdings liegt der Wert deutlich unter der erwarteten Verbesserung des Gehaltes. Eine weitere Feststofferhöhung könnte nur durch Wasserentzug herbeigeführt werden, was wiederum die Viskosität der Pülpe verschlechtern würde und damit den Einsatz als Bindemittel verhindert.

\subsubsection{Rheologische Eigenschaften der mechanisch-enzymatisch aufgeschlossenen Kartoffelpülpe bei der Verwendung als Bindemittel}

Unter dem Begriff Viskosität versteht man die Zähigkeit eines Stoffes bzw. die innere Reibung von Flüssigkeiten. Die zur Überwindung dieser Reibung erforderliche Kraft ist die Schubspannung $(\tau)$. Durch die Krafteinwirkung entsteht zwischen zwei Schichten der Flüssigkeit ein Geschwindigkeitsgefälle (D). Das Verhältnis der Schubspannung zum Geschwindigkeitsgefälle wird als dynamische Viskosität ( $\eta$ ) bezeichnet (AYLA, 1980): 


$$
\eta=\frac{\tau}{D}
$$

Die dynamische Viskosität wird in Pascalsekunde (mPa.s oder Pa.s) angegeben. Sie ist definiert durch die Kraft in Newton $(N)$, die notwendig ist um in einer Flüssigkeitsschicht von $1 \mathrm{~cm}^{2}$ Flächengröße und $1 \mathrm{~cm}$ Höhe, die eine Grenzfläche parallel zur gegenüberliegenden anderen Grenzfläche mit einer Geschwindigkeit von $1 \mathrm{~cm} \cdot \mathrm{s}^{-1} \mathrm{zu}$ verschieben. Daher gilt:

$1 \mathrm{~Pa} \cdot \mathrm{s}=1 \mathrm{Nsm}^{-2}=1 \mathrm{~kg} \mathrm{~m}^{-1} \mathrm{~s}^{-1}(\mathrm{HABENICHT}, 1997)$.

Größere zwischenmolekulare Reibungskräfte, die den Fließwiderstand erhöhen, beeinflussen die Viskosität eines Stoffes.

Bei der Untersuchung von scherbelastungsabhängigem Verhalten unterscheidet man zwischen idealviskosem, scherverdünnendem oder scherverdickendem Fließverhalten. Das idealviskose Fließverhalten eines Stoffes ist unabhängig von der Höhe und der Dauer der Scherbelastung. Bei scherverdünnendem Fließverhalten ist die Scherviskosität abhängig von der Höhe der Scherbelastung, d. h. die Steigung der Fließkurve nimmt mit wachsender Belastung ab. Anders verhält es sich beim scherverdickenden Verhalten, hier steigt die Fließkurve bei zunehmender Belastung an.

Die Viskosität ist ein wichtiger Faktor bei der Beleimung. Je höher die Viskosität eines Bindemittels ist, desto schwieriger ist die Beleimung der Fasern. Besonders die Stoffkonzentration und der Kondensationsgrad beeinflussen die Viskosität des Bindemittels. Diese hat direkten Einfluss auf die Eigenschaften des Bindemittels, wie das Fließverhalten, die Benetzungsfähigkeit, die Gebrauchsdauer und insgesamt die Verarbeitbarkeit. Das Bindemittel sollte zügig und ohne Luftblasen in die Beleimungsdüse gelangen und gleichmäßig auf die Fasern versprüht werden. Eine hohe Viskosität verhindert das gleichmäßige Transportieren und Versprühen. Die Viskosität eines Bindemittels ist abhängig vom Molekülaufbau, insbesondere von der Kettenlänge und der Länge der vorhandenen Seitenketten sowie von den polaren Gruppierungen. Die meisten Bindemittel zeigen kein idealviskoses Fließverhalten, sondern sind eher scherverdünnend und seltener scherverdickend. Nur im niedrigmolekularen Bereich treten einzeln idealviskose Fließverhalten auf. In der Pülpe liegen hauptsächlich hochmolekulare Stoffe vor wie Cellulose, Hemicellulose, Pektin und Stärke. Dies lässt auf eine relativ hohe Viskosität und auf ein scherverdünnendes Fließverhalten schließen.

Da die mechanisch-enzymatisch aufgeschlossene Pülpe teilweise mit HarnstoffFormaldehydharz gemischt wurden, musste überprüft werden wie sich das UF-Harz 
auf die rheologischen Eigenschaften der Pülpe auswirkten Das verwendete Harnstoff-Formaldehydharz Kauritec ${ }^{\circledR} 407$ flüssig weist bei Abfüllung im Werk eine Viskosität von 150 - $300 \mathrm{mPa} \cdot \mathrm{s}$ (bei $20{ }^{\circ} \mathrm{C}$ ) auf. Diese nimmt aber mit zunehmender Lagerzeit ebenfalls zu (BASF, 2002).

In der Abb. 4-19 sind die Viskositätskurven der Pülpe aufgezeigt, die mit verschiedenen UF-Harzanteilen und je einem Prozent Hydrophobierungsmittel als Bindemittel eingesetzt wurde. Auffällig ist, dass mit steigendem UF-Harzanteil die Viskositätskurve abnimmt, was eine Verbesserung für die technische Verarbeitung bedeutet.

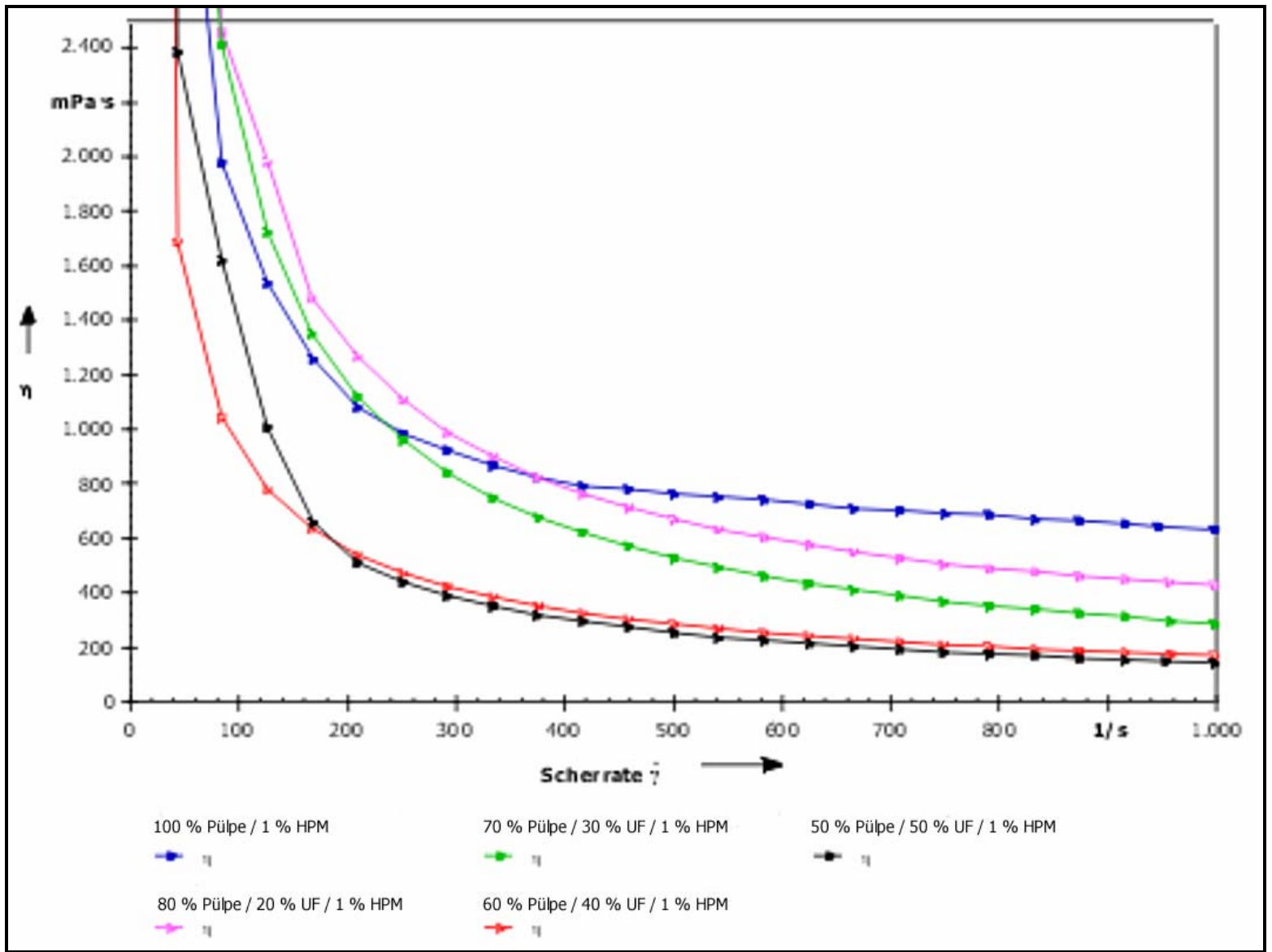

Abb. 4-19: Viskositätskurven der unterschiedlichen Pülpe- und UFHarzmischungen mit Zugabe von $1 \%$ Hydrophobierungsmittel (HPM)

Insgesamt zeigen alle Pülpemischungen wie erwartet ein scherverdünnendes Fließverhalten. Der Grund liegt in der Struktur der Pülpe aufgrund der relativ großen Feststoffbestandteile. Die pflanzlichen Zellen liegen teilweise in Zellverbänden vor, die noch zellgebundenes Wasser enthalten. Durch den Schervorgang werden viele dieser Zellverbände und deren Zellen zerstört und das 
darin gebundene Wasser wird freigesetzt. Dadurch bedingt verringert sich mit zunehmender Scherkraft die Viskosität der Pülpe.

Ein weiterer Grund für die Verringerung der Viskosität liegt bei dem HarnstoffFormaldehyd. Harnstoff fungiert als so genannter "hydrogen bond breaker" (HABENICHT, 1997), d. h. durch eine teilweise Zerstörung der Wasserstoffbrückenbindungen in den Bestandteilen der Pülpe, wie z. B. Cellulose und Pektin werden die intermolekularen Assoziationen innerhalb der jeweiligen Makromoleküle verhindert und die Viskosität verringert sich. Allerdings ist der Einfluss des Harnstoffs nicht überzubewerten, da der meiste Teil des Harnstoffs in gebundener Form vorliegt und nur ein geringer Anteil als "hydrogen bond breaker" fungieren kann. Das Hydrophobierungsmittel hat keinen nennenswerten Einfluss auf die Viskosität der mechanisch-enzymatisch aufgeschlossenen Kartoffelpülpe.

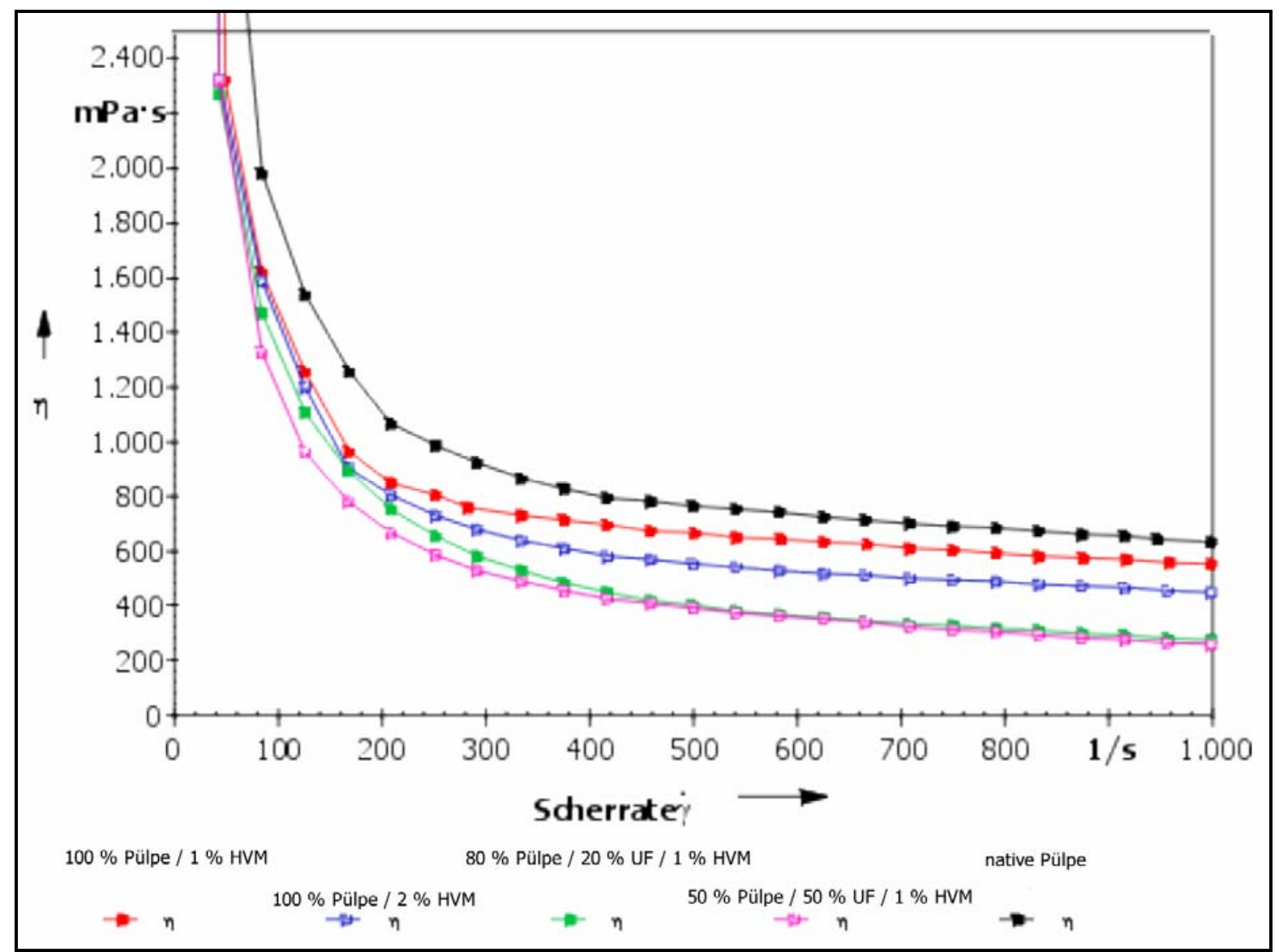

Abb. 4-20: Viskositätskurven der Pülpe- und UF-Harzmischungen mit Zugabe von Haftvermittler (HVM)

In der Grafik 4 sind die Viskositätskurven der Pülpe-UF-Harz-Mischungen aufgezeigt, die mit einem bis zwei Prozent (bezogen auf atro Faser) Haftvermittler versetzt wurden. Auch hier zeigen die Kurven ein ähnliches Verhalten wie in der 
Abb. 4-19. Insgesamt ist die Verringerung der Viskosität nicht so stark. Im Vergleich mit der Abb. 4-19 sieht man, dass durch die Zugabe der Haftvermittler (HVM) anscheinend eine Erhöhung der Viskosität stattgefunden hat (s. Abb. 4-20). Allerdings ist der Einfluss nicht gravierend, so dass eine technische Verarbeitung des Gemisches unproblematisch ist.

\subsubsection{Physikalisch-technologische Eigenschaften der hergestellten MDF-Platten nach EN 622-5}

Die MDF-Platten wurden hinsichtlich ihrer physikalisch-technologischen Eigenschaften nach EN 622-5 untersucht. Diese Eigenschaften geben Aufschluss über die Festigkeit und Verwendungsmöglichkeiten und sind unerlässlich für die Qualitätsprüfung der MDF-Platten. Die EN 622-5 gilt für MDF-Platten, die im Trockenbereich verwendet werden sollen. Wichtigste Faktoren bei der Prüfung sind die Dickenquellung nach 24 Stunden und die Querzugfestigkeit der MDF-Platten. Die physikalischen und mechanischen Eigenschaften werden direkt von der Rohdichte beeinflusst. Sie ist das hauptsächliche Klassifizierungsmerkmal der Faserplatten und wird durch das Verhältnis Masse : Volumen ( $\rho=\mathrm{m} / \mathrm{V}$ in $\mathrm{kg} / \mathrm{m}^{3}$ ) ausgedrückt (LAMPERT, 1967). Zwischen der Rohdichte und der Querzugfestigkeit besteht eine lineare Beziehung. Mit zunehmender Rohdichte erhöht sich auch die Querzugfestigkeit (STEVENS u. WOODSON, 1977). Unter der Querzugfestigkeit versteht man den Widerstand, den ein Holzwerkstoff einer Beanspruchung senkrecht zu seiner Oberfläche entgegensetzt. Durch die Rohdichte werden sowohl die Dickenquellung als auch die Querzugfestigkeit beeinflusst.

\subsubsection{MDF-Platten hergestellt mit mechanisch-enzymatisch aufge- schlossener Pülpe, UF-Harz und Hydrophobierungsmittel}

Die erste Versuchsreihe bestand aus MDF-Platten, die zum einen mit $100 \%$ mechanisch-enzymatisch aufgeschlossener Kartoffelpülpe als Bindemittel hergestellt wurden. Im Weiteren wurde die aufgeschlossene Pülpe mit Harnstoff-Formaldehyd in unterschiedlichen Verhältnissen gemischt. Zur Verringerung der Quellung erfolgte immer die Beimischung von einem Prozent Hydrophobierungsmittel, das auch in der industriellen Fertigung von MDF-Platten eingesetzt wird. Die Platten sollten eine Rohdichte von $800 \mathrm{~kg} / \mathrm{m}^{3}$ aufweisen, allerdings schwankte dieser Wert in den einzelnen Versuchen (s. Abb. 4-21). 
In der Abb. 4-22 sind die Ergebnisse der physikalisch-technologischen Prüfung der MDF-Platten aufgezeigt, die mit 100 \% Pülpe als Bindemittel hergestellt wurden. Die gemessenen Quellwerte liegen deutlich über dem zulässigen Maximalwert von $15 \%$, während die Querzugfestigkeiten nur etwa die Hälfte des erforderlichen Mindestwerts erreichen. Die unterschiedlichen Presszeiten hatten keinen erkennbaren Einfluss auf die physikalisch-technologischen Eigenschaften der MDFPlatten. Die Ergebnisse zeigen, dass die mechanisch-enzymatisch aufgeschlossene Kartoffelpülpe in dieser Form als Bindemittel für die Herstellung von MDF-Platten nicht eingesetzt werden konnte. Zur Verbesserung der physikalisch-technologischen Eigenschaften wurde im Weiteren die mechanisch-enzymatisch aufgeschlossene Kartoffelpülpe mit Harnstoff-Formaldehydharz (Kauritec ${ }^{\circledR} 407$, BASF) gemischt.

In der Abb. 4-23 sind die Ergebnisse der Holzwerkstoffprüfung aufgezeigt. Das Bindemittelgemisch, bestehend aus $80 \%$ aufgeschlossener Pülpe und $20 \%$ UFHarz bewirkte nur eine sehr geringe Verbesserung der Quellungswerte. Ebenso die Querzugfestigkeit, die weit unter dem erforderlichen Norm-Wert lag. Die Zugabe von 20 \% UF-Harz brachte keine nennenswerte Verbesserung der physikalischmechanischen Eigenschaften.

Bei einem Mischungsverhältnis von $70 \%$ mechanisch-enzymatisch aufgeschlossener Kartoffelpülpe zu 30 \% UF-Harz zeigten sich deutliche Verbesserungen in den Werten der Quellung (Abb. 4-24). Diese verringerten sich mit zunehmender Presszeit. Allerdings wurden die erforderlichen EN-Werte nicht annähernd erreicht. Vergleicht man die Ergebnisse mit Abb. 4-23, zeigt sich eine Verbesserung der Querzugfestigkeiten. Mit einer Zunahme der Presszeit konnte die Querzugfestigkeit auf etwa 0,4 N/mm² geringfügig erhöht werden. 


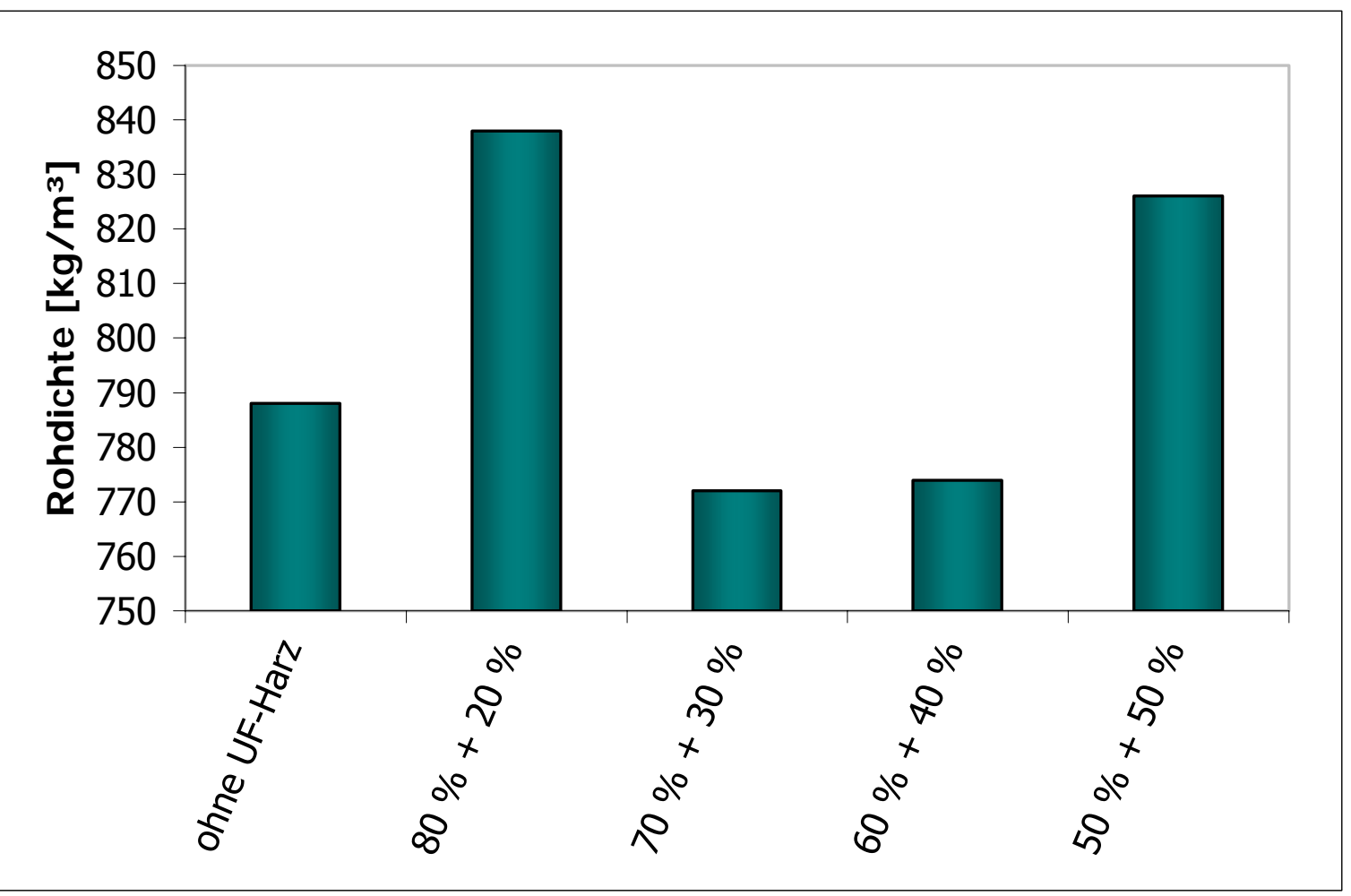

Abb. 4-21: Rohdichten (gemittelt) der MDF-Platten, die mit Pülpe, UF-Harz und $1 \%$ Hydrophobierungsmittel verleimt wurden.

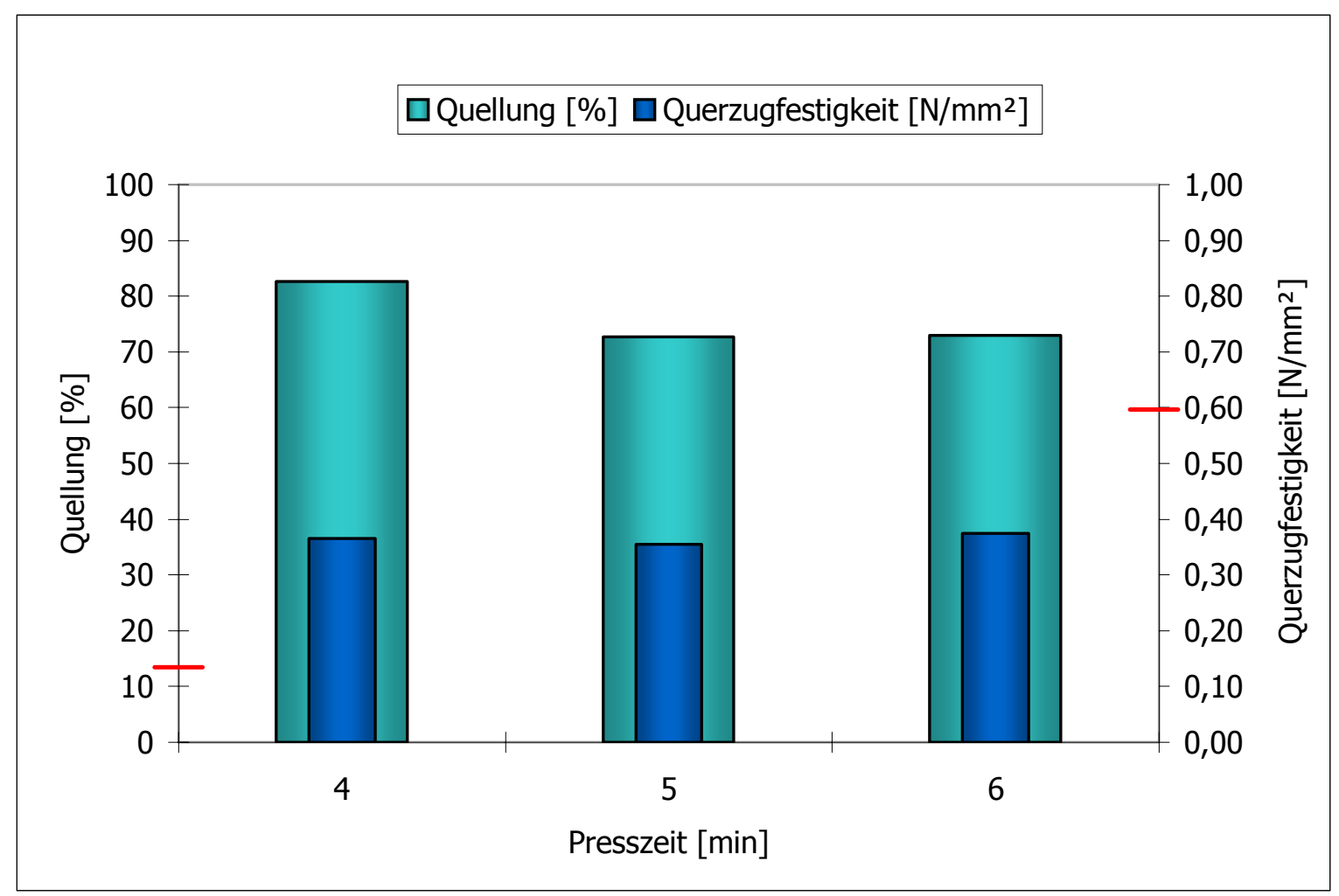

Abb. 4-22: Quellung nach 24 Stunden und Querzugfestigkeit der MDF-Platten, die mit $100 \%$ mechanisch-enzymatisch aufgeschlossener Pülpe als Bindemittel hergestellt wurden. 


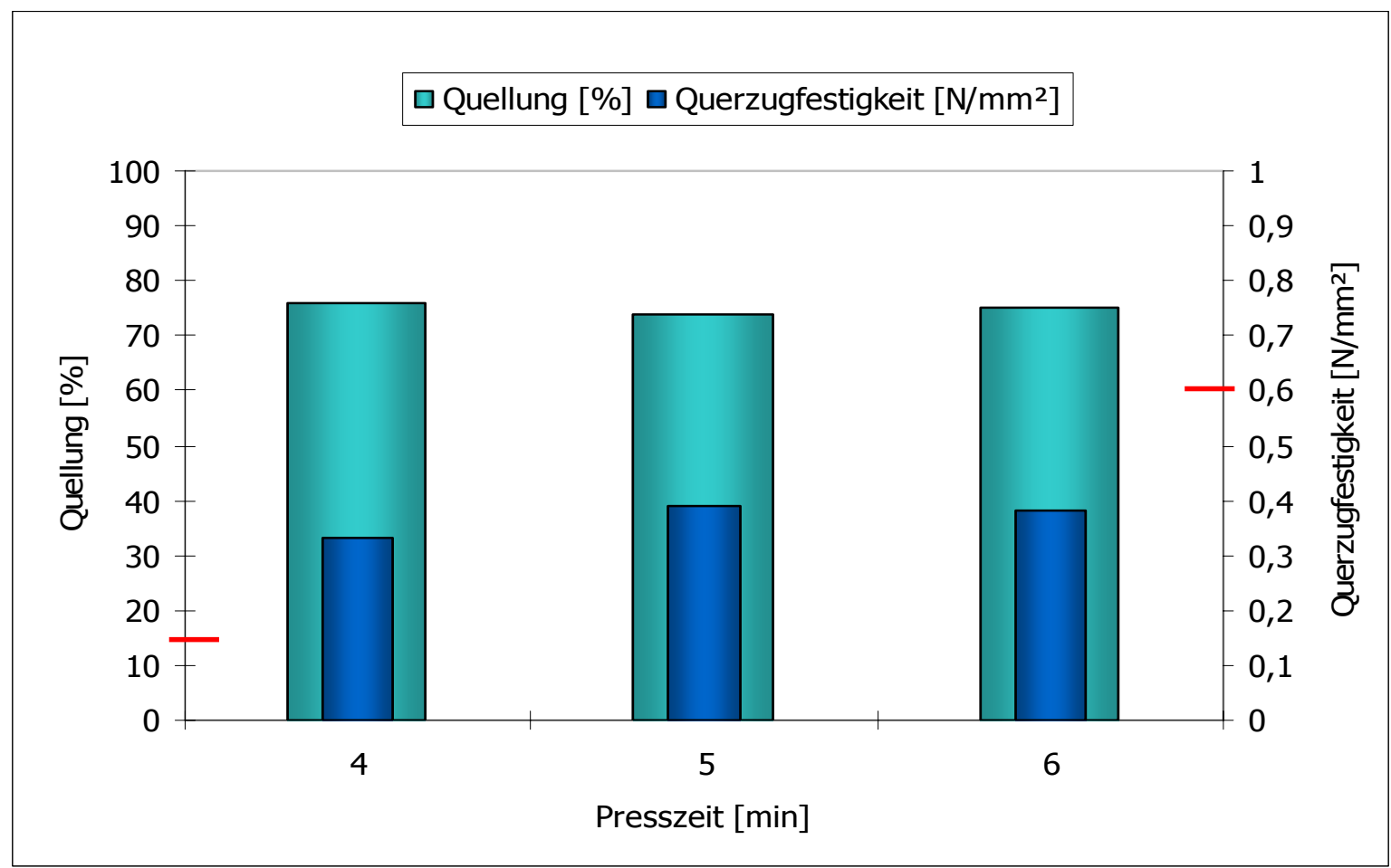

Abb. 4-23: Quellung nach 24 Stunden und Querzugfestigkeit der MDF-Platten, die mit einem Gemisch aus $80 \%$ mechanisch-enzymatisch aufgeschlossener Pülpe und 20 \% UF-Harz als Bindemittel hergestellt wurden.

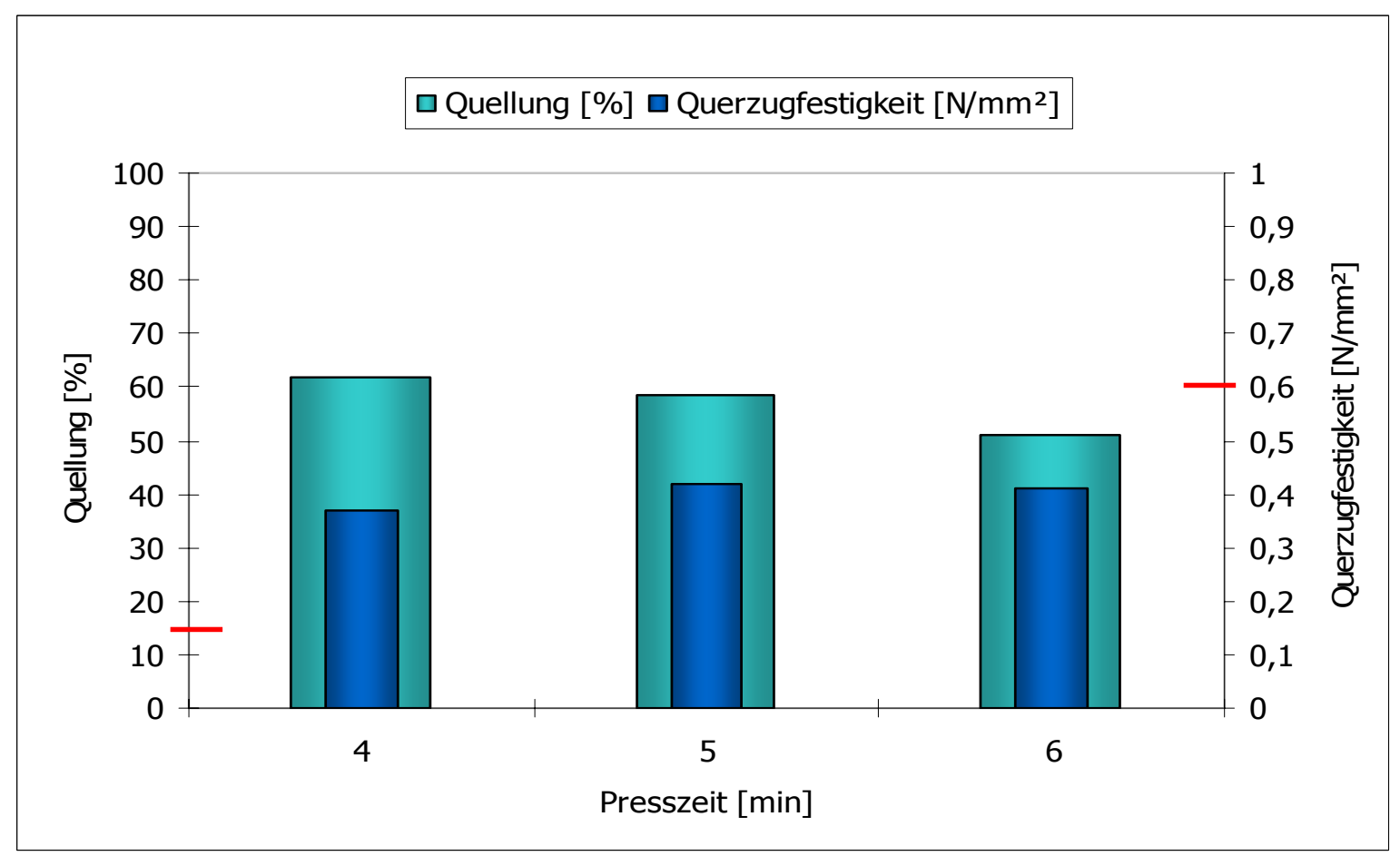

Abb. 4-24: Quellung nach 24 Stunden und Querzugfestigkeit der MDF-Platten, die mit einem Gemisch aus $70 \%$ mechanisch-enzymatisch aufgeschlossener Pülpe und 30 \% UF-Harz als Bindemittel hergestellt wurden. 


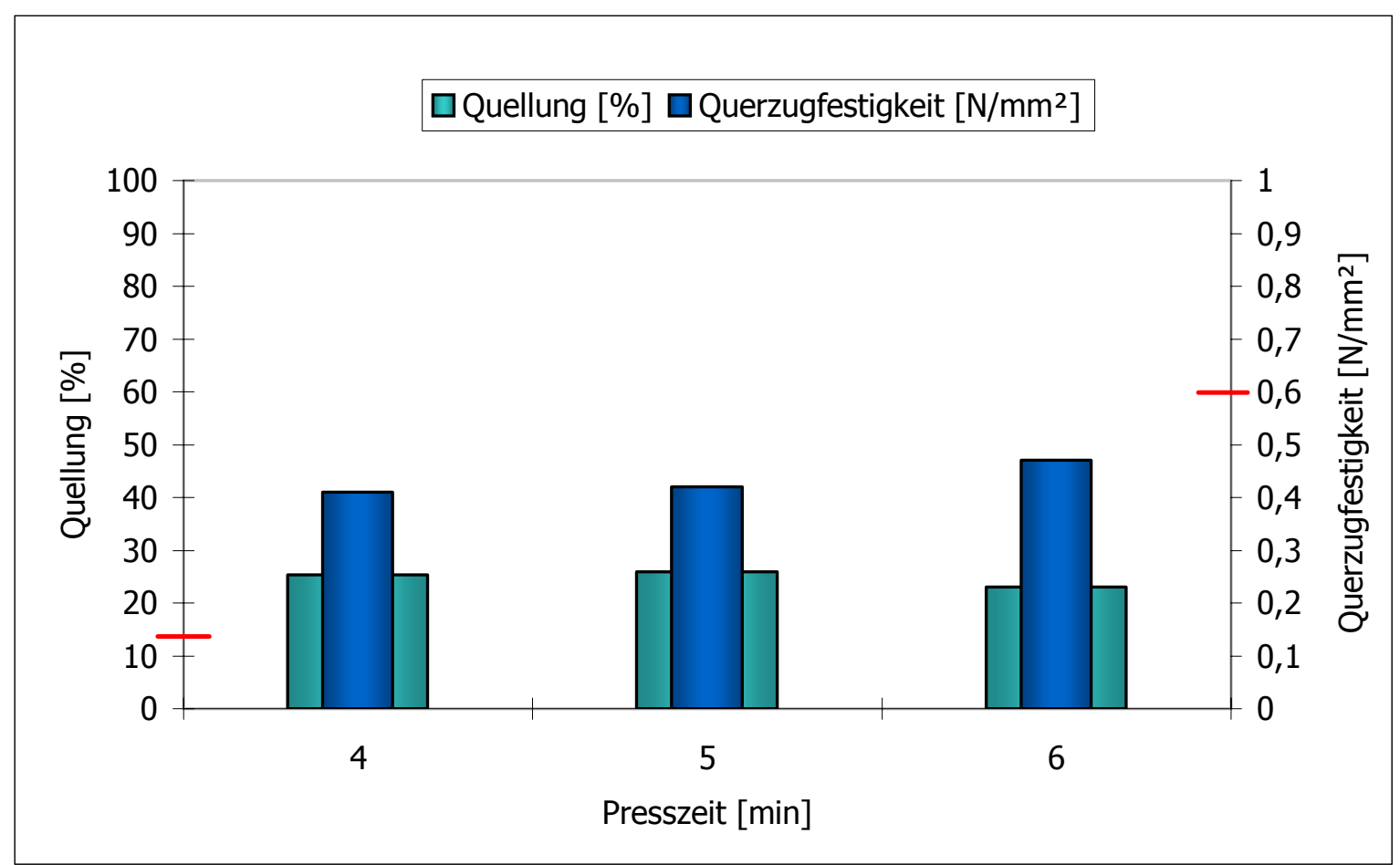

Abb. 4-25: Quellung nach 24 Stunden und Querzugfestigkeit der MDF-Platten, die mit einem Gemisch aus $60 \%$ mechanisch-enzymatisch aufgeschlossener Pülpe und 40 \% UF-Harz als Bindemittel hergestellt wurden.

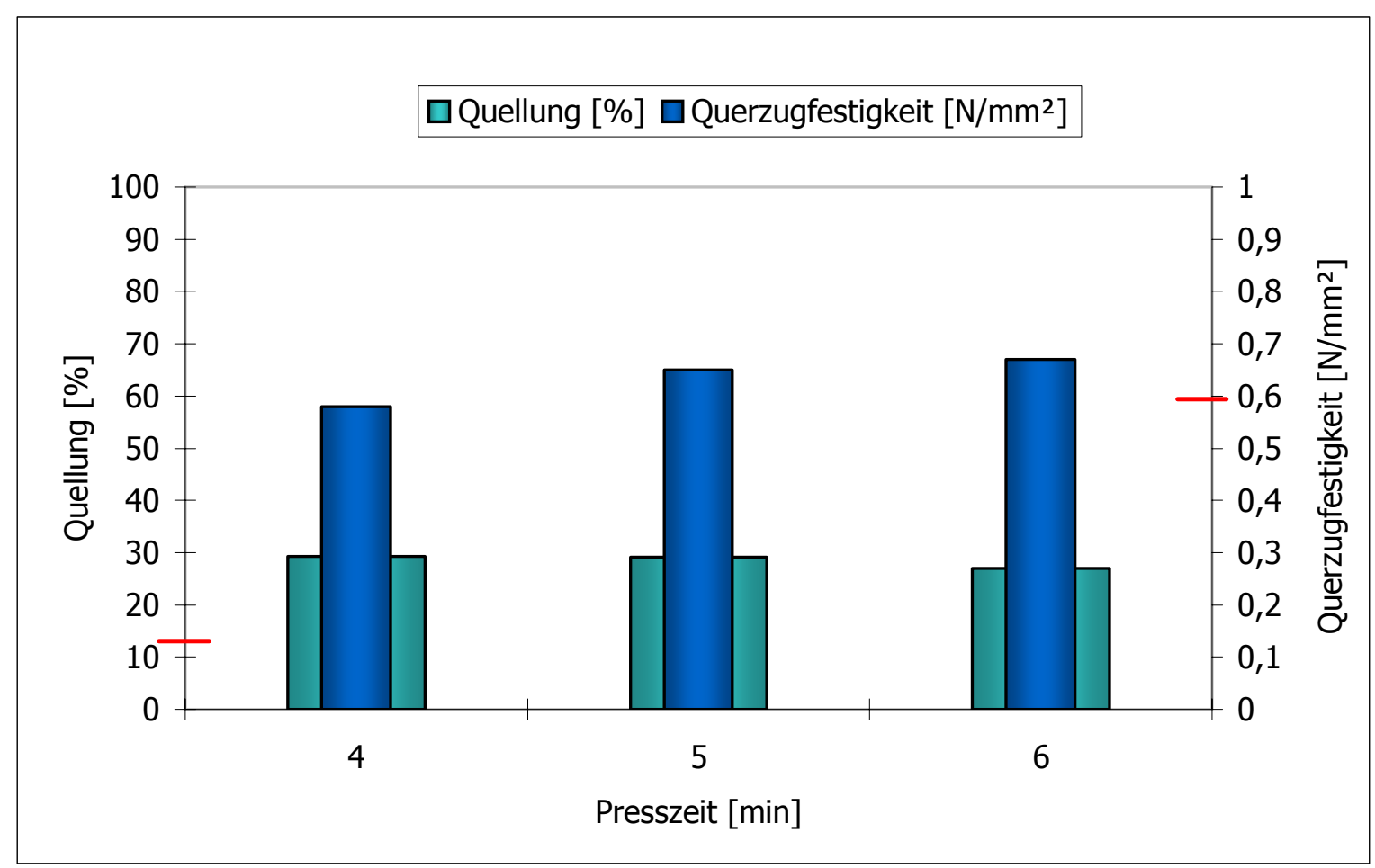

Abb. 4-26: Quellung nach 24 Stunden und Querzugfestigkeit der MDF-Platten, die mit einem Gemisch aus 50 \% mechanisch-enzymatisch aufgeschlossener Pülpe und 50 \% UF-Harz als Bindemittel hergestellt wurden. 
Durch ein Mischungsverhältnis von 60 \% aufgeschlossener Pülpe zu 40 \% UF-Harz zeigte sich eine deutliche Verbesserung der Quellungswerte (s. Abb. 4-25). Die Querzugfestigkeiten verbesserten sich nur minimal im Vergleich zu den vorherigen Ergebnissen (s. Abb. 4-24). Die Rohdichte entsprach auch in diesem Fall nicht den vorgegebenen $800 \mathrm{~kg} / \mathrm{m}^{3}$, sondern erreichte nur ca. $770 \mathrm{~kg} / \mathrm{m}^{3}$. Obwohl UF-Harz $40 \%$ des Bindemittels ausmachte, konnte hinsichtlich der Querzugfestigkeit keine Annäherung an die erforderlichen EN-Werte erzielt werden. Dennoch hatte das UFHarz eine positive Auswirkung auf die Quellungseigenschaften.

Eine 50 \%ige Substitution der mechanisch-enzymatisch aufgeschlossenen Kartoffelpülpe durch UF-Harz brachte gute Ergebnisse (s. Abb. 4-26). Die erforderliche Querzugfestigkeit konnte von allen Proben erfüllt werden. Die Rohdichte lag mit $830 \mathrm{~kg} / \mathrm{m}^{3}$ knapp über dem erforderlichen Wert und wirkte sich daher auch entsprechend auf die Querzugfestigkeit aus. Im Bereich der Dickenquellung wurden die EN-Werte nicht erfüllt. Mit Quellungswerten von etwa $30 \%$ wurde aber eine deutlichere Verbesserung erzielt.

\subsubsection{MDF-Platten hergestellt mit mechanisch-enzymatisch aufge- schlossener Pülpe, UF-Harz und Haftvermittler}

Zur Verbesserung der bisherigen Ergebnisse erfolgte ein $1 \%$ ige Zugabe (bezogen auf atro Faser) von einem Haftvermittler (1154). Die Aufgabe des Haftvermittlers war die Verstärkung der Haftungseigenschaften der mechanisch-enzymatisch aufgeschlossenen Kartoffelpülpe. Auf die Zugabe eines Hydrophobierungsmittels wurde verzichtet. Eine teilweise Substitution der Pülpe durch UF-Harz wurde ebenfalls untersucht.

Im ersten Versuch wurde $100 \%$ mechanisch-enzymatisch aufgeschlossene Kartoffelpülpe mit einer Zugabe von $1 \%$ Haftvermittler bezogen auf atro Faser als Bindemittel eingesetzt. Die geprüften Platten hatten sehr hohe Quellwerte von bis zu $70 \%$, die sich allerdings mit zunehmender Presszeit um etwa $20 \%$ verringerte (s. Abb. 4-28). Im Gegensatz dazu erreichte die Querzugfestigkeit annähernd ENWerte, wobei die Rohdichte zu hoch war (s. Abb. 4-27). Insgesamt waren die Prüfergebnisse zufrieden stellend in Anbetracht des verwendeten Bindemittels.

In der Abb. 4-29 sind die Ergebnisse der MDF-Platten dargestellt, die mit $80 \%$ mechanisch-enzymatisch aufgeschlossener Pülpe und $20 \%$ UF-Harz hergestellt wurden. Der Einsatz des UF-Harzes hatte nur geringen Einfluss auf die Quellwerte, die immer noch bei circa 55 \% lagen. Im Vergleich mit den Ergebnissen aus der 
Abb. 4-23 war eine Verbesserung der Quellung zu erkennen. Die Querzugfestigkeit der Platten, die 5 bzw. 6 Minuten gepresst wurden, erreichten fast EN-Werte. Deutlich schlechter waren die Querzugfestigkeiten der Platten, die nur 4 Minuten verpresst wurden. Die Rohdichte der Platten lag bei $790 \mathrm{~kg} / \mathrm{m}^{3}$ und war somit in etwa beim Sollwert.

Das Bindemittelgemisch von $50 \%$ mechanisch-enzymatisch aufgeschlossener Pülpe und $50 \%$ UF-Harz brachte keine eindeutige Verbesserung der Querzugfestigkeit (s. Abb. 4-30), allerdings wurde auch nicht die vorgegebene Rohdichte erreicht, so dass sich dies negativ auf die Querzugfestigkeit auswirkte. Die Platten mit einer vierminütigen Presszeit schnitten wieder deutlich schlechter ab. Die Werte der Quellung waren im Vergleich deutlich geringer als bei den vorherigen Proben. Trotzdem konnte das Ergebnis aus der Abb. 4-26 nicht ganz erreicht werden. Dies könnte bedingt sein durch das Fehlen von Hydrophobierungsmittel und der geringen hydrophoben Wirkung des Haftvermittlers.

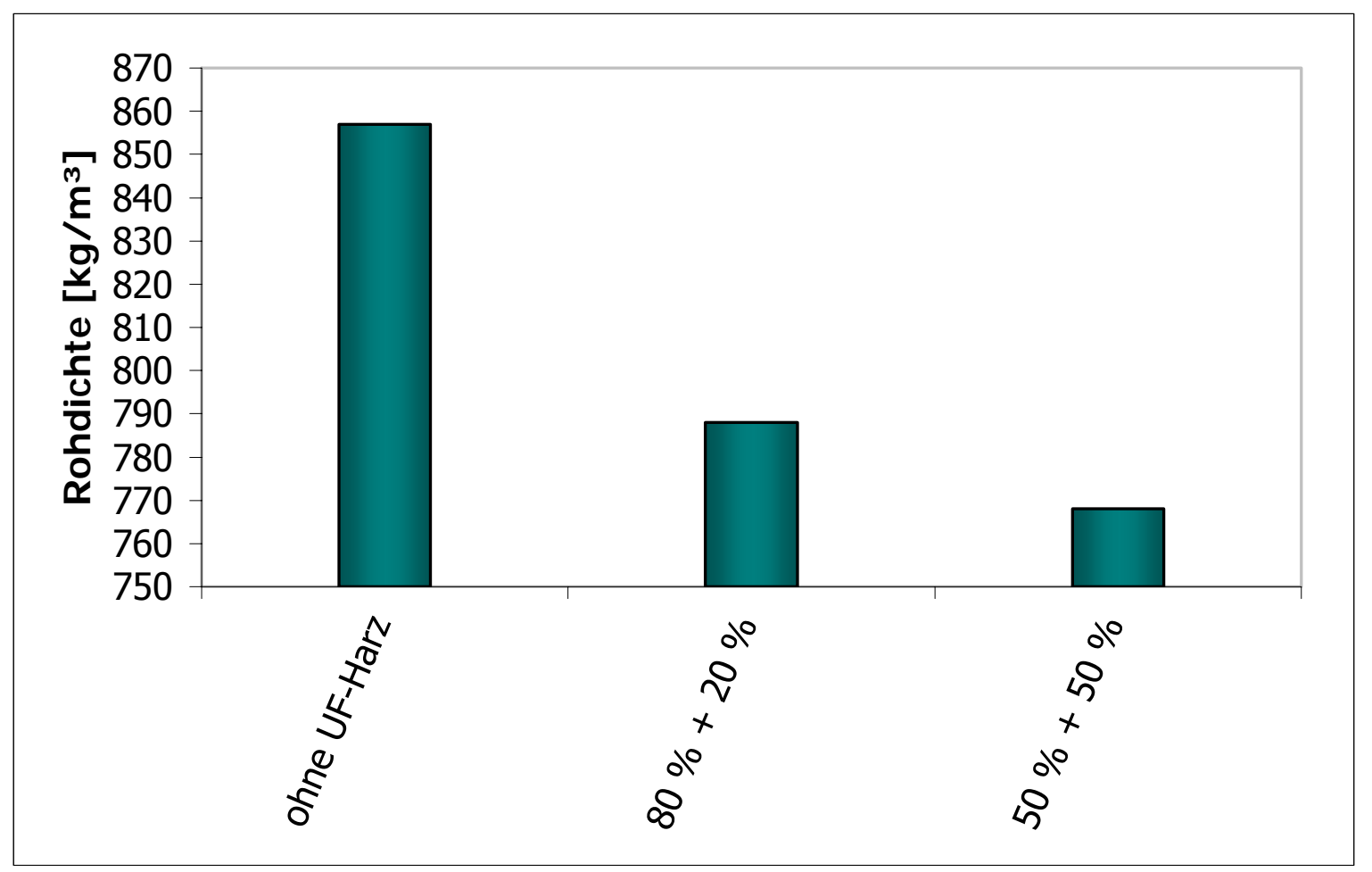

Abb. 4-27: Rohdichten (gemittelt) der MDF-Platten, die mit mechanischenzymatisch aufgeschlossener Kartoffelpülpe und UF-Harz unter Zugabe von einem Prozent Haftvermittler (bezogen auf atro Faser) hergestellt wurden. 


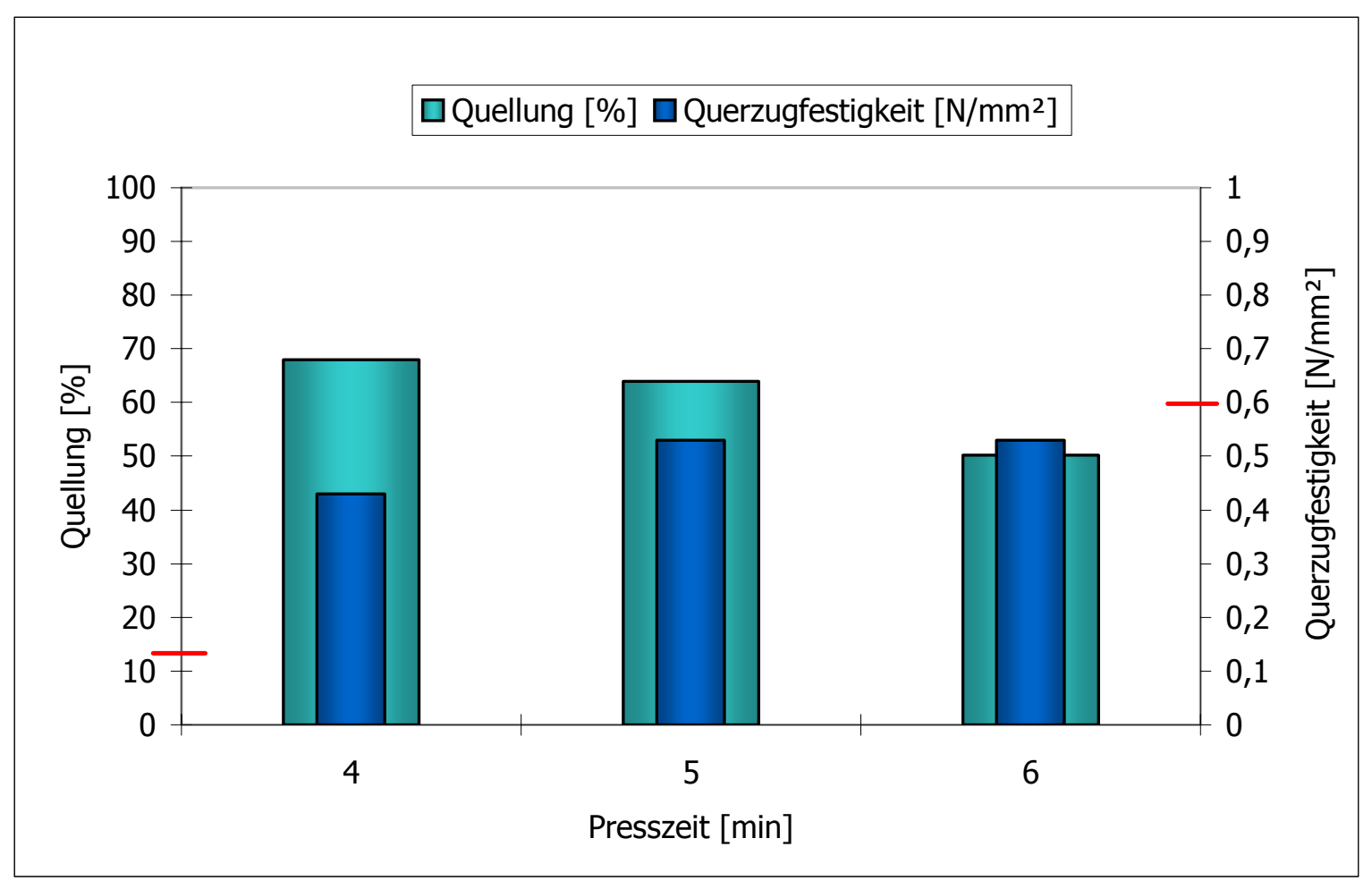

Abb. 4-28: Quellung nach 24 Stunden und Querzugfestigkeit der MDF-Platten, die mit $100 \%$ mechanisch-enzymatisch aufgeschlossener Pülpe als Bindemittel hergestellt wurden. Zugabe von einem Prozent Haftvermittler 1154.

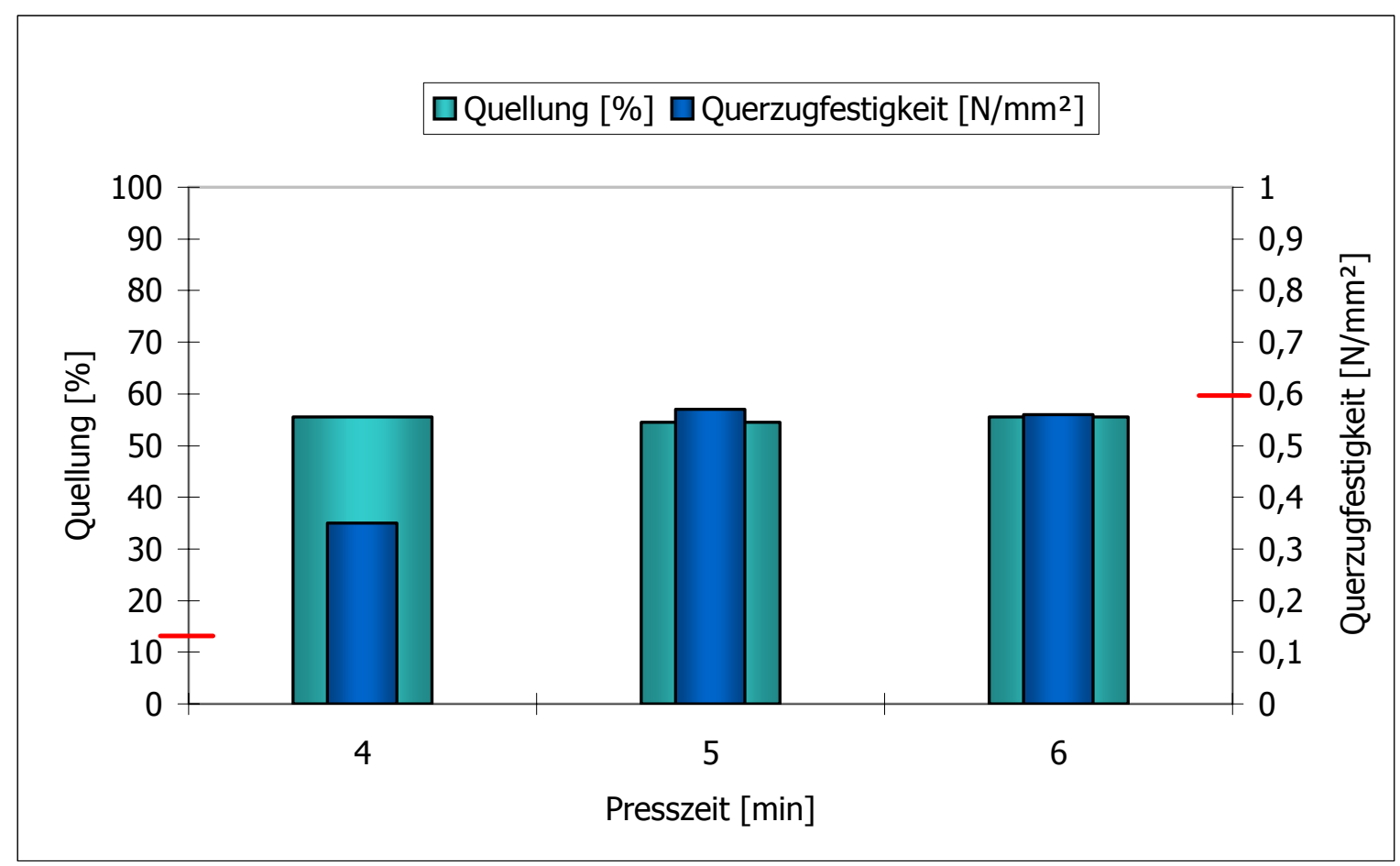

Abb. 4-29: Quellung nach 24 Stunden und Querzugfestigkeit der MDF-Platten, die mit einem Gemisch aus $80 \%$ mechanisch-enzymatisch aufgeschlossener Pülpe und 20 \% UF-Harz als Bindemittel hergestellt wurden. Zugabe von einem Prozent Haftvermittler 1154. 


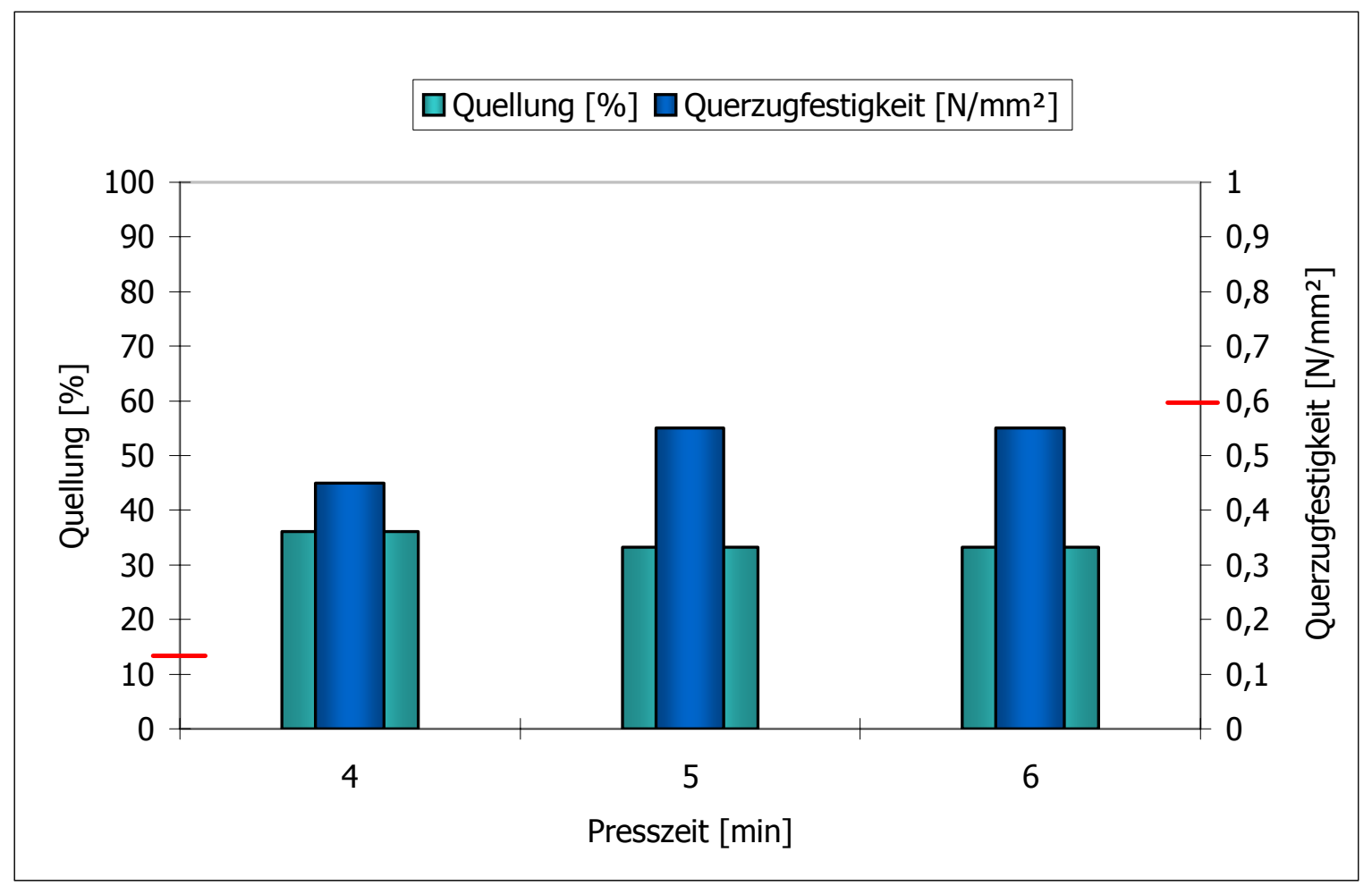

Abb. 4-30: Quellung nach 24 Stunden und Querzugfestigkeit der MDF-Platten, die mit einem Gemisch aus $50 \%$ mechanisch-enzymatisch aufgeschlossener Pülpe und 50 \% UF-Harz als Bindemittel hergestellt wurden. Zugabe von $1 \% 1154$.

Anhand dieser Versuchsreihe konnte nachgewiesen werden, dass die alleinige Verwendung von einem Prozent Haftvermittler, zusätzlich zu dem UF-Harz, keine eindeutige Verbesserung der physikalisch-technologischen Eigenschaften bewirkt. Im weiteren Verlauf der Versuche sollte daher der Anteil an Haftvermittler auf zwei Prozent erhöht werden.

\subsubsection{MDF-Platten hergestellt mit $100 \%$ mechanisch-enzymatisch aufgeschlossener Pülpe und $2 \%$ Haftvermittler}

In dieser Versuchsreihe wurden MDF-Platten nur mit $100 \%$ mechanischenzymatisch aufgeschlossener Kartoffelpülpe als Bindemittel hergestellt. Zur Steigerung der Bindungseigenschaften erfolgte die Zugabe von $2 \%$ Haftvermittler (auf atro Faser). Hierbei sollte die Wirkung der zwei unterschiedlichen Haftvermittler (1154 und 2909) hinsichtlich einer Verbesserung der physikalischtechnologischen Eigenschaften der MDF-Platten untersucht werden. 
In der Abb. 4-32 sind die Ergebnisse der Platteneigenschaften aufgezeigt, die mit dem Haftvermittler 1154 erzielt wurden. Die Platten mit einer vierminütigen Presszeit schnitten, wie bereits in den vorherigen Versuchen, am schlechtesten ab. Bei Presszeiten von 5 und 6 Minuten zeigte sich eine leichte Verbesserung der Querzugfestigkeiten, ohne die notwendigen EN-Werte zu erreichen. Die Rohdichte lag bei $830 \mathrm{~kg} / \mathrm{m}^{3}$ (s. Abb. 4-31) und verstärkte somit die Querzugfestigkeiten. Die Werte der Quellung lagen weit über 60 \% und waren inakzeptabel hoch.

Im zweiten Versuchsansatz dieser Reihe wurde der Haftvermittler 1154 durch den Haftvermittler 2909 ersetzt (s. Abb. 4-33). Die physikalisch-technologischen Eigenschaften der MDF-Platten verbesserten sich sowohl in der Quellung als auch bei der Querzugfestigkeit. Zwar lag die Quellung immer noch zwischen 40 und 55 \%, war aber im Vergleich zu Abb. 4-32 deutlich geringer. Die Querzugfestigkeiten erzielten annähernd EN-Werte, wobei die Rohdichte mit etwa $835 \mathrm{~kg} / \mathrm{m}^{3}$ zu hoch ausfiel. Die Presszeiten hatten keinen Einfluss auf die Querzugfestigkeiten, nur bei der Quellung machte sich ein Unterschied bemerkbar.

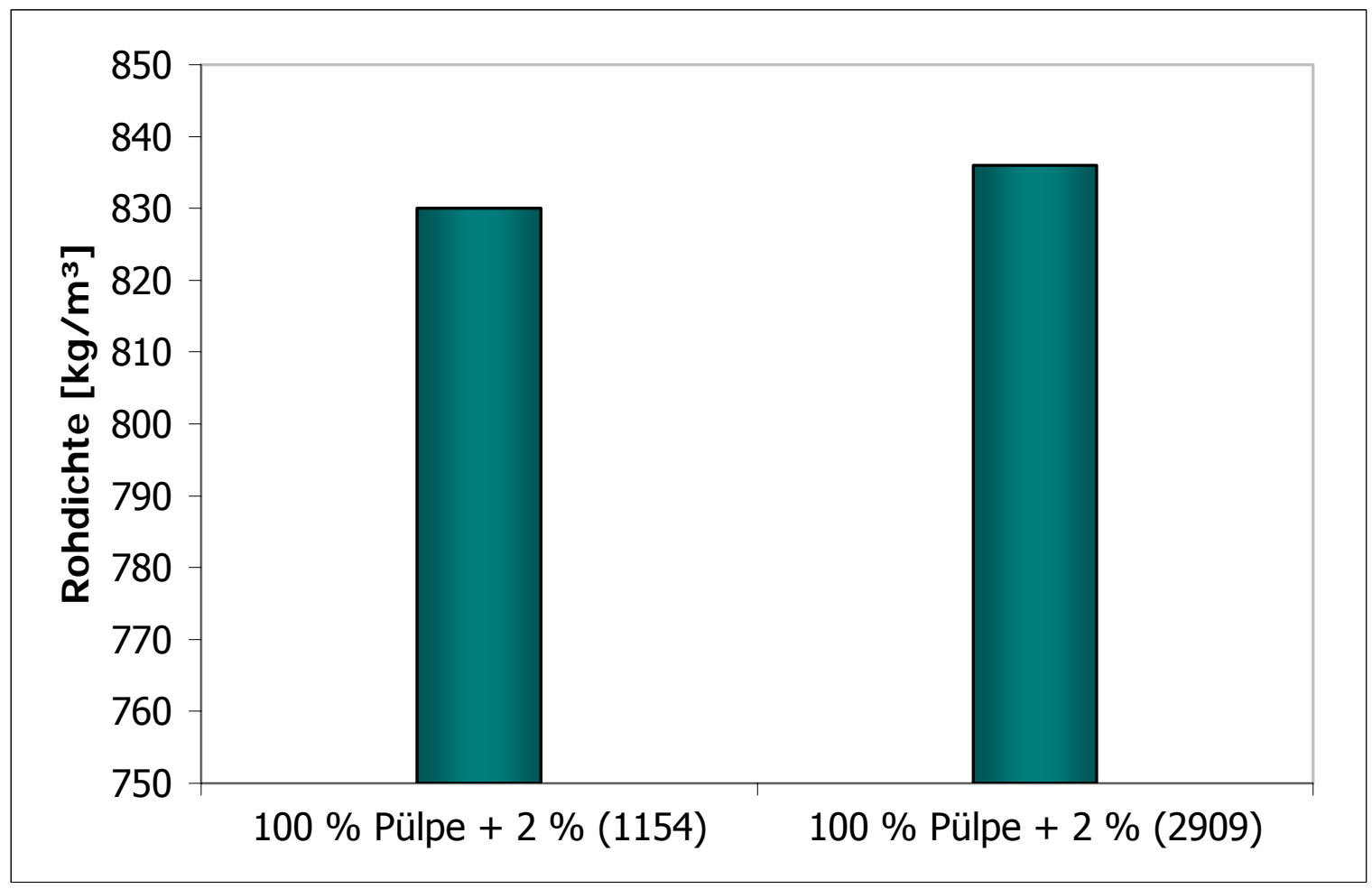

Abb. 4-31: Rohdichten (gemittelt) der MDF-Platten, die mit $100 \%$ Pülpe als Bindemittel und $2 \%$ Haftvermittler (bezogen auf atro Faser) hergestellt wurden. 


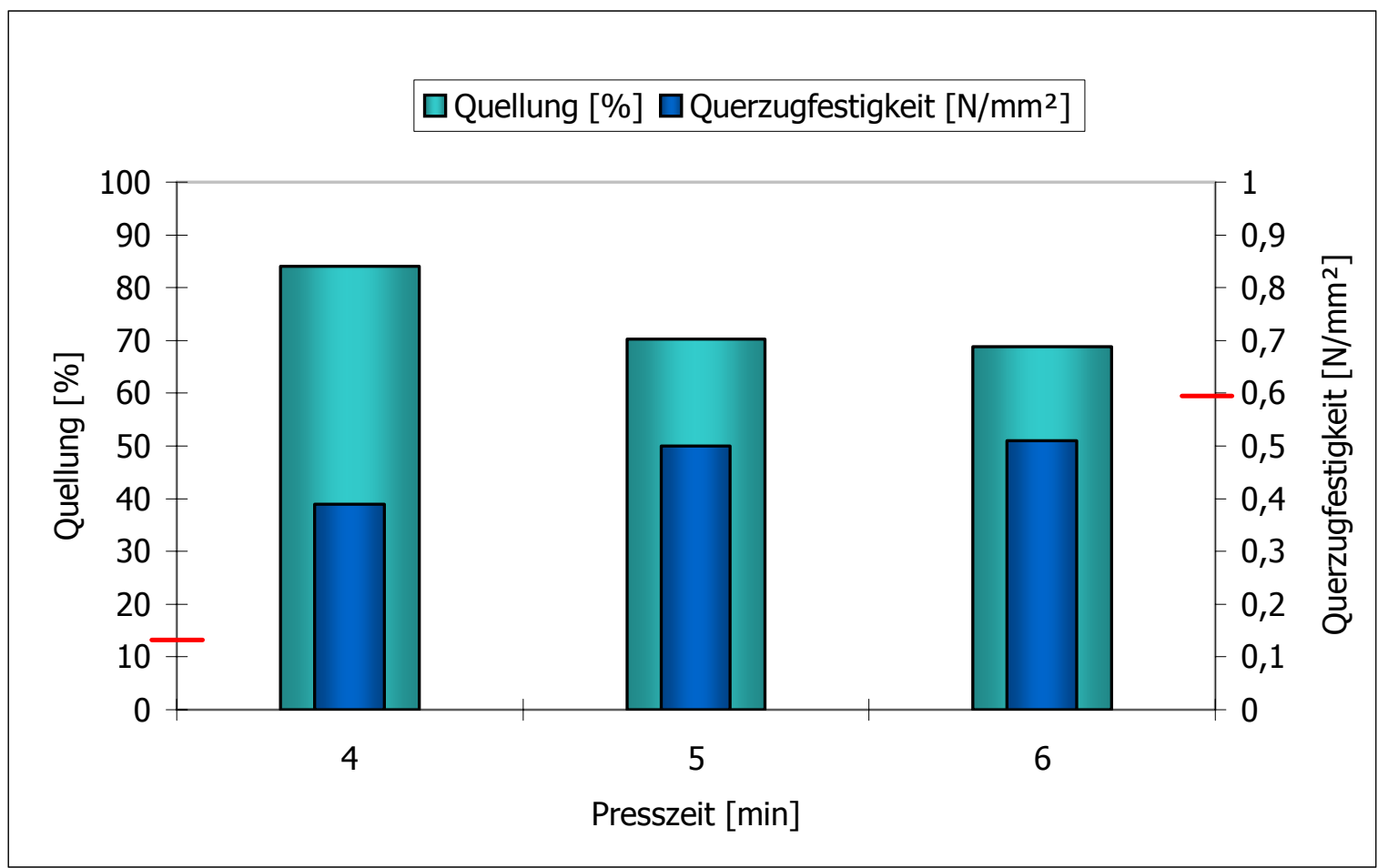

Abb. 4-32: Quellung nach 24 Stunden und Querzugfestigkeit der MDF-Platten, die mit $100 \%$ mechanisch-enzymatisch aufgeschlossener Pülpe als Bindemittel und $2 \%$ Haftvermittler (1154) hergestellt wurden.

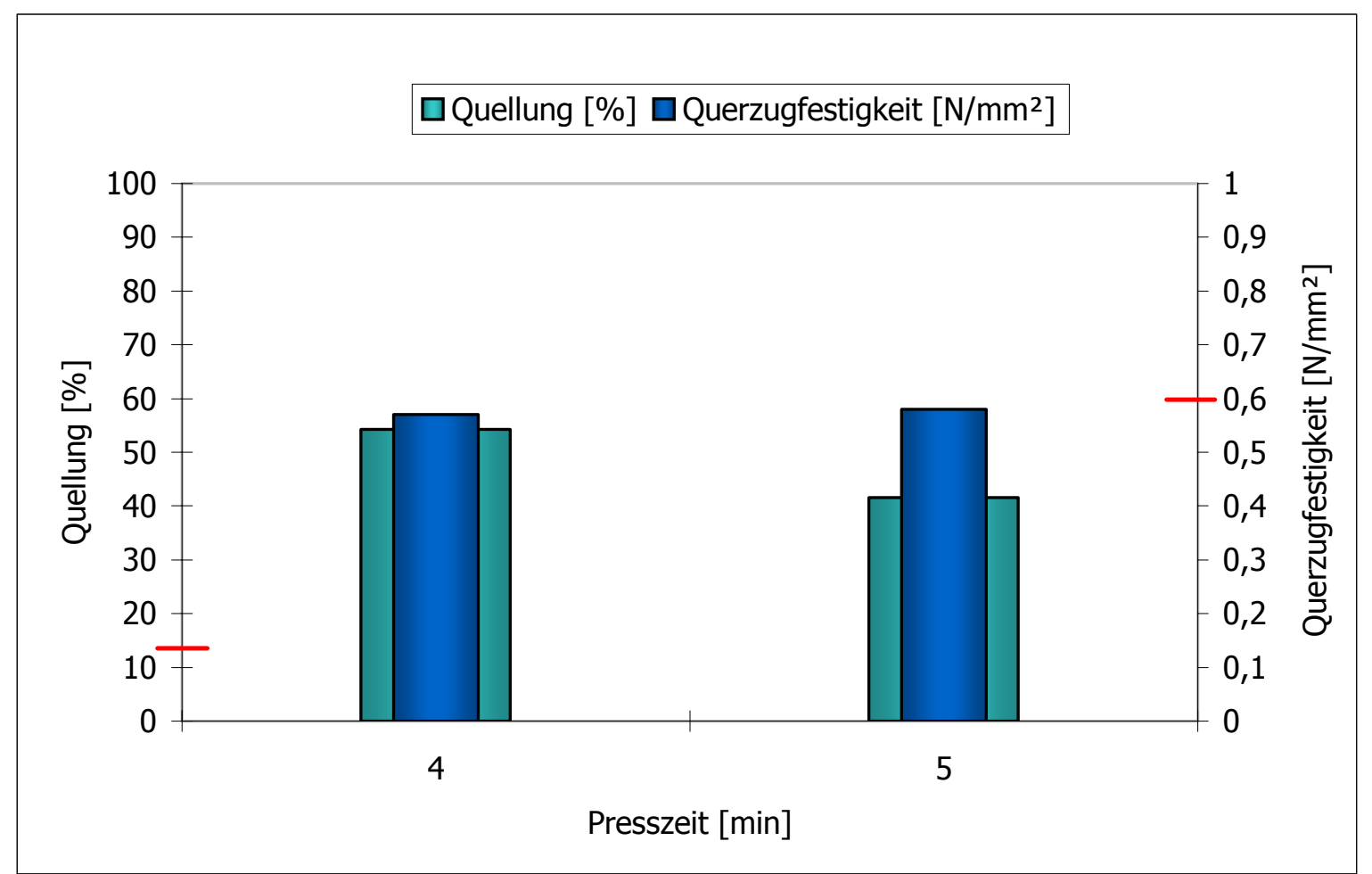

Abb. 4-33: Quellung nach 24 Stunden und Querzugfestigkeit der MDF-Platten, die mit $100 \%$ mechanisch-enzymatisch aufgeschlossener Pülpe als Bindemittel und $2 \%$ Haftvermittler (2909) hergestellt wurden. 
Zusammenfassend ist festzuhalten, dass die MDF-Platten, die mit $100 \%$ aufgeschlossener Pülpe und $2 \%$ Haftvermittler verklebt wurden, verhältnismäßig positive Eigenschaften aufwiesen. Aus diesem Grund wurde eine weitere Versuchsreihe durchgeführt, bei der ebenfalls $100 \%$ aufgeschlossene Pülpe, Haftvermittler und zusätzlich Hydrophobierungsmittel eingesetzt wurden.

\subsubsection{MDF-Platten hergestellt mit $100 \%$ mechanisch-enzymatisch aufgeschlossener Pülpe unter Zugabe von Hydrophobierungsmittel und Haftvermittler}

Bei dieser Versuchsreihe sollten die mechanisch-enzymatisch aufgeschlossene Kartoffelpülpe und Haftvermittler als Bindemittel zur Herstellung von MDF-Platten eingesetzt werden. Bei den Additiven handelte es sich um die Haftvermittler 1154 so wie 2909 und das Hydrophobierungsmittel Hydrowax 730.

In der Abb. 4-34 sind die Rohdichten der einzelnen Untersuchungsreihen aufgezeigt. Innerhalb der jeweiligen Reihen zeigten sich große Unterschiede zwischen den Rohdichten, die sich auch auf die physikalisch-technologischen Eigenschaften der MDF-Platten auswirkten.

In der ersten Reihe wurde neben der aufgeschlossenen Kartoffelpülpe je ein Prozent Haftvermittler 1154 und Hydrophobierungsmittel eingesetzt. Die Ergebnisse in der Abb. 4-35 zeigen, dass der Zusatz von einem Prozent Haftvermittler keine verbessernde Wirkung auf die Festigkeitseigenschaften der MDF-Platten hatte. Insbesondere die Platten mit einer fünfminütigen Presszeit wiesen deutlich schlechtere Querzugfestigkeiten auf. Die Werte sind ähnlich wie die in der Abb. 4-22. Die Quellung hingegen hat sich sichtbar verbessert, auch wenn keine ENWerte erreicht wurden.

Auch die Zugabe von einem Prozent des Haftvermittlers 2909 konnte keine deutliche Verbesserung der Querzugfestigkeit erreichen (s. Abb. 4-36). Vergleicht man die Werte mit denen in der Abb. 4-28, zeigt sich sogar eine Verschlechterung der Festigkeit. Im Gegenteil dazu konnte durch die Zugabe des Hydrophobierungsmittels eine deutliche Verbesserung der Quellungswerte erzielt werden. Diese lagen im Schnitt nur noch bei etwa $30 \%$. Es ist anzunehmen, dass eine Kombination aus Haftvermittler und Hydrophobierungsmittel einen positiven Einfluss auf die Quelleigenschaften ausgeübt haben. 


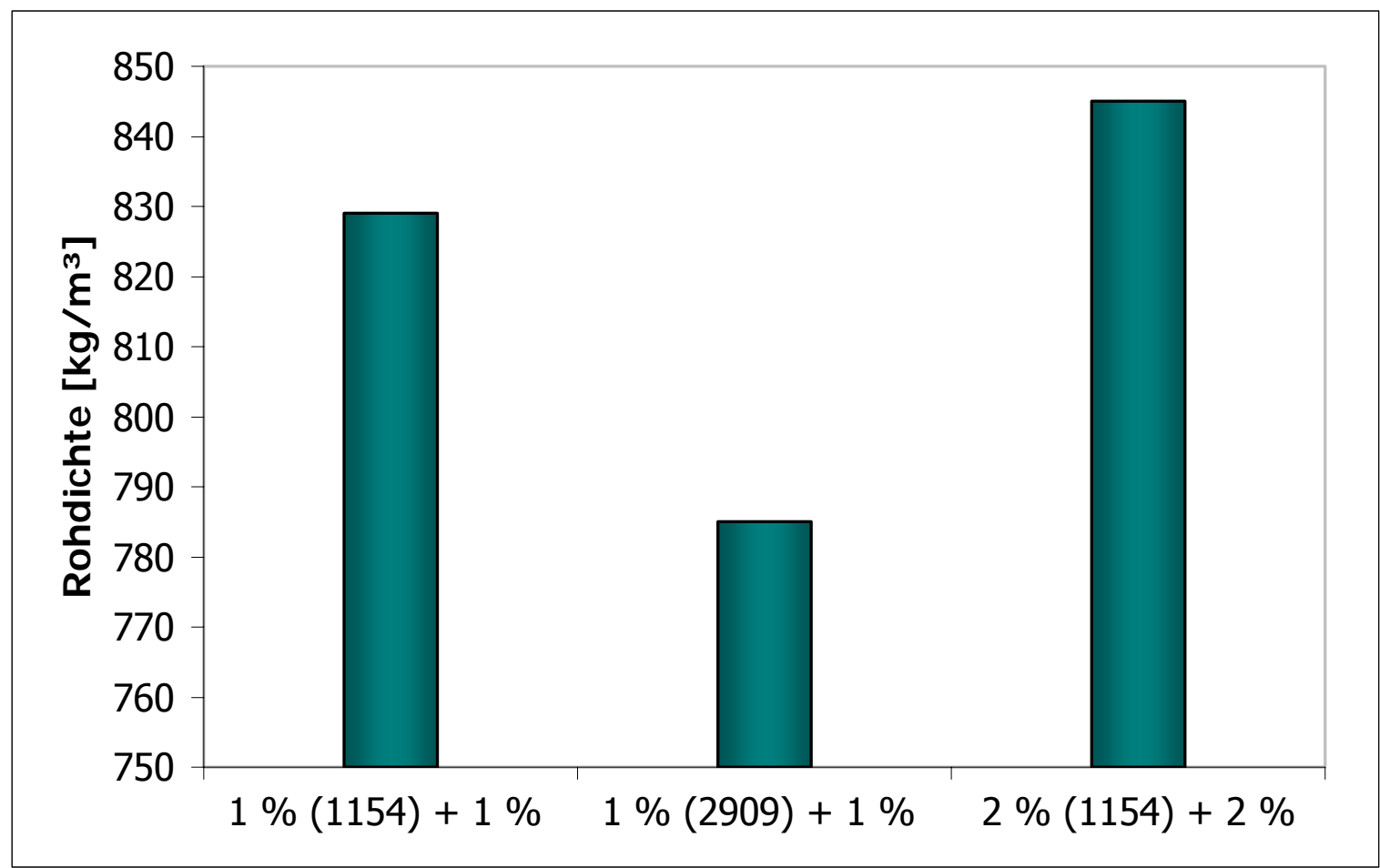

Abb. 4-34: Rohdichten (gemittelt) der MDF-Platten, die mit $100 \%$ Pülpe als Bindemittel hergestellt wurden. Additive waren Haftvermittler und Hydrophobierungsmittel.

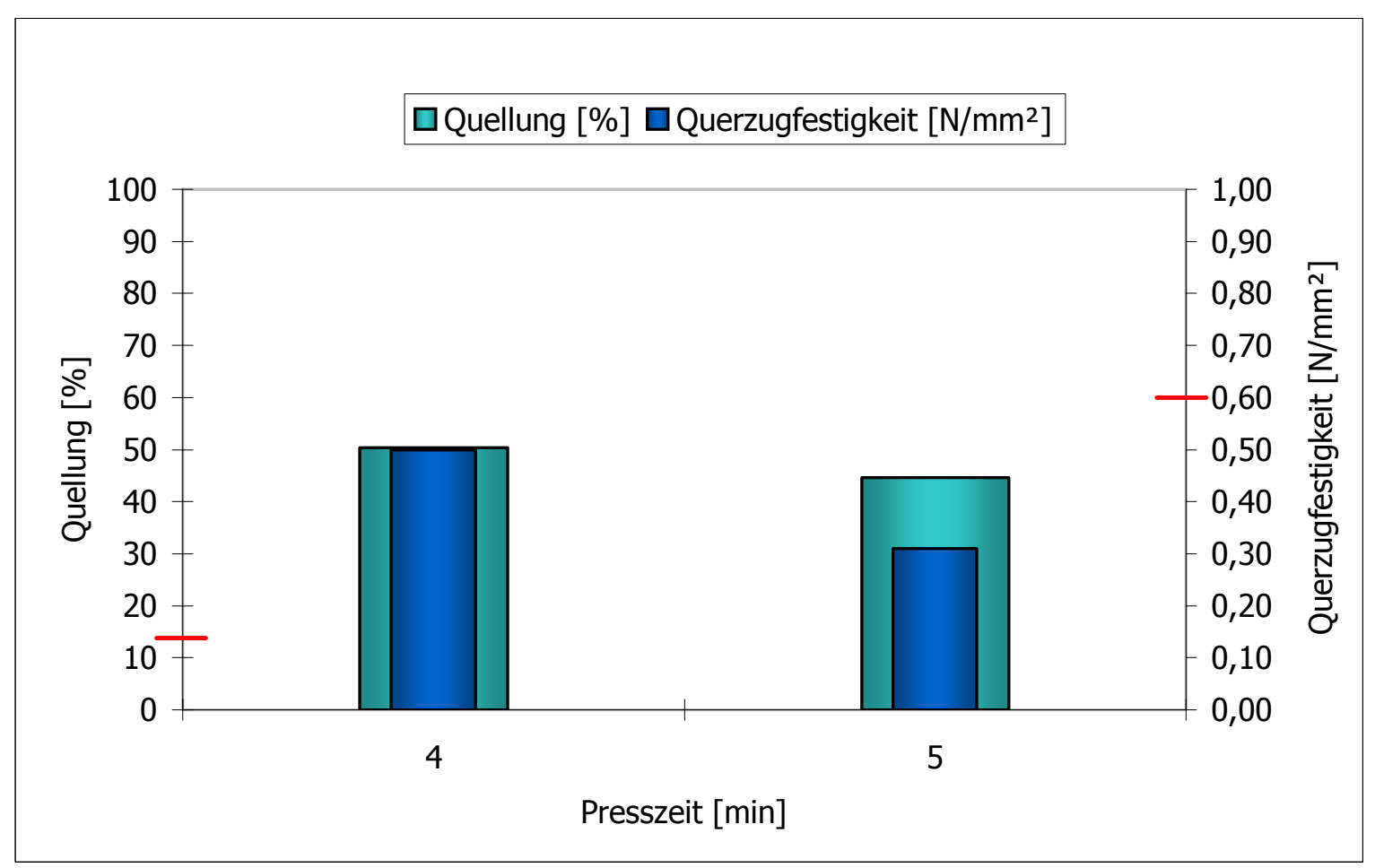

Abb. 4-35: Quellung nach 24 Stunden und Querzugfestigkeit der MDF-Platten, die mit $100 \%$ mechanisch-enzymatisch aufgeschlossener Pülpe als Bindemittel und $1 \%$ Haftvermittler (1154) sowie $1 \%$ Hydrophobierungsmittel (bezogen auf atro Faser) hergestellt wurden. 


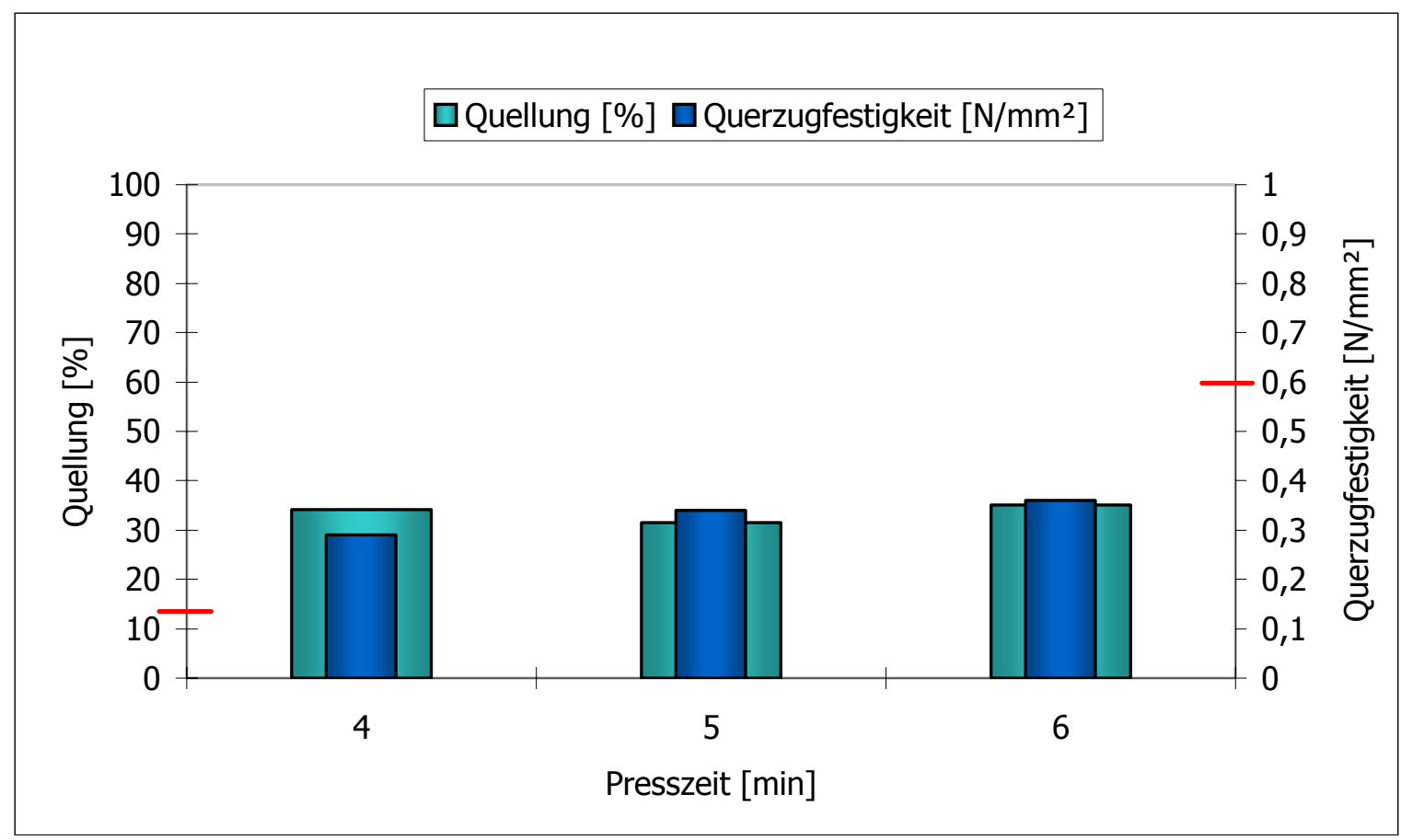

Abb. 4-36: Quellung nach 24 Stunden und Querzugfestigkeit der MDF-Platten, die mit $100 \%$ mechanisch-enzymatisch aufgeschlossener Pülpe als Bindemittel und $1 \%$ Haftvermittler (2909) sowie $1 \%$ Hydrophobierungsmittel (bezogen auf atro Faser) hergestellt wurden.

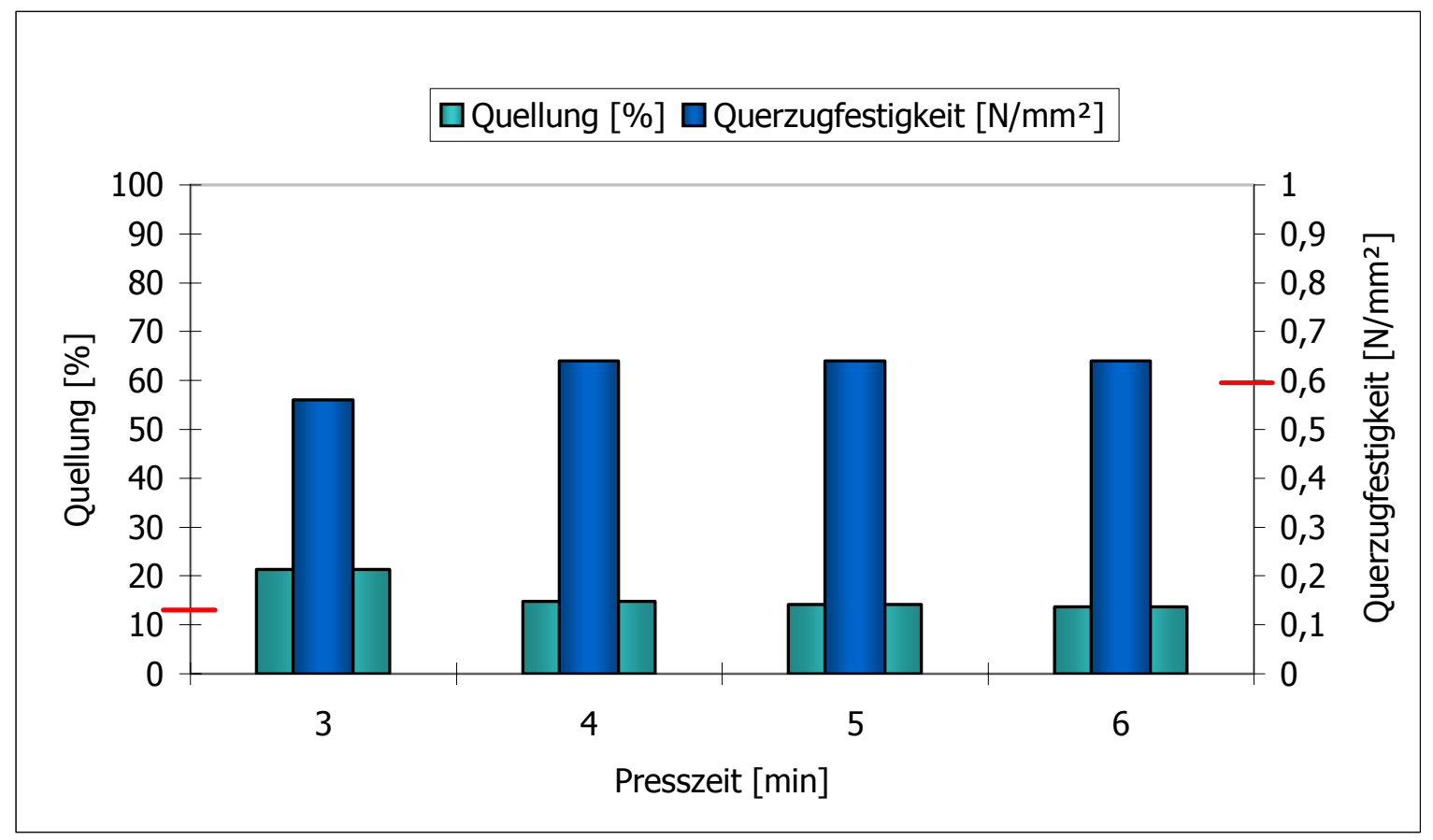

Abb. 4-37: Quellung nach 24 Stunden und Querzugfestigkeit der MDF-Platten, die mit $100 \%$ mechanisch-enzymatisch aufgeschlossener Pülpe als Bindemittel und $2 \%$ Haftvermittler (1154) sowie $2 \%$ Hydrophobierungsmittel (bezogen auf atro Faser) hergestellt wurden. 
Die Ergebnisse in der Abb. 4-37 zeigen, dass durch die Zugabe von je zwei Prozent Haftvermittler und Hydrophobierungsmittel EN-Werte erreicht werden können. Alle untersuchten MDF-Platten dieser Reihe, erfüllten ab einer vierminütigen Presszeit die Voraussetzungen der EN. Allerdings lag die Rohdichte der Platten mit 845 $\mathrm{kg} / \mathrm{m}^{3}$ deutlich zu weit über dem geforderten Wert. Dadurch wurden die Querzugfestigkeiten positiv beeinflusst. Bei der Quellung zeigte sich, dass mindestens zwei Prozent Hydrophobierungsmittel zum Erreichen der EN-Werte eingesetzt werden müssen.

\subsubsection{Fazit der Prüfung der physikalisch-technologischen Eigenschaf- ten und der Wirtschaftlichkeit der eingesetzten Bindemittel}

Die Qualitätsprüfung von MDF-Platten mit mechanisch-enzymatisch aufgeschlossener Kartoffelpülpe als Bindemittel wurde mit Hilfe der wichtigsten Bewertungskriterien (Querzugfestigkeit und Dickenquellung nach $24 \mathrm{~h}$ ) durchgeführt. Die Dickenquellung ist eine wichtige physikalische Eigenschaft von Holzwerkstoffen und wird definiert durch die Dickenzunahme der Faserplatte nach Wasser- bzw. Feuchteaufnahme (LAMPERT, 1967).

Das wichtigste Kriterium zur Prüfung der MDF-Platten stellte die EN 622-5 dar. Die Faserplatten sollten die Anforderungen dieser Norm erfüllen. In den einzelnen Versuchsreihen wurden die notwendigen EN-Vorgaben bis auf eine Ausnahme nicht erreicht. Das größte Problem bei der Prüfung der MDF-Platten zeigte sich in der Dickenquellung nach 24 Stunden. Diese Werte wurden zunächst weit überschritten. Bei den Bindemittelmischungen mit UF-Harz zeigte sich erst ab einer PülpeSubstitution von 60 und 50 \% eine Verbesserung in den Werten der Quellung. Auch die Zugabe von einem Prozent Haftvermittler zeigte keine relevante Verringerung der Dickenquellung. Das bestmögliche Ergebnis wurde mit $100 \%$ mechanischenzymatisch aufgeschlossener Pülpe und einer Zugabe von $2 \%$ Haftvermittler 1154 und $2 \%$ Hydrophobierungsmittel (bezogen auf atro Faser) erreicht. Die Zugabe von $2 \%$ Hydrophobierungsmittel hatte keinen negativen Einfluss auf die Festigkeitseigenschaften der MDF-Platten, obwohl RoFFAEL et al. (1982) für die Herstellung von Spanplatten nur eine maximale Zugabe von 1,5 \% Hydrophobierungsmittel empfehlen. Das Hydrophobierungsmittel blockiert die kapillaren Hohlräume des Faserverbandes und verhindert dadurch die Einwirkung quellend wirkender Reagenzien, gleichzeitig werden aber auch an diesen Stellen die festigkeitserhöhenden Kräfte reduziert (LAMPERT, 1967). Aufgrund dieser Ergebnisse sollte die maximale Dosierung von 2 \% Hydrophobierungsmittel zur Herstellung von 
Pülpe gebundenen MDF-Platten nicht überschritten werden. Neben der Zugabe eines Hydrophobierungsmittels wird die Quellung durch die Rohdichte, dem Pressdruck und der -temperatur beeinflusst. Die Pressparameter wurden bei den Versuchsreihen nicht verändert und die Schwankungen in der Rohdichte waren nicht so gravierend um großen Einfluss auf die Dickenquellung auszuüben.

Die Querzugfestigkeiten der einzelnen Versuchsreihen zeigten, dass durch die Zugabe von Harnstoff-Formaldehydharz die Festigkeiten erhöht werden konnten. Bei einer Pülpe-Substitution durch UF-Harz von $50 \%$ konnten MDF-Platten mit Querzugfestigkeiten im EN-Bereich hergestellt werden. Die einprozentige Zugabe eines Haftvermittlers hatte ebenfalls positive Auswirkungen auf die Querzugfestigkeit. Mit einer Erhöhung der Haftvermittlerzugabe auf zwei Prozent, bezogen auf atro Faser, konnte die Querzugfestigkeit so weit verbessert werden, dass EN-Werte erreicht wurden. Unterschiedliche Querzugfestigkeiten innerhalb der einzelnen Versuche sind auf ungleichmäßige Beleimung und Schwankungen der Rohdichte zurückzuführen.

Die Rohdichte ist der entscheidende Faktor, die sowohl die Dickenquellung als auch die Querzugfestigkeit beeinflusst. Die unterschiedlichen Werte der Rohdichte erklären sich durch leichte Unregelmäßigkeiten bei der Einstreumenge, bzw. der Faservliesbildung, der Materialfeuchte und dem Verdichtungsfaktor.

Nach mehrfacher Reproduzierung dieser Ergebnisse lässt sich zusammenfassend sagen, dass MDF-Platten, die mit $100 \%$ mechanisch-enzymatisch aufgeschlossener Pülpe als Bindemittel und ohne Additive hergestellt wurden, keine EN-Werte erreichten. Bei einer Mischung der Kartoffelpülpe mit Harnstoff-Formaldehydharz wurden die besten Ergebnisse bei einem Mischungsverhältnis von 50 \% Pülpe zu 50 $\%$ UF-Harz erzielt. Mit Hilfe von mindestens zwei Prozent Haftvermittler und Hydrophobierungsmittel konnten MDF-Platten auch mit $100 \%$ mechanischenzymatisch aufgeschlossener Kartoffelpülpe als Bindemittel hergestellt werden, die die Voraussetzungen der EN 622-5 erfüllten. Bei allen Versuchsreihen zeigte sich, dass die MDF-Platten, die mit einer Presszeit unter fünf Minuten verpresst wurden, immer schlechtere physikalisch-technologische Eigenschaften aufwiesen als Platten mit längerer Presszeit.

Neben den physikalisch-technologischen Eigenschaften spielt der Preis des Bindemittels eine zentrale Rolle bei der Herstellung von Holzwerkstoffen. Daher wurde eine ungefähre Aufstellung der Kosten für den enzymatischen Aufschluss erstellt. Die Berechnung der Wirtschaftlichkeit erfolgte mit Hilfe einer überschlägigen Kalkulation der Kosten, die bei der Herstellung von 1 t Bindemittel entstehen. Für den enzymatischen Aufschluss der Kartoffelpülpe entstehen folgende Materialkosten, die in der Tab. 4-4 aufgelistet sind: 
Tab. 4-4: Materialkosten für den enzymatischen Aufschluss von $1 \mathrm{t}$ Kartoffelpülpe

6, 7 t Pülpe direkt aus dem Produktionsprozess (feucht) mit: $\quad 8,50 € / \mathrm{t}$

entsprechen 1 t Pülpe (trocken) mit einem Feststoffgehalt von $15 \%$ : $\quad \mathbf{5 7} €$

$50 \mathrm{~kg}$ Enzymkomplex werden für einen enzymatischen Aufschluss mit

$5 \%$ Enzym (w/w) bezogen auf den Feststoff der Pülpe benötigt: $\quad 20 € / L$

$50 \mathrm{~kg}$ entsprechen (bei einer Dichte von 1,14 g/L) 43 Litern: $\quad \mathbf{8 6 0} €$

Gesamtkosten (ohne Produktionskosten):

$917 € / t$

Der reine Verkaufspreis von Harnstoff-Formaldehydharz liegt bei $0,4 € / \mathrm{kg}$, was einem Preis von $400 € / t$ entspricht. Der Einsatz des Enzyms beim Aufschluss der Kartoffelpülpe macht den größten Kostenfaktor aus, allerdings ist der veranschlagte Preis von $20 € / L$ nur ein Richtpreis. Mit zunehmender Abnahmemenge des Enzyms sinkt auch der Verkaufpreis, so dass in diesem Bereich noch ein Spielraum zur Kostensenkung besteht.

Zurzeit ist deshalb die Verwendung der mechanisch-enzymatisch aufgeschlossenen Kartoffelpülpe als Bindemittel unter ökonomischen Gesichtspunkten nicht möglich. Der Einsatz der Pülpe wird sich erst bei einer Verteuerung der herkömmlichen Bindemittel rentieren. 


\subsection{Abbau der MDF-Platten durch Weiß-, Braun- und Moderfäulepilze}

Der Einsatz von Holz bzw. Holzwerkstoffen erfordert in vielen Anwendungsbereichen eine große Nutzungsdauer. Allerdings ist die Beständigkeit von Vollholz aber auch Holzwerkstoffen durch biotische Faktoren (Bakterien, Pilze und Insekten) gefährdet. Durch entsprechende Witterungseinflüsse wie $z$. B. Luftfeuchtigkeit und Temperatur kann der Befall durch diese biotischen Faktoren begünstigt werden.

Um den möglichen Befall des Holzes bzw. der Holzwerkstoffe durch Holzschädlinge besser einordnen zu können, entwickelte man so genannte Gefährdungsklassen (DGfH, 1994). Diese gelten sowohl für Vollholz als auch für Holzwerkstoffe, allerdings immer mit spezifischen Kriterien für das jeweilige Produkt und den Verwendungszweck. Die Gefährdungsklassen (GK) für Faserplatten werden in Kategorien von 1 bis 5 unterteilt. Bei der GK 1 kann die Umgebung als trocken bezeichnet werden und die Gefahr eines Befalls durch Pilze als unbedeutend. Mit zunehmender GK steigt auch die relative Luftfeuchtigkeit der Umgebung und somit auch innerhalb der Faserplatten. Demzufolge erhöht sich die Gefahr eines Wachstums von holzzerstörenden Pilzen.

Bei der Einteilung der Faserplatten als Baustoff nach DIN EN 316 und DIN EN 622, Teil 2-5, unterscheidet man Verwendungszwecke für den Trockenbereich, Feuchtbereich und den Außenbereich (vgl. 2.3.2.3). Mitteldichte Faserplatten vom Typ MDF werden für allgemeine Zwecke zur Verwendung im Trockenbereich eingesetzt (DIX u. ROFFAEL, 1999). Der Trockenbereich ist definiert durch einen Feuchtegehalt des Werkstoffs, der einer Temperatur von $20^{\circ} \mathrm{C}$ und einer relativen Luftfeuchte der Umgebung entspricht, die nur wenige Wochen im Jahr $65 \%$ überschreitet. Platten für diesen Verwendungszweck liegen in der GK 1. Daher ist ein Befall durch holzzersetzende Pilze unter normalen Umständen gering. Allerdings sollte in diesem Versuch die gezielte Abbaubarkeit der hergestellten MDF-Platten durch holzzersetzende Pilze untersucht werden. Zu diesen zählt man die WeißfäuleBraunfäule- und Moderfäulepilze.

\subsection{1 Überwachsung der MDF-Proben mit Pilzmyzel}

Die visuelle Überprüfung des Überwachsungsgrads der MDF-Proben mit Pilzmyzel sollte einen Vergleich der unterschiedlichen Pilzarten hinsichtlich der 
Befallgeschwindigkeit und der Fungizidwirkung ermöglichen. Das eingesetzte Fungizid Mergal ${ }^{\circledR}$ S88 wurde zuvor mit $1 \%(w / w)$ bezogen auf den Feststoff des Bindemittels über die Beleimung in die MDF-Proben gebracht.

Willeitner (1964), SHEKHOLESLAmi (1986) und Winkelmann (1997) haben das Verfahren der Überwachsungskontrolle bzw. eine modifizierte Form bereits in ihren Untersuchungen verwendet. WiNKELMANN (1997) setzte ebenfalls Mergal ${ }^{\circledR}$ S88 ein. Aufgrund der visuellen Beobachtung kann man den Überwachsungsgrad allerdings nur als Richtlinie für das Wachstum der Pilze annehmen und noch keine Aussage über den Grad des Holzabbaus treffen.

\subsubsection{Myzelwachstum von Trametes versicolor}

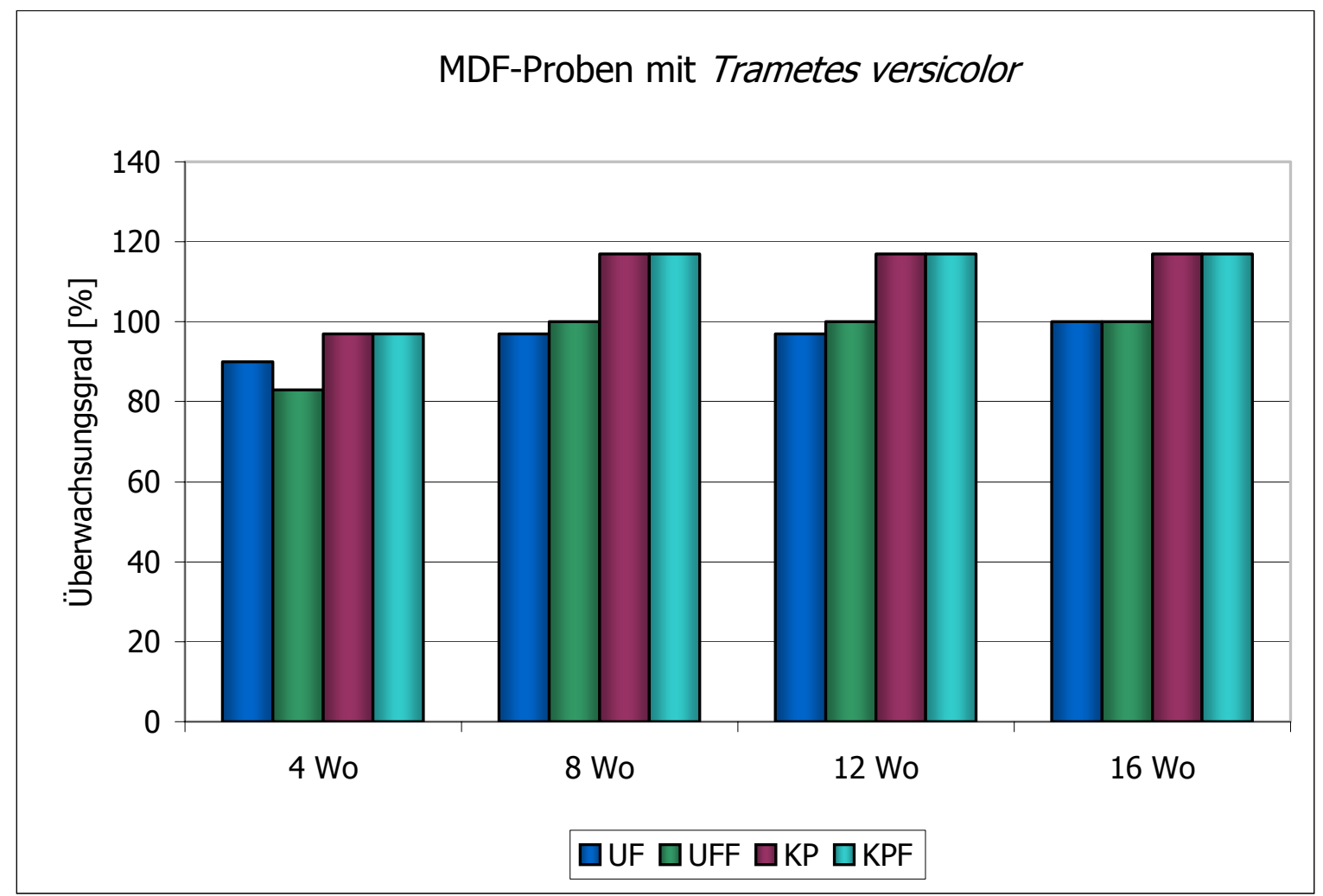

Abb. 4-38: Überwachsungsgrad der MDF-Proben, die mit Trametes versicolor inkubiert wurden (UF = nur UF-Harz; UFF = UF-Harz mit Zugabe von Fungizid; KP = nur Kartoffelpülpe; KPF = Kartoffelpülpe mit Zugabe von Fungizid).

Das Myzel von T. versicolor war bereits nach vier Wochen gleichmäßig über den Proben gewachsen, wobei die mit UF-Harz gebundenen MDF-Proben durchgehend ein geringeres Wachstum zeigten. Dabei war kein wesentlicher Unterschied zwischen den Proben ohne und mit Fungizid zu erkennen. 
In der Abb. 4-38 ist zu erkennen, dass sich das Myzel auf den mit Pülpe gebundenen MDF-Platten schneller ausgebreitet hat. Dabei schien das Fungizid keine erkennbare hemmende Wirkung auf das Myzelwachstum zu haben. Diese Ergebnisse zeigen, dass T. versicolor gute Wachstumsbedingungen auf den MDFProben vorgefunden hat. Das Fasergefüge wurde durch Quellung der MDF-Proben gelockert, was ein Eindringen der Hyphen erleichterte und die Pülpe hatte aufgrund ihrer Zusammensetzung ein starkes Nährstoffangebot für den Pilz. Das eingesetzte Fungizid Mergal ${ }^{\circledR}$ S88 hatte keinen sichtbaren Einfluss auf den Pilz.

\subsubsection{Myzelwachstum von Coniophora puteana}

Der Pilz auf den mit Pülpe gebundenen MDF-Proben zeigte nach den ersten vier Wochen ein deutlich stärkeres Wachstum als der auf den UF-Harz gebundenen Proben. Das Myzelwachstum nahm dann allerdings nur noch leicht zu, während das Myzel auf den mit UF-Harz gebundenen Proben noch leicht weiter wuchs. Nach Beendigung des Versuchs waren die mit Pülpe gebundenen Proben vollständig mit Myzel überwachsen und die Oberfläche der mit UF-Harz gebundenen bis zu etwa $90 \%$.

Das Fungizid hatte visuell keinen Einfluss auf das Wachstum des Braunfäulepilzes. Der Überwachsungsgrad war bei den jeweiligen MDF-Proben immer identisch. Dies bestätigen auch Ergebnisse von WiNKELMANN (1997). Es ist davon auszugehen, dass die Wirkstoffe des Fungizids nicht für $C$. puteana geeignet sind. In der Abb. 4-39 wird gezeigt, dass der Unterschied zwischen den verschiedenen eingesetzten Bindemitteln vernachlässigbar gering ist. Der kurze Vorsprung des Pilzes auf den mit Pülpe gebundenen MDF-Platten relativierte sich bereits nach achtwöchiger Inkubationszeit. Der geringere Bewuchs der MDF-Proben durch C. Puteana im Vergleich zu T. versicolor lässt sich dadurch erklären, dass die Braunfäulepilze mit Hilfe von Ektoenzymen das Holz abbauen. Diese Enzyme gelangen in die Zellwände des Holzes und verursachen einen erheblichen Wandabbau, ohne das dafür viele Hyphen gebildet werden müssen (vgl. LIESE, 1981). 


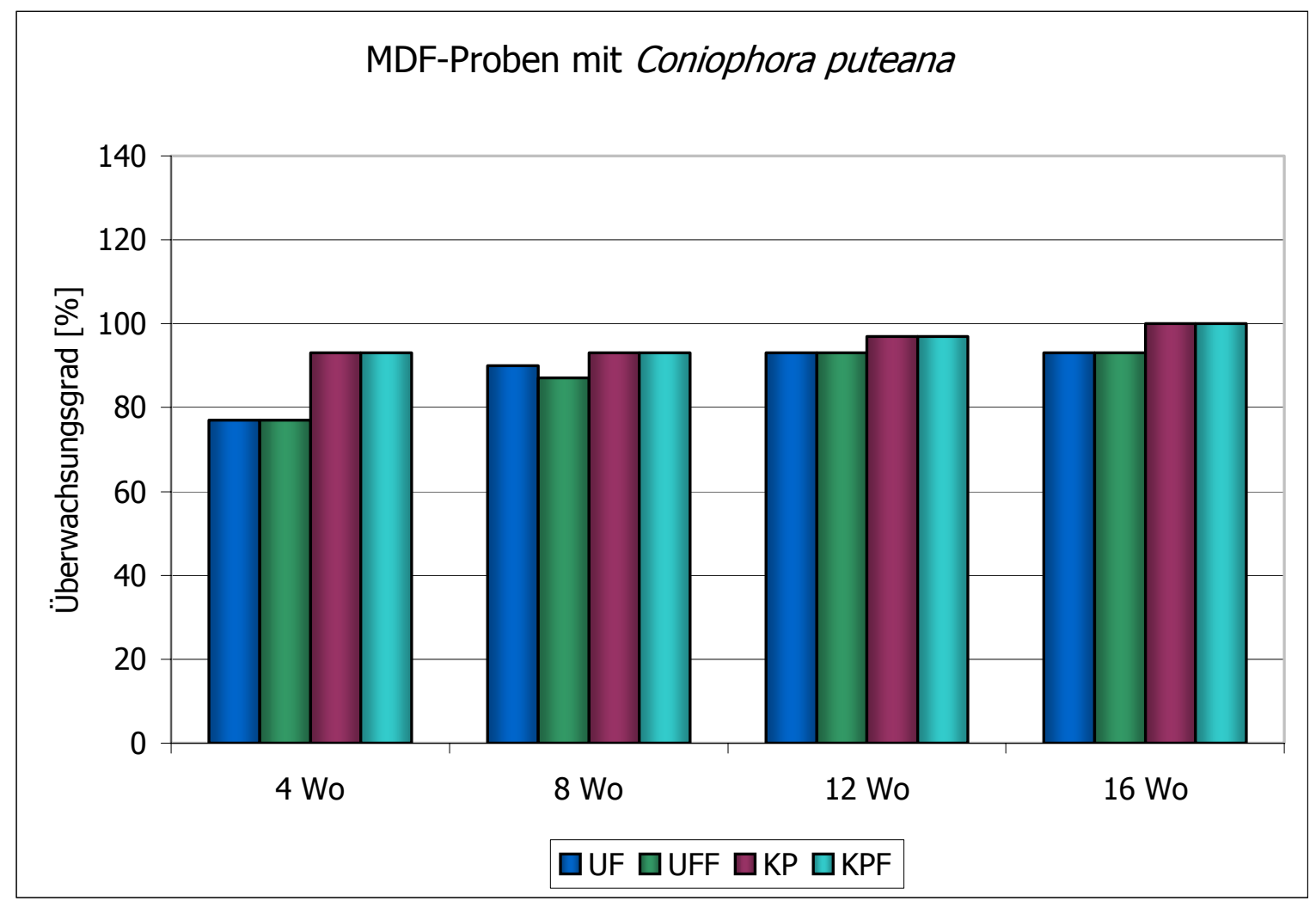

Abb. 4-39: Überwachsungsgrad der MDF-Proben, die mit Coniophora puteana inkubiert wurden (UF = nur UF-Harz; UFF = UF-Harz mit Zugabe von Fungizid; KP = nur Kartoffelpülpe; KPF = Kartoffelpülpe mit Zugabe von Fungizid).

\subsubsection{Myzelwachstum von Chaetomium globosum}

Ähnlich wie T. versicolor wies C. globosum bereits bei der ersten Kontrolle ein sehr starkes Wachstumsverhalten auf. Dies widerspricht anderen Untersuchungen (WinkelmanN, 1997) bei denen C. globosum immer ein schwächeres Wuchsverhalten zeigte. Alle Proben der MDF-Platten wurden gleichmäßig mit Myzel überwachsen, außer den UFF-Proben (s. Abb. 4-40). Da bei den übrigen Proben das Fungizid keinen sichtbaren Einfluss auf das Myzelwachstum hatte, ist davon auszugehen, dass nur die Kombination von UF-Harz und Fungizid eine wachstumshemmende Wirkung auf den Pilz ausübte. 


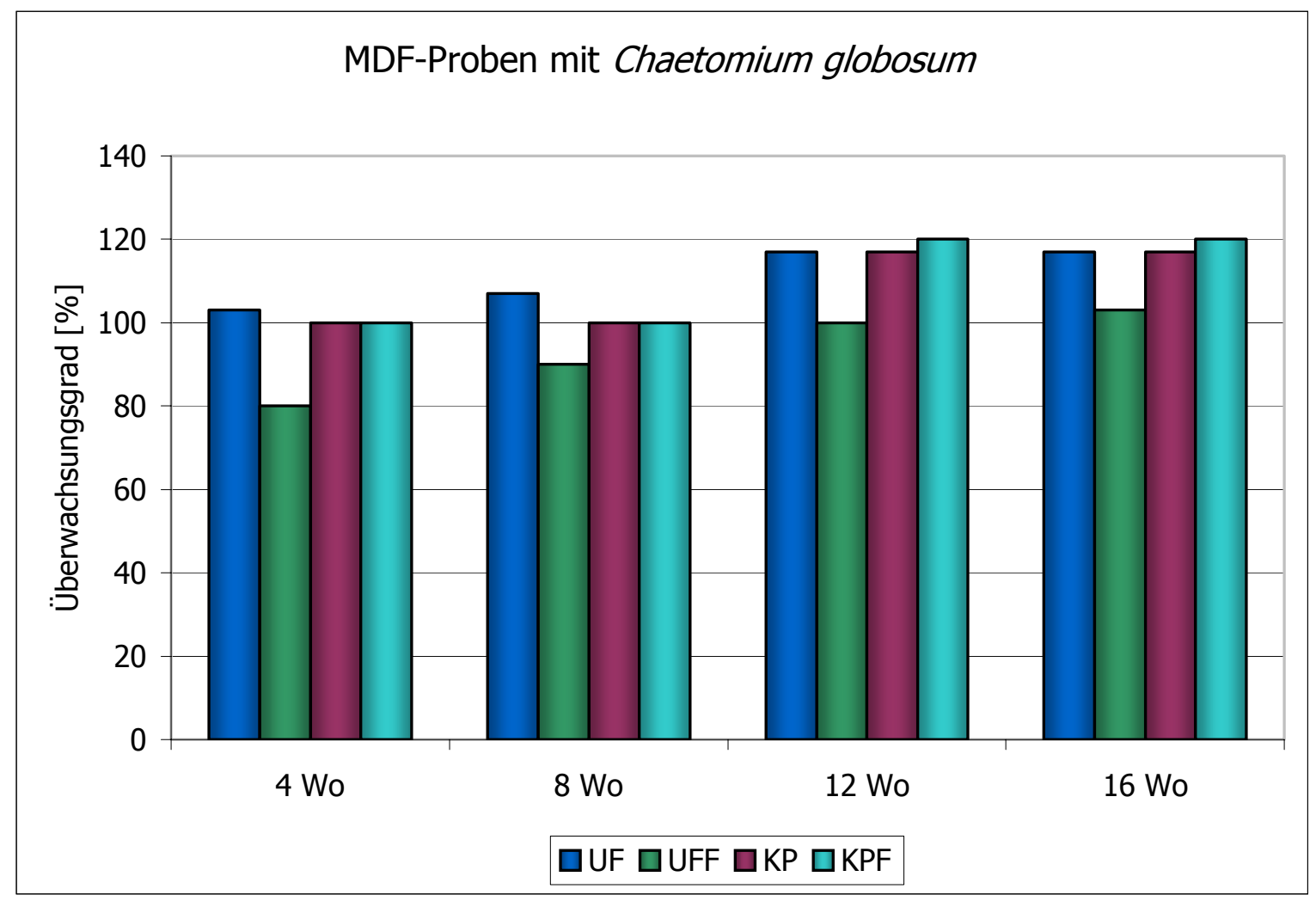

Abb. 4-40: Überwachsungsgrad der MDF-Proben, die mit Chaetomium globosum inkubiert wurden (UF = nur UF-Harz; UFF = UF-Harz mit Zugabe von Fungizid; KP = nur Kartoffelpülpe; KPF = Kartoffelpülpe mit Zugabe von Fungizid).

\subsubsection{Holzabbau durch holzzersetzende Pilze}

Der Einsatz von mechanisch-enzymatisch aufgeschlossener Kartoffelpülpe als Bindemittel erfolgte nur bei mitteldichten Faserplatten für den Trockenbereich. Aus diesem Grund waren die hergestellten Proben auch nur in der Gefahrenklasse 1, d. h. eine Holzzersetzung durch Pilze unter diesen Bedingungen ist auszuschließen. Somit steht nicht der Schutz der MDF-Platten im Vordergrund, sondern die Möglichkeit eines gezielten Abbaus der MDF-Platten durch holzzersetzende Pilze. Dadurch soll eine Kompostierung der Holzwerkstoffe ermöglicht werden.

Aufgrund der TA-Siedlungsabfall, die seit dem 1.1.2005 in Kraft getreten ist, ist es nicht erlaubt Siedlungsabfall mit mehr als $5 \%$ organischem Material auf einer Haushaltsdeponie zu lagern. Sofern diese Abfälle nicht vermeidbar sind, sollten sie stofflich oder energetisch verwertet oder umweltverträglich beseitigt werden (ROFFAEL, 1997b). Ein Großteil der heutigen Möbel besteht bis zu $90 \%$ aus organischem Material, wobei Span- und MDF-Platten den Hauptbestandteil bilden. Eine Deponierung solcher Altmöbel ist unter den oben genannten Umständen nicht 
mehr möglich, so dass neben der thermischen Nutzung auch eine Form von Kompostierung unter Zuhilfenahme von holzzersetzenden Pilzen in Frage käme. Bei der Verwendung von natürlichen Bindemitteln wie z. B. Kartoffelpülpe ließen sich solche Platten rückstandslos abbauen.

\subsubsection{Holzzersetzung der mit UF-Harz hergestellten Proben}

Insgesamt wiesen die MDF-Proben nach 16 Wochen eine Abbaurate unter $8 \%$ auf (s. Abb. 4-41). Die Proben, die mit C. globosum inkubiert wurden, zeigten die stärkste Holzzersetzung. Andere Arbeiten (vgl. MERILL, 1965) erreichten nach zwölfwöchiger Inkubation mit C. globosum bei Faserplatten sogar einen Masseverlust von $13 \%$.

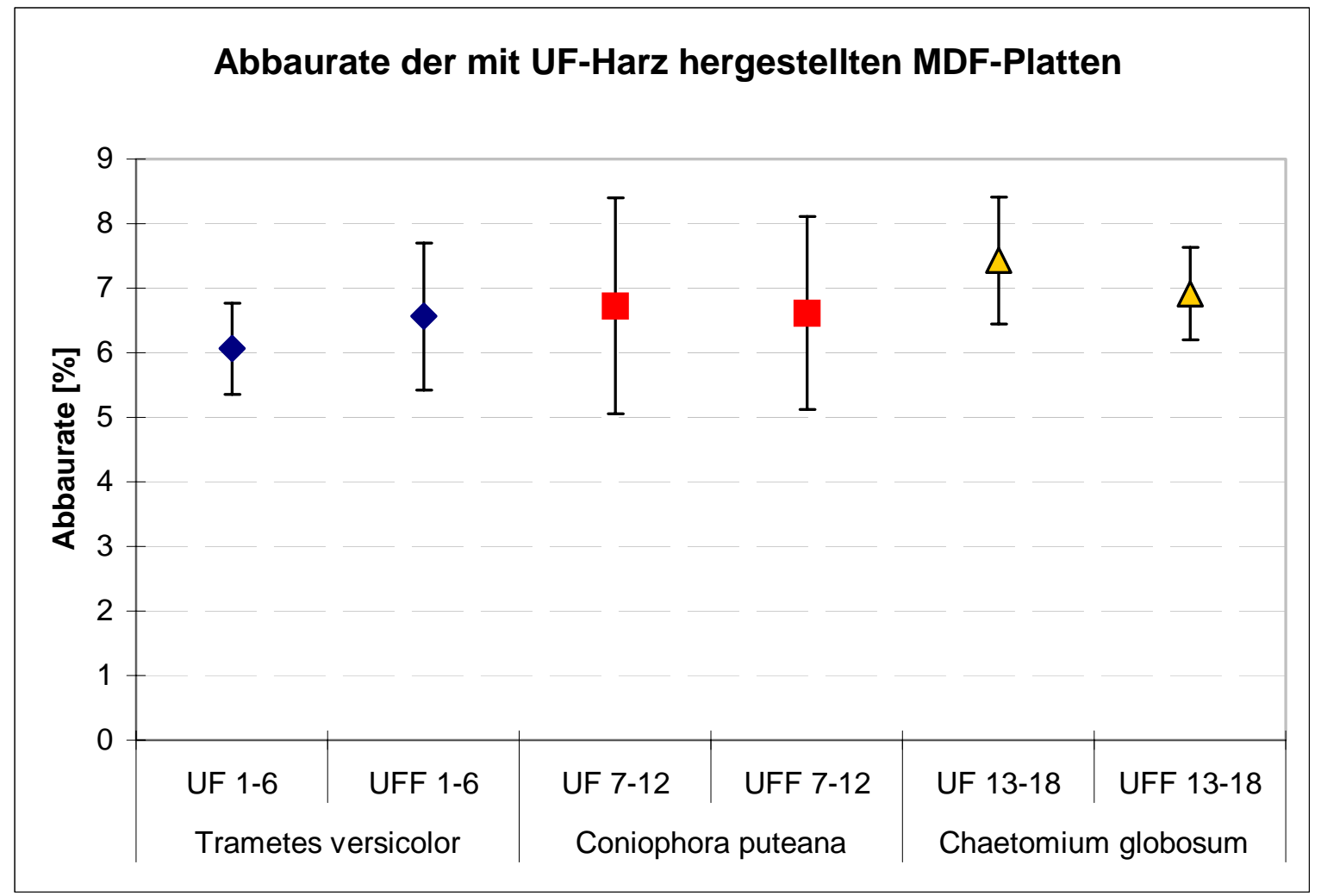

Abb. 4-41: Abbaurate der MDF-Proben, die mit Harnstoff-Formaldehydharz als Bindemittel hergestellt wurden (UF = nur UF-Harz; UFF = UF-Harz mit Zugabe von Fungizid).

Man konnte bei den Proben (UFF), die mit C. globosum inkubiert wurden, jedoch eine geringe Auswirkung des Fungizids auf das Pilzwachstum erkennen. Beim Weißund Braunfäulepilz hatte das Fungizid keine Wirkung. Im Gegenteil, die mit $T$. 
versicolor inkubierten UFF-Proben ließen eine höhere Abbaurate erkennen als die ungeschützten Proben. Insgesamt war der Abbau bei den Proben, die mit $T$. versicolor und $C$. puteana inkubiert wurden annähernd identisch.

\subsubsection{Holzzersetzung der mit mechanisch-enzymatisch aufgeschlossener Pülpe hergestellten Proben}

Die Proben, die mit den Weiß- und Braunfäulepilz inkubiert wurden, zeigten eine überdurchschnittlich hohe Abbaurate. Der Abbau durch $C$. puteana lag sogar bei durchschnittlich $55 \%$. T. versicolor konnte in dem Versuchszeitraum 30 bis $35 \%$ der Gesamtmasse abbauen, während $C$. globosum nur eine sehr geringe Rate von etwa $10 \%$ erreichte (s. Abb. 4-42).

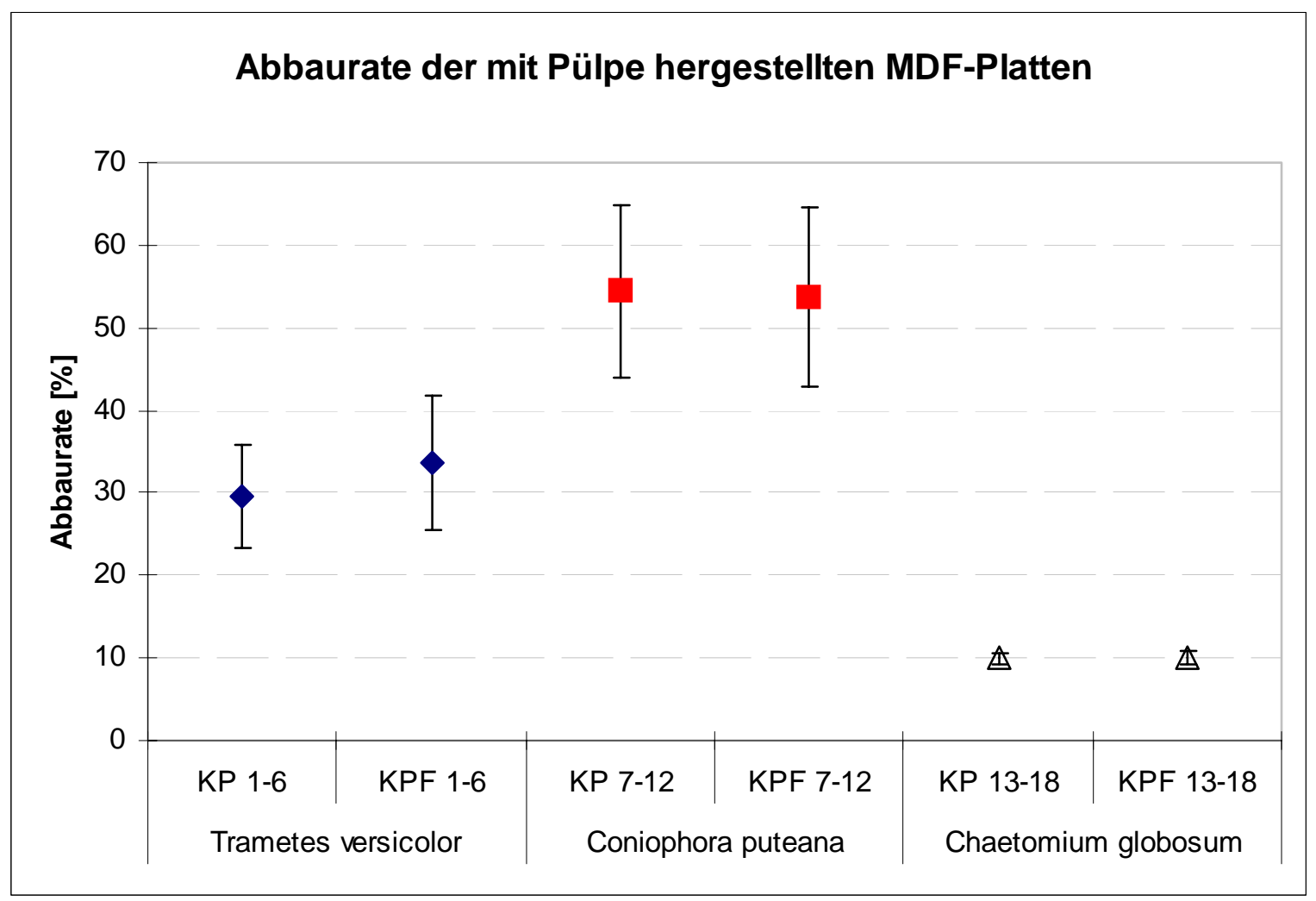

Abb. 4-42: Abbaurate der MDF-Proben, die mit mechanisch-enzymatisch aufgeschlossener Kartoffelpülpe als Bindemittel hergestellt wurden $(\mathrm{KP}=$ nur Kartoffelpülpe; KPF = Kartoffelpülpe mit Zugabe von Fungizid). 
Das Fungizid hatte bei keiner der unterschiedlichen Proben eine Auswirkung, teilweise wuchs der Pilz auf den geschützten Proben besser als auf den ungeschützten MDF-Proben.

\subsubsection{Holzzersetzung der Virulenzkontrollen}

In der Abb. 4-43 sind die Abbauraten der Virulenzkontrollen aufgezeigt. Die Virulenzkontrollen waren MDF-Proben, die sowohl mit UF-Harz als auch mit mechanisch-enzymatisch aufgeschlossener Pülpe als Bindemittel hergestellt wurden. Diese Proben wurden ohne Fungizid mit dem Pilz inkubiert, um die uneingeschränkte Abbauleistung der jeweiligen Pilze zu kontrollieren.

Ein deutlicher Unterschied zeigte sich bei den MDF-Proben, die mit mechanischenzymatisch aufgeschlossener Pülpe hergestellt und $C$. puteana inkubiert wurden. Die Abbaurate war fast $25 \%$ geringer als bei dem tatsächlichen Abbauversuch (vgl. 4.6.2.2). Ein möglicher Grund für den geringeren Abbau könnte ein schwächerer Pilzstamm gewesen sein. Bei den UF-Harz gebundenen Proben zeigte sich hingegen ein identisches Abbauverhalten wie bei Abschnitt 4.6.2.1.

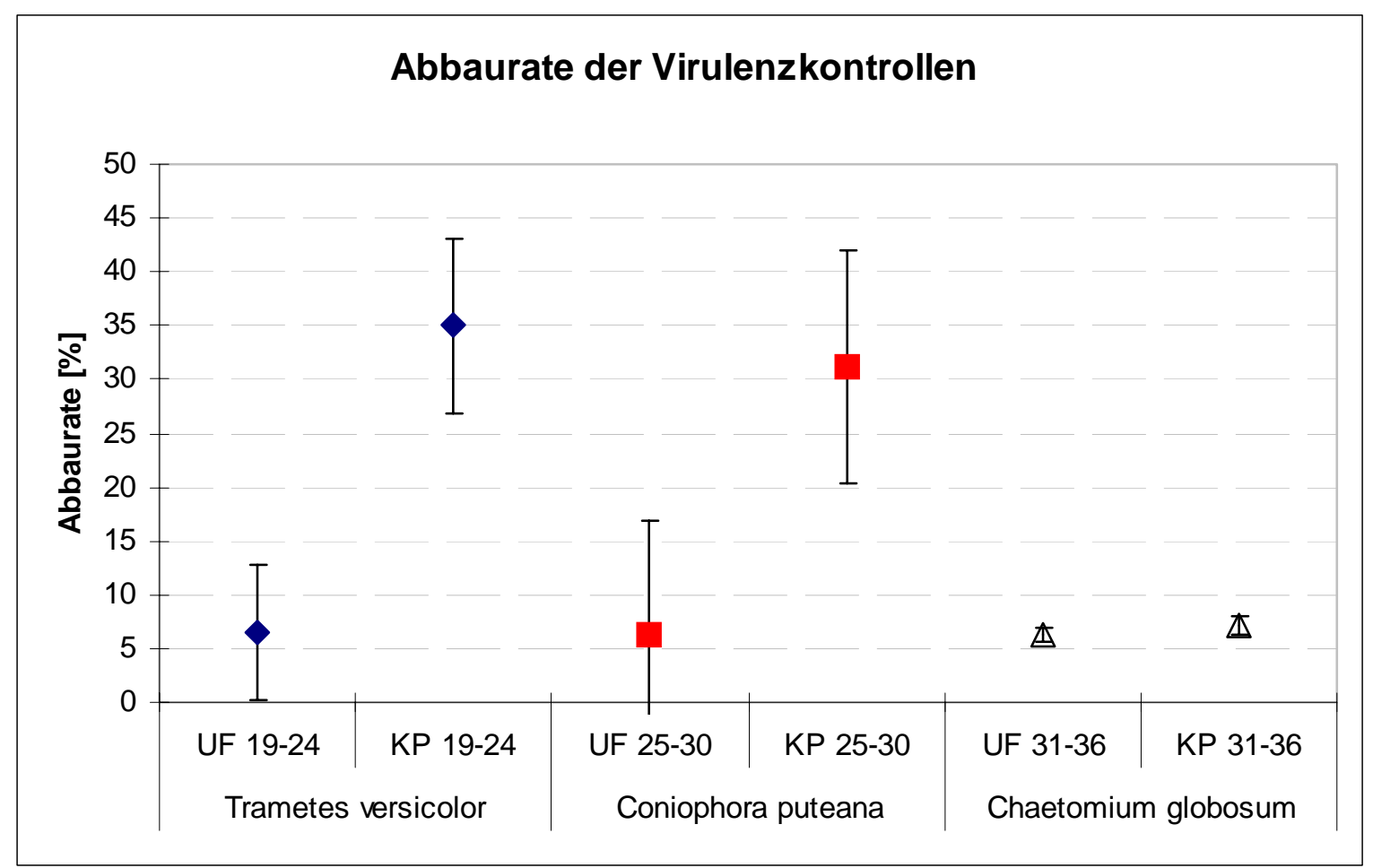

Abb. 4-43: Abbaurate der Virulenzkontrollen, die nur mit UF-Harz (UF) oder mechanisch-enzymatisch aufgeschlossener Kartoffelpülpe (KP) als Bindemittel hergestellt wurden, ohne Zugabe von Fungizid. 


\subsubsection{Fazit des Holzabbaus}

Der Abbauversuch hat gezeigt, dass sowohl T. versicolor als auch C. puteana als Vertreter der Weiß- und Braunfäulepilze geeignet sind, die MDF-Platten abzubauen. C. puteana erwies sich als der stärkste Holzzersetzer, was durch andere Arbeiten (PARAMESWARAN u. RofFAel, 1985; WinKELMANN, 1997) bereits bestätigt wurde. Der Moderfäulepilz C. globosum ist unter optimalen Bedingungen ebenfalls in der Lage mitteldichte Faserplatten zu zersetzen, allerdings benötigt er deutlich mehr Zeit. Ein Grund für den schwachen Abbau war die ungenügende Feuchtigkeit in den MDFProben.

Das Fungizid Mergal $^{\circledR}$ S88 wird zwar ursprünglich zum Schutz von Dispersionsfarben und Kunstharzputz eingesetzt, allerdings wurden bereits Versuche mit Mergal ${ }^{\circledR}$ zum Schutz von Holz- und Holzwerkstoffen durchgeführt (TrojAnOwSKI, 2005). Laut dem Technischen Datenblatt (Troy CHEMIE GMBH, 2003) ergab sich im Laborversuch für $C$. globosum eine minimale Hemmkonzentration (MHK-Wert) von 0,0001 \%. Dadurch lässt sich $u$. a. die relativ geringe Abbauleistung des Pilzes begründen. Der trotzdem starke Myzelwuchs lässt sich nur dadurch erklären, dass der Pilz seine Nährstoffversorgung hauptsächlich aus dem Nährmedium gedeckt hat. Die Wirksamkeit des Mergal ${ }^{\circledR}$ S88 könnte möglicherweise auch durch die hohe Temperatur von $190{ }^{\circ} \mathrm{C}$ beim Pressvorgang verringert bzw. zerstört worden sein. Zur Überprüfung müsste eine weitere Versuchsreihe mit einer höheren Konzentration des Fungizids durchgeführt werden.

Weitere Faktoren beim Holzabbau sind die verwendeten Bindemittel. Laut WilleITNER (1965) hat Harnstoff eine wachstumsfördernde Wirkung auf den Pilz, hervorgerufen durch den relativ hohen Stickstoffgehalt. Dieser Effekt wird allerdings gemindert mit steigendem Formaldehydgehalt im Bindemittel. PARAMESWARAN und RofFAel (1985) zeigten beim Abbau von Spanplatten, dass der Holzabbau durch Weiß- und Braunfäuleerreger dadurch nicht beeinflusst wurde. Von diesen Autoren wurden Bindemittel mit unterschiedlichen Molverhältnissen von Harnstoff zu Formaldehyd $(1: 1,27 \ldots .1: 2,1)$ untersucht. Nur C. globosum wurde ab einem Molverhältnis von 1:1,8 im Wachstum beeinträchtigt.

Das Bindemittel Kauritec ${ }^{\circledR} 407$, das für die Herstellung der MDF-Platten verwendet wurde, hat laut Technischem Datenblatt ein Molverhältnis von Harnstoff zu Formaldehyd von $1: 1,1 \ldots .1: 1,2$. Somit kann davon ausgegangen werden, dass das Formaldehyd das Wachstum der Pilze auf den MDF-Proben nicht negativ beeinflusste. 


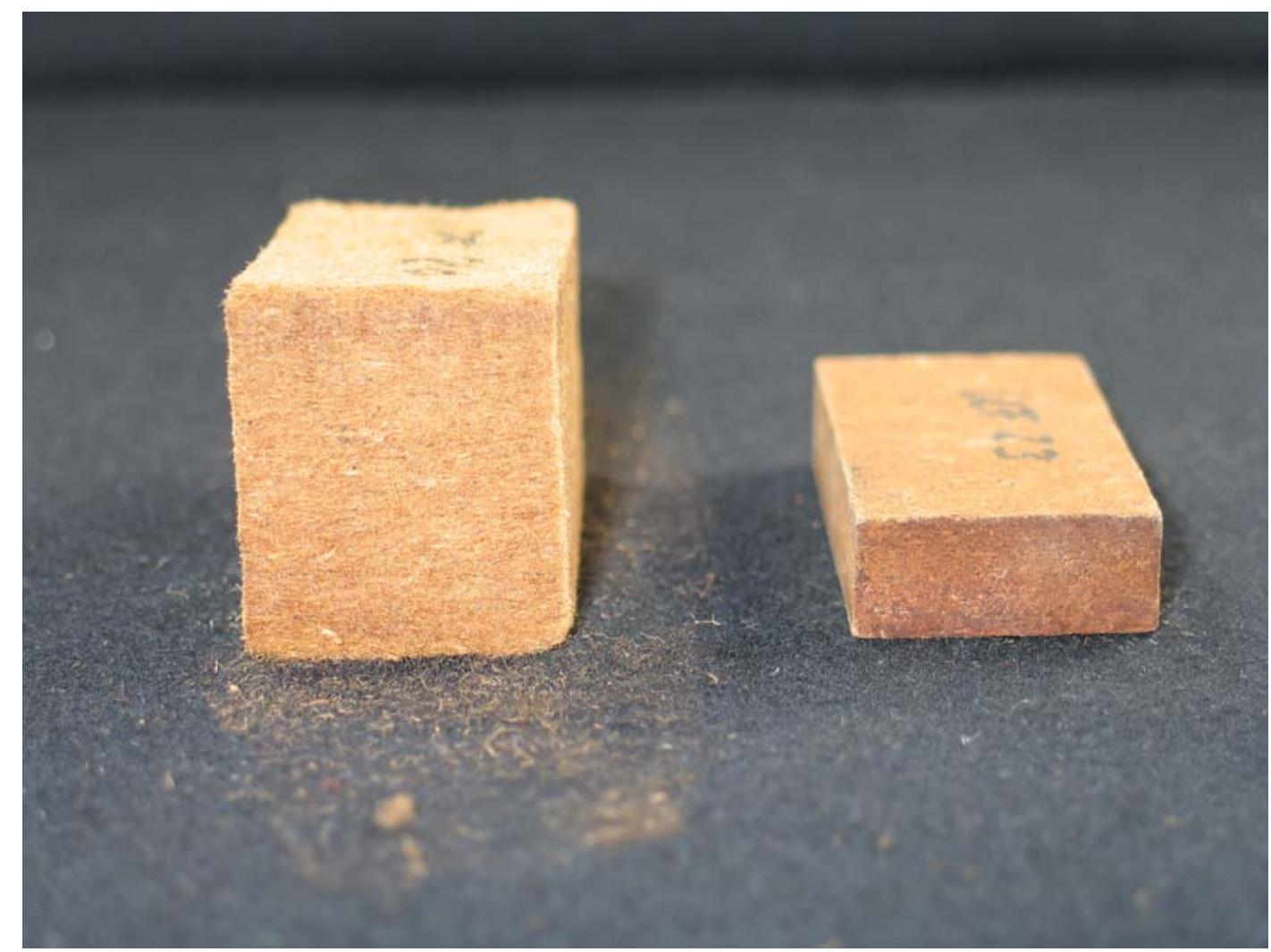

Abb. 4-44: Vergleich der Quellung der MDF-Proben am Beispiel zweier Proben, die mit mechanisch-enzymatisch aufgeschlossener Kartoffelpülpe (links) und UF-Harz (rechts) als Bindemittel hergestellt wurden. Inkubiert wurden die Proben mit $C$. puteana.

Insgesamt wurden die Proben, die mit mechanisch-enzymatisch aufgeschlossener Pülpe hergestellt wurden, deutlich besser von den jeweiligen Pilzen abgebaut als die Proben mit UF-Harz (vgl. Abb. 4-41 und Abb. 4-42). Daraus lässt sich schließen, dass das Harnstoff-Formaldehydharz eine wachstumshemmende Eigenschaft aufweist.

Da die Kartoffelpülpe ein rein pflanzliches Produkt ist, liefert sie ausreichend Stickstoff für das Pilzwachstum, was die deutlich stärkere Überwachsung der KPund KPF-Proben erklärt. Eine weitere Ursache für den erhöhten Abbau ist die Quellung der MDF-Proben durch Feuchtigkeit. Diese Quellung verursachte eine Lockerung des Fasergefüges, wodurch die Hyphen der Pilze leichter in die Proben eindringen konnten und aufgrund des erhöhten Feuchtigkeitsgehaltes bessere Wachstumsbedingungen vorfanden (s. Abb. 4-44).

Da die Fasern der MDF-Platten zu 100 \% durch Kiefernholz abgedeckt werden, fand C. puteana, der Nadelhölzer bevorzugt, gute Wachstumsbedingungen vor. Dies wäre auch eine Erklärung für die hohe Abbaurate der Proben. Eine Eigenart der Braunfäulepilze ist, dass sie sich zu Beginn des Abbaus ein Depot von leicht 
hydrolysierbaren Zwischenprodukten anlegen, die zur späteren Deckung des Energiebedarfs verwendet werden (SEIFERT, 1965). Das relativ langsame Wachstum des Myzels (s. Abb. 4-39) wurde bereits in früheren Arbeiten (SHEKHOLESLAMI, 1986) festgestellt. Der Grund liegt im typischen Abbauverhalten der Braunfäuleerreger (s. 3.1.9).

C. globosum baut die Cellulose des Holzes sofort zu $\mathrm{CO}_{2}$ und $\mathrm{H}_{2} \mathrm{O}$ ab, so dass erst gar keine Depolymerisate entstehen. Die Verbrauchsgeschwindigkeit der Abbauprodukte liegt über der Bildungsgeschwindigkeit (SEIFERT, 1965). Daher ist die Moderfäule unter optimalen Bedingungen ein äußerst aggressiver Holzzersetzer (AMMER u. LIESE, 1965).

Der T. versicolor zeichnet sich dadurch aus, dass er die einzelnen Holzbestandteile simultan zersetzen kann. Dadurch erreicht er eine relativ hohe Abbaurate bei den MDF-Proben. Allerdings wird erst durch ein intensives Hyphenwachstum in den Holzzellen die totale Nutzung der Zellwandmasse verursacht (LIESE, 1981).

Die Gemeinsamkeit des Wachstums der verwendeten Pilze liegt in dem Verlauf der Abbauintensität. In anderen Arbeiten wurde gezeigt, dass alle hier untersuchten Pilze in den ersten vier bis acht Wochen einen sehr starken Abbau zeigen, der mit zunehmender Versuchsdauer immer schwächer wird (vgl. AMMER u. LIESE, 1965). Dabei verläuft das Wachstum des Myzels nicht proportional zum Holzabbau. $C$. globosum zeigte ein starkes Myzelwachstum, allerdings war der ermittelte Holzverlust der geringste bei den untersuchten Proben (s. 4.6.1.3 und 4.6.2.1).

Insgesamt betrachtet, eignen sich die MDF-Platten, die mit mechanischenzymatisch aufgeschlossener Kartoffelpülpe als Bindemittel hergestellt wurden, deutlich besser für einen Abbau durch holzzerstörende Pilze. Da ihre Verwendung auch nur im Trockenbereich liegen sollte, ist die Wahrscheinlichkeit einer ungewollten Zerstörung durch holzabbauende Pilze äußerst gering. Allerdings sollte man die Ergebnisse des Versuchsmaßstabs nicht direkt in die Praxis übertragen (WILlEITNER, 1969), da alle Faktoren immer nur bedingt erfasst werden können. 


\section{$5 \quad$ Zusammenfassung}

Die industrielle Nutzung von Produkten aus nachwachsenden Rohstoffen hat in den letzten Jahrzehnten deutlich zugenommen. Dabei ist die Stärke nach den Fetten und Ölen das wichtigste Erzeugnis. Sie findet neben der Verwendung als Lebensmittel auch Einsatz in der Chemie-, Papier- und Wellpappenindustrie. Einer der bedeutendsten Stärkelieferanten ist die Industriekartoffel, deren Vorteile in den hohen Erträgen pro Hektar und der besonderen Stärkequalität liegen.

Die Nachteile der Stärkegewinnung aus Industriekartoffeln sind, dass sie zum einen nicht das ganze Jahr verfügbar ist und zum anderen eine enorme Menge an Nebenprodukt anfällt. Dabei handelt es sich hauptsächlich um Fruchtwasser und die so genannte Kartoffelpülpe. Je nach Produktionskampagne können dabei allein in Deutschland zwischen 0,8 und 1,0 Mio. t Kartoffelpülpe anfallen. Diese enthält neben 95 \% Wasser auch Reststärke, Zellwandreste und intakte Zellverbände. Aufgrund dieser Zusammensetzung aus organischen Polymeren und Aminosäuren unterliegt die Kartoffelpülpe sehr schnell einem Abbau durch Mikroorganismen. Zurzeit wird die Pülpe erst bis zu einem Feststoffgehalt von etwa $15 \%$ durch Pressen entwässert und anschließend als Viehfutter eingesetzt, wobei sie sowohl nass als auch mit vorheriger thermischer Trocknung verfüttert werden kann.

Das Besondere an der Kartoffelpülpe liegt in ihrer Zusammensetzung aus Zellwandresten und Stärkekörnern. Da die Kartoffel weitestgehend aus parenchymatischem Speichergewebe besteht, ist in den Zellwänden neben der Cellulose und Hemicellulose ein hoher Anteil an Pektin vorhanden, das den Zellwänden sowohl Stabilität als auch Elastizität verleiht. Bei Pektin handelt es sich um saure Polysaccharide, die wegen ihrer chemischen Struktur eine gelartige Konsistenz und reaktive Carboxylgruppen aufweisen. Mit Hilfe dieser Endungen erlangt das Pektin eine hohe Bindungsfähigkeit, die für spätere Verklebungen benötigt wird. Ein weiterer Faktor bei der Verwendung der Pülpe als Bindemittel ist die Reststärke, die zumeist in zellgebundener Form vorliegt und somit nicht ohne weiteres zur Verfügung steht. Stärke wird bereits seit langem in der Industrie als Bindemittel in verschiedenen Bereichen eingesetzt. Neben der Stärke enthält die Pülpe auch große Mengen an zellgebundenem Wasser, das nur durch starke thermische Trocknung aus den Zellen entfernt werden kann. Allerdings hätte eine Trocknung der Pülpe bei hohen Temperaturen zur Folge, dass die Oberfläche aufgrund der Maillard'schen Reaktion karamellisiert und die Bindungseigenschaften zerstört werden.

Daher war ein Ziel dieser Arbeit, durch einen mechanischen und enzymatischen Aufschluss mit pektolytischen Enzymen die Zellwände teilweise bzw. ganz aufzulösen. 
Dabei werden die polymeren Galacturonsäuren der Pektine gespalten und die zellgebundene Stärke ebenso wie das zellgebundene Wasser freigesetzt. Der Effekt ist, dass die entstandenen Galacturonsäure-Monomere neue reaktive Endungen aufweisen und bei Verklebungen wieder neue Verbindungen in Form von Wasserstoffbrücken-Bindungen eingehen. Die freie Reststärke, die bis zu $30 \%$ (bezogen auf den Feststoff) ausmachen kann, ist eine weitere bindungsfähige Komponente der Kartoffelpülpe. Ein Großteil des Wassers in der aufgeschlossenen Pülpe kann anschließend mit relativ geringer Wärmezufuhr entfernt werden. Diese mechanisch-enzymatisch aufgeschlossene Kartoffelpülpe eignet sich aufgrund der bereits genannten Komponenten als Bindemittel. Sie wird zur Herstellung von mitteldichten Faserplatten eingesetzt, die einen steigenden Marktanteil bei den Holzwerkstoffen aufweisen.

Die Holzwerkstoffindustrie ist einer der größten Abnehmer für Bindemittel, üblicherweise handelt es sich dabei um Kunstharze. Diese gehen mit bis zu $20 \%$ in die Endherstellungskosten für Holzwerkstoffe ein. Der Nachteil der Kunstharze ist der steigende Preis aufgrund steigender Rohölpreise. Daher ist die Holzwerkstoffindustrie aus Kostengründen bestrebt, Alternativen aus nachwachsenden Rohstoffen einzusetzen bzw. die herkömmlichen Bindemittel teilweise zu substituieren. Die Anforderungen an natürliche Bindemittel für Holzwerkstoffe sind hoch, d. h. sie müssen eine ausreichende Festigkeit der Holzwerkstoffe gewährleisten, ganzjährig verfügbar sein und eine gute Verarbeitbarkeit aufweisen. Für die Kartoffelpülpe bedeutet es, dass sie lagerfähig sein muss, eine ausreichende Bindungsfähigkeit und eine entsprechende Viskosität aufweist. Um dies zu erreichen, wird der mechanische und enzymatische Aufschluss eingesetzt.

Beim alleinigen mechanischen Aufschluss der Kartoffelpülpe im Labormaßstab wurde zwar eine Erhöhung der Teilchenanzahl und eine Verringerung der Teilchengröße erreicht, allerdings keine ausreichende Verringerung der Viskosität, sowie keine messbare Freisetzung des zellgebundenen Wassers. Durch eine Kombination aus mechanischem und enzymatischem Aufschluss erhielt man das erwünschte Ergebnis. Für den enzymatischen Aufschluss wurden $10 \%$ (bezogen auf den Pülpefeststoff) eines Enzymkomplexes eingesetzt, der normalerweise in der Fruchtsaftindustrie Verwendung findet. Dabei handelte es sich um eine Polygalacturonase in Kombination mit einer Cellulase. Nach der enzymatischen Behandlung konnte durch Zentrifugation ein Entwässerungsgrad, bezogen auf den Gesamtwassergehalt, von bis zu $80 \%$ erreicht werden.

Damit die mechanisch-enzymatisch aufgeschlossene Kartoffelpülpe ganzjährig zur Verfügung steht, erfolgte eine Konservierung durch Wasserentzug, d. h. die Pülpe wurde mit Hilfe von Wirbelschicht-Spühgranulation bei Temperaturen bis maximal 
$40{ }^{\circ} \mathrm{C}$ auf einen Trägerstoff in Form von Maisstärke aufgesprüht. Dabei legten sich die Pülpepartikel schichtweise an den Trägerstoff an und es entstehen kleine Granulate mit einer zwiebelartigen Struktur. Durch Zugabe von Wasser erlangte die so getrocknete Pülpe wieder einen flüssigen Zustand und konnte als Bindemittel eingesetzt werden.

Für die Herstellung von mitteldichten Faserplatten wurde die aufgeschlossene Pülpe im feuchten Zustand mit einem durchschnittlichen Feststoffgehalt von $17 \%$ eingesetzt. Die MDF-Platten mit einer $15 \%$ igen Beleimung (bezogen auf atro Faser) hatten annähernd eine Rohdichte von $800 \mathrm{~kg} / \mathrm{m}^{3}$, bei einer Plattendicke von $10 \mathrm{~mm}$. Die MDF-Platten, die ausschließlich mit mechanisch-enzymatisch aufgeschlossener Kartoffelpülpe als Bindemittel hergestellt wurden, erreichten noch keine EN-Werte. Bei einer Mischung von $50 \%$ aufgeschlossener Pülpe mit $50 \%$ HarnstoffFormaldehydharz konnten die Voraussetzungen der Querzugfestigkeiten fast erfüllt werden. Problematisch blieben die Werte der Dickenquellung nach 24 Stunden. Zur Erhöhung der Querzugfestigkeiten erfolgte der Einsatz eines Haftvermittlers auf der Basis siliziumorganischer Verbindungen. Für die Reduzierung der Dickenquellung wurde ein herkömmliches Hydrophobierungsmittel auf Paraffinbasis verwendet. Bei allen Versuchen kam es zu leichten Schwankungen in der Rohdichte, was sich teilweise auf die physikalisch-technologischen Eigenschaften der MDF-Platten auswirkte.

Bei einer ein- bis zweiprozentigen Zugabe des Haftvermittlers zu einem Bindemittel aus $100 \%$ mechanisch-enzymatisch aufgeschlossener Kartoffelpülpe konnte keine Verbesserung bei den Eigenschaften der Faserplatten erzielt werden. Allerdings wurden die Vorgaben der EN 622-5 mit einem Bindemittel bestehend aus $100 \%$ mechanisch-enzymatisch aufgeschlossener Kartoffelpülpe und einer Zugabe von $2 \%$ Haftvermittler und $2 \%$ Hydrophobierungsmittel erfüllt. Nachteilig bei der Verwendung der mechanisch-enzymatisch aufgeschlossenen Kartoffelpülpe sind die relativ hohen Kosten des Enzymkomplexes, die allerdings durch steigende Abnahmemengen verringert werden können.

Wichtig für die Verwendung der Pülpe als Bindemittel ist das rheologische Verhalten. Bei der mechanisch-enzymatisch aufgeschlossenen Kartoffelpülpe handelt es sich um einen Stoff, der sich strukturviskos verhält, d. h. bei einer Zunahme der Scherbelastung verringert sich die Viskosität. Im Vergleich zur nativen Kartoffelpülpe hatte die aufgeschlossene Pülpe eine verarbeitungsfähige Viskosität. Alle Bindemittelmischungen der Versuchsreihen zeigten das gleiche viskose Verhalten, wobei das Harnstoff-Formaldehydharz viskositätssenkend wirkte, während die Zugabe des Haftvermittlers eine leichte Zunahme der Viskosität zur Folge hatte. 
Es hat sich gezeigt, dass die aufgeschlossene Kartoffelpülpe als Bindemittel oder zumindest zur teilweisen Substitution von herkömmlichen Bindemitteln eingesetzt werden kann. Im Weiteren sollte die Möglichkeit der Entsorgung der mit Pülpe hergestellten Faserplatten überprüft werden. Zum Vergleich wurden MDF-Proben, die zum einen unter Verwendung von UF-Harz und zum anderen mit mechanischenzymatisch aufgeschlossener Kartoffelpülpe als Bindemittel hergestellt wurden, jeweils mit dem Weißfäulepilz Trametes versicolor, dem Braunfäulepilz Coniophora puteana und dem Moderfäulepilz Chaetomium globosum für 16 Wochen inkubiert. Je eine Hälfte der Proben war mit einem Fungizid versetzt und die andere ungeschützt.

Beim Abbau durch die holzzersetzenden Pilze zeigte sich, dass das verwendete Fungizid keine signifikante Auswirkung auf die Pilze hatte. C. puteana erwies sich als stärkster Zersetzer, gefolgt von $T$. versicolor und am schwächsten war der Moderfäulepilz C. globosum. Die MDF-Proben, die unter Verwendung von Pülpe als Bindemittel hergestellt wurden, zeigten einen fast zehnmal stärkeren Holzabbau als die mit UF-Harz gebundenen Platten. Aufgrund dieser Ergebnisse ist davon auszugehen, dass Faserplatten, die mit mechanisch-enzymatisch aufgeschlossener Kartoffelpülpe als Bindemittel hergestellt werden, sich gut kompostieren lassen und sich ohne Rückstände in den Stoffkreislauf zurückführen lassen. 


\section{Ausblick}

Die Holzwerkstoffindustrie ist nach der Sägeindustrie der wichtigste Abnehmer des Rohstoffes Holz. Der jährliche Rohholzbedarf der deutschen Holzwerkstoffindustrie liegt zurzeit bei rund 16 Mio. Festmetern, was etwa $40 \%$ des hiesigen Holzeinschlages entspricht (KHARAZIPOUR, 2004) und man rechnet mit einer weiteren Steigerung der Produktionskapazitäten.

Bei der Herstellung von Span- und Faserplatten wurde in den letzten Jahren verstärkt auch die Verwendung von Bindemitteln aus nachwachsenden Rohstoffen erprobt. Der Einsatz von mechanisch-enzymatisch aufgeschlossener Kartoffelpülpe als Bindemittel bei der MDF-Herstellung ist eine durchaus einsetzbare Alternative zu den herkömmlichen Bindemitteln auf petrolchemischer Basis. Auch wenn die alleinige Verwendung von mechanisch-enzymatisch aufgeschlossener Kartoffelpülpe fraglich ist, so ist doch eine Mischung mit UF-Harz eine sinnvolle Substitution dieses Bindemittels um Einsparungen fossiler Ressourcen zu erreichen.

Da die hier erzielten Ergebnisse nur im Technikumsmaßstab durchgeführt wurden, ist im Anschluss eine Übertragung in den Pilotmaßstab notwendig. Die Prozessschritte bestehen aus dem mechanisch-enzymatischen Aufschluss und der Trocknung der Kartoffelpülpe, sowie der Herstellung von MDF-Platten. Im Rahmen solcher nachfolgender Versuche ist es sinnvoll, die mechanisch-enzymatisch aufgeschlossene Kartoffelpülpe mit weiteren Kunstharzen zu mischen um somit eine eventuelle Verbesserung der physikalisch-technologischen Eigenschaften zu erzielen. Das Spektrum der Holzwerkstoffe bietet eine vielfältige Auswahl an Material und Herstellungsmethoden, so dass eine Erweiterung des Einsatzes der mechanischenzymatisch aufgeschlossenen Kartoffelpülpe als Bindemittel bei anderen Holzwerkstoffen denkbar ist.

Durch die Verwendung von Kartoffelpülpe als Bindemittel besteht später die Möglichkeit einer einfachen und rückstandslosen Kompostierung der Holzwerkstoffe. Dies ist insbesondere wichtig hinsichtlich der Abfall- und Recyclingmaßnahmen der Bundesregierung, deren Bestandteile die TA-Siedlungsabfall und das Kreislaufwirtschafts- und Abfallgesetz sind. Die TA-Siedlungsabfall (1.1.1993) besagt, dass Produkte mit einem Gehalt von mehr als $5 \%$ organischen Stoffen nicht mehr auf Hausmülldeponien gelagert werden dürfen. Das Kreislaufwirtschafts- und Abfallgesetz (7.10.1996) hat eine Schonung der Ressourcen und eine umweltfreundliche Beseitigung von Abfällen zum Ziel.

Durch den Einsatz der Pülpe als Bindemittel könnten große Mengen davon industriell zur Rohstoffherstellung eingesetzt werden und dadurch eine nachhaltige Nutzung dieses nachwachsenden Rohstoffs ermöglichen. 


\section{$7 \quad$ Literaturverzeichnis}

AB Enzyme (2001):

Technisches Datenblatt

Abousteit, O. (1978):

CCB. Rev.Chocol. Confect. Bakery 3, Nr. 1, S. 48-50

Abousteit, O. u. W. Kempf (1974):

starch/stärke 26, S. 417 - 421

Agrarmärkte (2003): Jahresheft 2003.

Hrsg. Landesanstalt für Entwicklung der Landwirtschaft, Landesstelle für landwirtschaftliche Marktkunde.

Alana, A., M. J. Llama und J. L Serra. (1991):

Purification and some properties of the pectin lyase from Penicillium italicum. FEBS Letters 280, 335-340

Ammer, U. u. W. Liese (1965):

Das Abbauvermögen holzzerstörender Pilze. In: Holz und Organismen. Nr. 1. Hrsg. G. Becker und W. Liese. Beihefte zu Material und Organismen. Duncker \& Humblot, Berlin

Ayla, C. (1980):

Herstellung von feuchtigkeitsbeständigen Leimen aus nachwachsenden Rohstoffen für die Holzindustrie - dargestellt am Beispiel des Rindenextraktes von Pinus brutia Tenore und das Äthanollignings. Dissertation, Hamburg

Bader, J., P.V. Kishore, U. Klingspohn, B. Kruse, K. Schürgerl (1989): Bioconversion of potato pulp - a byproduct from starch industry. Dechema biotechnology conferences. VCH Verlagsgesellschaft, W.Germany

Bahn, M., R.-D. Schmid (1986):

Waschmittelenzyme; Labor 2000. S. 16

BASF (2002):

Technisches Merkblatt. Kauritec ${ }^{\circledR} 407$

Bauer, H. (1979):

GB-PS 2014423 
Beldman, G., F. M. Rombouts, A. G. J. Voragen, W. Pilnik (1984): Application of cellulase and pectinase from fungal origin for the liquefaction and saccharifiction of biomass.. Enzyme and Microbiol. Technol. 6, S. 503-507

Beutler, H.-O. (1978):

Enzymatische Bestimmung der von Stärke in Lebensmitteln mit Hilfe der Hexokinase-Methode. starch/stärke 30, S. 309-312

Blechschmidt, J., O Bloszfeld, C. Bäurich, P. Engert, M. Graf und S. Wurdinger (1988):

Eigenschaften von CTMP aus einheimischen Holzarten (Teil II). Zellstoff und Papier 37 (2), 43-46

Blumenkrantz, N., G. Asboe-Hansen (1973):

New Method for the quantitative determination of uronic acids. Anal. Biochem. 54, S. 484-489

BMFT (Bundesministerium für Forschung und Technik) (1990):

Nachwachsende Rohstoffe. Konzept zur Forschungsförderung 1990-1995

Buhr, H., W. Neye (1958):

Die Kartoffel. Ziemsen Verlag, Wittenberg Lutherstadt

Cauvin, S. P. (1985):

Effects of some enzymes on loaf volume in the Chorleywood Bread Process. FMBRA Bulletin, Vol. 1, S. 11

Cheeseman, G. C. (1981):

Rennet and cheesemaking. In: Birch, Blakebrough, Parker (eds.). Enzymes and Food Processing; S. 195 ff., Appl. Science Publishers Ltd., London

Dalton, L. K. (1953):

Resins from sulphited tannins as adhesives for wood. Australien Journal of Applied Science 4, S. 136-145

Deppe, H.-J. und K. Ernst (1996):

MDF-Mitteldichte Faserplatten. DRW-Verlag, LeinfeldenEchterdingen

Deuel, H., E. Stutz (1958):

Pectic substances and pectic enzymes. Advances in Enzymology and Related Subjects of Biochemistry 20, S. 341-382 
DGfH Deutsche Gesellschaft für Holzforschung (1994):

Holzschutz. Hrsg. Wirtschaftsministerium Baden-Württemberg, Stuttgart

DIN-Taschenbuch 213 (1996):

Papier, Pappe und Halbstoff. DIN Deutsches Institut für Normung e. V., 3. Auflage, Beuth Verlag

DIN-Taschenbuch 60 (1999):

Holzfaserplatten, Spanplatten, Sperrholz. DIN Deutsches Institut für Normung e. V., 6. Auflage, Beuth Verlag

Dinwoodie, J. M. (1983):

In: Wood Adhesives Chemistry and Technology, Vol. 1 (Hrsg. A. Pizzi), Marcel Dekker, New York; S. 1-58

Dix, B. und E. Roffael (1996):

New Challenges for Wood-Based Panels Industry: Technology, Productivity and Ecology. Posterpräsentation anlässlich des Joint Wood-Based Panels Symposium: $3^{\text {rd }}$ EUROWOOD Symposium and $4^{\text {th }}$ FESYP Technical Conference. 1. und 2.10.1996, Braunschweig

Dix, B. und E. Roffael (1999):

Zum Schutz von Holz und Holzwerkstoffen. Hrsg.: Institut für Holzbiologie und Holztechnologie, Universität Göttingen

Dix, B., F. Loth, E. Roffael (1998) :

Stärke-Tannin-Bindemittelsysteme für Span- und mitteldichte Faserplatten. Schriften aus der Forstlichen Fakultät der Universität Göttingen und der Niedersächsischen Forstlichen Versuchsanstalt, Band 124, S. 135-156

Dix, B., R. Marutzky (1985) :

Tannin extracts from spruce and pine barks. J. Appl. Polym. Sc. Appl. Polym. Symp. 40, S. 91-100

Dongowski, G. (1993):

Untersuchung an Kartoffelpülpe als Ballaststoffquelle. Zum Einfluss von pektolytischen und cellulolytischen Enzymen. starch/stärke 45 (5), S. 166-171, VCH Verlagsgesellschaft

Dubourdieu, D., B. Fournet Riberau-Gayon (1981) :

Carbohydrate Research. Vol. 93, S. 294-299

Dunky, M., P. Niemz (2002):

Holzwerkstoffe und Leime, Technologie und Einflussfaktoren. Springer Verlag 
EPF (2004):

European Panel Federation: $4^{\text {th }}$ European Wood-Based Panels Symposium. Hannover, 15. - 17. September 2004

Ernst, K. (1997):

Entwicklungsmöglichkeiten von MDF. Holz als Roh- und Werkstoff. Vol. 55, S. 3-8, Springer-Verlag

European Standard EN 113 (1996):

Wood preservatives- Test method for determining the protective effectiveness against wood destroying basidiomycetesDetermination of the toxic values.

Euwid Holzspecial (2003):

Holzwerkstoffe und Oberflächen. S. 34-41, EUWID Europäischer Wirtschaftsdienst $\mathrm{GmbH}$, Gernsbach

Fengel F., G. Wegener (1984):

Wood Chemistry, Ultrastructure, Reactions. Berlin, New York

Forss, K. und A. Fuhrmann (1976):

Karatex - The lignin-based adhesives for plywood, particleboard and fibreboard. Paperi ja Puu 58, S. 817-824

Freudenberg, K., A. Neish (1968):

Constitution and Biosynthesis of lignin. Springer Verlag, Berlin, Heidelberg, New York, S. 129

Geißler, G. (1980):

Die Kartoffel in: Pflanzenbau. Ein Lehrbuch - Biologische Grundlagen und Technik der Pflanzenproduktion. Berlin \& Hambug, P. Parey-Verlag

Giesemann, H.-G. u. G. Knobloch (1979):

DE-PS 2909015

Glasser, W. G. (1981):

Paper and Timber 63, S. 30-52

Glatt GmbH (2003) :

Wirbelschicht-Anlagen. Laborgeräte Firmenprospekt

Gschwend, W. u. W. Kempf, (1978):

Zucker-Süßwarenwirtschaft 31

Habenicht, G. (1997):

Kleben, Grundlagen, Technologie, Anwendungen. 3. Auflage, Springer Verlag 
Hillebrandt, J.-O. (1994):

Kartoffelpülpe als landwirtschaftliches Abfallprodukt und ein nachwachsender Rohstoff. Versuche zu ihrer mikrobiologischen Charakterisierung, ihrer Konservierung und ihrem Abbau. Dissertation. Universität Göttingen

Hinterwaldner, R. (1986):

Polymerisierbare Stärken. Coating 19, S. 364-368

http://bs.shinshu-u.ac.jp/html/gene/works/cellulase/cellulase.html; Download vom 02.11.2004

http://www.avebe.com, Download vom 04.11.2004

http://www.biosicherheit.de/kartoffeln/30.doku.html, Download vom 20.09.2004

http://www.carmen-ev.de/dt/hintergrund/nawaros.html, Download vom 15.01.2005

http://www.emsland-staerke.de, Download vom 04.11.2004

http://www.forst.uni-

freiburg.de/fobawi/fob/211b/material_2003/11holzwerkstoffe. pdf; Download vom 27.05.2004

http://www.imvt.tu-bs.de/files/Praktikum_Zellauf-schluss.pdf; Download vom 26.11.2003

http://www.infoholz.de/html/f_page.phtml?p1=1109756677\&p3=6693, Download vom 26.05.04

http://www.starch.dk/isi/market/EUtm.htm, Download vom 14.07.2004

Huchette, M. u. Bussière, G. (1976) :

\section{DE-PS 2651791}

IENICA, 2003:

Report from the state of Germany Interactive European Network for Industrial Crops and their Applications. Fachagentur Nachwachsende Rohstoffe e. V., Deutschland

IUB International Union of Biochemistry (1965):

Enzyme Nomenclature: Recommendations 1964 of the International Union of Biochemistry. Elsevier Verlag

IUB International Union of Biochemistry (1979):

Units of enzyme activity: Recommendations 1978. European Journal of Biochemistry, Vol. 97, S. $319-320$ 
IUBMB (2001):

http://www.chem.qmul.ac.uk/iubmb/ International Union of Biochemistry and Molecular Biology

Jung, A. und E. Roffael (1989):

Verwendung von Tanninen als Bindemittel in Holzwerkstoffen. Adhäsion 33 (7/8), S. 28-34

Kempf, W. (1980):

Beitrag zur mechanischen Entwässerung von Kartoffelpülpe. starch/stärke 32 (1), S. 14-20, VCH Verlagsgesellschaft, Germany

Keppler, D. und K. Dekker (1974):

Glycogen: Bestimmung mit Amyloglycosidase. S. 1171-1176. In: Bergmeyer, H.-U.: Methoden der enzymatischen Analyse. 3. Auflage, Bd. 2, Verlag Chemie, Weinheim

Keusch, P.:

http://www.uni-

Regensburg.de/Fakultaeten/nat_Fak_IV/Organische_ Chemie/Didaktik/Keusch/D-Starch-d.htm, Download vom 17.01.05

Kharazipour, A. (1983):

Optimierung eines Verfahrens zur Herstellung von Bindemitteln für Holzwerkstoffe auf der Basis von Ligninsulfonat und Laccase. Dissertation, Göttingen

Kharazipour, A., A. Hüttermann, F. Mayer (1990):

Verfahren zur Gewinnung von phenoloxidierenden Enzymen aus Kulturen von Weißfäulepilzen. DP 4010873

Kharazipour, A., A. Hüttermann (1993):

Enzymatische Behandlung von Holzfasern als Weg zu vollständig bindemittelfreien Holzwerkstoffen. In: Hüttermann, A., Kharazipour, A. (Hrsg.): Schriften aus der Forstlichen Fakultät der Universität Göttingen und der Niedersächsischen Forstlichen Versuchsanstalt. Band 113, S. 83-98, J. D. Sauerländer's Verlag Frankfurt am Main

Kharazipour, A., A. Hüttermann, J. Trojanowski (1994a):

Herstellung verrottbarer Formkörper unter Verwendung von Kartoffelpülpe als Bindemittel. EP 94103099 
Kharazipour, A., J. Trojanowski, A. Hüttermann (1994b):

Direct utilization of potato-starch processing wastes by fungal fermentation. In: Chartier, Ph.., Beenackers, A. A. C. M., Grassi, G. (Hrsg.), Biomas for Energy, Enviroment, Agriculture and Industry. Vol. 2, S. 1303-1307, London: Pergamon

Kharazipour, A., A. Hüttermann, J. Trojanowski, K. Nonninger, (1994c):

Formkörper, insbesondere in Form einer Faserplatte. EP 0613906 A1 und DP 4306493

Kharazipour, A. (1996):

Enzyme von Weißfäulepilzen als Grundlage für die Herstellung von Bindemitteln für Holzwerkstoffe. Schriften aus der Forstlichen Fakultät der Universität Göttingen und der Niedersächsischen Forstlichen Versuchsanstalt. Band 121. J. D. Sauerländer's Verlag Frankfurt am Main.

Kharazipour, A. u. K. Bergmann (1998):

Die Verwendung von parenchymatischem Zellwandmaterial als Bindemittel für Holzwerkstoffe. In: Kharazipour, A. und Polle, A. (Hrsg.): Ansätze in der Biotechnologie des Holzes. Schriften aus der Forstlichen Fakultät der Universität Göttingen und der Niedersächsischen Forstlichen Versuchsanstalt, Band 124, S. 1331, Sauerländer's Verlag, Frankfurt/M.

Kharazipour, A. (2004):

Holz als Werkstoff. In: C.A.R.M.E.N. Jahrbuch 2004/2005. Nachwachsende Rohstoffe. Wirtschaftsfaktor Biomasse, S. 325-336

Kirchner, R. (1997):

Spanplattenrecycling durch thermohydrolytische Spaltung. Diplomarbeit, Universität Göttingen

Kishore, P.V., U. Klingspohn, K. Schürgerl (1988):

Production of polysaccharide hydrolases by fungal species cultured on the potato-starch processing waste (unveröffentlicht)

Klingspohn, U., J. Bader, B. Kruse, P. Vijai Kishore, K. Schügerl (1993): Utilization of Potato Plp from Potato Starch Processing. Process Biochemistry 28, S. $91-98$

Kloeser, L. (2004):

Herstellung von dreischichtigen Spanplatten im Labormaßstab gebunden mit Bindemitteln auf Weizenproteinbasis. Masterarbeit (unveröffentlicht). Universität Göttingen 
Kneule, F. (1975):

Das Trocknen. Grundlagen der chemischen Technik. Verfahrenstechnik der chemischen und verwandter Industrien. 3. überarb. Auflage. Sauerläner

Krug, D., H.-J. Sirch (1999):

Protein als Kleber. Holz-Zentralblatt, Nr. 52, S. 773

Krusenbaum, J. (1991):

Versuche zur Optimierung eines Substrates auf der Basis von Kartoffelpülpe und Kartoffelfruchtwasser für die Anzucht von Pilzen. Diplomarbeit. Universität Göttingen

Lampert, H. (1967):

Faserplatten; Rohstoffe, Herstellungsverfahren, Eigenschaften. VEB Fachbuchverlag Leipzig

Lehninger. L., D. L. Nelson, M. M. Cox (1994) :

Prinzipien der Biochemie, Heidelberg

Liese, W. (1981):

In: Der Wald als Rohstoffquelle. A. Hüttermann (Ed.) Schriften aus der Forstlichen Fakultät der Universität Göttingen und der Niedersächsischen Versuchsanstalt. Band 69, Sauerländer's Verlag, Frankfurt/M.

Liiri, O., H. Sairanen, H. Kilpeläinen (1982):

Bark extractives from spruce as constituents of plywood bonding agents. Holz Roh- und Werkstoff 40, S. 51-60

Lüttge, U., M. Kluge, G. Bauer (1999):

Botanik. 3. Auflage.Wiley-VCH Verlag, Weinheim

Majcherczyk, A., A Hüttermann, V. Grothey, F. Mayer (1991 b):

Verfahren zum Abbau von organischen Schadstoffen mit Hilfe von lignin-abbauenden Mikroorganismen. DP 4104624

Majcherczyk, A., A. Hüttermann, V. Grothey, F. Mayer (1991 a): Verfahren zur Anzucht von Pilzmyzelien. DP 4104625

Mantau, U., H. Weimer, R. Wierling (2002):

Standorte der Holzwirtschaft; Holzwerkstoffindustrie, Abschlußbericht im Auftrag von Holzabsatzfonds (HAF) und Verband Deutscher Papierfabriken (VDP) 
Marihart, J. (1983):

Unspezifischer Abbau komplexer stärke-, cellulose-, hemicelluloseund pektinhaltiger Rohstoffe mittels Säure am Beispiel von Kartoffelpülpe und die Verwertung der Hydrolysate. In: Verwertungsmöglichkeiten von Pentosen. S. 102-110. IEAForestry, Energy Agreement Congress, TU-Wien

Maurer, H. W. (1998):

Opportunities and challenges for starch in the paper industry. starch/stärke 50, Nr. 9, S. 396-402. VDH Verlagsgesellschaft

Mayer, F. (1993):

Bestandteile der primären Zellwand als Matrixelement und Bindemittel für Holzwerkstoffe am Beispiel Kartoffelpülpe. Schriften der Forstlichen Fakultät der Universität Göttingen und der Niedersächsischen Forstlichen Versuchsanstalt. Band 113. J.D. Sauerländer's Verlag Frankfurt a. M., S. 46-54

Mayer, F. (1996):

Klebstoff auf der Basis von Kartoffelpülpe sowie Herstellung und Verwendung des Klebstoffs Europäische Patentanmeldung, EP 0 732386 A1

Mayer, F. (1998):

Potato pulp: properties, physical modification and applications" Polymer Degradation and Stability 59, S. $231-235$

Mayer, F., A. Kharazipour, A. Hüttermann (1990):

Formkörper aus holz- oder cellulosehaltigen Stoffen sowie Verfahren zu ihrer Herstellung. DP 3933279

Mayer, F., A. Kharazipour, A. Hüttermann (1991):

Formpresslinge aus holz- oder cellulosehaltigen Stoffen sowie Verfahren zu ihrer Herstellung. DP 4020969

McCleary, B. V. (1986):

Enzymatic modification of plant polysaccharides. Int. J. Biol. Macromol., Vol. 8, S. 349

McCleary, B. V.; E. Nurthen (1986):

Journal of the Institute of Brewing. Vol. 92; Nr. 2, S. 168-173 
Merill, W. (1965):

Decay of Wood and Wood Compounds by Common Fungi Imperfecti. In: Holz und Organismen. Nr. 1. Hrsg. G. Becker und W. Liese. Beihefte zu Material und Organismen. Duncker \& Humblot, Berlin

Mittenzwey, R., Th. Seidensrücker, H.-G. Fritz, R. Süssmuth (1998):

Testing of the Environmental Compatibility of Newly Developed Polymeric Materials Based on Renewable Resources Using a Simple Testing System. Starch, Bd. 50 (1998), 10, S. 438-442

Mohabir, G., P. John, (1988):

Effect of temperature on starch sythesis in potato tuber tissue and in amyloplasts. Plant Physiol. 88, S. $1222-1228$

Mohr, H., P. Schopfer (1992):

Pflanzenphysiologie. 4. Auflage, Springer-Verlag

Moskowitz, G. J., S. Noelck, S. Suellen (1987):

Enzyme-modified cheese technology. J. Dairy Sci., Vol. 70; Nr. 8, S. 1761

Müller, C. (2001):

Versuche zur Optimierung eines biotechnologischen Verfahrens für die Gewinnung von parenchymatischen Zellwandbestandteilen. Masterarbeit, Universität Göttingen

Neusser, H. (1957):

Entwicklung und Stand der Faserplattenentwicklung. Holz-Zbl. 83, S. $79-82$

Nielson, M. H., J. S Jepsen, H. Outtrup (1981):

Enzymes for low temperature washing. J. Am. Oil Chem. Soc., Vol. 58 (5), S. 644

Niro Soavi (2002):

Technisches Datenblatt.

Novozym (2002):

Determination of Pectintranseliminase. UPTE of $\mathrm{pH} 3,5$. Methodenbeschreibung der Firma Novozymes

Oetjen, G.-W. (1997):

Gefriertrocknen. Weinheim: VCH 
Okum, J. (1999):

Entwicklung von umweltfreundlichen, reaktiven Bindemittelsystemen aus Reststoffen der Holznutzung (technische Lignine, Rinde) für die Herstellung von emissionsarmen Span- und Faserplatten. Dissertation an der Universität Göttingen. Tectum Verlag, Marburg

Olson, H. S. (2000): Kartoffeln ohne Abfälle verarbeiten. Biotimes. No. 3, September

Parameswaran, N. und E. Roffael (1985):

Zum biologischen Abbau von Harnstofformaldehydharzgebundenen Spanplatten unterschiedlichen Formaldehydgehaltes. WKI-Bericht 397

Paulitsch, M. (1989):

Moderne Holzwerkstoffe; Grundlagen, Technologien, Anwendungen. Springer-Verlag Berlin, Heidelberg, New York

Pecina, H. und G. Kühne (1986):

Holzteerklebstoffe für die Holzwerkstoffherstellung - einBeitrag zur komplexen Holzverwertung. Wissenschaftliche Zeitschrift der Technischen Universität Dresden 35 (4), S. 101-103

Petterson, R. C. (1984):

The chemical composition of wood. In: The chemistry of solid wood. American araghi society, Washington, D.C.

Pfeiffer, S., U. Langhorst (2000):

Branchenreport Nr. 3, IG Metall Branche Holz und Kunststoff. Spannung in der Branche: Die Spanplattenindustrie, S. 6

Pilnik, W., F.M. Rombouts (1981):

Enzymes and Food Processing. Hrsg. G.G. Birch, N. Blakeborough und K.J. Parker. Applied Science Publisher Ltd., S. 105-128

Pitt, D. (1988):

Pectin Lyase fromm Phoma medicaginis var. pinodella. Methods in Enzymology. Vol. 161, S. 350-352. Academic Press

Pizzi, A. (1982):

Pine tannin adhesives for particleboard. Holz Roh- und Werkstoff 40, S.293-301

Pizzi, A. (1992):

Holzforschung. Holzverwertung. 44, S. 6-10. 
Plomley, K. F., W. E. Hills, K. Hirst (1976):

The influence of wood extractives on the glue-wood bond. The effect of kind and amount of commercial tannins and crude wood.. Holzforschung 30 (1), S. 14-19

Poller, S. und J. Kletzin (1990):

Holztechnologie 31 (3), S. 117-119

Potente, H., V. Schöppner, A. Rücker (1991):

Verarbeitung von Kartoffelstärke auf KunststoffVerarbeitungsmaschinen. starch/stärke 45, Nr. 6, S. 231-235. VDH Verlagsgesellschaft

Präve, P. (1994):

Handbuch der Biotechnologie. Oldenbourg Verlag München, Wien., S. $625-651$

Raven, P. H., R. F. Evert, S. E. Eichhorn, ins Deutsche übertragen von R. Langenfeld-Heyser, (2000):

Biologie der Pflanzen. 3. Auflage, de Gruyter-Verlag.

Reed, G. (1975):

Enzymes in Food Processing. $2^{\text {nd }}$ Edition. Academic Press

Rexova-Benkova, L., O. Markovic (1976):

Pectic enzymes. In: Advances in carbohydrate chemistry and biochemistry. Hrsg. Pigman, W. W., 33, s. 323-385. Acad. Press New York

Roffael, E. (1976):

Beiträge zur verwendung von alkalischen

Phenolformaldehydharzen und Ligninsulfonaten bei der Verleimung von Holzspänen. Wilhelm-Klauditz-Institut für Holzforschung and der Technischen Universität Braunschweig-Fraunhofer-Gesellschaft

Roffael, E. (1982):

Die Formaldehydabgabe von Spanplatten und andren Werkstoffen, DRW-Verlag, Stuttgart

Roffael, E. (1997a):

Bindemittel aus nachwachsenden Rohstoffen. Aus: Klebstoffe für Holzwerkstoffe und Faserformteile: Neue Entwicklungen, Applikationen und Analysetechniken. WKI-Bericht Nr. 32, Hrsg. J. Klein, Marutzky, R. 
Roffael, E. (1997b):

Stand der Kenntnisse beim Recycling von Holzwerkstoffen. In: Recyclingkonzepte in der Holzwerkstoffindustrie. Schriftenreihe: Wald, Holz und Holzwerkstoffe. Hrsg. A. Kharazipour und E. Roffael, Göttingen

Roffael, E. und B. Dix (1994):

Tannine als Bindemittel für Holzwerkstoffe / von A. Roffael und B. Dix. - Braunschweig: Wilhelm-Klauditz-Institut, 1994; WKIMitteilung; 601

Roffael, E., B. Dix, T. Schneider, (2001a):

Thermomechanical (TMP) and Chemo-Thermomechanical Pulps (CTMP) for Medium Density Fibreboards (MDF). Holzforschung 55 (2), S. 214-218

Roffael, E., B. Dix, T. Schneider (2001b):

Zur Verwendung von Tanninen als Bindemittel in der Holzwerkstoffindustrie. Hrsg. Institut für Holzbiologie und Holztechnologie der Georg-August-Universität Göttingen

Roffael, E., H. Schriever, A. May (1982):

Hydrophobierung von Spanplatten mit Paraffinen. Teil 1: Kenntnisse und eigene Untersuchungen. Adhäsion, 26 (11). WKIMitteilungen 349/1982)

Rombouts, F. M., W. Pilnik (1978):

Enzymes in Fruit and Vegetable Juice Technology. Process Biochemistry: Incorporating Biochemical Engineering; Food, Brewing. 13, S. 9-13

Rombouts, F. M., W. Pilnik (1980):

Pectic Enzymes. In: Economic Microbiology: Microbial Enzymes and Bioconversions. Hrsg. Rose, A.H. 5, S. 227-282. Academic Press, New York

Rosamah, E. (2003):

Einige Aspekte der Tanninverleimung. Dissertation, Göttingen

Sandermann, W. u. O. Künnemeyer (1956):

Stand der neuen Verfahren zur Herstellung von Faserplatten nach dem Trocken- und Halbtrocken- (Dry- and Semidry-) Prozess und Versuche über die wasserlöslichen Anteile. Papier 10, S. 287-294 
Sarathi Reddy, O. V., S. C. Basappa (1993):

Selection and characterisation of Endomycopsis fibuligera strains for one- step fermentation of starch to ethanol". starch/stärke 45, Nr. 5, S. 187-194. VDH Verlagsgesellschaft

Schöpper, C. (2005):

Dissertation in Vorbereitung

Seifert, K. (1965):

Über den Abbau der Holzcellulose durch Organismen. In: Holz und Organismen. Nr. 1. Hrsg. G. Becker und W. Liese. Beihefte zu Material und Organismen. Duncker \& Humblot, Berlin

Shekholeslami, M. (1986):

Untersuchung zur biologischen Abbaubarkeit von ungeschützten Holzspanplatten durch Weiß- und Braunfäulepilze. Diplomarbeit. Georg-August-Universität

Shekholeslami, M. (1991):

Optimierung der Enzymproduktion von Weißfäulepilzen für den Einsatz bei der biotechnologischen Erzeugung von Bindemitteln. Dissertation, Universität Göttingen

Sirch, H.-J; E. Kehr (1997):

Untersuchungen zur Eignung von Proteinen als Bindemitteln für Holzpartikel-Werkstoffe. WKI-Bericht Nr. 32

Slominska, L., G. Starogardzka (1987):

Application of a multi-enzyme complex in the utilization of potatopulp". starch/stärke. 39 Nr. 4, S. 121-125. VDH Verlagsgesellschaft

Sprößler, B. (1978):

Tätige Makromoleküle. Röhm-Spectrum, Vol. 21, S. 12-15

Stein, W. (1994):

Holz- und Kunststoffverarbeitung. 29, S. 830-831. DRW-Verlag

Stevens, R. U. G. E. Woodson (1977):

High-Frequency and Hot-Platen curing of Medium-Density

Fiberboards. Forest Products Journal Vol. 27 (1), S. 46-50

Strasburger; E., F. Noll, H. Schenk, A. F. W. Schimper (1991):

Lehrbuch der Botanik für Hochschulen. Gustav Fischer Verlag, Stuttgart, Jena, New York 
Stroot, S. (2001):

Eine praxisbezogene Labormethode zur Ermittlung der Wirksamkeit von Pektinasen für die Sekundärmembran-Minderung bei Membrantrenn-Prozessen. Dissertation. Universität Oldenburg

Troy Chemie GmbH (2003):

Technisches Datenblatt für Mergal ${ }^{\circledR}$ S88 Paste/Pulver

Tegge, G. (1984/88):

Stärke und Stärkederivate. Behr's Verlag, Hamburg

Trojanowski, J., A. Kharazipour, F. Mayer, A. Hüttermann (1995):

Verwendung von Kartoffelpülpe und -fruchtwasser als Nährmedium zur Anzucht von Laccase-produzierenden Pilzen. starch/stärke 47 (3), S. 116-118

Trojanowski, J. A. (2005):

mündliche Mitteilung

Turquois, T., M. Rinaudo, F. R. Taravel und A. Heyraud (1999) :

Extraction of highly gelling pectic substances from sugar beet pulp and potato pulp: influence of extrinsic parameters on their gelling properties". Food Hydrocolloids, Vol. 13, pp. 255-262

Uhlig, H. (1991):

Enzyme arbeiten für uns: technische Enzyme und ihre Anwendung. Carl Hanser Verlag München Wien, S. 20 ff.

VHI, Verband der Deutschen Holzwerkstoffindustrie (2004): http://www.vhi.de/ . Download vom 03.06.04

Völksen, W. und W. Kröner (1944):

DE-PS 745044

Wallhäusser, K.-H. (1990):

Lebensmittel und Mikroorganismen: Frischware-Konservierungs methoden-Verderb. Steinkopff Verlag, Darmstadt

Walter, M. (2002):

Die parallele $\beta$-Helix der Pektat-Lyase aus Bacillus subtilis. Stabilität, Faltungsmechanismen und Faltungsmutanten. Dissertation an der Universität Potsdam. 
Warvel, S. (1998):

Technische Produktion durch Umwandlung von Stoffen der Natur mit Methoden der Natur. In: Biokonversion nachwachsender Rohstoffe. Workshop 1997 in Detmold. Landwirtschaftsverlag $\mathrm{GmbH}$, Münster.

Weiland, P., N. Sintawardani (1991):

Anaerobe Behandlung von Reststoffen aus der Kartoffelstärkeproduktion. Achema 1991. Institut für Technologie. Bundesforschungsanstalt für Landwirtschaft, Braunschweig.

Wen-chi Hou, Wei-Hsien Chang and Chii-Ming Jiang (1999):

Qualitative distinction of carboxyl group distributions in pectins with ruthenium red". Botanical Bulletin of Academia Sinica, Vol. 40, p. $115-119$

Willeitner, H. (1964):

Untersuchung über das Verhalten von Holzspanplatten beim Befall durch einige Basidiomyceten. Dissertation. Universität Hamburg

Willeitner, H. (1965):

Zerstörung von Spanplatten durch Basidiomyceten. Holz als Rohund Werkstoff 23 (7), S. 264-271

Willeitner, H. (1969):

Über die Laboratoriumsprüfung von Holzspanplatten gegen Pilzbefall.

Beih. 2 zu Material u. Organismen: Berlin, Duncker \& Humblot, S. 109-122.

Williams, T. P. (1973):

GB-PS 1463073

Wing, R. A., J. Yamaguchi, S. K. Larabell, V.M. Ursin, S. McCormick (1990):

Molecular and genetic characterization of two pollen-expressed genes that have sequence similarity to pectate lyases of the plant pathogen Erwinia". Plant Molecular Biology, 14 (1), S. 17-28

Winkelmann, A. (1997):

Herstellung von emissionsarmen Holzwerkstoffen auf der Basis von nachwachsenden Rohstoffen. Dissertation, Georg-AugustUniversität, Göttingen

Wittmann, O. und H. Lehnert (1974):

Diisocyanate als Bindemittel zur Herstellung von Holzwerkstoffen mit Diisocyanaten. Holz-Zentralblatt, Nr. 59, 100. Jahrgang 


\section{Lebenslauf}

\section{Persönliche Daten}

Name:

Cora Müller

geboren am:

31. Januar 1975

Geburtsort:

Höxter

Familienstand:

verheiratet

\section{Schulbildung}

$09 / 81-07 / 85$

Gemeinschaftsgrundschule Nicolaitor in Höxter

$09 / 85-06 / 94$

König-Wilhelm-Gymnasium in Höxter

Schulabschluss:

Allgemeine Hochschulreife

\section{Praktika}

$11 / 94-06 / 95$

Praktikum in einem landwirtschaftlichen Betrieb in St. Jean de Buèges (Südfrankreich)

\section{Studium}

$10 / 95-07 / 96$

$10 / 96-08 / 01$

Abschluss:

\section{Promotion}

seit Oktober 2001

2 Semester der Sozialwissenschaften an der Universität Hannover

Studium an der Fakultät für Forstwissenschaften und Waldökologie der Georg-August-Universität Göttingen

Schwerpunkt: Holzbiologie / Holztechnologie Master of Science (M.Sc.)

Stipendiatin der Deutschen Bundesstiftung Umwelt (DBU) am Institut für Forstbotanik der GeorgAugust-Universität Göttingen 
Hiermit versichere ich gemäß $\S 4(2 e)$ der Promotionsordnung des Fachbereichs für Forstwissenschaften und Waldökologie der Georg-August-Universität Göttingen vom 08.01.1986, dass ich die vorliegende Arbeit selbstständig verfasst habe und keine anderen als die angegebenen Quellen und Hilfsmittel benutzt habe.

Göttingen, am 01. Mai 2005

(Cora Müller) 